Portland State University

PDXScholar

$1-1-2011$

\title{
Feedbacks of Methane and Nitrous Oxide Emissions from Rice Agriculture
}

Alec Sithole

Portland State University

Follow this and additional works at: https://pdxscholar.library.pdx.edu/open_access_etds Let us know how access to this document benefits you.

Recommended Citation

Sithole, Alec, "Feedbacks of Methane and Nitrous Oxide Emissions from Rice Agriculture" (2011).

Dissertations and Theses. Paper 43.

https://doi.org/10.15760/etd.43

This Dissertation is brought to you for free and open access. It has been accepted for inclusion in Dissertations and Theses by an authorized administrator of PDXScholar. Please contact us if we can make this document more accessible: pdxscholar@pdx.edu. 
Feedbacks of Methane and Nitrous Oxide Emissions from Rice Agriculture

by

Alec Sithole

A dissertation submitted in partial fulfillment of the requirements for the degree of

\author{
Doctor of Philosophy \\ in \\ Applied Physics
}

Dissertation Committee:

M. Aslam K. Khalil, Chair

Anna -L. Reysenbach

Todd N. Rosenstiel

Mark D. Sytsma

Andrew L. Rice

Erik Bodegom

Portland State University

(C)2011 


\begin{abstract}
The effect of global warming on methane $\left(\mathrm{CH}_{4}\right)$ and nitrous oxide $\left(\mathrm{N}_{2} \mathrm{O}\right)$ emissions from agriculture was investigated and simulated from a soil warming experiment. Experiments were designed and installed in a temperature controlled greenhouse. The relationships between elevated temperatures and $\mathrm{CH}_{4}$ and $\mathrm{N}_{2} \mathrm{O}$ emissions were determined and calculated as the $\mathrm{Q}_{10} \mathrm{~S}$ of production, emission and oxidation. A study of the populations of methanogens and methanotrophs at a range of soil temperatures was performed based on soil molecular DNA analysis.
\end{abstract}

This study showed that global warming would increase $\mathrm{CH}_{4}$ emissions from rice agriculture and that the resultant emissions will be potentially large enough to cause changes in the present atmospheric concentrations. This research also showed that this increase was most evident for soil temperatures below $30^{\circ} \mathrm{C}$, above which emissions decreased with increasing temperature. The seasonal average $\mathrm{Q}_{10} \mathrm{~S}$ of $\mathrm{CH}_{4}$ emission, production, oxidation, methanogen and methanotroph populations were found to be 1.7 , 2.6 and $2.2,2.6$ and 3.8 , respectively, over a temperature of $20-32{ }^{\circ} \mathrm{C}$. Considering that the processes of $\mathrm{CH}_{4}$ production and emission are similar to those in natural wetlands, which is the largest source of atmospheric $\mathrm{CH}_{4}$, the contribution of this feedback is likely to cause a significant increase to the present $\mathrm{CH}_{4}$ atmospheric budget if the current global warming trend persists over the next century. 
The $\mathrm{Q}_{10} \mathrm{~S}$ of $\mathrm{N}_{2} \mathrm{O}$ emissions and production were $0.5-3.3$ and $0.4-2.9$, respectively. The low $\mathrm{Q}_{10}$ values found for $\mathrm{N}_{2} \mathrm{O}$ suggest that although global warming will have a direct impact on the production and emission rates. Nevertheless, the magnitude of the impact of global on both $\mathrm{CH}_{4}$ and $\mathrm{N}_{2} \mathrm{O}$ emissions from agriculture is likely to vary from one region to another due to the spatial variations in agricultural soil temperatures and the likely changes in the global regional distribution of water resources (water tables, rainfall patterns), water management practices and the responses of terrestrial $\mathrm{CH}_{4}$ and $\mathrm{N}_{2} \mathrm{O}$ sources such as natural wetlands and plants. 


\section{Acknowledgements}

Today, this incredible and monumental journey has come to an end, but with a prize. This prize has come largely as a result of the unwavering guidance from my supervisors, moral support from colleagues and family members, and all those who proof read my work.

First and foremost, this research would not have been completed without financial support from my doctoral advisor Professor Aslam Khalil through his grant from the Office of Science (BER), U.S. Department of Energy grant (DE-FG02-08ER64515) during my entire graduate studies at Portland State University. He was very instrumental in defining the direction of this research, and was always available and open to discuss new ideas and answer my pertinent questions. I am also indebted to Dr. Andrew L. Rice for his guidance on designing isotope experiments, making his Continuous-flow Gas Chromatography-Isotope Ratio Mass Spectrometer available for running these samples, and for discussions of the results. From our research group, I am very grateful to Martha J. Shearer who helped me in the purchasing of material and setting-up my experiments. Special thanks also go Dr. Christopher Butenhoff who took a great task of proof reading my draft papers and dissertation.

My profound gratitude also goes to Professor Anna-Louise Reysenbach for her wealth of advice, good ideas and directives on running molecular DNA experiments, being available to discuss my experiments and for giving me full access to her lab instruments 
and material that were funded through her grant from the U.S. National Science Foundation (OCE-0728391). I also learned a lot from her expertise and constructive criticism. In this work, I got great help from Gilbert Flores. He taught me protocols for soil molecular DNA extraction and the use of qPCR techniques in quantifying methanogens and methanotrophs, and how to interpret the results. Gilbert was very patient and available to assist me despite his tight schedule.

The enormous tasks involved in this research could not have been finished in time without the help of Austin Fischer and Erica Hanson who helped me with running of flux and isotope samples, respectively.

Lastly, I would like to thank my family for their encouragement and moral support during my studies. 


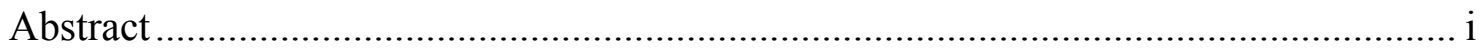

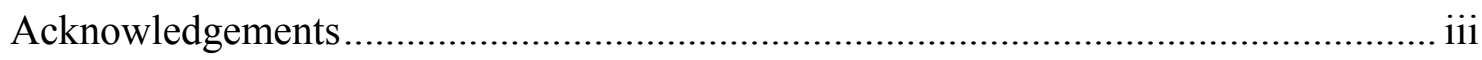

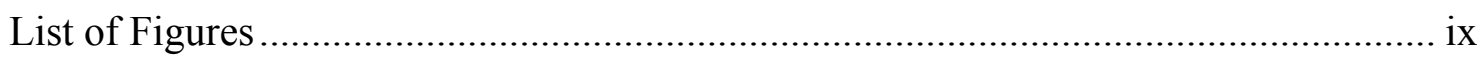

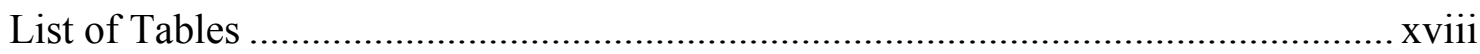

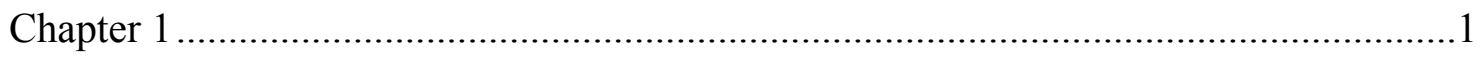

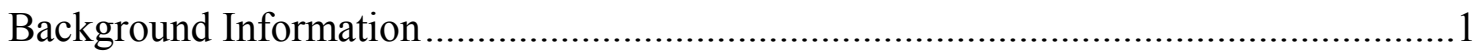

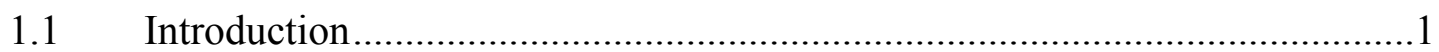

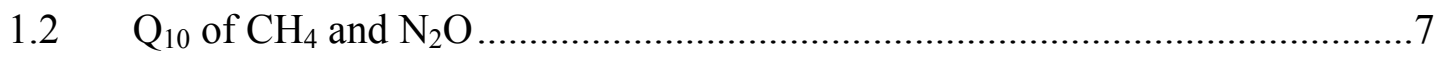

1.3 Research Objectives..........................................................................

1.4 Scope and General Outline ................................................................ 10

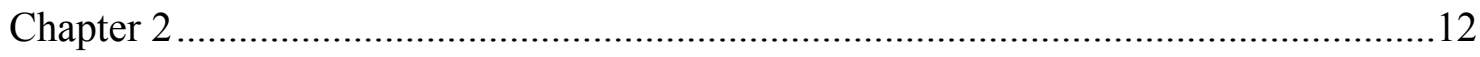

Experimental Design, Construction and Validation ..............................................12

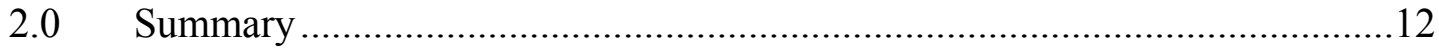

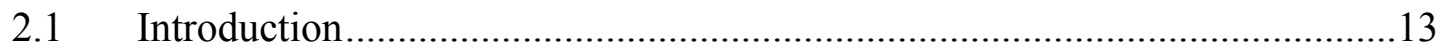

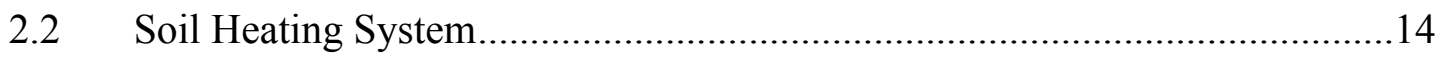

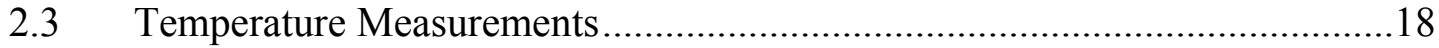

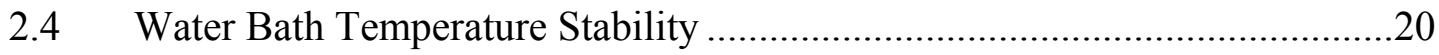

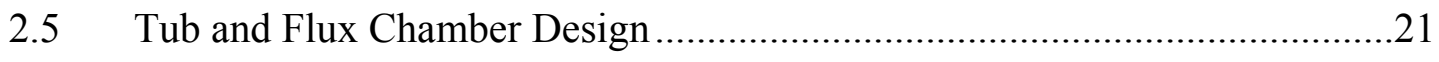

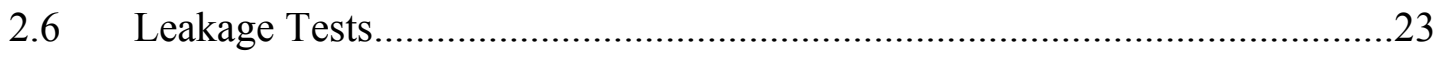

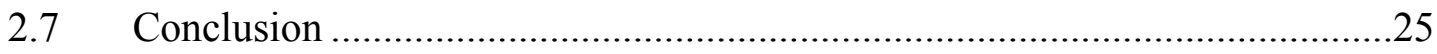

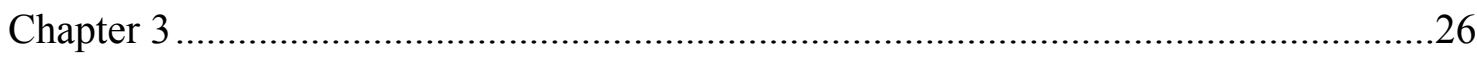

Temperature Limits and Dynamics of Methane Fluxes from Rice Agriculture ............26

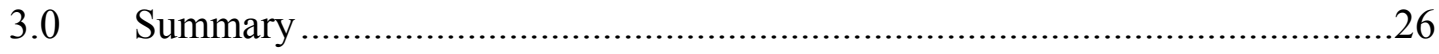

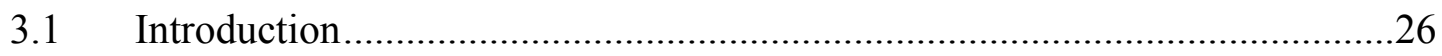

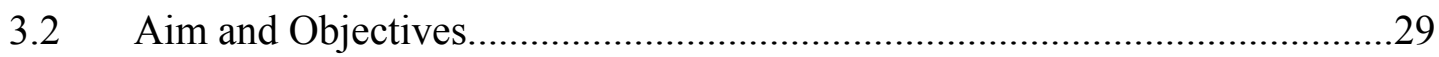

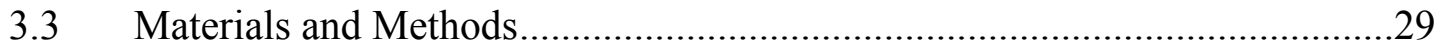

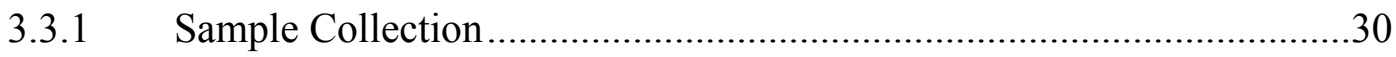

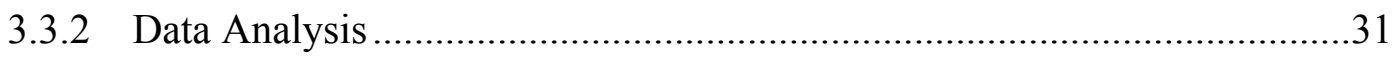

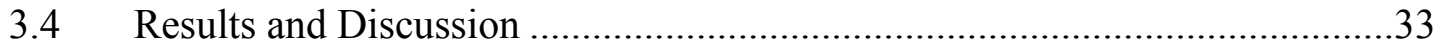


3.4.1 Seasonal Flux Variations ……………………............................................33

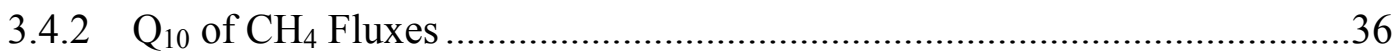

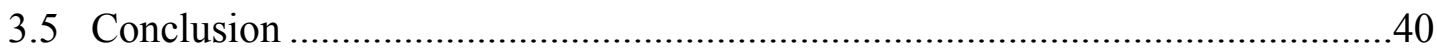

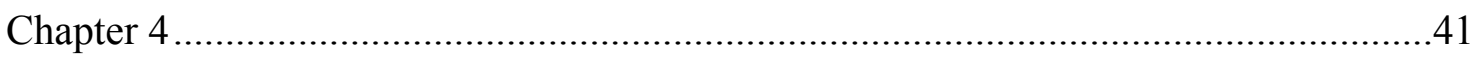

Dynamics of $\mathrm{CH}_{4}$ Concentration in Pore Water under Elevated Soil Temperature .......41

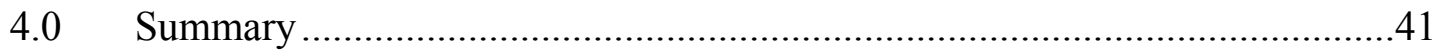

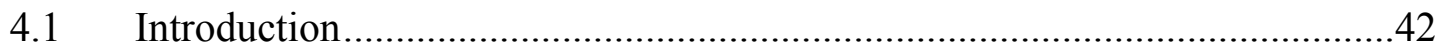

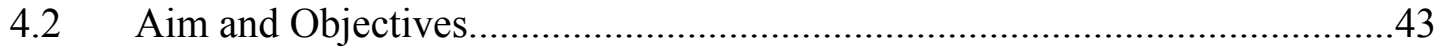

4.3 Materials and Methods..............................................................................4

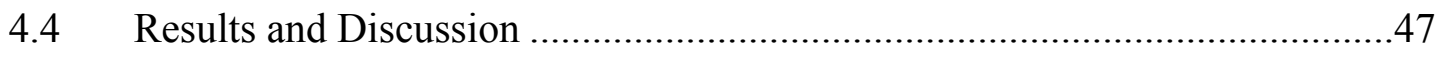

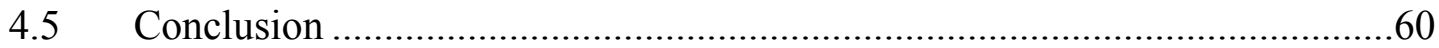

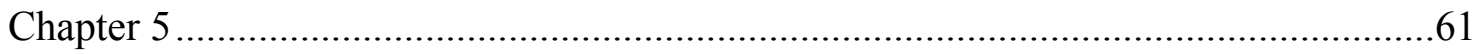

Temperature Dependence of Methane Production .........................................................61

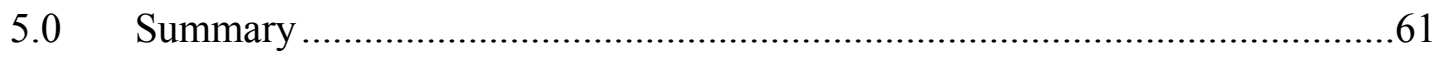

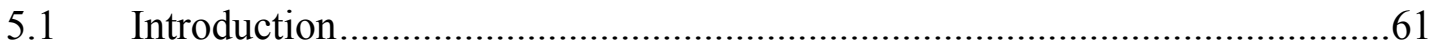

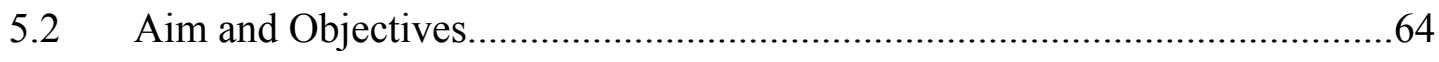

5.3 Material and Methods ………………………….....................................65

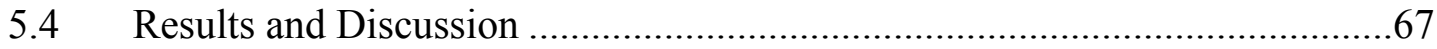

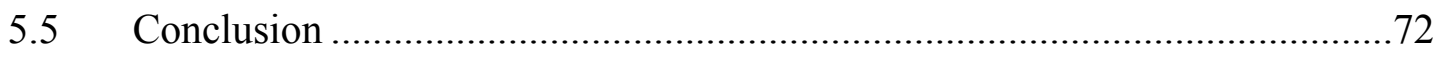

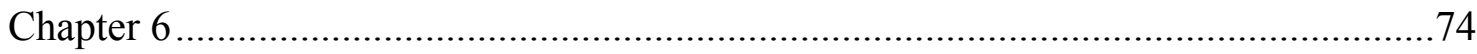

Quantifying Temperature Effect on Methane Oxidation in Rice Ecosystems using Stable Carbon and Hydrogen Isotope Ratios ......................................................................... 74

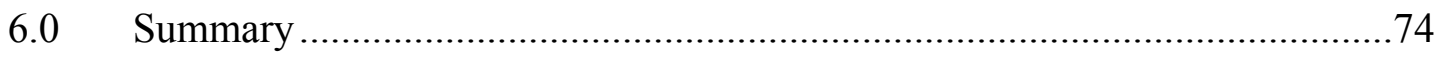

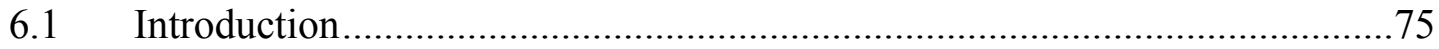

6.1.1 Other Factors Affecting $\mathrm{CH}_{4}$ Oxidation in Flooded Soils .............................77

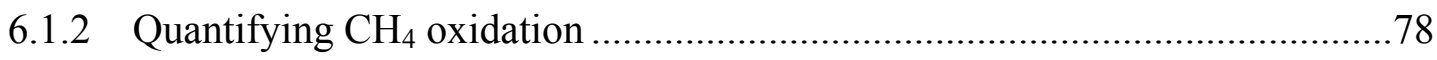

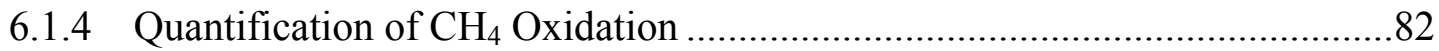

6.1.5 Isotope Fractionation by Transport...............................................................85

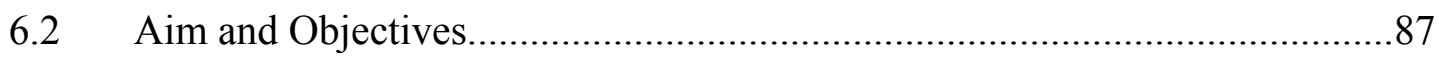

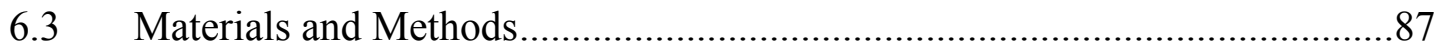




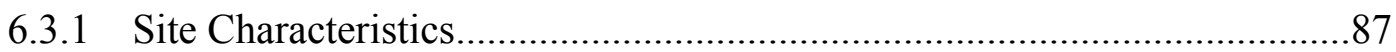

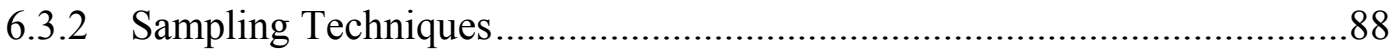

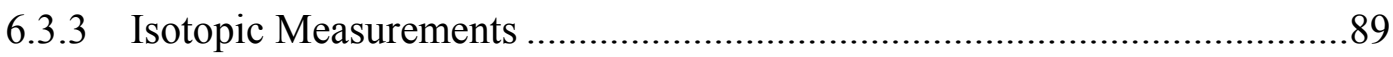

6.3.4 Determination of Fraction of $\mathrm{CH}_{4}$ Oxidized ....................................... 90

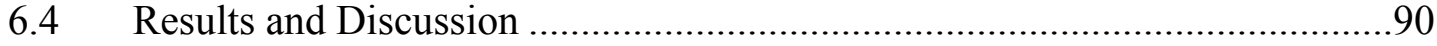

6.4.1 Carbon Isotopic Composition .........................................................90

6.4.2 Relationships between $\delta^{13} \mathrm{C}$ and $\delta \mathrm{D}$ in Emitted and Dissolved $\mathrm{CH}_{4} \ldots \ldots \ldots 96$

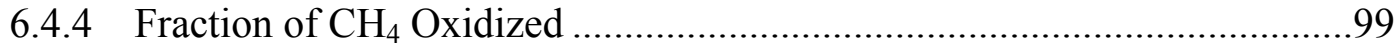

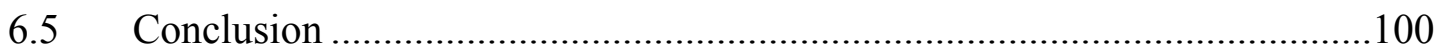

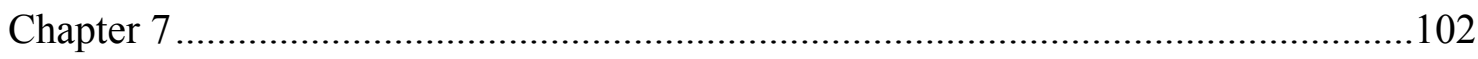

Response of $m c r A$ and $p m o A$ Gene Copies and Methane Fluxes .............................102

to Soil Temperature Changes in Rice Microcosms...................................................102

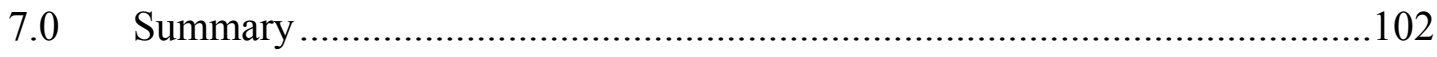

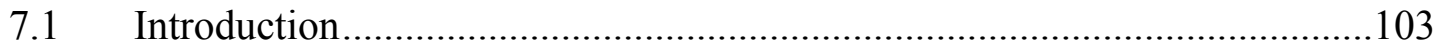

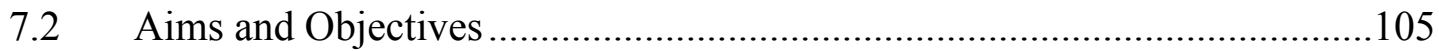

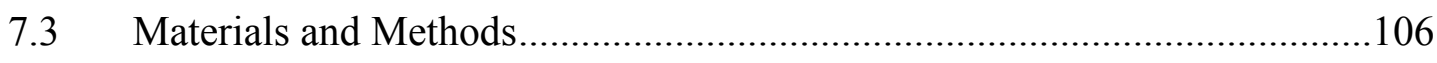

7.3.1 Preparation and Collection of Soil Samples ......................................106

7.3.2 Soil Microbial DNA Extraction, Quantitation and Purity .......................107

7.3.3 qPCR Detection of Methanogens and Methanotrophs............................108

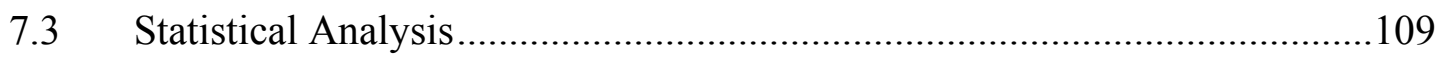

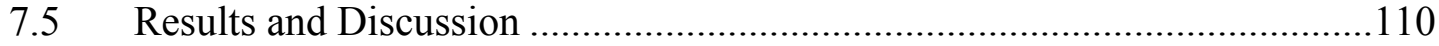

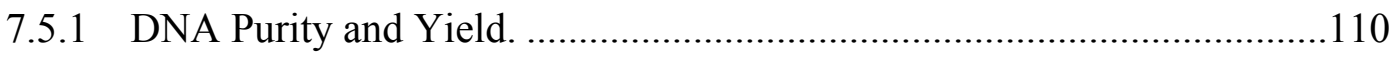

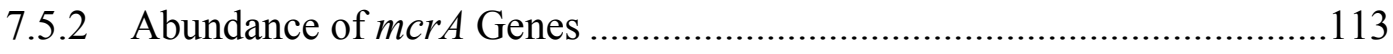

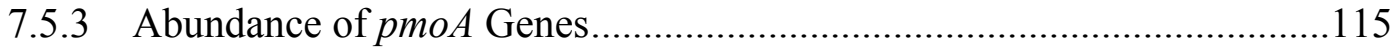

7.5.4 Relative Abundance between $m c r A$ and $p m o A$ Genes ...........................117

7.5.5 Regression between $p m o A, m c r A$ Copies and Temperature .....................120

7.5.6 Relationships between $\mathrm{CH}_{4}$ Fluxes and $m c r A$ and pmo $A$ Copies .............123

7.5.7 $\mathrm{Q}_{10}$ of Methanogens and Methanotrophs .......................................... 125

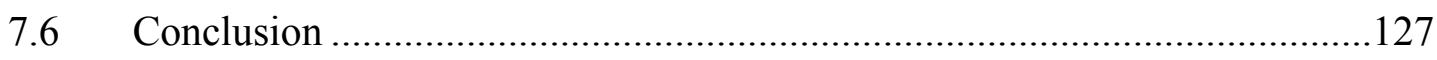

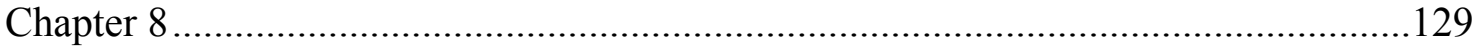


Nitrous Oxide Emissions from Rice Agriculture under Elevated Soil Temperatures ..129

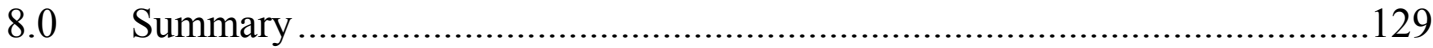

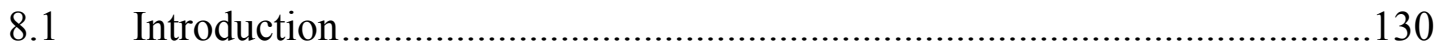

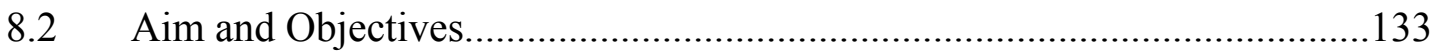

8.3 Materials and Methods.............................................................................133

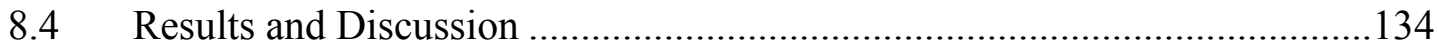

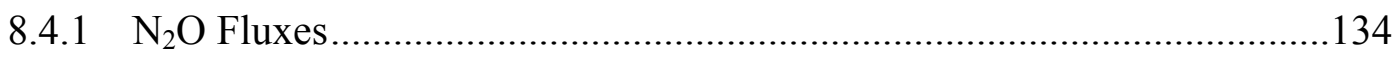

8.4.2 Effect of Soil Temperature on Fluxes .....................................................136

8.4.3 Effect of Temperature on $\mathrm{N}_{2} \mathrm{O}$ Production Rates .....................................139

8.4.3 Pore Water Concentrations .................................................................... 140

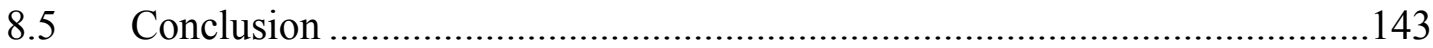

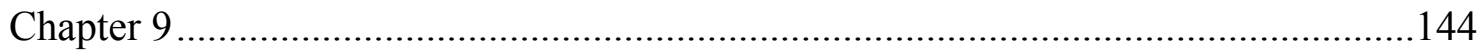

Summary and General Conclusion ....................................................................144

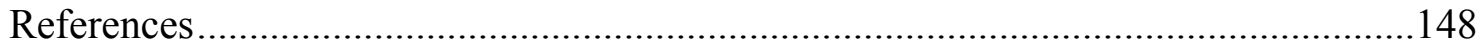

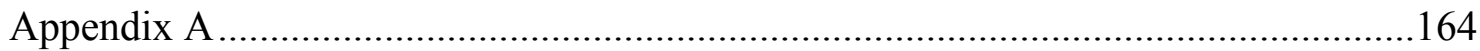

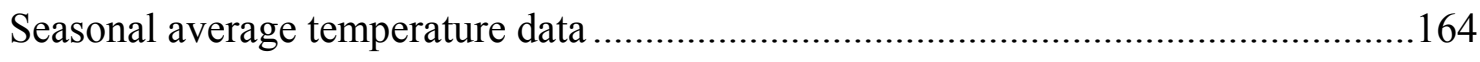

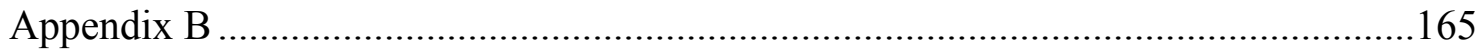

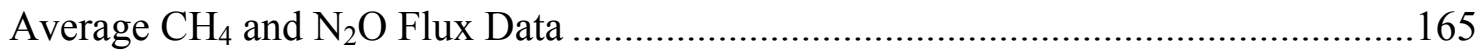

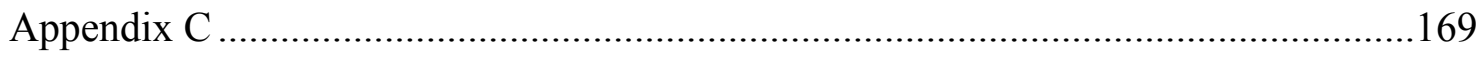

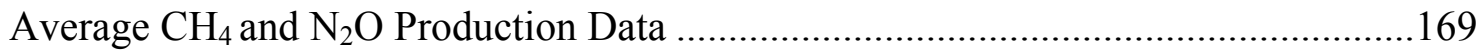

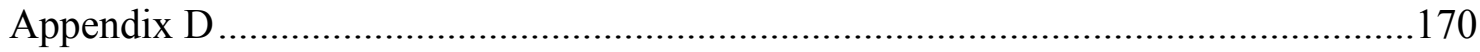

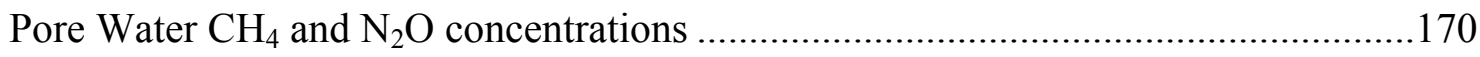

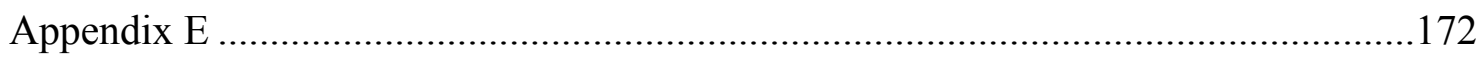

Average $\mathrm{CH}_{4}$ Isotope Measurements ..................................................................172 


\section{List of Figures}

Fig. 1.1: The combined radiative forcing estimates of $\mathrm{CH}_{4}$ and $\mathrm{N}_{2} \mathrm{O}$ is about $40 \%$ that

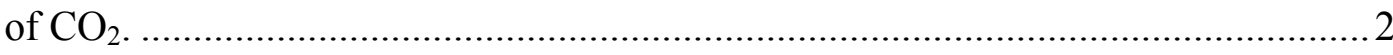

Fig. 1.2: Estimates of $\mathrm{CH}_{4}$ from rice paddies as a percentage of the global annual total.

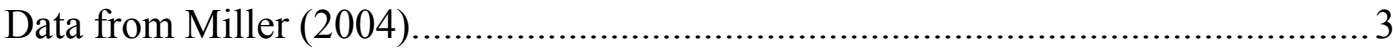

Fig. 1.3: Three major mechanisms involved in $\mathrm{CH}_{4}$ emission from rice paddies are production, oxidation and transport. Modified diagram adapted from Neue and Roger (1993).

Fig. 1.4: Estimates of $\mathrm{N}_{2} \mathrm{O}$ emissions from agriculture as a percentage of total anthropogenic emissions. Data from EDGAR, 1995 ....................................... 5

Fig. 2.2: Water bath and heating tanks were thermally insulated using fiberglass material. The top of water bath containers covered with Thermasheath 3 Insulation material to reduce heat loss 17

Fig. 2.3: Set-up with digital Immersion heater/circulator (enlarged) connected to the heating reservoir, showing the main components of the heating system: heater, circulator and a temperature sensor (PolyScience Inc). The immersion heaters had inbuilt circulators and thermostats that would help to control the water temperatures. The circulation speed was set to 15 liters/minute and temperatures were set at either, $20,26,30$ or $39{ }^{\circ} \mathrm{C}$. Flow valves were installed onto the water circulation system of each of the four heating systems to control the flow rate and allow mixing of warm water inside the water bath tanks. 18

Fig. 2.4: Schematic of the temperature measurement unit for the water bath. Components labeled TH1-TH12 are Type-T thermocouples (solid red lines) that 
were fitted to the production zone $(\sim 10 \mathrm{~cm}$ depth) in both planted and unplanted tubs. The thermocouples labeled TH9-12 (blue) were connected to production experiment jars (solid blue lines and circles).

Fig. 2.5: Microloggers connected to the thermocouples and covered (inside a reflective cover) to protect them against adverse greenhouse conditions such as wetting and direct heating. The microloggers were programmed to measure temperatures every 5 and 30 minute intervals. To determine $\mathrm{CH}_{4}$ and $\mathrm{N}_{2} \mathrm{O}$ concentrations, pore water samplers (Khalil et al., 2008) were embedded into the soil in both planted and unplanted tubs. 20

Fig. 2.7: Acrylic flux chambers fitted with 12VDC fans to homogenize the air inside the flux during sampling, and a septum through which the gas samples were drawn (design based on Khalil et al., 1991). The edges were joined together using a hot glue gun. Thin PVC strips were glued from the bottom of the chamber to strengthen the chamber and prevent any gas leakage during sampling. A rubber septum was installed at the top of each flux chamber and was used to draw gas samples for $\mathrm{CH}_{4}$ and $\mathrm{N}_{2} \mathrm{O}$ flux measurements. 22

Fig. 2.8: A schematic representation of the components of production experimental setup. The glass jars were made from modified Erlenmeyer flasks (necks extended by $20 \mathrm{~cm}$ ). Inside the jars were $5 \mathrm{~mL}$ cylinders (cut from $30 \mathrm{ml}$ plastic syringes) held by a very thin and in extensible string. Air-tight inlet and outlet valves, and insulated thermocouple temperature probes were fitted onto the stoppers and glued using a hot glue gun. 23 
Fig. 3.1: (a) Rice field fluxes from Tu Zu China (reported in Khalil et al., 1998a), and (b) New Delhi, India (Parasher et al., 1993). Parashar et al. (1993) reported a distinct increase in $\mathrm{CH}_{4}$ emission from rice plots with increase in soil temperature from 26 to $34.5{ }^{\circ} \mathrm{C}$ and a decrease in the rate of emission above the temperature under controlled soil temperature. Similar results can be observed in results reported by Khalil et al. (1991). All data indicate a sharp decline in $\mathrm{CH}_{4}$ fluxes after reaching an optimum value or peak, an indication that the Arrhenius model

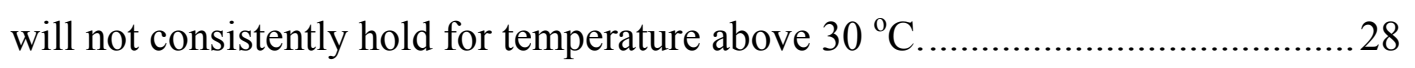

Fig. 3.3: Seasonal $\mathrm{CH}_{4}$ fluxes across different temperature treatments and between winter and summer seasons. 34

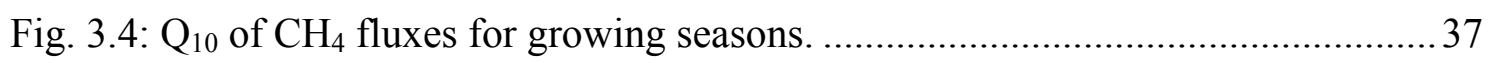

Fig. 3.5: Uncertainties in the $\mathrm{Q}_{10}$ of $\mathrm{CH}_{4}$ fluxes during the growing season...................38

Fig. 3.6: $\mathrm{Q}_{10}$ of $\mathrm{CH}_{4}$ fluxes during the growing season, showing high values of $\mathrm{Q}_{10}$ for low flux values. 39

Fig. 4.1: Schematic diagram of pore water samplers (Khalil et al., 2008) inside the tubs. The samplers were inserted at 5,10,15 and $20 \mathrm{~cm}$ soil depths in each of the tubs. The cylinders were covered with gauze fabric to allow water movement between their interior and the surroundings. 44

Fig. 4.2: Pictures of pore water tubes embedded into flooded soils inside tubs containing temperature probes. The tubes were fitted with valves to which the syringes were hooked during sampling. .45 
Fig. 4.3: Temperature effect on the seasonal average $\mathrm{CH}_{4}$ concentration vertical profiles in the soil water in for planted tubs. In all four different temperature treatments, the average values are close to each other, with highest values at $20 \mathrm{~cm}$ depth............ 48

Fig. 4.4: Vertical pore water $\mathrm{CH}_{4}$ concentrations profiles for 0-60 DAT, indicating layering in different temperature treatments. In each treatment, highest values occur between 10 and $15 \mathrm{~cm}$. Differences in the profiles shows that temperature is an important factor during this phase of the season..............................................50

Fig. 4.5: Effect of temperature on $\mathrm{CH}_{4}$ concentration in pore water, showing higher concentrations at $32{ }^{\circ} \mathrm{C}$ at the beginning and lower at the end of the growing season. Lowest concentrations were present at lowest temperatures. Concentrations increase at the start of the growing season, reaching a peak at mid-season, and decrease as the season ended.

Fig. 4.6: Average concentration of $\mathrm{CH}_{4}$ is higher at $32{ }^{\circ} \mathrm{C}$ at the start and lower at the end than at other temperatures. Concentrations were low at $20{ }^{\circ} \mathrm{C}$ throughout the

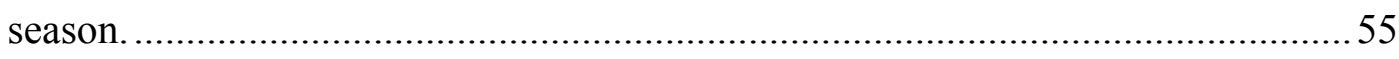

Fig. 4.7: Average concentration per temperature set-up. Effect of transport and temperature on pore water $\mathrm{CH}_{4}$ concentrations. Generally higher concentrations of $\mathrm{CH}_{4}$ in control tubs at the beginning of the season, but lower at the end. These observations could be due to bacteria degrading decaying roots............................56

Fig. 4.8: Trends of pore water $\mathrm{CH}_{4}$ concentrations across different temperatures. Concentration of $\mathrm{CH}_{4}$ at $32{ }^{\circ} \mathrm{C}$ is higher till mid-season, but lower than that at 28 ${ }^{\circ} \mathrm{C}$ thereafter. This is consistent with flux observations, in which fluxes have been 
found to be higher at for $32{ }^{\circ} \mathrm{C}$ at the start of season, but quickly diminished after mid-season, with concentration at $28^{\circ} \mathrm{C}$ becoming higher beyond this point.........57

Fig. 4.9: Between 1 and DAT 60, pore water $\mathrm{CH}_{4}$ concentration was the limiting factor in $\mathrm{CH}_{4}$ fluxes. During this period fluxes increased to a maximum. In all treatments, $\mathrm{CH}_{4}$ concentrations were highest and lowest at $32{ }^{\circ} \mathrm{C}$ and $20{ }^{\circ} \mathrm{C}$ 58

Fig. 4.11: $\mathrm{CH}_{4}$ fluxes reaches maximum $\left(25-40 \mathrm{mg} / \mathrm{m}^{2} / \mathrm{hr}\right)$ at $60 \mathrm{DAT}$ (while the pore water concentrations increased from $60 \mu \mathrm{g} / \mathrm{L}$ to $1000 \mu \mathrm{g} / \mathrm{L}$ ), and then level off despite continuous increase in $\mathrm{CH}_{4}$ pore water concentration. 59

Fig. 5.1: Effect of temperature on the percentage contribution of acetate and $\mathrm{H}_{2} / \mathrm{CO}_{2}$ to methanogenesis in anoxic rice soil. The data shows that as temperature was continuously increased above $35{ }^{\circ} \mathrm{C}, \mathrm{CH}_{4}$ production contribution from $\mathrm{H}_{2} / \mathrm{CO}_{2}$ became predominant, while that from acetate diminished. Data extracted from Conrad (2002). 63

Fig. 5.2: Picture of production jars mounted onto the water bath system. The jars are fitted with valves and thermocouples connected to microloggers (not shown in picture). Temperature was continuously monitored and recorded every 5 minutes during the growing season. The glass jars were purged with $\mathrm{N}_{2}$ several times before each sample was collected. .66

Fig. 5.3: $\mathrm{CH}_{4}$ production rates, showing increases after 2 weeks following flooding. The highest production rates were associated with highest temperature after 17 days following transplanting (DAT). .68

Fig. 5.4: (a) Average $\mathrm{CH}_{4}$ production rates as a function of temperature, and (b) $\mathrm{Q}_{10} \mathrm{~S}$ of $\mathrm{CH}_{4}$ production based on the incubation technique. 70 
Fig. 5.5: $\mathrm{CH}_{4}$ oxidation rates and fractions calculated from production and flux data... 72

Fig. 6.1: Typical models proposed for the variation of $\alpha_{o x}$ with temperature. There is generally an agreement between the slopes, but with significantly different intercepts. 85

Fig. 6.2: Seasonal variation of $\delta^{13} \mathrm{C}$ of $\mathrm{CH}_{4}$ emitted from rice planted tubs (solid lines) and unplanted tubs (broken lines) for different temperature treatments. In all treatments, the samples from planted tubs were more depleted during the middle part of the growing season than at the start. That feature was not evident in unplanted (control), except in one particular treatment $\left(20^{\circ} \mathrm{C}\right)$ in which the trend was similar to those in planted tubs.

Fig. 6.3: Seasonal variation of $\delta^{13} \mathrm{C}_{\text {of }} \mathrm{CH}_{4}$ in pore water from planted tubs (solid lines) and unplanted tubs (broken lines) for different temperature treatments.

Fig. 6.4: Time series of $\delta \mathrm{D}$ of $\mathrm{CH}_{4}$ showing hydrogen isotopic composition in rice planted tubs (solid lines) and unplanted (control) tubs (broken lines) for different temperature treatments. Generally, the value are enriched at the start, and then depleted till the end of sampling period.

Fig. 6.5: Time series of pore water $\mathrm{\delta D}$ of $\mathrm{CH}_{4}$ showing hydrogen isotopic composition in rice planted tubs (solid lines) and unplanted (control) tubs (broken lines) for different temperature treatments. 94

Fig. 6.6: Classification of bacterial and thermogenic natural gas by the combination of $\delta^{13} \mathrm{C}-\mathrm{CH}_{4}$ and $\delta \mathrm{D}-\mathrm{CH}_{4}$ information (Adapted from Whitcar 1999). Compared with $\delta{ }^{13} \mathrm{C}-\mathrm{CH}_{4}$ and $\delta \mathrm{D}-\mathrm{CH}_{4}$ found in this research, results showed that the predominant source of $\mathrm{CH}_{4}$ was acetate (red circle), and not through $\mathrm{CO}_{2}$ reduction. 95 
Fig. 6.7: Effect of temperature on the relationship between isotopic composition, $\delta^{13} \mathrm{C}$ and $\delta \mathrm{D}$ values in the air samples from planted tubs. 97

Fig. 6.8: Temperature effect on the relationship between isotopic composition, $\delta^{13} \mathrm{C}$ and $\delta \mathrm{D}$ values in pore water from planted tubs. 98

Fig.7.1: Schematic of the replicates (Rice planted tubs) and tubs from which the soil samples for population studies will be taken (rice-planted sampling tubs), and controls for each set of experiment (unplanted/Control tubs). 107

Fig. 7.2: Protocol for the qPCR thermal profile set-up for $m c r A$ gene quantitation were as follows: $95{ }^{\circ} \mathrm{C}$ for $15 \mathrm{~min}, 40$ cycles of $94{ }^{\circ} \mathrm{C}$ for $30 \mathrm{~s}, 56{ }^{\circ} \mathrm{C}$ for $30 \mathrm{~s}, 72{ }^{\circ} \mathrm{C}$ for 1 min, followed by a single cycle of $82{ }^{\circ} \mathrm{C}$ for $10 \mathrm{~s}$

Fig. 7.3: Ratios of 260/230 (e.g. >2) and 260/280 (e.g. >1.7) are indicative of pure DNA, while the low ratios are indicative of humic acid and protein contamination, respectively.

Fig. 7.4: Total DNA yields ranged from of 10 to $45 \mu \mathrm{g}$ of DNA per $\mu 1$. Data showed no notable differences across different temperature treatments.

Fig. 7.5: Average values of DNA concentration at different soil horizons at different soil temperature treatment

Fig. 7.6: Average values of $m c r A$ copies at different soil horizons at different soil temperature treatment. Highest $m c r A$ copies were found at 28 and $32{ }^{\circ} \mathrm{C}$. 114

Fig. 7.7: Average values of $p m o A$ copies at different soil horizons at different soil temperature treatment. Highest $p m o A$ copies were found at 28 and $32{ }^{\circ} \mathrm{C}$ 116

Fig. 7.8: Methanogen and methanotroph populations at different soil horizons at different soil temperature treatments. 117 
Fig. 7.9: Relative abundance of $m c r A$ and $p m o A$ (copies $\mathrm{g}^{-1}$ dry soil) at different depths 119

Fig. 7.10: Regressions: natural $\log \left(p m o A\right.$ copies $\mathrm{g}^{-1}$ dry soil) versus natural $\log$ ( $m c r A$ copies $\mathrm{g}^{-1}$ dry soil) 121

Fig. 7.11: $\mathrm{CH}_{4}$ fluxes vs $m c r A$ a copies at $5-10 \mathrm{~cm}$ depth 124

Fig. 7.12: $\mathrm{CH}_{4}$ fluxes vs $p m o A$ copies at $5-10 \mathrm{~cm}$ depth 125

Fig. 7.13: (a) Dependence of methanogen and methanotroph populations on soil temperature. (b) $\mathrm{Q}_{10}$ of methanogen and methanotrophs for different soil horizons. 126

Fig. 7.14: Variation of $\mathrm{Q}_{10}$ values of methanogens and methanotrophs during the season for different temperature treatments and soil depth. 127

Fig. 8.1: Dominant processes involved in the formation of $\mathrm{N}_{2} \mathrm{O}$ in soils: (I) Nitrification (oxidation of ammonium to nitrite and nitrate, or a biologically induced increase in the oxidation state of nitrogen and occurs under aerobic conditions) and (II) Denitrification (biological reduction of nitrate, $\mathrm{NO}_{3}{ }^{-}$or nitrite, $\mathrm{NO}_{2}^{-}$, to nitrogen oxides or molecular nitrogen under anaerobic conditions). Adapted from Sithole (2009) 131

Fig. 8.2: $\mathrm{N}_{2} \mathrm{O}$ emissions from both (a) planted and (b) unplanted tubs. Higher fluxes occurred in unplanted than in planted tubs, and the peaks coincide with episodes of fertilization. Elsewhere, the fluxes were nearly close to zero or slight negative. The impact of temperature was more apparent in unplanted tubs than in planted ones. 
Fig. 8.3: Effect of soil temperature on $\mathrm{N}_{2} \mathrm{O}$ fluxes during (a) Winter and (b) Summer.

Fig. 8.3: Effect of soil temperature on fluxes as indicated by $\mathrm{Q}_{10}$ values. No discrepancy was observed between the data from (a) Winter and (b) Summer...................... 138

Fig. 8.5: Average pore water concentrations of $\mathrm{N}_{2} \mathrm{O}$ with increasing soil temperature in the rhizosphere. The differences could be due to plant transport (increased transport through rice) and $\mathrm{N}$ utilization by plants. 


\section{List of Tables}

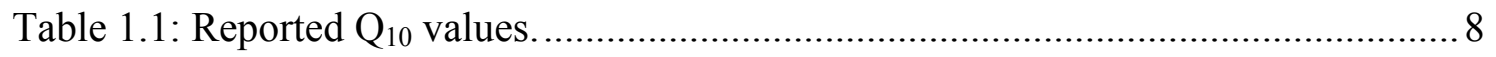

Table 2.1: The t-statistic values and slope (ppm/minute) of regression between measured concentrations for: (a) $\mathrm{CH}_{4}$, and (b) $\mathrm{N}_{2} \mathrm{O}$. $\mathrm{H}_{\mathrm{o}}$ was rejected for $\mathrm{t}_{\alpha=0.025} \leq$ 3.184 and $t_{\alpha=0.025} \geq+3.184$ for $\mathrm{n}=5$ (two-tailed test) .................................. 24

Table 6.1: Overview of typical isotope measurements on $\mathrm{CH}_{4}$ from rice paddies.......79

Table 6.2: Overview of the kinetic isotopic effects during $\mathrm{CH}_{4}$ oxidation by anaerobic

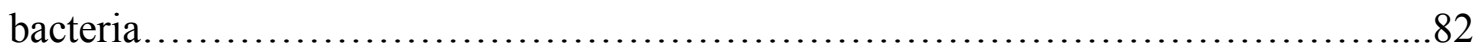




\section{Chapter 1}

\section{Background Information}

\subsection{Introduction}

One of the major environmental threats our planet faces today is the potential for rapid global warming. Determining the potential causes of global climate change has been a long term process that has involved work from scientists around the globe. From more than three decades of scientific studies, questions have been raised about the magnitude of the projected global warming, its environmental impacts, and the role of feedbacks between greenhouse gases and elevated global temperatures over the next century.

It is noteworthy that the combined global warming contribution from these non- $\mathrm{CO}_{2}$ greenhouse gases is quite substantial. For example, among non- $\mathrm{CO}_{2}$ greenhouse gases, methane $\left(\mathrm{CH}_{4}\right)$ has the highest radiative forcing, contributing about $3.3 \mathrm{GtCO}_{2}$-eq/yr (IPCC, 2007d). At its present atmospheric concentration of $1775 \mathrm{ppb}$, which is about three times its pre-industrial level (Rasmussen and Khalil, 1981; Khalil et al., 1989), it has an estimated radiative forcing (RF) of $+0.48 \pm 0.05 \mathrm{Wm}^{-2}$ (IPCC, 2007b), nearly one third the contribution of $\mathrm{CO}_{2}$ (Fig 1.1).

The predominant source of $\mathrm{CH}_{4}$ is microbial activities in anaerobic environments such as gastrointestinal tracts of ruminants, rice paddies, landfills and natural wetlands (Khalil and Shearer, 1993a; Khalil and Shearer, 1993b; Bodelier et al., 2000). 


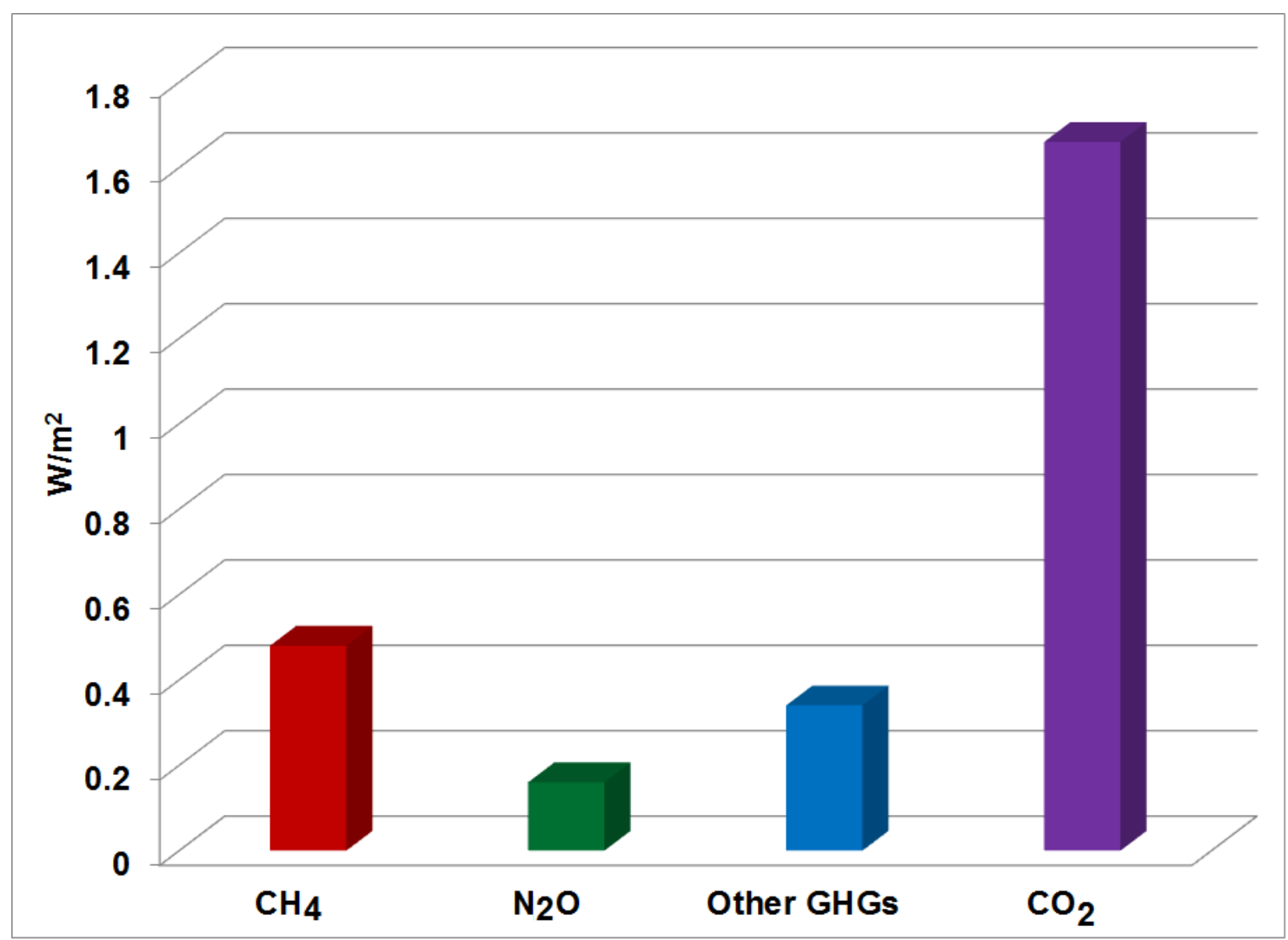

Fig. 1.1: The combined radiative forcing estimates of $\mathrm{CH}_{4}$ and $\mathrm{N}_{2} \mathrm{O}$ is about $40 \%$ that of $\mathrm{CO}_{2}$.

While anthropogenic sources account for about $70 \%$ of global annual total $\mathrm{CH}_{4}$ emissions (Allen et al., 2003; IPCC, 2007a), about 40-60\% of this contribution comes from agriculture (Zou et al., 2004; Minami, 1997; Whiting and Chanton, 1993). On a global scale rice fields contribute an estimated $14 \%$ total global $\mathrm{CH}_{4}$ emission (Fig. 1.2). 


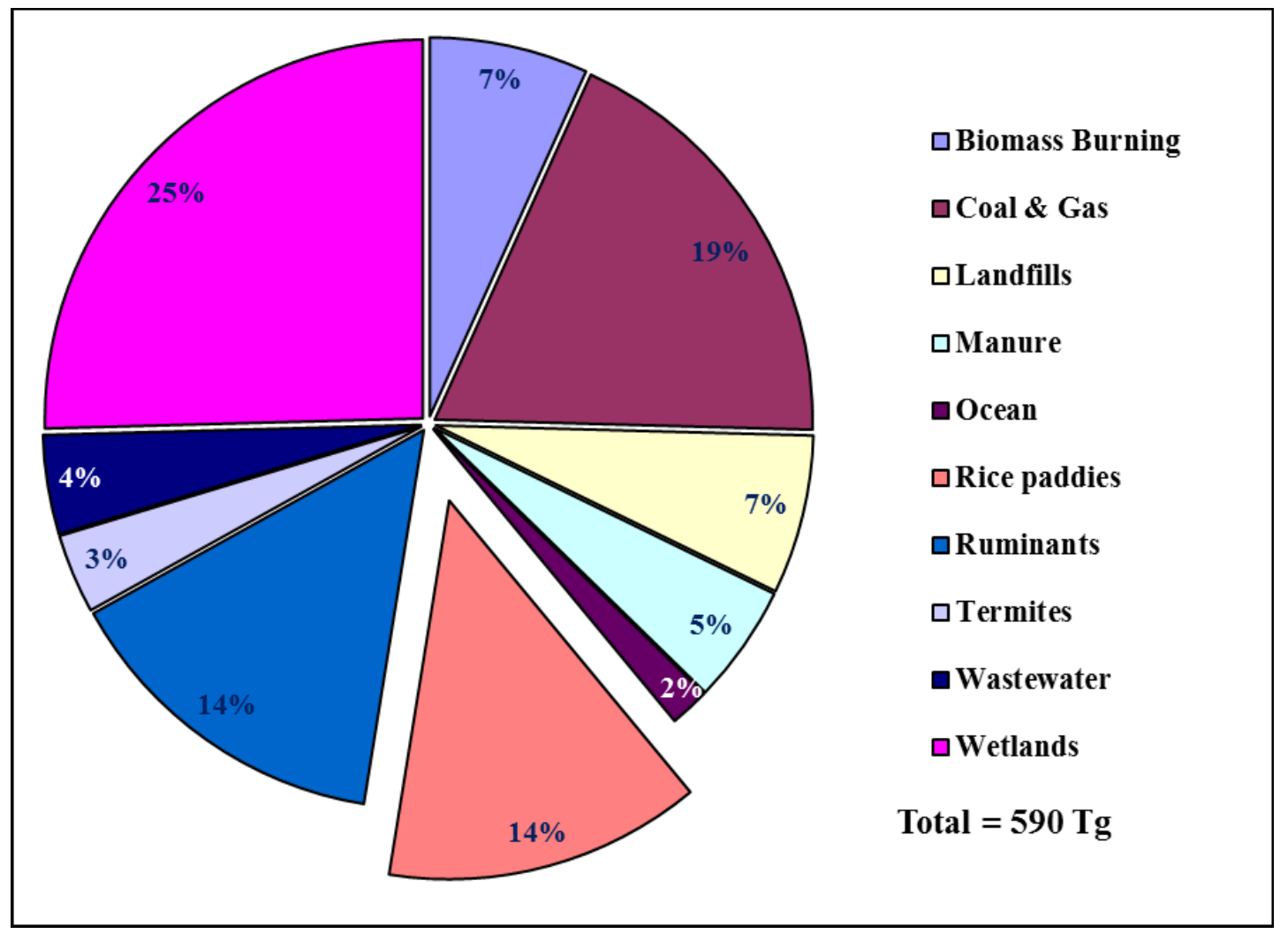

Fig. 1.2: Estimates of $\mathrm{CH}_{4}$ from rice paddies as a percentage of the global annual total. Data from Miller (2004).

The source of $\mathrm{CH} 4$ production substrates is decaying organic material by microorganisms. One group of these microorganisms (methanogens) produces $\mathrm{CH}_{4}$ by utilizing acetate or through $\mathrm{CO}_{2}$ reduction, while the other group (methanotrophs) oxidizes some of the $\mathrm{CH}_{4}$. The production and oxidation of $\mathrm{CH}_{4}$ are exclusively anaerobic and aerobic processes, respectively. The $\mathrm{CH}_{4}$ that is not oxidized is transported by physical processes such as diffusion, ebullition and ventilation. Ventilation through the aerenchyma is the major transport process rice paddies, while the other transport processes are predominantly active during the first two weeks before crop establishment after transplanting. 


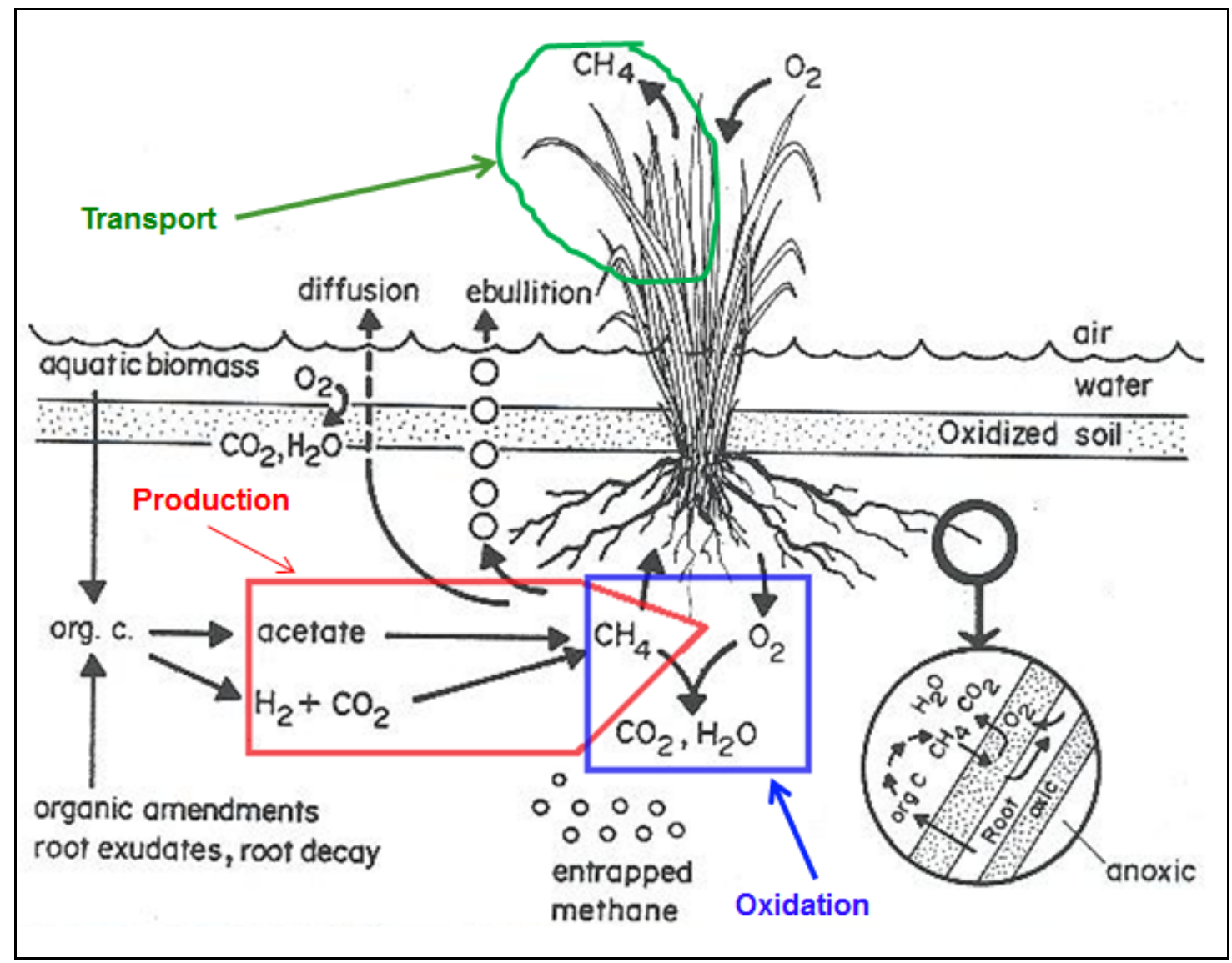

Fig. 1.3: Three major mechanisms involved in $\mathrm{CH}_{4}$ emission from rice paddies are production, oxidation and transport. Modified diagram adapted from Neue and Roger (1993).

Another important greenhouse gas, $\mathrm{N}_{2} \mathrm{O}$, is about 300 times more effective in global warming than $\mathrm{CO}_{2}$ per molecule (Minami 1997). At its current level of about $319 \mathrm{ppbv}$ (Beerling et al. 2007), which represents an increase of $18 \%$ from its pre-industrial level

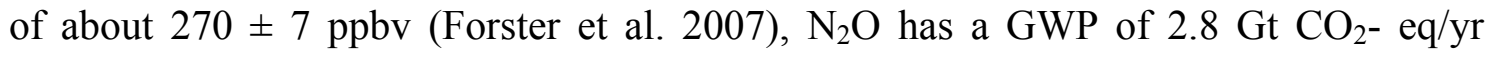
(Smith et al. 2007), and is mainly produced from agricultural soils (Fig.1.4). 


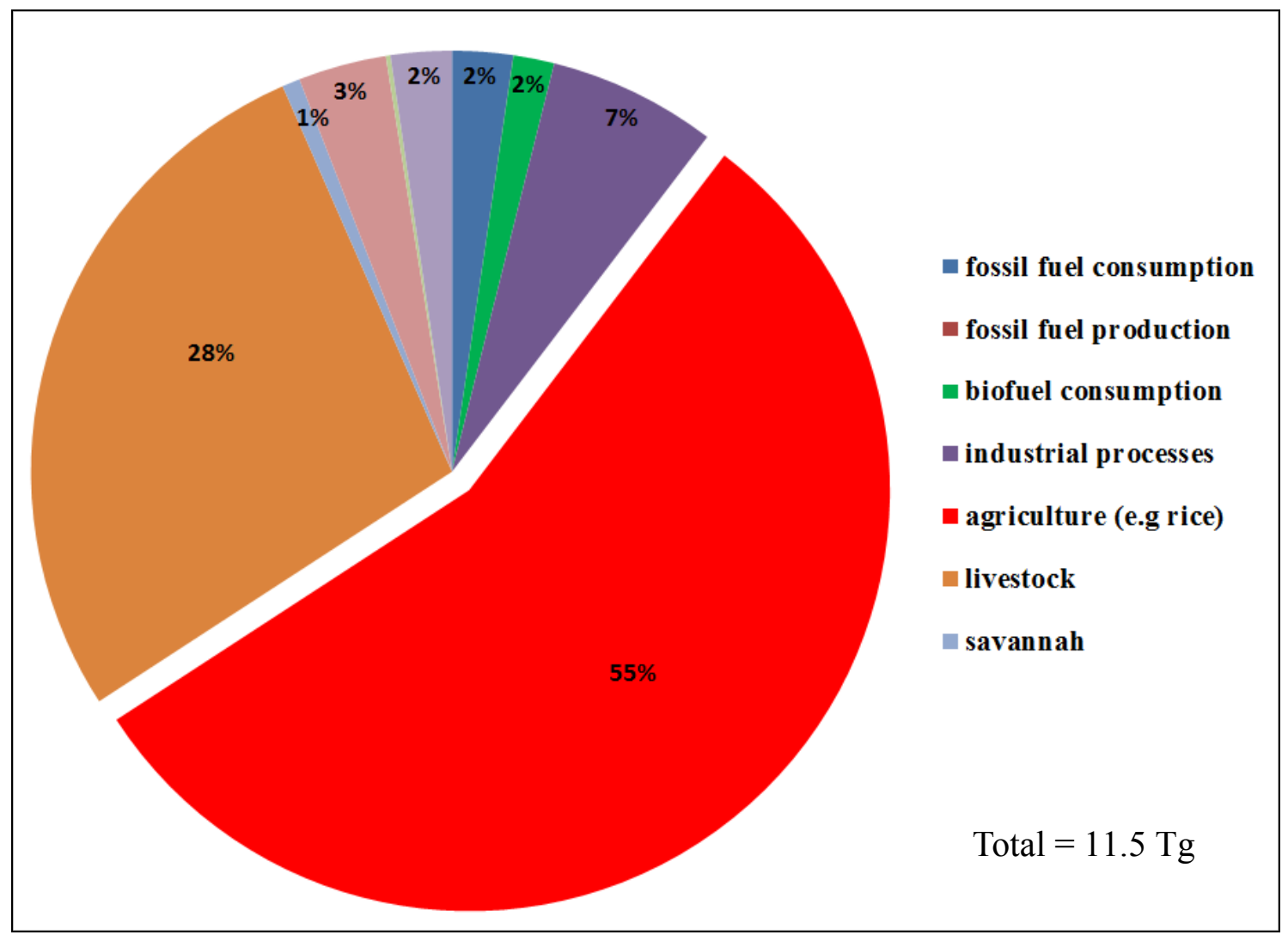

Fig. 1.4: Estimates of $\mathrm{N}_{2} \mathrm{O}$ emissions from agriculture as a percentage of total anthropogenic emissions. Data from EDGAR, 1995.

Ranked according to contribution to global warming so far, $\mathrm{CH}_{4}$ and $\mathrm{N}_{2} \mathrm{O}$ are considered second and third respectively after $\mathrm{CO}_{2}$.

While it is clear from field and laboratory studies that higher soil temperatures affect $\mathrm{CH}_{4}$ and $\mathrm{N}_{2} \mathrm{O}$ emissions (Tab. 1.1), quantitative answers as to how global warming will affect these emissions are presently not well known. Considering that rice paddies are similar to wetlands, with a gross contribution of about $40-50 \%$ of the global source, the contribution of this feedback to global warming is likely to be quite substantial. Undoubtedly, this feedback between global warming and these greenhouse gases will be 
an important component of the future climate change. While the atmospheric concentration of gases is critically dependent upon the long-term sensitivity of these emissions to global warming, the lack of precise information about this sensitivity means that climate models may underestimate climate change over the next century. Thus, there is need to distinguish the different processes that lead to $\mathrm{CH}_{4}$ and $\mathrm{N}_{2} \mathrm{O}$ emissions, their temperature dependency, and their response to global climate change. The ability to adequately address these issues is the key to understand these feedbacks, explain the observed trends, know what to manage and what to include in the strategy to control the future concentrations of these greenhouse gases.

Previous greenhouse results indicated increases of $\mathrm{CH}_{4}$ and $\mathrm{N}_{2} \mathrm{O}$ fluxes from flooded rice tubs in response to increased soil temperatures (Sithole, 2009). From these early experiments, more questions emerged, and the need for further investigations was highlighted: (I) how will an increase in soil temperature affect the production, oxidation and transport of these gases, and subsequently the $\mathrm{Q}_{10}$ of the net emissions? (II) What is the linkage between the $\mathrm{Q}_{10}$ of plant-mediated transport and the $\mathrm{Q}_{10} \mathrm{~S}$ of production and oxidation? The need to develop the theory and relationships between these $\mathrm{Q}_{10} \mathrm{~S}$ was stressed in order to understand the complexity of the response of these processes to any change in temperature.

The IPCC projections have indicated that global temperature may rise by between 1.4 and $6{ }^{\circ} \mathrm{C}$ by 2100 (depending on the scenario). Because of large variations in data reported from different studies, one of the thorny issues is to unify these results and use 
the data to project future emissions. It is important to note that this feedback should be incorporated into climate model to improve the predictability of future $\mathrm{CH}_{4}$ and $\mathrm{N}_{2} \mathrm{O}$ emissions from rice paddies and similar ecosystems such as natural wetlands. For this purpose, it is necessary to quantify this feedback in order to understand whether global warming will promote any preferential enhancement of either sources or sinks.

\section{$1.2 \mathrm{Q}_{10}$ of $\mathrm{CH}_{4}$ and $\mathrm{N}_{2} \mathrm{O}$}

Already, several studies have shown that that $\mathrm{CH}_{4}$ and $\mathrm{N}_{2} \mathrm{O}$ fluxes increase with increasing soil temperature (Table 1.1). The large variation in the reported $\mathrm{Q}_{10}$ values is clear testimony that temperature plays an important but poorly understood role in regulating these greenhouse gas emissions. Either non-biological processes may be influencing this response (Grant and Pattey, 2008) or the large $\mathrm{Q}_{10}$ values could reflect the anomalous temperature behavior of microbial processes or their interactions in the underlying processes (Segers, 1998). For example, simultaneous changes in temperature and substrate availability (Whiting and Chanton, 1993) or changes in substrate availability coincident with temperature increase are being mistaken for a temperature response. 
Table 1.1: Reported $\mathrm{Q}_{10}$ values.

\begin{tabular}{|c|c|c|c|c|}
\hline$Q_{10}$ values & Process & Method & $\begin{array}{c}\text { Temperature } \\
\left({ }^{\circ} \mathrm{C}\right)\end{array}$ & Source \\
\hline $1.27-2.25$ & $\mathrm{CH}_{4}$ oxidation & $\begin{array}{l}\text { Incubation: drained } \\
\text { peatland soil }\end{array}$ & $5.5-15$ & Crill et al., 1994 \\
\hline $3.0-3.3$ & $\begin{array}{l}\text { Net } \mathrm{CH}_{4} \\
\text { emission }\end{array}$ & $\begin{array}{l}\text { Static closed chambers: } \\
\text { individual plants }\end{array}$ & $5.0-30$ & MacDonald et al., 1998 \\
\hline $\begin{array}{l}1.1 \\
1.5\end{array}$ & $\mathrm{CH}_{4}$ oxidation & $\begin{array}{l}\text { Incubation: slurried peat } \\
\text { samples }\end{array}$ & $\begin{array}{l}4.0-13.5 \\
135-30\end{array}$ & Hulzen et al., 1999 \\
\hline $1.3-28$ & $\mathrm{CH}_{4}$ production & $\begin{array}{l}\text { Incubation: slurried peat } \\
\text { samples }\end{array}$ & - & Segers, 1998 \\
\hline $1.2-2.0$ & $\mathrm{CH}_{4}$ oxidation & $\begin{array}{l}\text { Incubation: peat soil from } \\
\text { fertilized \& unfertilized } \\
\text { plots }\end{array}$ & - & Crill et al., 1991 \\
\hline $1.7-4.7$ & $\mathrm{CH}_{4}$ production & $\begin{array}{l}\text { Incubation: anaerobic soil } \\
\text { from Northern Canadian } \\
\text { wetlands }\end{array}$ & $10-20$ & Valentine, 1994 \\
\hline $3.1-8.7$ & $\mathrm{CH}_{4}$ production & $\begin{array}{l}\text { Soil slurries measured } \\
\text { using flux chambers. }\end{array}$ & $2-24$ & Priemé, 1994 \\
\hline $1.5-2.3$ & $\begin{array}{l}\mathrm{CH}_{4} \text { net } \\
\text { emissions from } \\
\text { rice fields }\end{array}$ & $\begin{array}{l}\text { Static closed chambers: } \\
\text { individual plants. }\end{array}$ & $20-42$ & Khalil et al., 1998d \\
\hline$<1-6$ & $\mathrm{CH}_{4}$ emissions & Incubation flooded soil & $15-25$ & Rath et al., 2002 \\
\hline$>1-5$ & $\begin{array}{l}\text { from flooded } \\
\text { soils }\end{array}$ & samples & $25-35$ & \\
\hline 16 & $\begin{array}{l}\mathrm{CH}_{4} \text { emissions } \\
\text { from flooded } \\
\text { soils }\end{array}$ & Incubated paddy soil cores & $20-25$ & $\begin{array}{l}\text { Tsutsuki and } \\
\text { Ponnamperuma, } 1987\end{array}$ \\
\hline 6 & $\mathrm{~N}_{2} \mathrm{O}$ emission & $\begin{array}{l}\text { Automated flux chamber } \\
\text { measurements from potato } \\
\text { field soils. }\end{array}$ & $10-30$ & Flessa et al., 2002 \\
\hline 50 & $\mathrm{~N}_{2} \mathrm{O}$ emission & Incubated soil cores & $5-50$ & Dobbie and Smith 2001 \\
\hline 8.9 & & $\begin{array}{l}\text { fertilized with ammonium } \\
\text { nitrate. }\end{array}$ & $12-18$ & \\
\hline 3.7 & & & $5-50$ & \\
\hline 2.3 & & $\begin{array}{l}\text { Incubated grassland soil } \\
\text { cores }\end{array}$ & $12-18$ & \\
\hline $2.2-7.7$ & $\mathrm{CH}_{4}$ & $\begin{array}{l}\text { Emission from rice } \\
\text { ecosystems in the }\end{array}$ & $19-23$ & Sithole, 2009 \\
\hline $1.1-3.6$ & $\mathrm{~N}_{2} \mathrm{O}$ & greenhouse & & \\
\hline
\end{tabular}

\subsection{Research Objectives}

Because of the complexity and gaps in the understanding of temperature dynamics of the processes involved in the formation and emission of these gases, the magnitude of 
this feedback in the real earth system remain highly uncertain. From previous experiments, preliminary simplified experiments to measure $\mathrm{Q}_{10}$ of $\mathrm{CH}_{4}$ and $\mathrm{N}_{2} \mathrm{O}$ were carried out. From this scoping study, $\mathrm{Q}_{10}$ s for $\mathrm{CH}_{4}$ and $\mathrm{N}_{2} \mathrm{O}$ were found be 2-6 and $>1-7$, respectively (Sithole, 2009). These results, although general, were informative and a compelling proof of concept. While increasing soil temperatures will increase emissions from rice agriculture, it is also important to note that other processes such as oxidation and transport may respond in similar manner, and these add the complexity to the present $\mathrm{Q}_{10}$ experiments and theory. Because there was so much variation in the $\mathrm{Q}_{10} \mathrm{~s}$, a more detailed look at the processes from a mechanistic approach is therefore needed to understand the factors that caused this variation. Only then can a global estimate be made because the $\mathrm{Q}_{10}$ will not be the same for all places and under all conditions. It is important that these processes be isolated and their response to temperature be investigated since the final $\mathrm{Q}_{10}$ strongly depends on the $\mathrm{Q}_{10} \mathrm{~S}$ of the three processes above. For example, high $\mathrm{Q}_{10}$ values may be due to simultaneous changes in temperature and other environmental factors such as moisture content or substrate availability and/or changes in substrate availability coincident with temperature increase being mistaken for a temperature response.

The interaction between the different processes may result in widely different $\mathrm{Q}_{10} \mathrm{~S}$ of the fluxes from one place to another. This is analogous to the fact that $\mathrm{CH}_{4}$ emissions are measured to vary from $1-2 \mathrm{mg} / \mathrm{m}^{2} / \mathrm{hr}$ for seasonal averages to $50 \mathrm{mg} / \mathrm{m}^{2} / \mathrm{hr}$ under normal field conditions. This is because of the interaction between the basic processes of production, oxidation and transport. 
Just as it is not possible to extrapolate fluxes found in one set of greenhouse experiments to the world, the $\mathrm{Q}_{10} \mathrm{~S}$ cannot be extrapolated either. Instead the factors that control the $\mathrm{Q}_{10}$ are needed for extrapolation and upscaling. In the quest for answers to these questions, the feedbacks between global warming and two non- $\mathrm{CO}_{2}$ greenhouse gases, $\mathrm{CH}_{4}$ and $\mathrm{N}_{2} \mathrm{O}$, emitted from rice agriculture were simulated and investigated in this research. To achieve these objectives, this research was aimed at designing and developing methods to quantify the effect of temperature on $\mathrm{CH}_{4}$ emission, production and oxidation from a mechanistic approach. The same experiments were used to investigate behavior of $\mathrm{N}_{2} \mathrm{O}$ emissions and production under different temperature treatments under greenhouse conditions.

\subsection{Scope and General Outline}

In this work, the $\mathrm{Q}_{10} \mathrm{~S}$ were determined from a mechanistic point of view. Experiments were designed, constructed and tested as outlined in Chapter 2. The $\mathrm{Q}_{10} \mathrm{~s}$ of emission, oxidation and production were measured and results presented and discussed in Chapters 3, 4, and 5, respectively. Production rates were determined from standard incubation techniques, and oxidation fractions were determined from non-invasive natural stable carbon isotopic compositions. Concentrations of dissolved $\mathrm{CH}_{4}$ in pore water were investigated and results are presented in Chapter 6. Considering that $\mathrm{CH}_{4}$ is produced and oxidized in the rhizosphere by methanogens and methanotrophs, respectively, DNA and qPCR experiments were designed and performed to determine 
the number of $m c r A$ and $p m o A$ copies in the rhizosphere. The mcrA and pmoA genes were the functional gene markers used to detect $\mathrm{CH}_{4}$-producing Archea (methanogens) and $\mathrm{CH}_{4}$-oxidizing bacteria (methanotrophs), respectively. The data are presented in Chapter 7. Experiments and results of $\mathrm{N}_{2} \mathrm{O}$ emissions and production are presented in Chapter 8. A general summary of the key issues, the new discoveries, and the future research direction are presented in Chapter 9. 


\section{Chapter 2}

\section{Experimental Design, Construction and Validation}

\subsection{Summary}

A controlled soil heating system for simulating global warming and its impact on greenhouse gas emissions from rice agriculture was developed and validated. The system consisted of 16 soil tubs whose temperatures were controlled by four water bath heating systems that were set-up in the research greenhouse at Portland State University, Oregon. This greenhouse environment was equipped with humidifiers, fans, automatic vents, HID fluorescent halide lamps and temperature control system. The system reported here supported studies of the $\mathrm{Q}_{10}$ of $\mathrm{CH}_{4}$ flux, production and oxidation, and concentrations in pore water and microbial populations under four different elevated soil temperature regimes. Flux and production studies of $\mathrm{N}_{2} \mathrm{O}$ were also studied under the same conditions.

Four different temperature treatments, with a $4{ }^{\circ} \mathrm{C}$ differential between them, were achieved through the use of four digital temperature control units. In order to achieve the correct environmental field conditions, the Wadsworth environmentally-controlled greenhouse ambient temperature was kept low by constraining it to between 18 and 24 ${ }^{\circ} \mathrm{C}$ whilst the daily "sunset" was maintained at 10:30 pm throughout the sampling period to match field conditions. Each of the four temperature treatments was thermally insulated to maximize the energy use of the system, and comprised a heating tank and the water bath container that housed four locally constructed tubs. To achieve the 
required temperature range, the digital Immersion Circulator/Heater temperature set points were maintained at $20,26,32$, and $39{ }^{\circ} \mathrm{C}$, and the measured soil temperatures were 20, 24, 28 and $32{ }^{\circ} \mathrm{C}$, respectively. These set points were maintained throughout the data acquisition period, with the exception of the two-week period between seasons during which the system maintenances were performed, a demonstration of the superior control of temperature as desired in these experiments. Highest heat losses occurred in the treatments that had the highest set point temperatures relative to ambient, where the set-point temperature was $39{ }^{\circ} \mathrm{C}$, but the recorded soil temperature was $32{ }^{\circ} \mathrm{C}$.

Tubs for holding soil and plants were constructed of PVC, flux chambers were constructed from Plexiglas sheets, and production glass containers were Erlenmeyer flasks with necks extended by $20 \mathrm{~cm}$. The tubs were tested for water leaks, and flux chambers and production containers were tested gas leaks before deployment. A statistical test (5\% significance level) to determine gas leakage on these glass containers indicated that the slopes of the regressions between the concentration and time were not significantly different from zero, a confirmation of the robustness of the production experiment apparatus over a 40-minute period for which $\mathrm{CH}_{4}$ and $\mathrm{N}_{2} \mathrm{O}$ production studies were performed on each treatment on a weekly basis.

\subsection{Introduction}

In previous experiments a heating pad at the base of the tub was used. Although these experiments produced a response of higher emissions with increasing temperatures, 
there were a number of drawbacks. Most important were the fact that it was difficult to maintain constant temperatures and the heating of the soil was not uniform with warmest temperatures at the bottom while under natural conditions, warmer temperatures are expected at the top. Nevertheless, the experiments, although not precise, yielded a very important result that greenhouse gas emissions from agriculture, particularly, $\mathrm{CH}_{4}$ indeed increased with elevated soil temperature. Equipped with these ideas, a robust system was designed and constructed to address problems outlined above, and ensure the correct quantification of effect of temperature on mechanisms that lead to the emissions of $\mathrm{CH}_{4}$ and $\mathrm{N}_{2} \mathrm{O}$ from rice agriculture.

\subsection{Soil Heating System}

Several water bath heating methods have been in use for several decades (Heninger and White, 1974; Borges and Chaney, 1989). Examples include the use of antifreeze to regulate temperatures or submerged pots in the heated water bath (Turner and Jarvis, 1975). In this research, the latter method was considered, but based on original ideas that were developed in this research. Temperatures of $-2{ }^{\circ} \mathrm{C},+2{ }^{\circ} \mathrm{C}$, (mid-double $\mathrm{CO}_{2}$ result) and $+5{ }^{\circ} \mathrm{C}$ (IPCC scenario for 2100 ) relative to global average temperature were considered in the design of the water bath set-up. Expecting that beyond a certain critical temperature, flux would start dropping, a slightly higher temperature above the base $\left(+10^{\circ} \mathrm{C}\right)$ was chosen in order to catch the downturn point. 


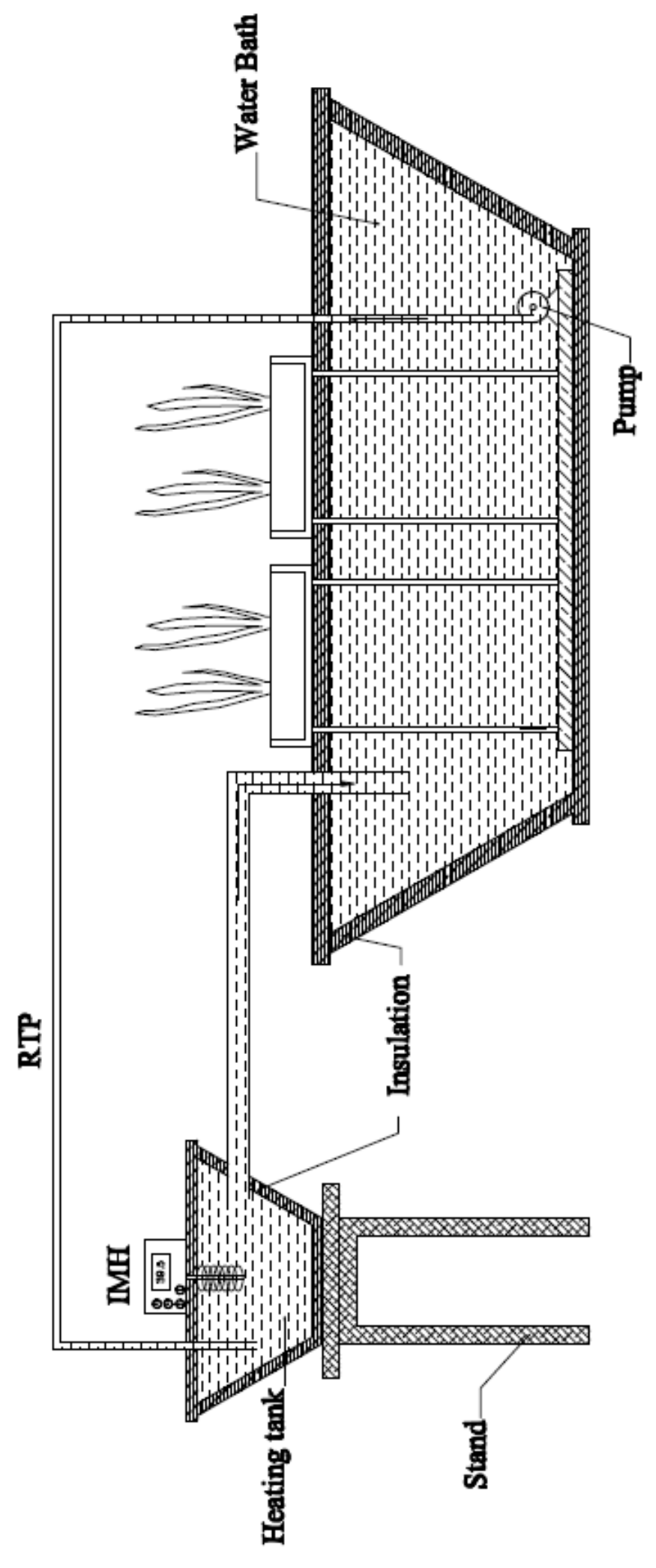

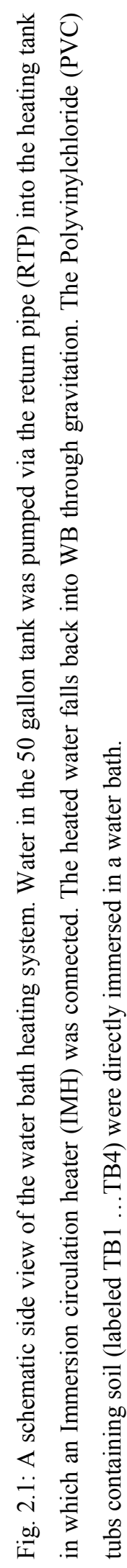


The system was designed and constructed such that the relationship between soil temperature and the rates of processes that lead to $\mathrm{CH}_{4}$ and $\mathrm{N}_{2} \mathrm{O}$ emissions (namely: production, transport and consumption) could be quantified.

The designed temperature control system for soil heating experiments comprised four water heating systems and 16 tubs. The tubs were constructed using hardened PVC materials were mounted into the water bath heating systems as shown in Fig. 2.1. Each of the heating system consisted of two tanks: (I) a heating tank fitted with an Immersion Heater (IMH), and (II) a water bath container fitted with a water pump and four tubs. Inside the heating tank, the water was circulated through a spiral-shaped pipe connected to heating rods. To protect the Immersion Heaters (CIRC, 7306, IMM, 120/60, PolyScience Inc.) when the level of water fell below the recommended manufacturer's level, water was separately heated in the heating tank and channeled back into the water bath containing the tubs through gravity.

To preserve heat, the water was recycled by pumping back from the water bath to heating tank through RTP. The water flow rate was adjusted by setting the water pump flow rate to 15 liters/minute and through the pressure control valves to prevent overflow, and consequently unnecessary heat loss. To reduce heat loss, the tanks were insulated using a $10 \mathrm{~cm}$ thickness Fiberglass-R30 material and wrapped in Du Pont Tyvek Home Wrap. The top and base of WB covered with Thermasheath 3 Insulation (Fig. 2.2). Each WB comprised four tubs: one bare tub and three rice planted tubs. For each of four temperature treatments, the three rice planted tubs and one unplanted one each 
contained temperature probes made in our laboratory using thermocouples positioned at the center of each tub. Seedlings were grown in potting soil and transplanted into the tubs after three weeks. The planting density and amount of fertilizer was similar to that applied under field conditions in China. This set-up allowed comparisons to be made between emissions from planted tubs and those from the unplanted tubs (control), and also within the same temperature treatment.

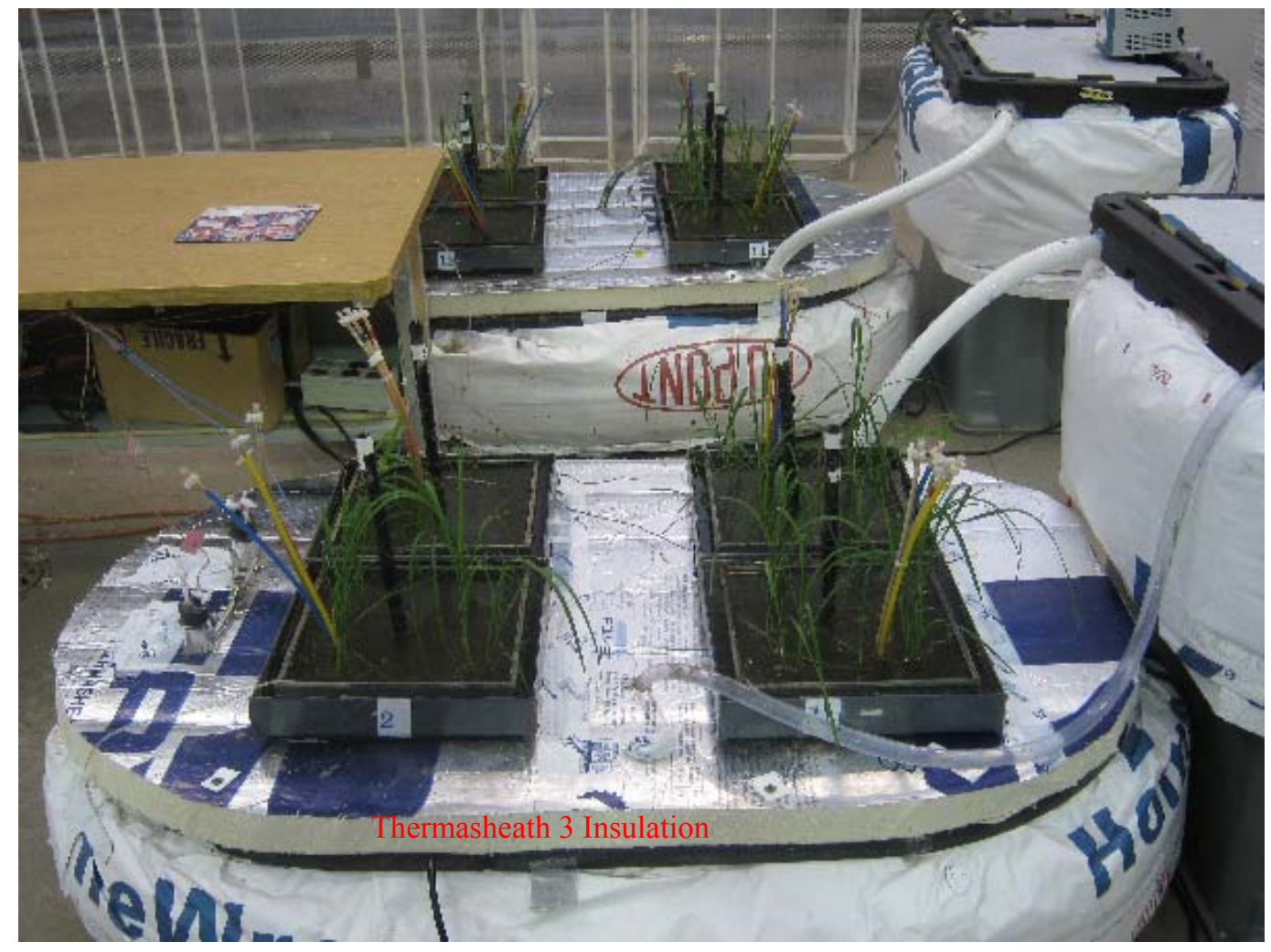

Fig. 2.2: Water bath and heating tanks were thermally insulated using fiberglass material. The top of water bath containers covered with Thermasheath 3 Insulation material to reduce heat loss.

Different temperatures were set to each of the four water heating systems by setting different set temperatures on immersion heaters as shown in Fig. 2.3. 


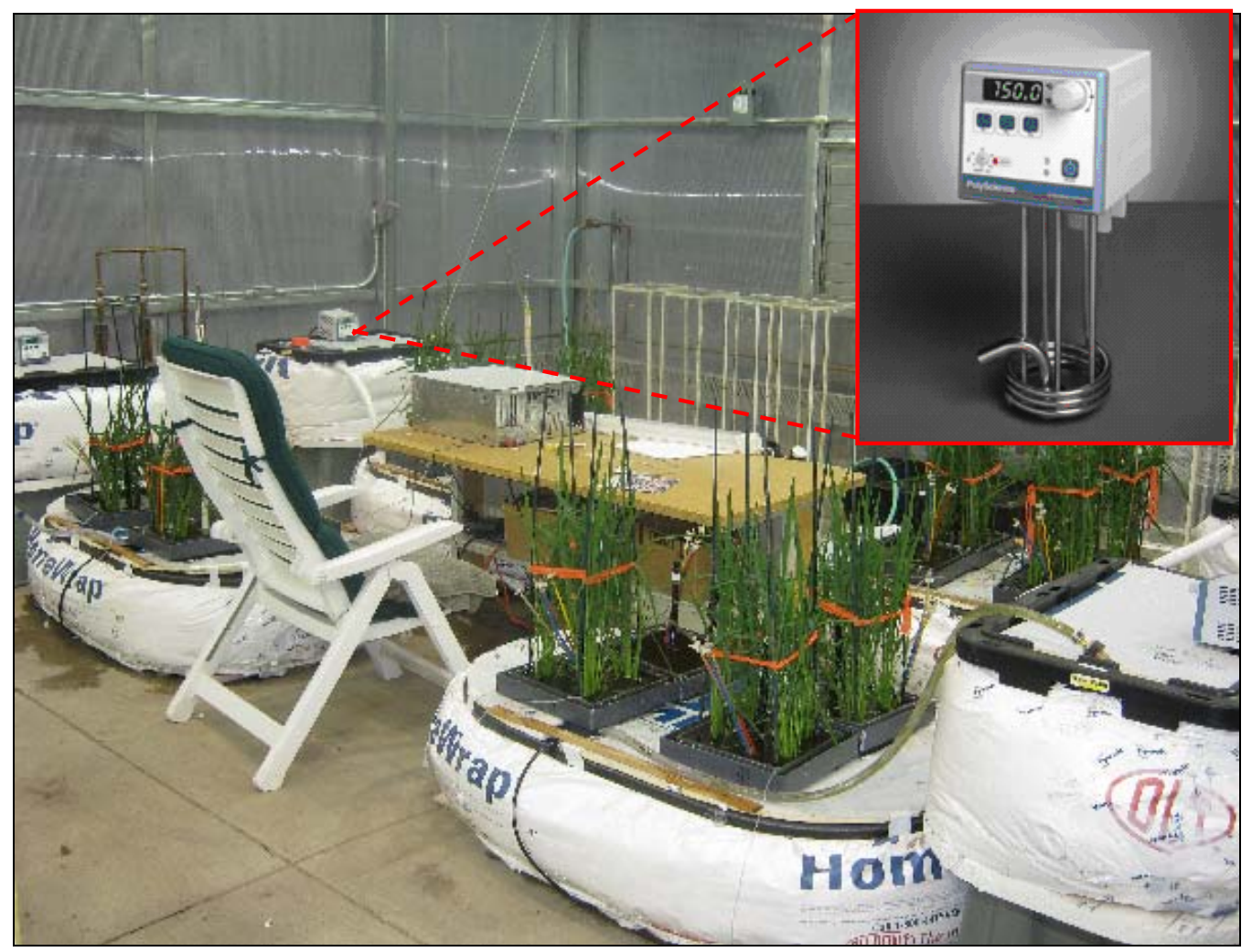

Fig. 2.3: Set-up with digital Immersion heater/circulator (enlarged) connected to the heating reservoir, showing the main components of the heating system: heater, circulator and a temperature sensor (PolyScience Inc). The immersion heaters had inbuilt circulators and thermostats that would help to control the water temperatures. The circulation speed was set to 15 liters/minute and temperatures were set at either, 20,26, 30 or $39^{\circ} \mathrm{C}$. Flow valves were installed onto the water circulation system of each of the four heating systems to control the flow rate and allow mixing of warm water inside the water bath tanks.

\subsection{Temperature Measurements}

Two CR3000 microloggers (Campbell Scientific Inc.) were connected to Type TThermocouples (DigKey Inc.) inserted into the soil (at 10cm depth) in each of the tubs (Fig. $2.4 \& 2.5$ ). The microloggers were set to read, calculate and record soil temperature data every 5 seconds and average it over 5 - and 30 minutes. 


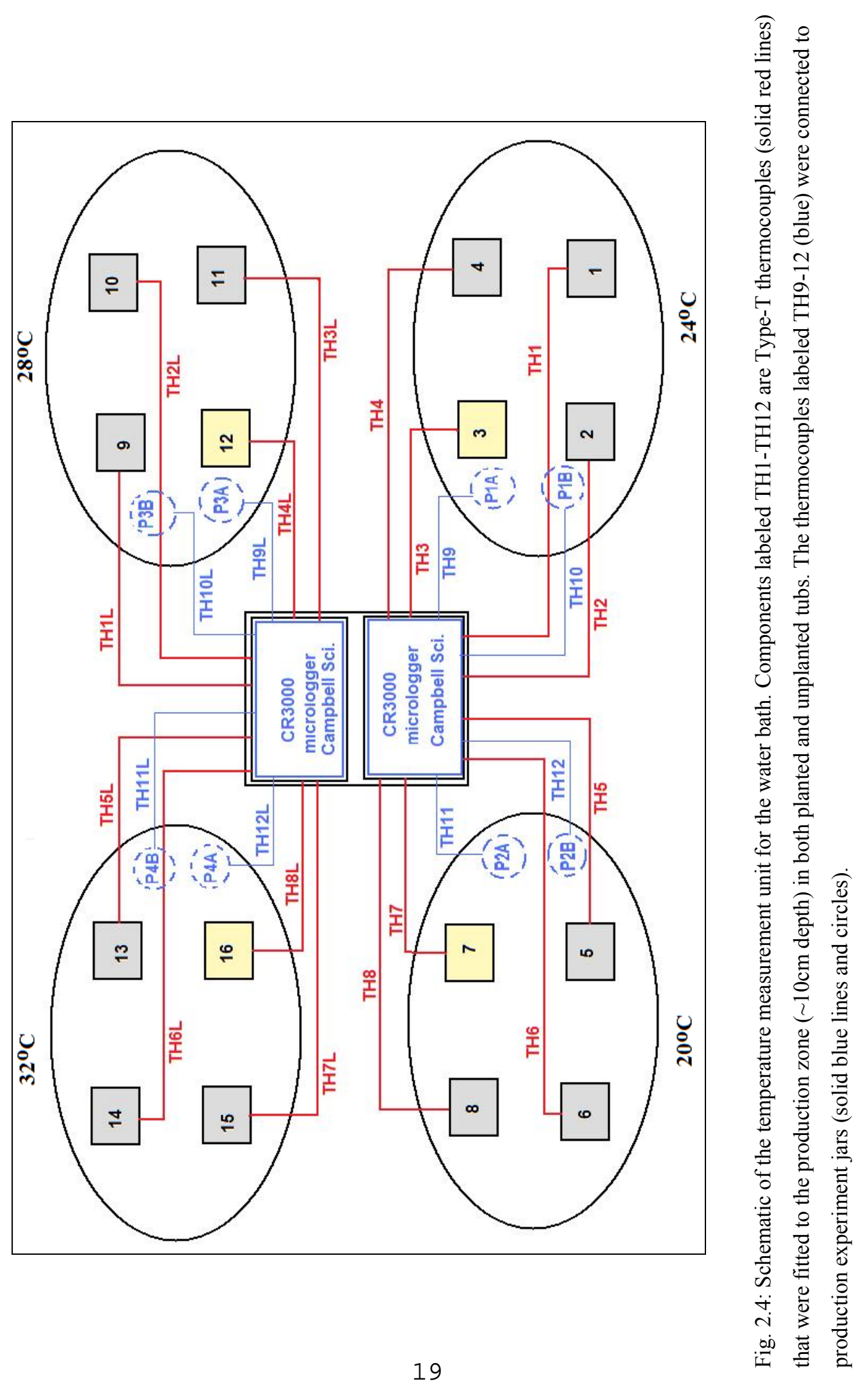




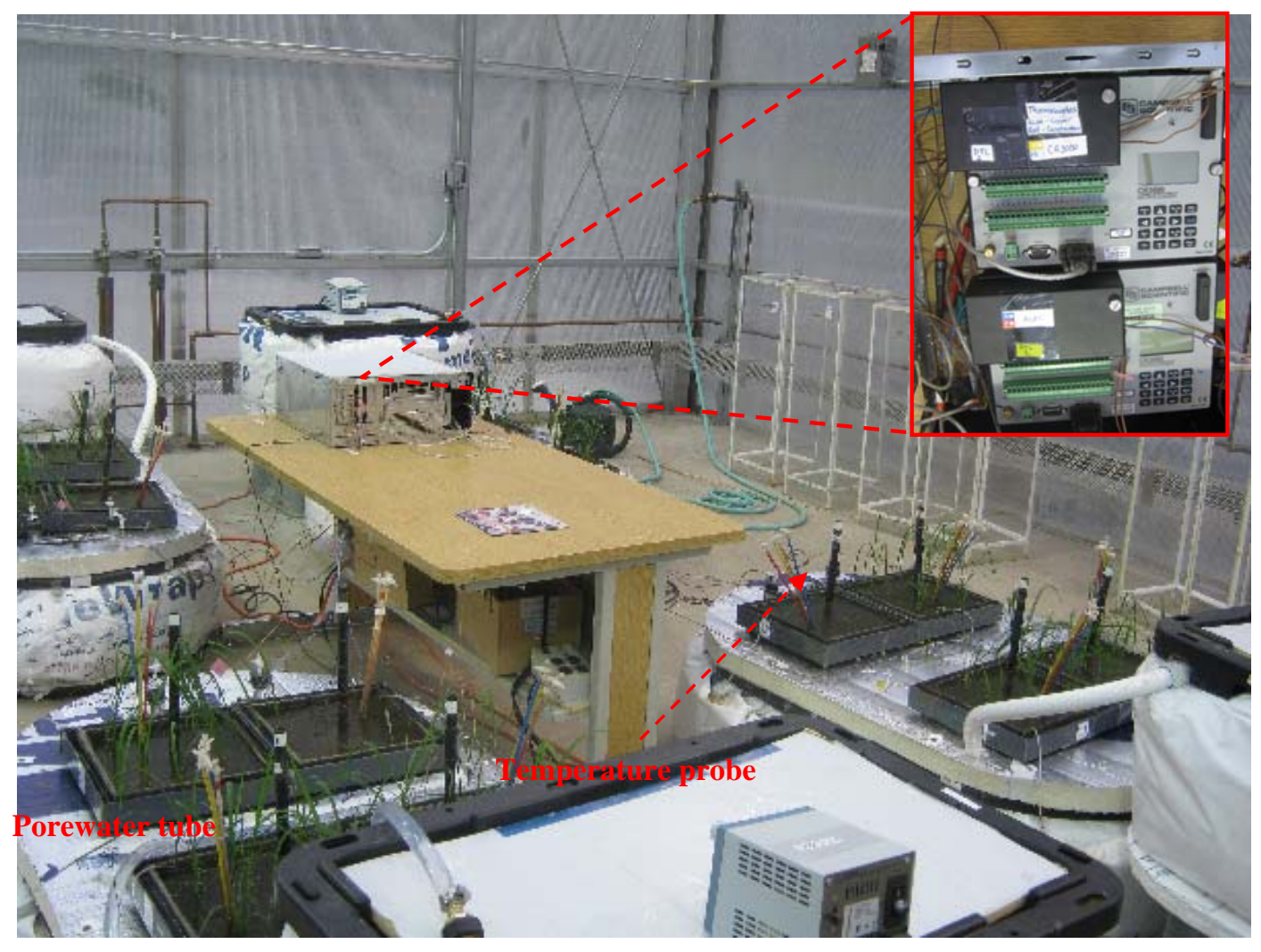

Fig. 2.5: Microloggers connected to the thermocouples and covered (inside a reflective cover) to protect them against adverse greenhouse conditions such as wetting and direct heating. The microloggers were programmed to measure temperatures every 5 and 30 minute intervals. To determine $\mathrm{CH}_{4}$ and $\mathrm{N}_{2} \mathrm{O}$ concentrations, pore water samplers (Khalil et al., 2008) were embedded into the soil in both planted and unplanted tubs.

\subsection{Water Bath Temperature Stability}

To determine the robustness of the system stability after installation, different parameters were monitored and evaluated for stability of the heat control system during the first two-week period and monthly thereafter. The temperature sampling interval was maintained at 5 minute intervals to capture any temperature disturbance during the 10-minute interval between flux measurements. Within each of the treatments, the soil temperatures were uniform across tubs, such that measurements from a single tub in 
each set-up could provide a reliable estimate of the average soil temperature in each treatment. Analysis of temperature data during the first week showed that it took about one week for all the soil temperatures to reach thermal equilibrium with the water bath temperature. Thereafter, a time series analysis of the data revealed minimal changes in soil temperatures to changes in the ambient temperature (Fig. 2.6).

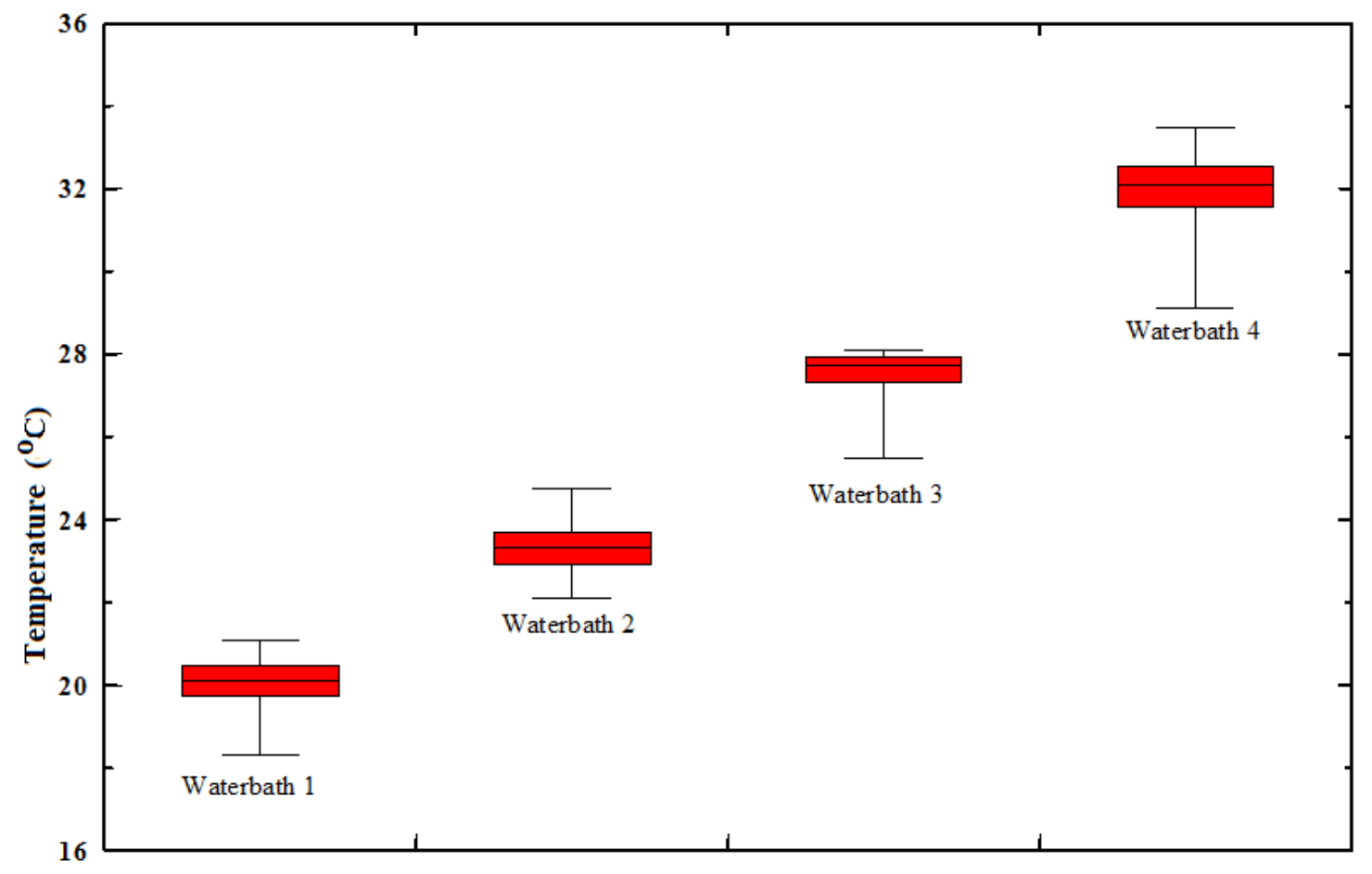

Fig. 2.6: Results of test for soil temperature stability over the first two weeks after installation of the experimental set-up. The data showed a steady state temperature differential of $\sim 4{ }^{\circ} \mathrm{C}$ as desired. The box plots indicate the 1 st and 3 rd quartiles.

\subsection{Tub and Flux Chamber Design}

The tubs were constructed from (1/8 inch thickness) polyvinyl chloride (PVC) panels to allow four tubs to fit into each of the 50 gallon water bath containers. The gutters were 
made from hollow rectangular PVC pipes and welded onto the tubs by using tuckwelding followed by a PVC welding machine, and eventually tested for leakage. The gutters were designed to fit the flux chambers and be flooded when the chambers were attached. This would create an air-tight seal between the chamber and the tub.

Flux chambers were constructed using Plexiglas and Blind Stop Vinyl materials. Fittings were achieved through the use of hot glue and brass screws. Fans were fitted to the top to homogenize the air inside the flux chamber.

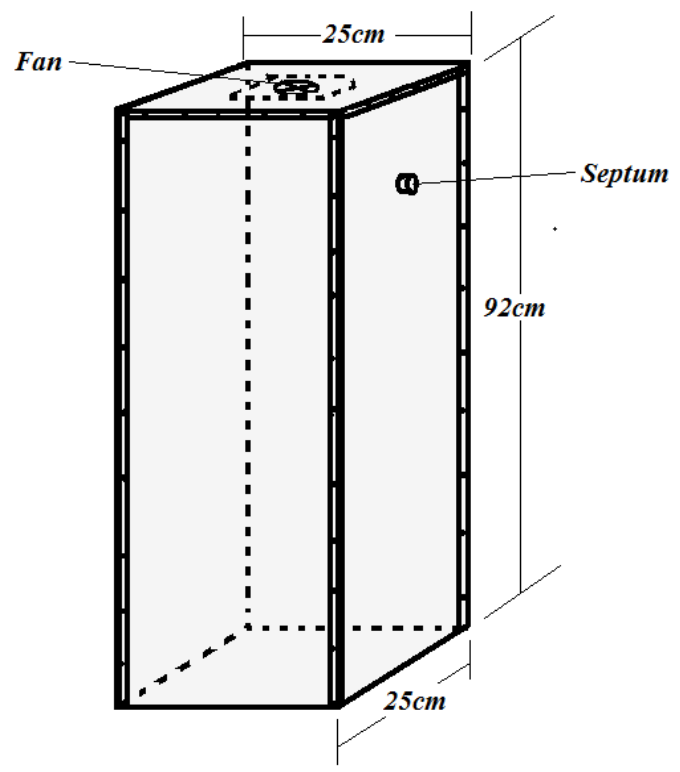

Fig. 2.7: Acrylic flux chambers fitted with $12 \mathrm{VDC}$ fans to homogenize the air inside the flux during sampling, and a septum through which the gas samples were drawn (design based on Khalil et al., 1991). The edges were joined together using a hot glue gun. Thin PVC strips were glued from the bottom of the chamber to strengthen the chamber and prevent any gas leakage during sampling. A rubber septum was installed at the top of each flux chamber and was used to draw gas samples for $\mathrm{CH}_{4}$ and $\mathrm{N}_{2} \mathrm{O}$ flux measurements. 


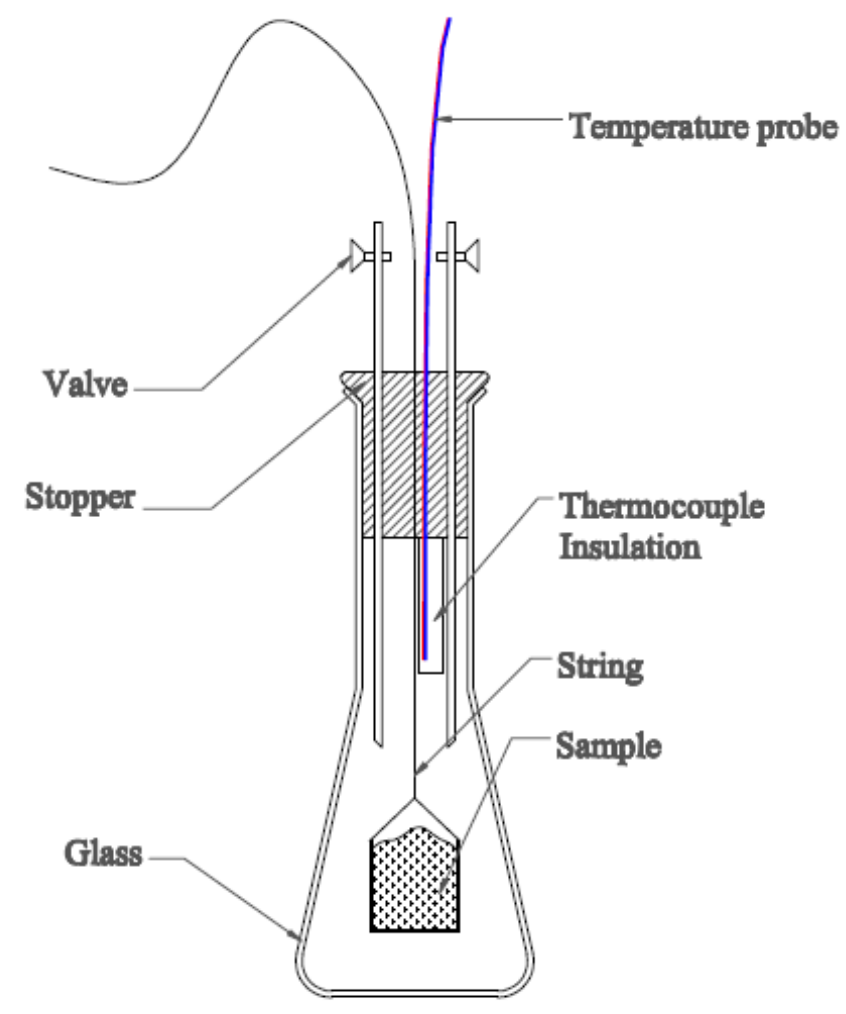

Fig. 2.8: A schematic representation of the components of production experimental set-up. The glass jars were made from modified Erlenmeyer flasks (necks extended by $20 \mathrm{~cm}$ ). Inside the jars were $5 \mathrm{~mL}$ cylinders (cut from $30 \mathrm{ml}$ plastic syringes) held by a very thin and in extensible string. Air-tight inlet and outlet valves, and insulated thermocouple temperature probes were fitted onto the stoppers and glued using a hot glue gun.

\subsection{Leakage Tests}

Before the set-up in Fig 2.7 was deployed into the greenhouse, the system was tested for $\mathrm{CH}_{4}$ leakage. After a known dose of $1 \% \mathrm{CH}_{4}$ was injected into each of the 10 jars, the valve was immediately closed and five air samples were collected at 10-minute intervals. The collected gas samples were measured for both $\mathrm{CH}_{4}$ and $\mathrm{N}_{2} \mathrm{O}$ by a gas chromatography with FID (flame ionization detector) and ECD (electron capture 
detector). From the slope, $b$, regression of concentration and time, $\mathrm{t}$ statistic was calculated.

Table 2.1: The t-statistic values and slope ( $\mathrm{ppm} /$ minute) of regression between measured concentrations for: (a) $\mathrm{CH}_{4}$, and (b) $\mathrm{N}_{2} \mathrm{O}$. $\mathrm{H}_{\mathrm{o}}$ was rejected for $\mathrm{t}_{\alpha=0.025} \leq-3.184$ and $t_{\alpha=0.025} \geq+3.184$ for $\mathrm{n}=5$ (two-tailed test).

(a) $\mathrm{CH}_{4}$

\begin{tabular}{ccccc}
\hline $\begin{array}{c}\text { Set- } \\
\text { up }\end{array}$ & $b$ & $S_{Y X}$ & $\sum_{i=1}^{n}\left(X_{i}-\bar{X}\right)^{2}$ & $t_{\text {value }}$ \\
\hline 1 & -0.056 & 8.673 & 228.804 & -0.098 \\
2 & -0.111 & 4.686 & 78.109 & -0.209 \\
3 & -0.059 & 4.849 & 73.997 & -0.104 \\
4 & 0.112 & 7.760 & 193.102 & 0.199 \\
5 & -0.008 & 2.877 & 24.881 & -0.013 \\
6 & 0.019 & 1.044 & 3.647 & 0.035 \\
7 & 0.264 & 2.071 & 82.520 & 1.157 \\
8 & -0.005 & 3.115 & 29.133 & -0.009 \\
\hline
\end{tabular}

(b) $\mathrm{N}_{2} \mathrm{O}$

\begin{tabular}{cccc}
\hline$b$ & $S_{Y X}$ & $\sum_{i=1}^{n}\left(X_{i}-\bar{X}\right)^{2}$ & $t_{\text {value }}$ \\
\hline-0.0002 & 0.01000 & 0.000342 & -0.00038 \\
$3.23 \mathrm{E}-05$ & 0.00329 & $3.34 \mathrm{E}-05$ & $5.69 \mathrm{E}-05$ \\
$-6.8 \mathrm{E}-05$ & 0.00235 & $2.11 \mathrm{E}-05$ & -0.00013 \\
0.000301 & 0.00525 & 0.000174 & 0.000756 \\
$5.47 \mathrm{E}-05$ & 0.00241 & $2.04 \mathrm{E}-05$ & 0.000103 \\
$-1.3 \mathrm{E}-05$ & 0.00438 & $5.77 \mathrm{E}-05$ & $-2.3 \mathrm{E}-05$ \\
0.00026 & 0.00155 & $7.46 \mathrm{E}-05$ & 0.00145 \\
0.00037 & 0.00183 & 0.000149 & 0.00249 \\
\hline
\end{tabular}

The test showed that the slope in the linear regression between concentration and time was not significantly different from zero, and that the set-ups could hold the gas for up to 40 minutes as desired for in these experiments. As a result, 40 minutes were chosen as the maximum time during which production samples were taken. None of the set-ups failed the hypothesis test, and thus from this set eight of the set-ups were selected randomly, and installed directly into the water bath that contained the tubs. 


\subsection{Conclusion}

In this study, a system that could simulate soil temperature conditions under global warming conditions was successfully designed and tested, and could be adjusted to any desired temperature. The reliability and validity of the system was demonstrated over a period greater than twelve months without any breakdown. The system successfully replicated the desired soil temperature increases, but with very low diurnal variations. Such constant temperature in the whole soil profile may not be common in the real world of global warming. Nevertheless, compared to pilot attempts to develop a similar system based on heating pads, the set-up reported in this research enabled better control of soil temperature as desired, and was therefore used in the mechanistic studies of the effects of temperature on $\mathrm{CH}_{4}$ and $\mathrm{N}_{2} \mathrm{O}$ emissions from rice microcosms, as illustrated in the subsequent chapters. A typical system may also be used in the study of the feedback between global warming and greenhouse gas emissions from wetlands. 


\section{Chapter 3}

Temperature Limits and Dynamics of Methane Fluxes from Rice Agriculture

\subsection{Summary}

Most studies have shown that soil temperature is positively correlated to $\mathrm{CH}_{4}$ emissions, and this was confirmed using controlled greenhouse experiments in this research. The magnitude of the positive feedback is potentially large enough to affect the future atmospheric $\mathrm{CH}_{4}$ concentrations. Above $28{ }^{\circ} \mathrm{C}$, fluxes decreased with increasing temperature. This observation raises the question whether the Arrhenius model is right even below this temperature since the emissions are not from only biological processes. Nevertheless, the magnitude of the impact of projected global warming on $\mathrm{CH}_{4}$ emissions from rice agriculture will vary regionally and latitudinally, given that the soil temperature for flooded rice varies from about $15^{\circ} \mathrm{C}$ in northern latitudes to about $40{ }^{\circ} \mathrm{C}$ in equatorial wetlands. Because of the similarity of flooded rice paddies to natural wetlands, the overall projected change due to this feedback is likely to cause a significant change to atmospheric $\mathrm{CH}_{4}$ concentrations in future.

\subsection{Introduction}

The current global $\mathrm{CH}_{4}$ emission rate from natural and agricultural sources is about 40$50 \%$ of the total $\mathrm{CH}_{4}$ emissions (Whiting and Chanton 1993). Irrigated rice agriculture contributes an estimated $10-15 \%$ of the total global $\mathrm{CH}_{4}$ emission, and was probably contributed more in the past than now (Khalil and Shearer, 1993b). Among other factors, 
temperature has been found to have a great effect on the rate of $\mathrm{CH}_{4}$ emissions from the root zone to the atmosphere. Several studies have indicated that methane fluxes increase when the temperature was elevated (Holzapfel-Pschorn and Seiler, 1986; Parasher et al. 1993; Khalil et al., 1998c). The reported results vary from a marked influence of soil temperature on the methane flux with doubling of emission rates at a temperature increase of $20-25{ }^{\circ} \mathrm{C}$ (Holzapfel-Pschorn and Seiler, 1986) to diurnal change in fluxes correlated with temperature from field experiments (Khalil et al., 1998a,b,c; Schütz et al., 1989; Neue and Roger, 1994; Wang et al., 1997; Wang et al., 1999; Seiler et al., 1984; Schütz et al., 1990; Satpathy et al., 1997; Sass and Fisher, 1994). Under field temperature conditions, $\mathrm{CH}_{4}$ fluxes increased with morning rising soil temperature, reached a maximum during early afternoon, and decreased rapidly during nighttime. The cause of this observation still remains a puzzle, and a subject of debate. While there is a general agreement in all studies that temperature plays a significant role, (I) the processes that are triggered by the change in temperature, resulting in the observed changes in $\mathrm{CH}_{4}$ fluxes in heating experiments, and (II) the magnitude of this feedback, are not yet known.

The relationship between soil temperature and $\mathrm{CH}_{4}$ fluxes has been quantified using the Arrhenius equation (Schütz et al., 1990; Wang et al., 1997, 1999:

$F=A \exp (-E / R T)$,

Where $\mathrm{F}=$ flux, $\mathrm{A}=$ Arrhenius constant, $\mathrm{E}=$ Activation energy (in $\mathrm{kJ} / \mathrm{mole}$ ), and $\mathrm{R}$ is the universal gas constant $\left(8.31 \mathrm{Jmol}^{-1} \mathrm{~K}^{-1}\right)$. 
The use of this model has also been extended to global climate models, with $\mathrm{Q}_{10}$ values between 1.5 and 2.5 being chosen for use in these models (Gedney et al., 2004). The relationship assumes that $\mathrm{CH}_{4}$ emissions from rice agriculture will continue to increase exponentially with increasing soil temperature. While this assumption could be valid within the reported temperature ranges, various field and greenhouse experimental data do not support this assumption for temperatures above $30{ }^{\circ} \mathrm{C}$. A close examination of results presented by Khalil et al. (1998a) and Parasher et al. (1993) indeed show that the tipping point lies between 28 and $35{ }^{\circ} \mathrm{C}$ (Fig. 3.1).

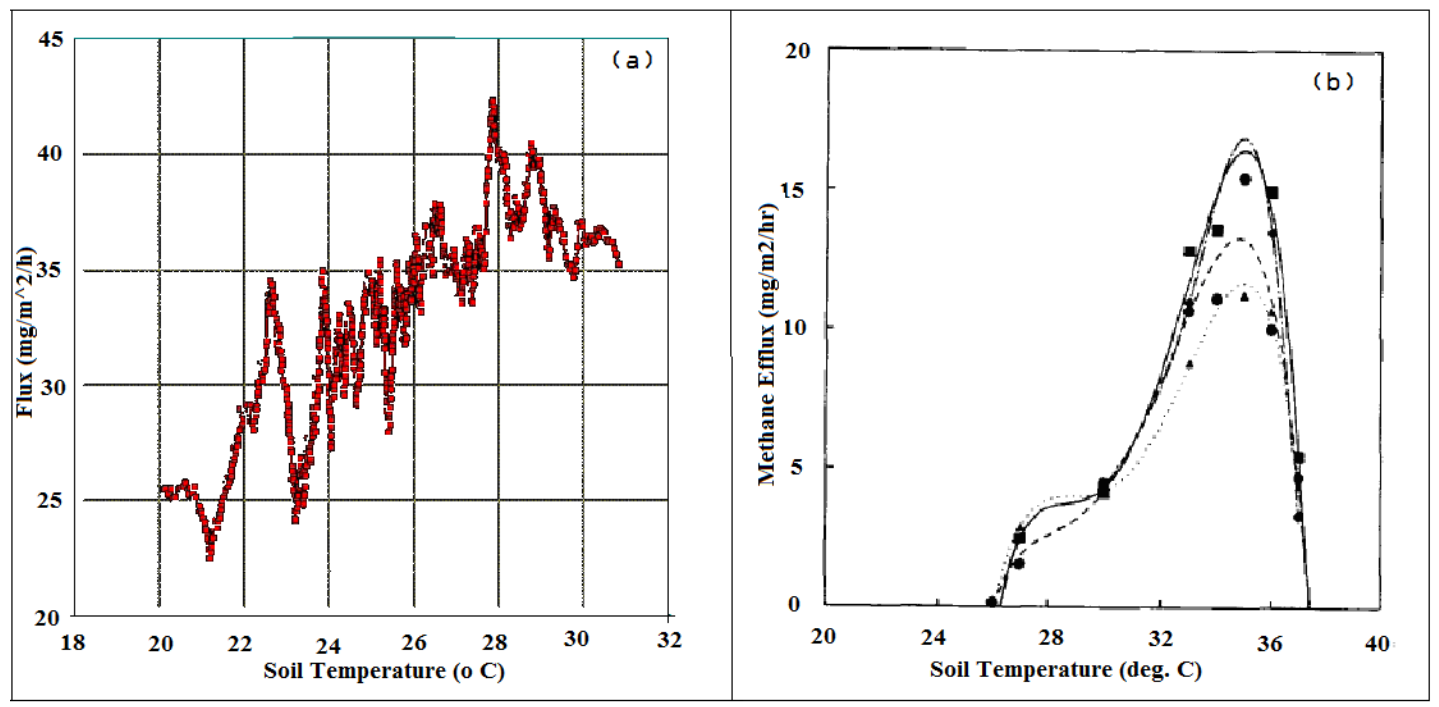

Fig. 3.1: (a) Rice field fluxes from Tu Zu China (reported in Khalil et al., 1998a), and (b) New Delhi, India (Parasher et al., 1993). Parashar et al. (1993) reported a distinct increase in $\mathrm{CH}_{4}$ emission from rice plots with increase in soil temperature from 26 to $34.5{ }^{\circ} \mathrm{C}$ and a decrease in the rate of emission above the temperature under controlled soil temperature. Similar results can be observed in results reported by Khalil et al. (1991). All data indicate a sharp decline in $\mathrm{CH}_{4}$ fluxes after reaching an optimum value or peak, an indication that the Arrhenius model will not consistently hold for temperature above $30{ }^{\circ} \mathrm{C}$. 
Similar results were observed in the previous greenhouse experiments (Sithole, 2009) and in plots of $\mathrm{CH}_{4}$ flux versus temperature shown in Pangala et al. (2010). Because of the large variation in $\mathrm{Q}_{10}$ values reported from various studies, the major challenge is the unification of these results. This limits the accuracy of model estimates of future global $\mathrm{CH}_{4}$ emissions under a warmer world. To improve the quantification of this temperature feedback and model output, knowledge of the representative $\mathrm{Q}_{10}$ value is required.

\subsection{Aim and Objectives}

In this experiment the aim was to design and run experiments that would be used to quantify the relationship between temperature and $\mathrm{CH}_{4}$ fluxes and to determine how $\mathrm{CH}_{4}$ fluxes will be affected by global warming.

\subsection{Materials and Methods}

Intensive experiments were conducted for two different rice growing seasons. To simulate climatic conditions under which the rice is grown, factors such as day length, day and night temperatures were controlled to match field environmental conditions in China. Since the planting density will determine the amount of fluxes, the plant density was maintained by multiplying the surface area of each tub to the field plant density. 


\subsubsection{Sample Collection}

Gas samples were sequentially collected from Plexiglas flux chambers that were placed on top of planted and unplanted (control) tubs over 10-minute intervals (Fig. 3.1). This method has been used extensively in previous studies, and few problems associated with this method have been identified. To minimize these problems, (I) the length of time the chamber is placed on the rice, (II) the area and height of the chamber, (III) the frequency of measurements, and (IV) number of spatial replicates have to be considered (Khalil et al., 1998c). To avoid feedbacks and saturation effects on $\mathrm{CH}_{4}$ concentration in the flux chambers (Khalil et al., 1998c), the exposure time was constantly maintained at 30 minutes, and the sampling frequency was about three to four days. It has been observed that a very low sampling frequency would increase the uncertainty of the seasonal flux (Khalil et al., 1998c; Khali and Butenhoff, 2008). 


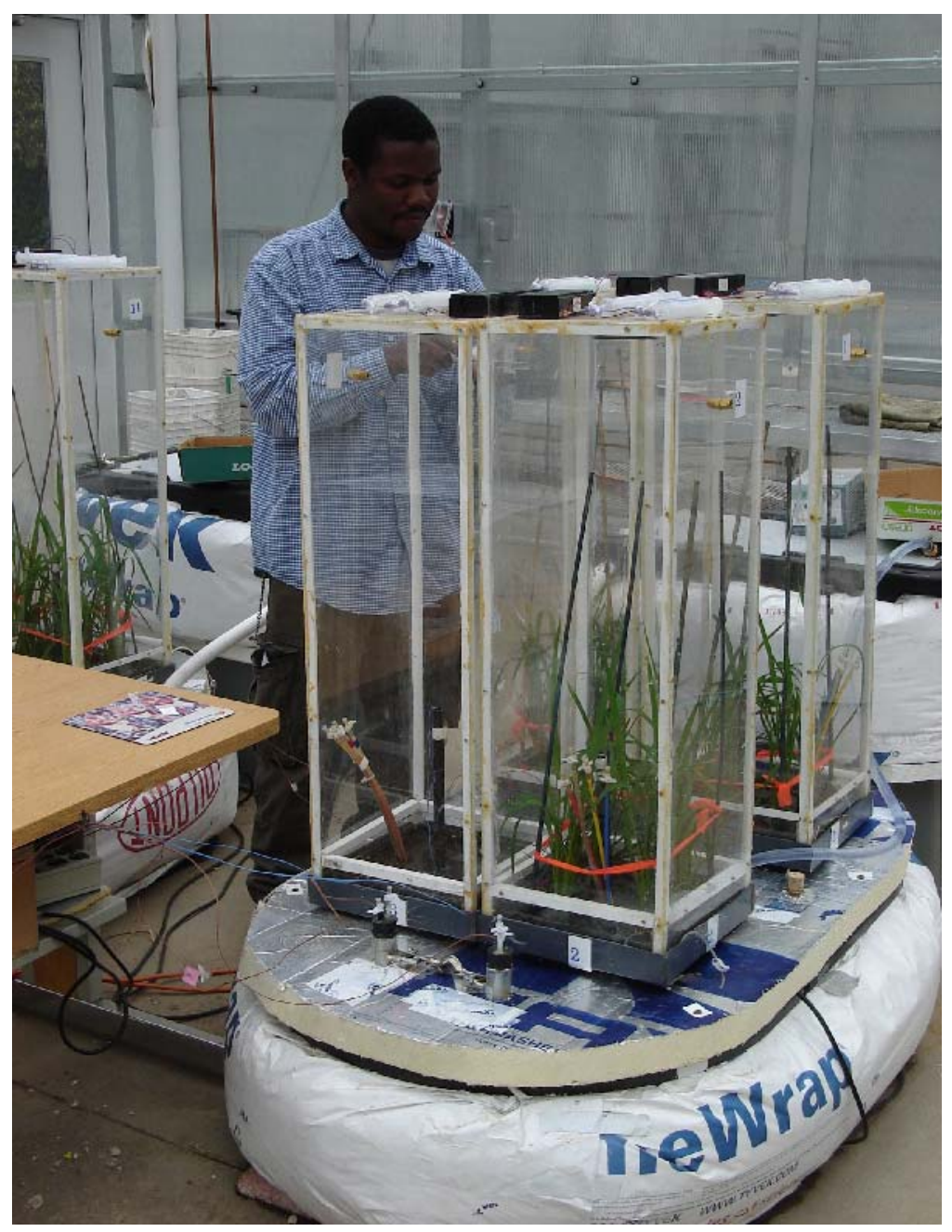

Fig. 3.2: Flux samples were collected from air-tight flux chambers in 10 minute intervals. Details of the construction of these chambers are presented in Chapter 2.

\subsubsection{Data Analysis}

The collected samples were analyzed with gas chromatograph (GC), equipped with a $\mathrm{CH}_{4}$ flame ionization detector (FID) and an electron capture detector (ECD) as shown in Fig 3.3. About $5 \mathrm{~mL}$ of the gas sample was injected though the septum into four sampling columns of the $\mathrm{GC}$, with nitrogen as the carrier gas. The net $\mathrm{CH}_{4}$ fluxes $\mathrm{F}$ [in $\left.\mu \mathrm{g} \mathrm{m}^{-2} \mathrm{~h}^{-1}\right]$ were determined from linear regression of the observed concentrations with 
sampling time. For the purpose of quality assurance, any slope not close to zero and the coefficient of determination $\left(r^{2} \geq 0.90\right)$ were checked for non-linearity (Khalil et al., 1998c).

The calculated net fluxes were corrected for tub headspace following the gradient technique (Khalil et al., 1998c):

$F=\gamma\left[\frac{\rho M_{w}\left(V_{\text {chamber }}+V_{\text {correction }}\right)}{A_{\text {surface }} N_{o}}\right] \frac{\Delta C}{\Delta t}$

Where $V_{\text {chamber }}, V_{\text {correction }}$ and $\gamma$ are volume of chamber, volume correction of tub headspace, and a factor equal to $6.0 \times 10^{-5} \mathrm{mg} \mathrm{min}^{-1} g h^{-1} p p b v^{-1}$, respectively. $A_{\text {surface }}$ is the water surface area in the bucket.

Considering the flux, $\mathrm{F}$ to be a function of $\mathrm{T}$ and using the linear regression model: $\ln (\mathrm{F})=\beta+\alpha \mathrm{T}$ from which $\alpha$ was determined for the $90 \%$ confidence limits. The daily $\mathrm{Q}_{10}$ was calculated as $\mathrm{Q}_{10}(\mathrm{t})=\mathrm{e}^{10 \alpha(\mathrm{t})}$. Where $t$ is the time (DAT) when the sample was taken. The seasonal average $\mathrm{Q}_{10}$ was then calculated as:

$$
Q_{10}=\frac{\int_{\text {season }} Q_{10}(t) \times F(t)}{\int_{\text {season }} F(t)}
$$

Here $F(t)$ is the base flux- that is the flux at the lowest temperature. 
The uncertainty was calculated as $\mathrm{Q}_{10}(\max )-\mathrm{Q}_{10}(\min )$ based on the $90 \%$ confidence limits of the calculated Q10s for each day of the data.

\subsection{Results and Discussion}

\subsubsection{Seasonal Flux Variations}

Large temporal variations in $\mathrm{CH}_{4}$ fluxes were observed. In planted tubs under different temperature treatments, $\mathrm{CH}_{4}$ fluxes increased from zero at the start of the growing period, reaching maxima of between 20 and $60 \mathrm{mg} / \mathrm{m}^{2} / \mathrm{hr}$ during mid-season, and falling back to almost zero at the end of the season (Fig. 3.4). This work is consistent with the findings of Khalil et al. (2008c) in which values as high as $60 \mathrm{mg} / \mathrm{m}^{2} / \mathrm{hr}$ were observed under field conditions. The observed peak has been shown in previous studies, and has been attributed in part to the increase in root exudation, root and leaf surface area which would increase the efficiency of $\mathrm{CH}_{4}$ transport from the soil to the atmosphere. The other factor is an increase in dissolved $\mathrm{CH}_{4}$ pore water concentration.

This study also indicated that $\mathrm{CH}_{4}$ fluxes were positively correlated with soil temperature at $10 \mathrm{~cm}$ depth, and that temperature was major driving factor in the increase of $\mathrm{CH}_{4}$ fluxes, consistent with reports from other studies (Schütz et al., 1989). $\mathrm{CH}_{4}$ fluxes differed greatly between different temperature treatments. Lowest $\mathrm{CH}_{4}$ fluxes were observed at the lowest temperature set-up $\left(20^{\circ} \mathrm{C}\right)$, whist the values were consistently high at higher temperatures throughout both seasons (Fig. 3.3). 


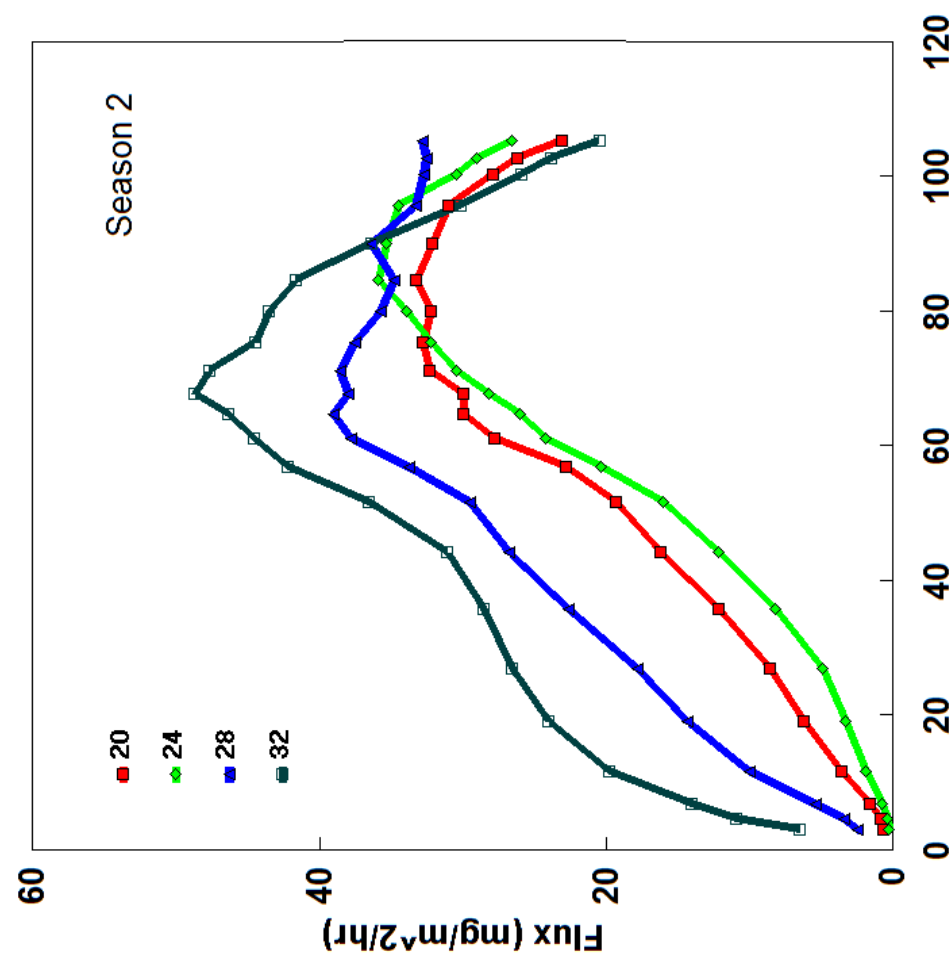

ิㅗำ

움

ஃ

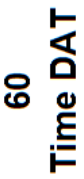

우

กิ

。

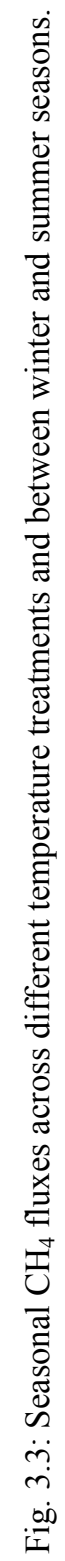


This observation is not new; various studies have reported lower $\mathrm{CH}_{4}$ fluxes to be associated with lower temperatures (Jiang et al., 2006). Several explanations have been given to account for the observed increase of flux with temperature. It is thought that the temperature around the roots greatly affects the $\mathrm{CH}_{4}$ transport process in rice plants, and that the diffusion coefficient of dissolved $\mathrm{CH}_{4}$ in pore water increases with increasing temperature. A factor of 1.5 times higher has been observed at $30{ }^{\circ} \mathrm{C}$ than that at $15{ }^{\circ} \mathrm{C}$ (Hosono and Nouchi, 1997).

In summer season, at $32{ }^{\circ} \mathrm{C}, \mathrm{CH}_{4}$ emission rates consistently increased at an accelerating rate at the beginning of the season, reaching a maximum during the mid-season, but falling below the emission rate at $28{ }^{\circ} \mathrm{C}$. Similar results have been reported in other studies (Khalil et al., 1998; Parasher et al., 1993). $\mathrm{CH}_{4}$ emission rates as well as soil temperatures showed a significant seasonal pattern. Between 10 and 50 DAT, $\mathrm{CH}_{4}$ emissions increased by a factor of 2 for every 4 degree increase in soil temperature. Similarly, $\mathrm{CH}_{4}$ emissions increases with successive increases in temperature between 5 and $20{ }^{\circ} \mathrm{C}$ were reported (Gauci et al., 2004) and between 20 and $28{ }^{\circ} \mathrm{C}$. Such data has been found to fit the Arrhenius model from which apparent activation energies were calculated from correlations. The observation of this strong correlation has led to the general application of the model, irrespective of the temperature domain (Aselmann and Crutzen, 1990; Wang et al., 1997; Schutz et al., 1990). 
However, these results show that for temperatures above $28{ }^{\circ} \mathrm{C}$, fluxes declined. Early studies by Acharya (1935) reported by Neue and Roger (1994) found the optimum temperature to be $30-35{ }^{\circ} \mathrm{C}$. Wang et al. (1997) found that raising soil temperature to about $30{ }^{\circ} \mathrm{C}$ sharply increased $\mathrm{CH}_{4}$ emission rates, but not at $40{ }^{\circ} \mathrm{C}$. They proposed that the low rate at $40{ }^{\circ} \mathrm{C}$ was because much of the $\mathrm{CH}_{4}$ had already been emitted when the soil temperature was raised. However, these results and those presented in their paper, are all an indication of the breakdown between the Arrhenius projected (continuous flux increase with temperature increase) and experimental results. From these experiments, and analysis of results published in literature cited herein, it was observed that the Arrhenius equation generally fits best when the temperature is below the optimum, and above this point the relationship breaks down. First, it is important to note that these temperatures may not all be the same, at different soil temperatures. A correct model may be some other functional form that will be consistent with results of falling flux after a critical temperature.

\subsection{2 $\mathrm{Q}_{10}$ of $\mathrm{CH}_{4}$ Fluxes}

The $\mathrm{Q}_{10}$ values were as high 34 at the start of the season and as low as 2 at the end of the growing season. The variation between temperature treatments was much higher during crop establishment (0-40 DAT) than the mid- to late season period (Fig. 3.5). The seasonally averaged $\mathrm{Q}_{10}$ s for Seasons 1 and 2 were found to be 2 and 1.7. These $\mathrm{Q}_{10}$ values are similar to those found during the flowering stages, periods during which large fluxes were recorded. 

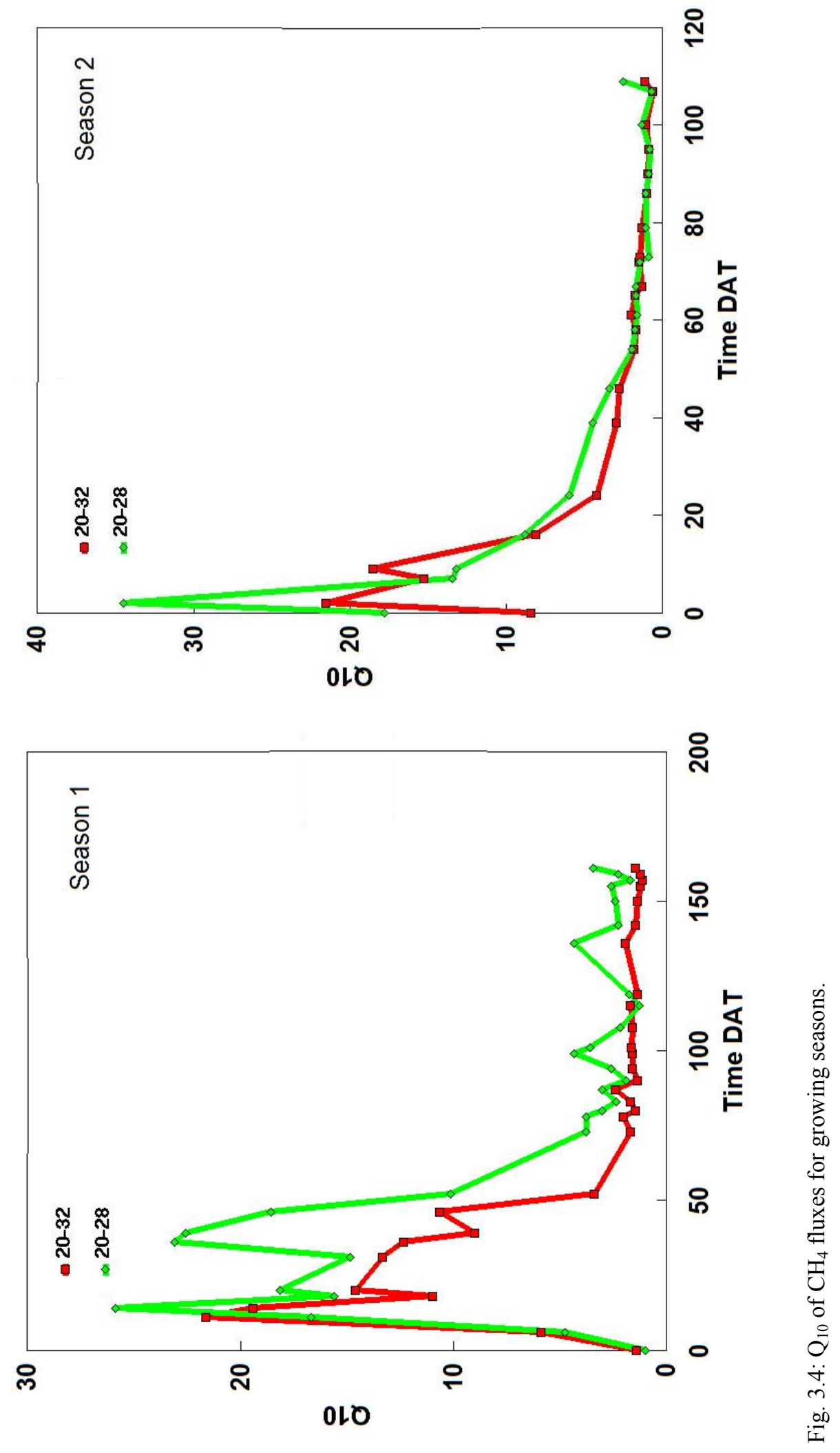
While the $\mathrm{Q}_{10}$ may be high during the early period, the flux is very low so the overall effect of the high $\mathrm{Q}_{10}$ for the total seasonal emissions is not much. These seasonally averaged $\mathrm{Q}_{10}$ values are slightly lower than those in previous studies: 4.3, 3.1 and 2.9 (Khalil et al., 1998b), 4.9 (Yao and Chen, 1994b), and 3.5-4.0 (Sass et al., 1991). For example, Segers (1998) found an average $\mathrm{Q}_{10}$ of 4.1 from incubation experiments in which temperature was the single varying factor. Within these experiments, values as high as 28 (Segers, 1998; Yao and Chen, 1994a), and 71 (Yao and Chen, 1994b) were recorded. Similarly, in three occasions, such values were recorded during the first three weeks after flooding and transplanting. An analysis of these $\mathrm{Q}_{10}$ values showed that very high uncertainties were common in the first three weeks after the start of the growing season (Fig. 3.5).
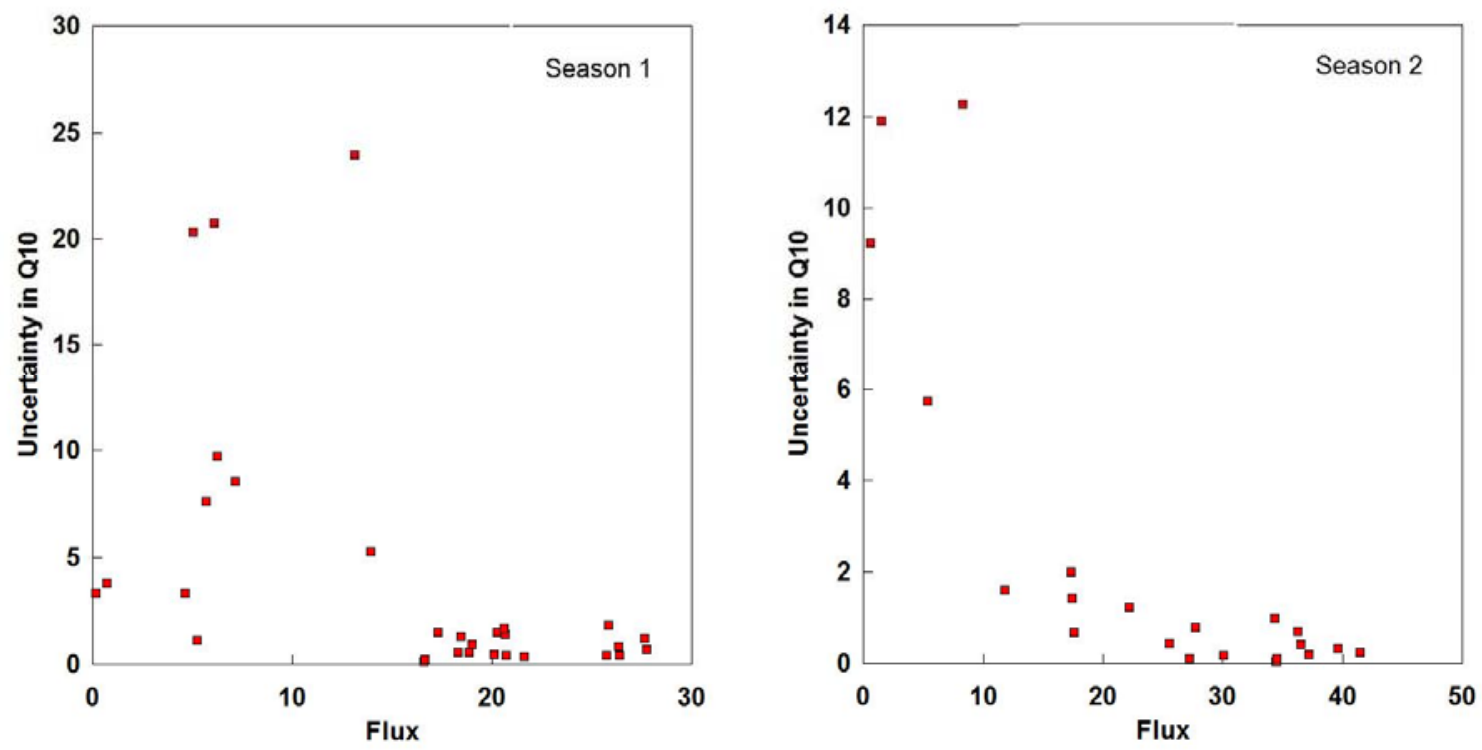

Fig. 3.5: Uncertainties in the $\mathrm{Q}_{10}$ of $\mathrm{CH}_{4}$ fluxes during the growing season. 
Segers (1998) proposed that the observed high $\mathrm{Q}_{10}$ values are a result of the effect of temperature increases on the rate of electron acceptor reduction, which lowers electron acceptor concentrations which have an additional positive effect on $\mathrm{CH}_{4}$ production. However, it is noteworthy that during the first three week period, very low fluxes were measured (Fig. 3.6). Such highly variable values, including the low base fluxes, will result in large and highly variable calculated $\mathrm{Q}_{10}$ values. Hence these values are not a true reflection of the response between $\mathrm{CH}_{4}$ fluxes from rice ecosystems. These high $\mathrm{Q}_{10}$ values could be representative of other processes such as ebullition, an artifact of experimental sampling procedures and calculations, or a composite of various unknown factors.
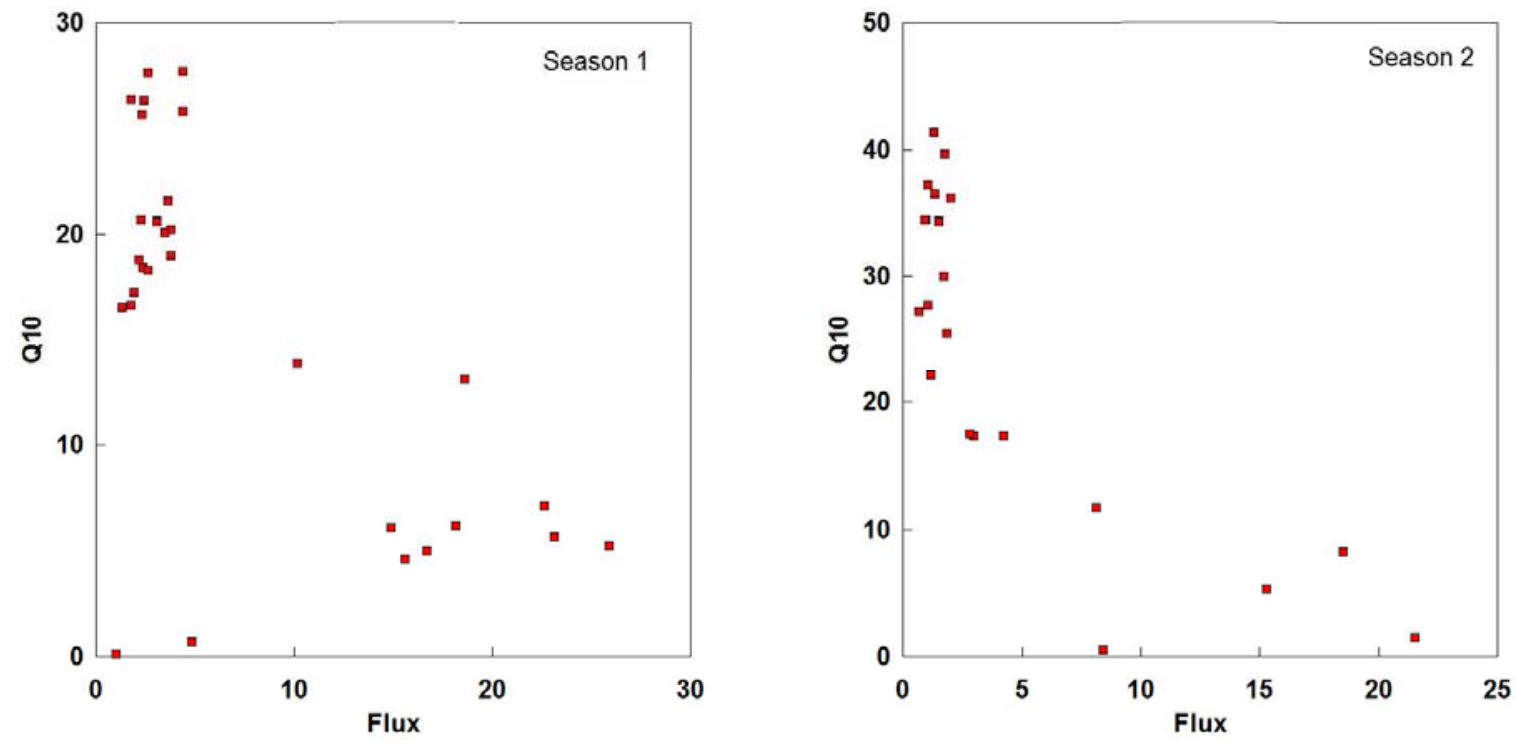

Fig. 3.6: $\mathrm{Q}_{10}$ of $\mathrm{CH}_{4}$ fluxes during the growing season, showing high values of $\mathrm{Q}_{10}$ for low flux values.

Because of the large uncertainties, it is very difficult to insure that the observed change of flux is due only to temperature change. It is quite possible that some of the high $\mathrm{Q}_{10} \mathrm{~S}$ 
occur because of other factors. Considering that the $\mathrm{Q}_{10}$ values calculated here are potentially a product of the $\mathrm{Q}_{10} \mathrm{~s}$ of methanogenic and methanotrophic activities, $\mathrm{CH}_{4}$ production and oxidation (Khalil et al., 1998b), the $\mathrm{Q}_{10}$ values of these mechanistic processes will be determined and presented in the subsequent chapters.

\subsection{Conclusion}

$\mathrm{CH}_{4}$ fluxes and $\mathrm{Q}_{10}$ values were found to be highly variable and dependent on the season. If these results are generally true for flooded rice ecosystems, the implication is that the net $\mathrm{Q}_{10}$ of $\mathrm{CH}_{4}$ fluxes is base temperature-dependent (high for low base temperature and low for high base temperature) and changes with season. The other reason is that the $\mathrm{Q}_{10}$ varies by season because the underlying processes vary during the season. Considering that rice is grown in different regions and under a wide range of temperature regimes (15 ${ }^{\circ} \mathrm{C}$ in northern latitudes to $40{ }^{\circ} \mathrm{C}$ in equatorial region), the net $\mathrm{Q}_{10}$ of $\mathrm{CH}_{4}$ fluxes cannot be represented by a single value when used in global upscaling. 


\section{Chapter 4}

Dynamics of $\mathrm{CH}_{4}$ Concentration in Pore Water under Elevated Soil Temperature

\subsection{Summary}

Concentrations of dissolved $\mathrm{CH}_{4}$ in rice ecosystems were monitored to determine the effect of global warming on the concentration profiles and distributions to further elucidate the dynamics of how $\mathrm{CH}_{4}$ is emitted to the atmosphere. The concentrations of $\mathrm{CH}_{4}$ in pore water from four different temperature treatments at four different soil depths within the rice tubs were measured over two seasons using standard techniques. Our results suggested that $\mathrm{CH}_{4}$ concentration is highly dependent on soil temperature, but only for a limited period during the rice growing season. In all the four temperature treatments, concentration values ranged from $1360 \mu \mathrm{g} / \mathrm{L}$ at the start of season to 7,290 $\mu \mathrm{g} / \mathrm{L}$ at the end of the season, with highest and lowest mean concentrations of 3,373 $\mu \mathrm{g} / \mathrm{L}\left(24^{\circ} \mathrm{C}\right.$ ) and $4,362 \mu \mathrm{g} / \mathrm{L}$ (at $28{ }^{\circ} \mathrm{C}$ ), respectively. The highest concentration values were found between $10 \mathrm{~cm}$ and $15 \mathrm{~cm}$. The concentrations at different depths were significantly correlated to fluxes from 11 to 60 DAT. During this period, the dependence of pore water $\mathrm{CH}_{4}$ concentrations on temperature was more distinct than in any other part of the season. When $\mathrm{CH}_{4}$ fluxes were compared to pore water concentrations for $>60$ DAT, the fluxes flattened out around $30 \mathrm{mg} / \mathrm{m}^{2} / \mathrm{hr}$ despite increases in pore water concentrations. From this observation, we inferred that $\mathrm{CH}_{4}$ transport capacity of the plant was the predominant limiting factor for fluxes during this plant growth phase. 


\subsection{Introduction}

The $\mathrm{CH}_{4}$ produced from anaerobic decomposition of soil organic matter (Conrad 1989; Conrad, 1993; Rothfuss and Conrad, 1993) is oxidized in the floodwater and some is emitted to the atmosphere, while the remainder is trapped in soil-water solution as dissolved methane (Alberto et al., 2000). Dissolved $\mathrm{CH}_{4}$ is the primary source of $\mathrm{CH}_{4}$ emissions from rice agriculture into the atmosphere (Aselman and Crutzen, 1989; Rothfuss and Conrad, 1993; Alberto et al., 2000). Dissolved $\mathrm{CH}_{4}$ in pore water is an important intermediate of $\mathrm{CH}_{4}$ emissions in rice paddies. The longer the residence time of $\mathrm{CH}_{4}$ in the soil, the more likely they will be oxidized by methane-oxidizing bacteria (Alberto et al., 2000) and thus, reduce $\mathrm{CH}_{4}$ emission to the atmosphere.

Despite countless measurements of $\mathrm{CH}_{4}$ emissions over the past four decades, few studies have focused on the effect of temperature on $\mathrm{CH}_{4}$ pore water concentrations. In the majority of the studies, less than $10 \%$ of the reported results have been devoted to $\mathrm{CH}_{4}$ pore water concentration, and hence the likely effect of global temperature increase is poorly understood at present.

In rice paddies, $\mathrm{CH}_{4}$ release into the atmosphere depends on the production, consumption and transport from anoxic zones (Conrad 1989; Wilson et al., 1989; Schultz et al. 1989; Conrad 1993; Alberto et al., 2000; Schultz et al., 1989; Sass et al., 1990; Yagi and Minami 1991; Khalil et al., 1991). Differences in pore water $\mathrm{CH}_{4}$ concentrations have been reported from field experiments performed during winter and summer seasons (Borken et al., 1999). In a similar way, other studies have shown diel variations vertical 
profiles, with increased $\mathrm{CH}_{4}$ concentrations following sunrise, reaching maxima around 9:00 AM within the 5-15 and $25 \mathrm{~cm}$ depths, and at 12:00 PM for 30-35 cm depths (Ding et al., 2004). The results indicated that temperature is an important factor for $\mathrm{CH}_{4}$ concentration in pore water, among other environmental factor. However, due to heterogeneity of various factors between the seasons, it is important to perform the experiments under carefully controlled conditions in order to understand these factors, and hence develop the means towards reducing $\mathrm{CH}_{4}$ emissions from rice paddies.

Increases in soil temperatures due to global warming may cause significant changes to the rates of fundamental processes that produce $\mathrm{CH}_{4}$ in rice paddies. To understand these impacts, it is important to make an assessment of the $\mathrm{CH}_{4}$ pool in rice paddies.

\subsection{Aim and Objectives}

The present experimental study was designed to: (I) quantify the effect of temperature, (II) determine the seasonal characteristics of dissolved $\mathrm{CH}_{4}$ in rice paddies, and (III) to evaluate $\mathrm{CH}_{4}$ concentrations in rice paddy soil. The objective was to understand how an increase in temperature would affect the $\mathrm{CH}_{4}$ pool from which $\mathrm{CH}_{4}$ is released into the atmosphere. 


\subsection{Materials and Methods}

\subsubsection{Introduction}

Pore water $\mathrm{CH}_{4}$ concentrations were determined by sampling pore water at four different depths during the winter and summer seasons of 2010. The samples were collected through plastic sampling tubes that were installed in the soil-filled tubs as shown in Fig. 4.1.

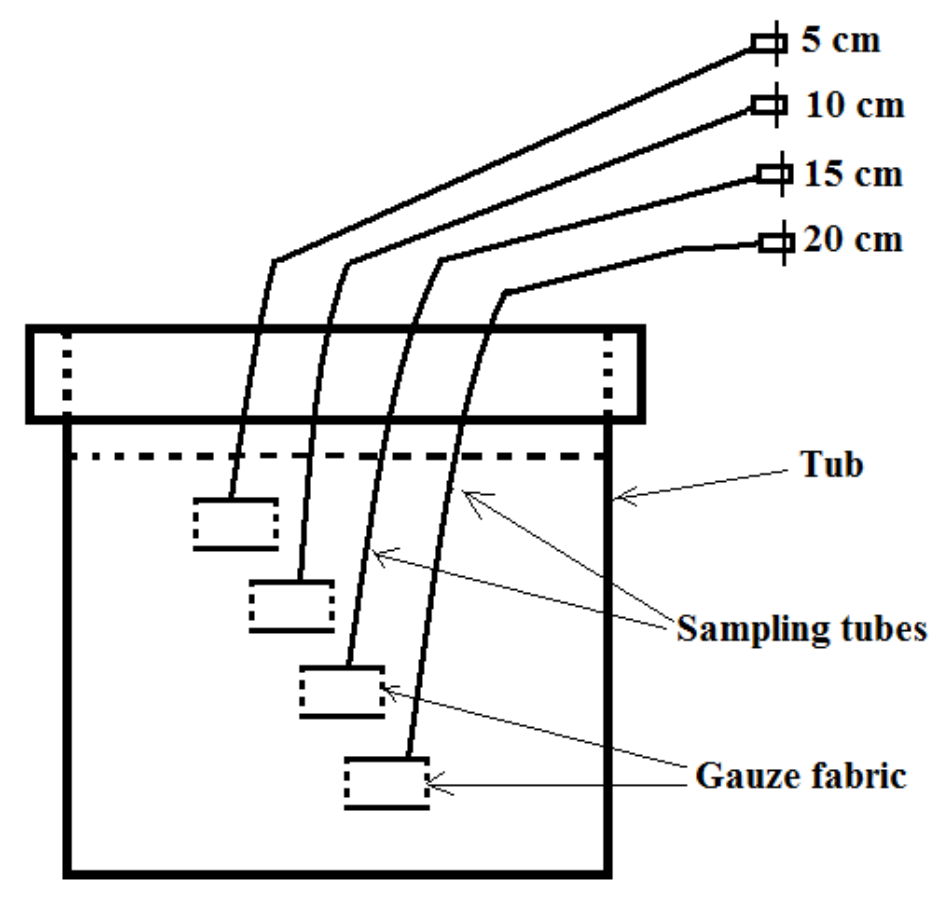

Fig. 4.1: Schematic diagram of pore water samplers (Khalil et al., 2008) inside the tubs. The samplers were inserted at 5, 10, 15 and $20 \mathrm{~cm}$ soil depths in each of the tubs. The cylinders were covered with gauze fabric to allow water movement between their interior and the surroundings.

Rice seedlings were immediately transplanted after fertilization and flooding. Samples were taken three days following transplanting rice and every week thereafter, and analyzed for dissolved $\mathrm{CH}_{4}$. 


\subsubsection{Sampling Method}

Before taking samples, about $10 \mathrm{~mL}$ of pore water was flushed out of each sampler to remove trapped air and impurities in the plastic tube lining. After some 30 minutes, 15 $\mathrm{mL}$ of pore water was drawn-out from each tube using the syringe. Every time a sample was drawn, the valve on the tubing was closed immediately after disconnecting the syringe from the tube.

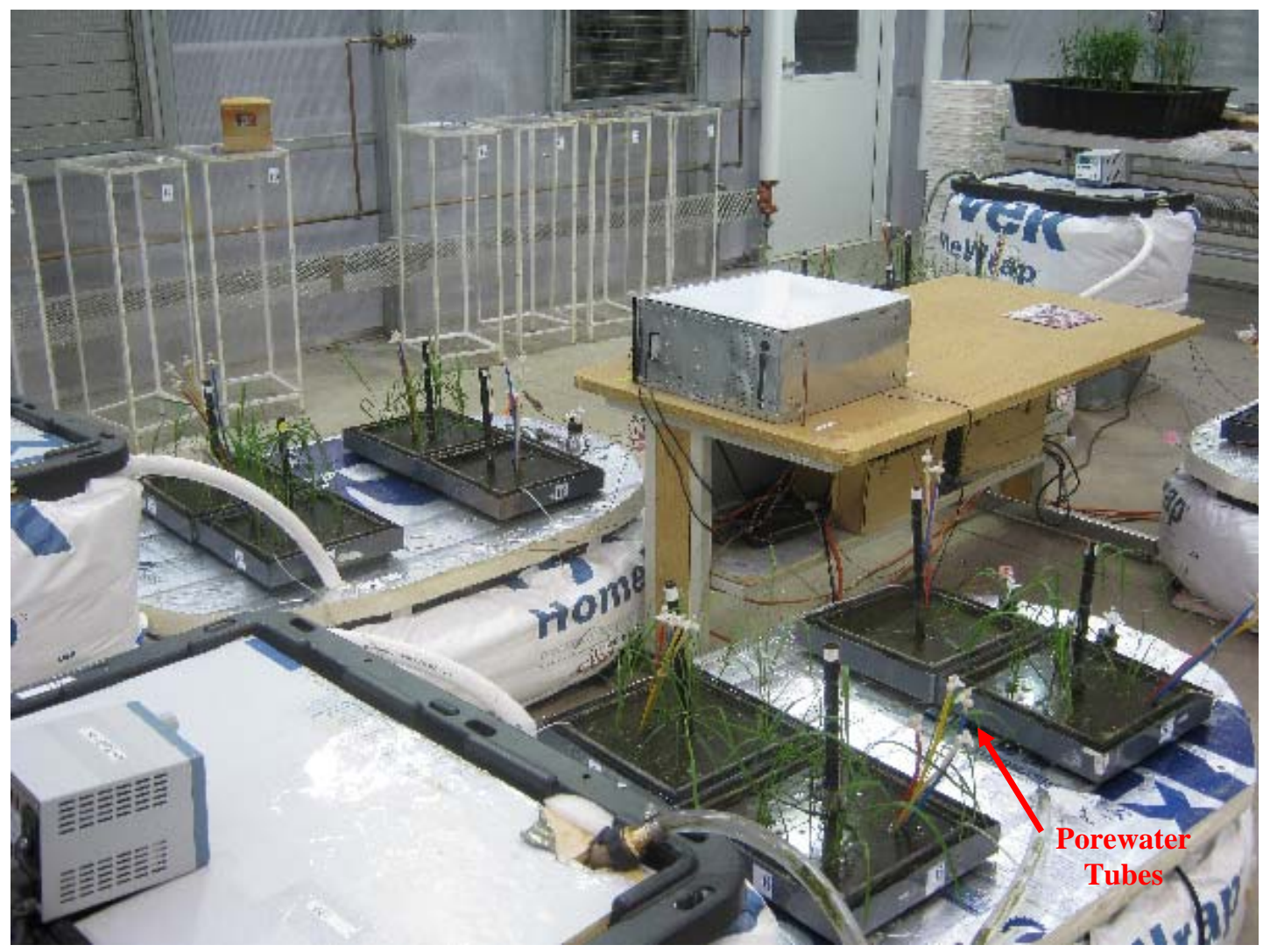

Fig. 4.2: Pictures of pore water tubes embedded into flooded soils inside tubs containing temperature probes. The tubes were fitted with valves to which the syringes were hooked during sampling.

Trapped air bubbles inside the syringe were immediately removed by slightly tapping and flushing out some of the pore water with the syringe nozzle facing upwards leaving 
exactly $10 \mathrm{~mL}$ of the sample pore water. Maintaining the syringe in that position, the valve was closed to prevent any contamination due to exposure to ambient air. Immediately after collection, the $10 \mathrm{~mL}$ samples were taken to the laboratory and the temperature of the $10 \mathrm{~mL}$ samples were brought to room temperature.

\subsubsection{Sample Analysis and Measurements}

Samples were returned to the laboratory and analyzed the following day. For analysis, to each $10 \mathrm{ml}$ sample, $20 \mathrm{~mL}$ of $99.9 \% \mathrm{~N}_{2}$ was added (Khalil et al., 1998). The gassolution-mixture was shaken vigorously for $5 \mathrm{~min}$ to drive dissolved $\mathrm{CH}_{4}$ from pore water into the headspace (Ding et al., 2004).

The headspace gas was collected and analyzed for $\mathrm{CH}_{4}$ using an FID and ECD equipped GC. Concentrations of the dissolved $\mathrm{CH}_{4}$ in headspace were determined as outlined in $\mathrm{Lu}$ et al. (2000):

$$
[X]_{\text {dissolved }}=\left[\frac{[X]_{h} \times\left(V_{h}+P V_{s}\right)-[X]_{a} V_{h}}{16 V_{s}}\right] \times \rho_{X}
$$

Where $[X]_{h}$ and $[X]_{a}$ are the headspace and the ambient air concentrations $\left(\right.$ in $\left.\mu \mathrm{molL}^{-1}\right)$; $V_{h}$ and $V_{s}$ are the headspace volume and soil solution volume $(\mathrm{mL})$, respectively. $P$ is the partition coefficient $\left(0.03 \mathrm{~mL}\right.$ air $\mathrm{mL}^{-1}$ water at laboratory temperature $), \rho_{x}$ is the density of the gas, respectively. 


\subsection{Results and Discussion}

\subsubsection{Profiles of dissolved $\mathrm{CH}_{4}$ in the rhizosphere}

Results indicated that from 0 to $15 \mathrm{~cm}$, there was a general increase in the concentration of dissolved $\mathrm{CH}_{4}$, with slight differences between different temperature treatments (Fig. 4.3). Similarly, Rothfuss and Conrad (1993) reported $\mathrm{CH}_{4}$ concentrations that increased with depth, reaching a maximum in $5-13 \mathrm{~cm}$ soil layer. Studies under both field and greenhouse conditions have shown similar vertical distributions in $\mathrm{CH}_{4}$ concentrations (Gross et al., 1993; Sebacher et al., 1985; Liblik et al., 1997) and profiles of methanogenesis in the submerged paddy soil (Schültz et al., 1989). In all four treatments in this study, highest concentration values occurred between 5 and $15 \mathrm{~cm}$, except in the 24 and $28^{\circ} \mathrm{C}$ where the highest values occurred at $20 \mathrm{~cm}$. Using a photoacoustic technique, the same results were observed in a paddy field (Rothfuss et al., 1996). In other studies on an Italian rice field, from vertical profiles of the respiratory index, Rothfuss and Conrad (1993) found that acetate was more degraded by methanogenesis in $5-11 \mathrm{~cm}$ soil depth compared to other soil layers, an indication that this layer is generally the zone for $\mathrm{CH}_{4}$ production ( $\mathrm{Lu}$ et al., 2000).

Comparing different temperature treatments, highest concentration values occurred in the $32{ }^{\circ} \mathrm{C}$ tubs. The profiles showed that over the whole season, the average dissolved $\mathrm{CH}_{4}$ in the pore water was generally higher in the $10-20 \mathrm{~cm}$ zone than in the $5-10 \mathrm{~cm}$ layer, consistent with what has been reported in other studies (Wilson et al., 1989; Schultz et al., 1989). It is important to note that the $5-10 \mathrm{~cm}$ zone contains more oxygen and higher populations of $\mathrm{CH}_{4}$ oxidizing-bacteria than other layers. Thus, as the season progressed, 
the number of $\mathrm{CH}_{4}$ oxidizing bacteria would also respond, depending on the supply of methanogenic substrates (Schutz et al., 1990) and temperature. In the $32{ }^{\circ} \mathrm{C}$ temperature set-up, $\mathrm{CH}_{4}$ concentrations were much higher in the $10-15 \mathrm{~cm}$ layer. This dependence on temperature could also be due to stimulation of bacterial population growth (HolzapfelPschorn et al., 1985; Dunfield et al., 1993) or enzyme synthesis that results in the production of $\mathrm{CH}_{4}$ (Schutz et al., 1990), or a combination of both. High seasonal fluctuations were also common in the near-surface zone $(0-5 \mathrm{~cm})$.

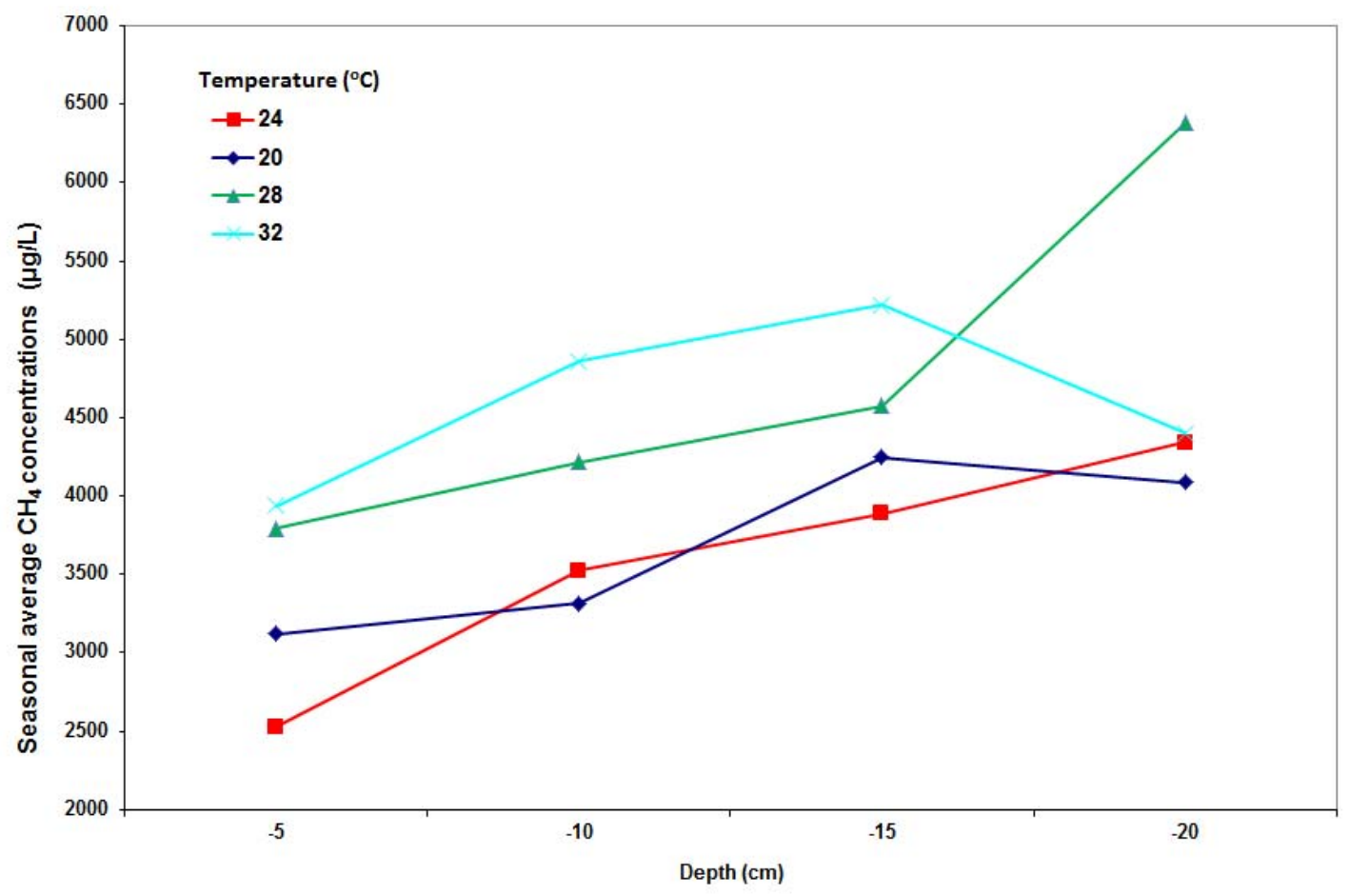

Fig. 4.3: Temperature effect on the seasonal average $\mathrm{CH}_{4}$ concentration vertical profiles in the soil water in for planted tubs. In all four different temperature treatments, the average values are close to each other, with highest values at $20 \mathrm{~cm}$ depth.

The variations could be due to changes in surface water temperatures and supply of organic materials (Wilson et al., 1989). Typically, such fluctuations have been attributed 
to the high variations in the supply of organic materials (such as leaf litter) than in the levels below.

The high concentrations at the bottom could also be due to transport processes. At the bottom there is no flux, while all the flux is at the top. So even if there is no production at the bottom the concentration would be high. Throughout the seasons, the average dissolved $\mathrm{CH}_{4}$ concentrations in all treatments were lowest at $5 \mathrm{~cm}$ depth, followed by that at the $20 \mathrm{~cm}$ depth, except in one particular case in which the highest occurred at 20 cm (Fig. 4.3). However, when only the 0-60 DAT was considered, the average $\mathrm{CH}_{4}$ concentrations of the $32{ }^{\circ} \mathrm{C}$ treatment at $10-15 \mathrm{~cm}$ depth were about three times higher than that at $20{ }^{\circ} \mathrm{C}$ (Fig. 4.4). This indicates that the rate of accumulation of $\mathrm{CH}_{4}$ was highly temperature dependent during the start of the season. In one study in which light treatments were used, the same effect was observed, with vertical profiles showing higher concentration in light- than dark-incubated treatment (Rothfuss et al., 1996). The observation was attributed to differences in the response of photosynthetic rates of algae to light. However, temperature measurements in these treatments were not reported or inferred. From these results (planted and un-planted tubs), it was inferred that temperature is the major factor that influenced the observed rate of increase of $\mathrm{CH}_{4}$ in pore water. On the other hand, the concentration within this zone was about 1.5-2.0 times higher than in the other two zones, indicating that production in flooded soil generally occurred between 10 and $15 \mathrm{~cm}$ depth. As the season progressed, the parabolic profile got distorted, as the profile shifted towards the linear case, in which the highest concentration occurred at $20 \mathrm{~cm}$ and the lowest at $5 \mathrm{~cm}$. This shift can also be noted in field pore water 
$\mathrm{CH}_{4}$ concentration profiles reported by Rothfuss and Conrad (1993). This transition could be due to $\mathrm{CH}_{4}$ accumulation under limited transport and oxidation processes.

In all treatments, differences of $\mathrm{CH}_{4}$ pore water concentration profiles were also apparent between planted and unplanted tubs during the period 0-30 DAT, and diminished thereafter. Similar shifts were noted for $\mathrm{CH}_{4}$ concentration profile results between DAT 21 and 40 reported in Landu (1994). At $>60$ DAT, highest concentrations occurred in unplanted treatments similar to observations in Gross et al. (1993).

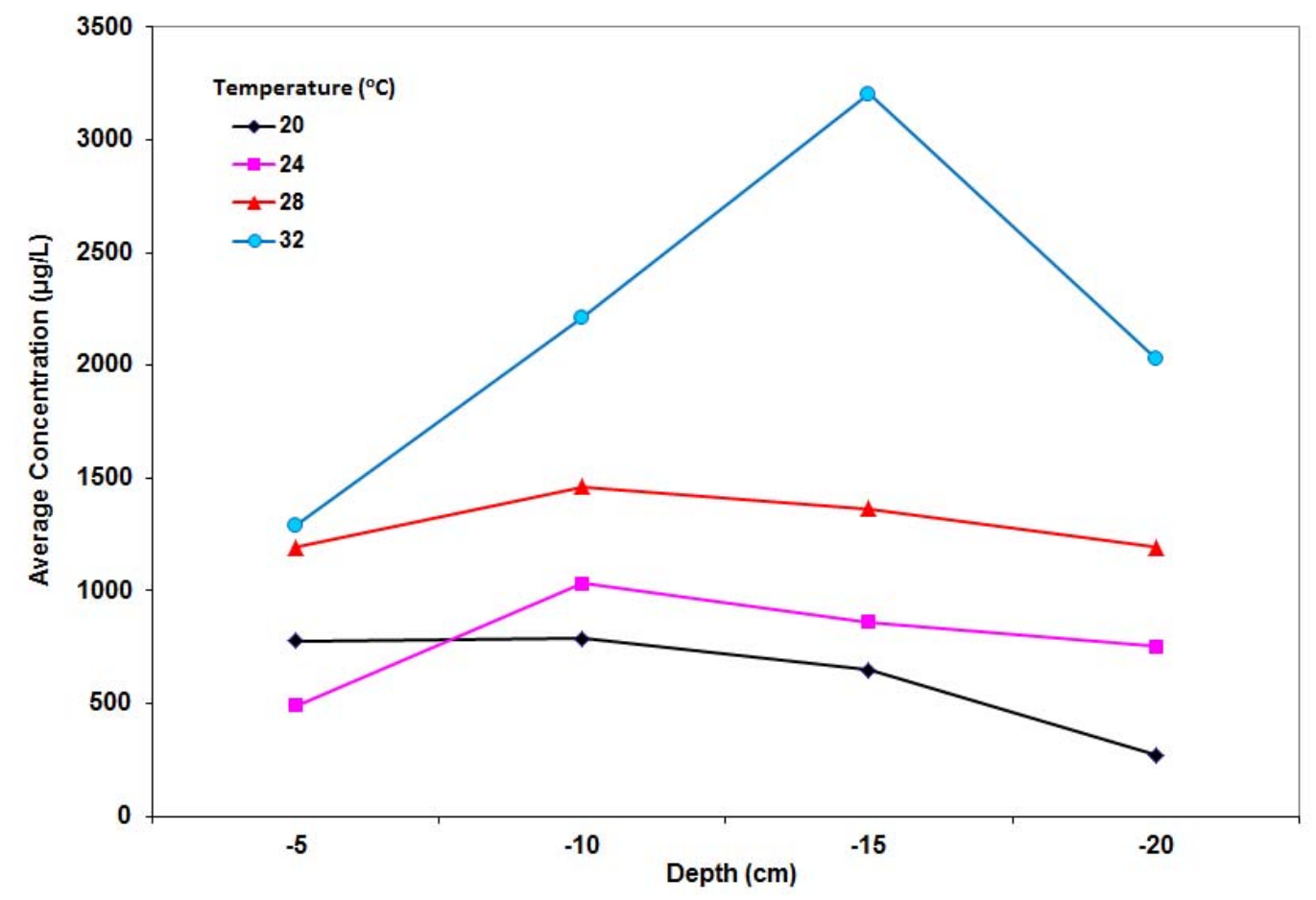

Fig. 4.4: Vertical pore water $\mathrm{CH}_{4}$ concentrations profiles for 0-60 DAT, indicating layering in different temperature treatments. In each treatment, highest values occur between 10 and $15 \mathrm{~cm}$. Differences in the profiles shows that temperature is an important factor during this phase of the season. 
These higher values in planted tubs during this part of season could be due to additional $\mathrm{CH}_{4}$ produced from roots exudates (Schutz et al., 1990), root/rhizome distributions (Gross et al., 1993), while the low values after mid-season could be due to the effect of transport mechanisms from the soil to the atmosphere and $\mathrm{O}_{2}$ transport into the root zone through plants (Schutz et al., 1990; Lindau, 1994; Lu et al., 1999; Lu et al., 2000).

In bare tubs (not shown), no distinct parabolic profiles were observed. Seasonally, the concentrations of $\mathrm{CH}_{4}$ in the unplanted tubs were more variable over time than those in planted tubs, particularly in the $5 \mathrm{~cm}$ zone. However, just as in planted tubs, the minimum values were consistently found with the $5 \mathrm{~cm}$ zone, with highest values at 20 $\mathrm{cm}$. It was also found that the pore water $\mathrm{CH}_{4}$ concentrations in the planted tubs were slightly lower than those in control tubs, except within the production zone. It was inferred that the production of $\mathrm{CH}_{4}$ and its accumulation was more governed by availability and population size of both $\mathrm{CH}_{4}$ producing bacteria and readily decomposable organic material (Davidson and Janssens, 2006; Bridgham et al., 1995; Inubushi et al., 2002; Khalil et al. 1998; Dunfield et al., 1993; Sass et al., 1991), root exudates, and changes in the effectiveness of plant roots as conduits for both $\mathrm{O}_{2}$ into the soil and $\mathrm{CH}_{4}$ into the atmosphere (Gross et al., 1993).

\subsubsection{Temporal Variations}

Results showed that in all treatments, dissolved $\mathrm{CH}_{4}$ concentrations were lowest at the time of transplanting and increased as the season progressed. The low values at the start of the growing season have been attributed to elevated soil redox potential and 
adjustment of microorganisms to flooded soil conditions (Lindau, 1994). During the first two months after transplanting, pore water $\mathrm{CH}_{4}$ concentrations were highly dependent on temperature - the higher the temperature, the higher the concentration during the $0-60$ DAT. The differences in the seasonal temperature response of rate of accumulation of $\mathrm{CH}_{4}$ in pore water could be due to the increases in methanogen populations (and their metabolic rates), methanogenic substrates (Wilson et al., 1989; Lu et al., 2000), and selflimiting processes such as transport and oxidation. However, over the season, there was no significant difference between $\mathrm{CH}_{4}$ concentrations in the pore water across the four temperature treatments. Temporally, the concentrations at different layers showed very distinct weekly variations. Typical variability has been reported in various studies (Gross et al., 1993; Liblik et al., 1997). $\mathrm{CH}_{4}$ concentrations generally increased from the onset to mid-season stage, and thereafter, the concentrations decreased gradually till the season ended. Similar trends were observed at all layers and different temperature set-ups. The decline in $\mathrm{CH}_{4}$ concentrations in both planted and unplanted tubs towards the end of the season has been attributed to the decrease in the pool of decomposable dissolved organic material (Kimura et al., 1993; Lu et al., 2000) and population of $\mathrm{CH}_{4}$ consuming bacteria in the soil (Dunfield et al., 1993). Despite the variations in the mean seasonal concentrations at different layers, the trends were similar for $10-20 \mathrm{~cm}$ soil layers and temperatures. However, there were variations across different temperature treatments in the $0-5 \mathrm{~cm}$ soil horizons.

Seasonally, the differences in the mean concentrations were statistically the same between concentrations in 20 and $24{ }^{\circ} \mathrm{C}$ temperature zones. Significant differences were 
however, noted between low temperature treatments and concentrations in the $32{ }^{\circ} \mathrm{C}$ tubs. These observations suggest that the optimum temperature for production is somewhere close to this temperature.

Contrary to studies by other researches, there was a significant relationship between $\mathrm{CH}_{4}$ concentration and soil temperature at all depths during the first half of the season, with stratification between different layers. In general, the correlations between $\mathrm{CH}_{4}$ concentration and soil temperature at different depths were weak. Seasonal patterns of $\mathrm{CH}_{4}$ fluxes closely followed the same dynamics of $\mathrm{CH}_{4}$ concentrations between 0 and 60 DAT. 


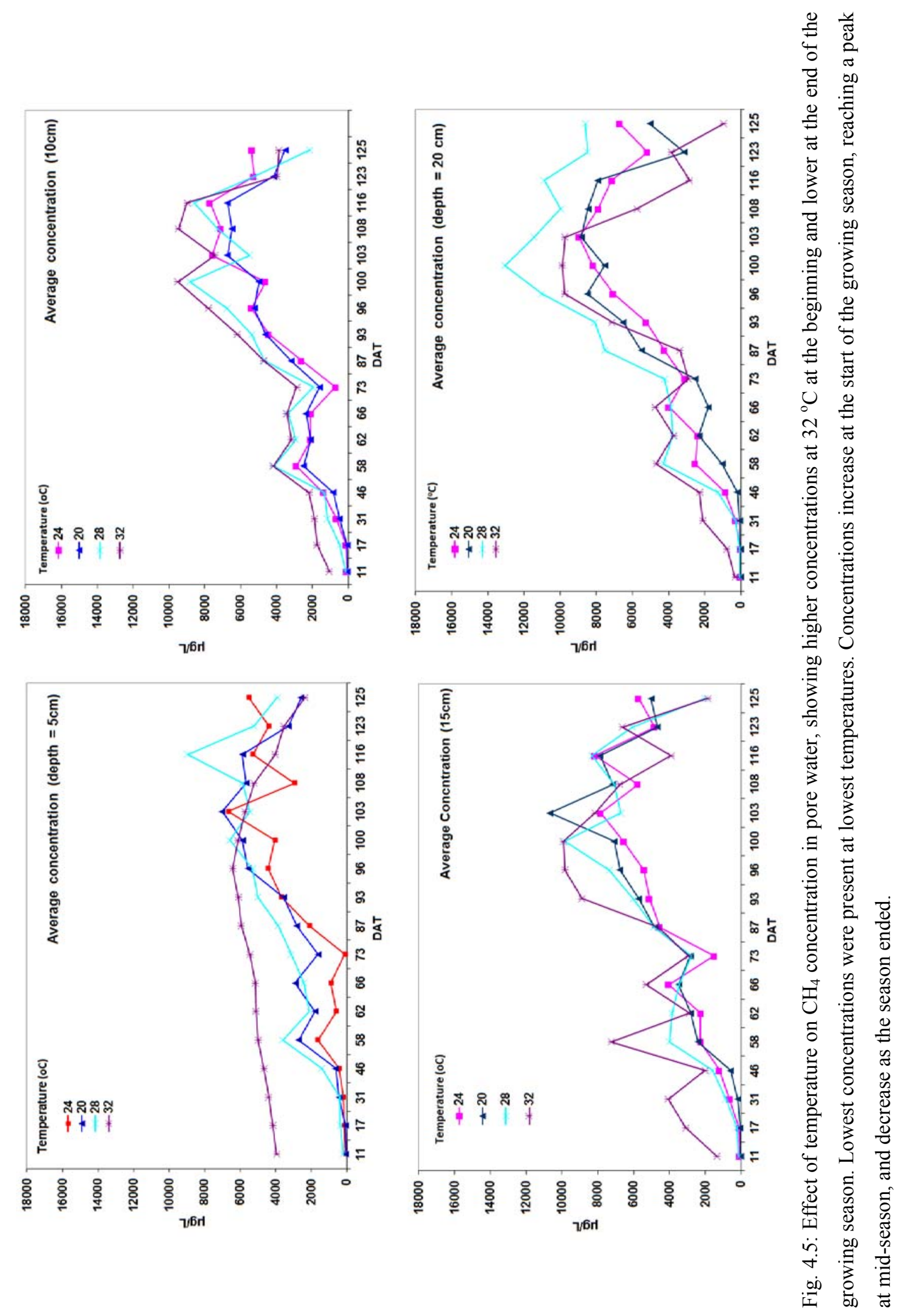


In control (bare) tubs, similar trends, but higher concentrations $(\sim 11,000 \mu \mathrm{g} / \mathrm{L})$ were observed than in rice planted tubs (Fig. 4.5). In a similar fashion, the effect of temperature was apparent. The $32{ }^{\circ} \mathrm{C}$ tubs had the highest $\mathrm{CH}_{4}$ concentrations, while the $20{ }^{\circ} \mathrm{C}$ had the lowest values in the 0-73 DAT period. Beyond this period, there was no discernable indication of temperature dependence.

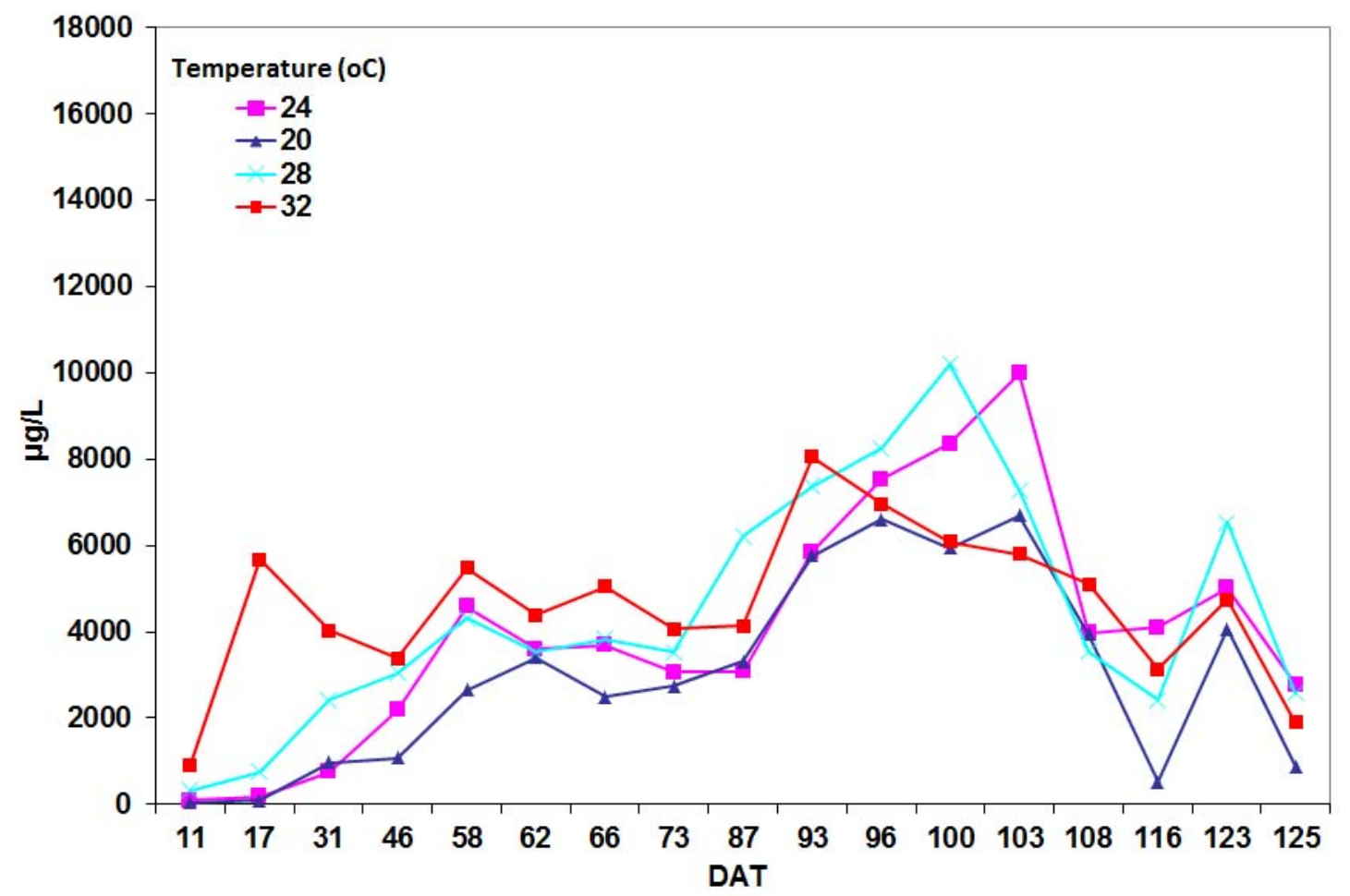

Fig. 4.6: Average concentration of $\mathrm{CH}_{4}$ is higher at $32{ }^{\circ} \mathrm{C}$ at the start and lower at the end than at other temperatures. Concentrations were low at $20{ }^{\circ} \mathrm{C}$ throughout the season. 

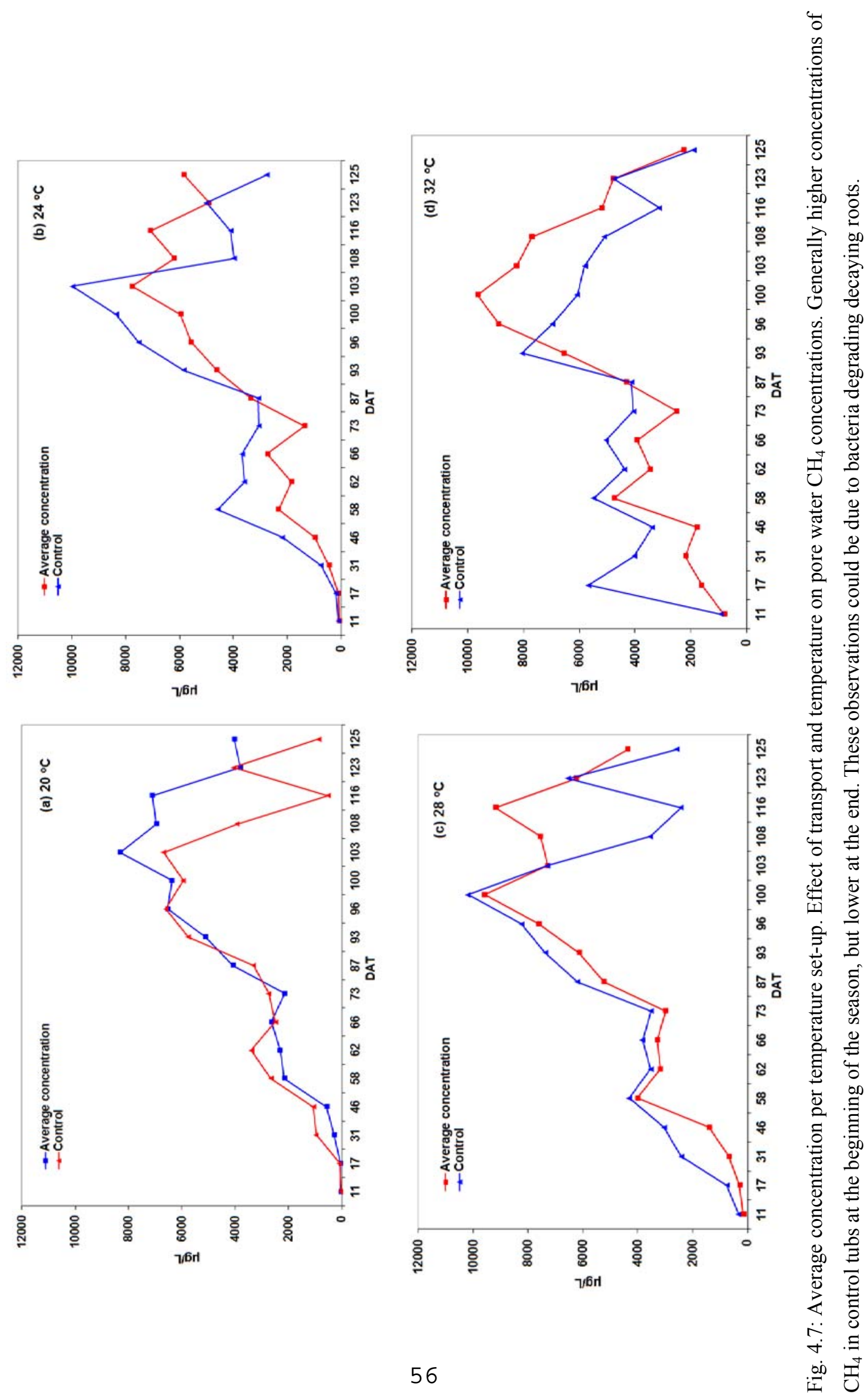


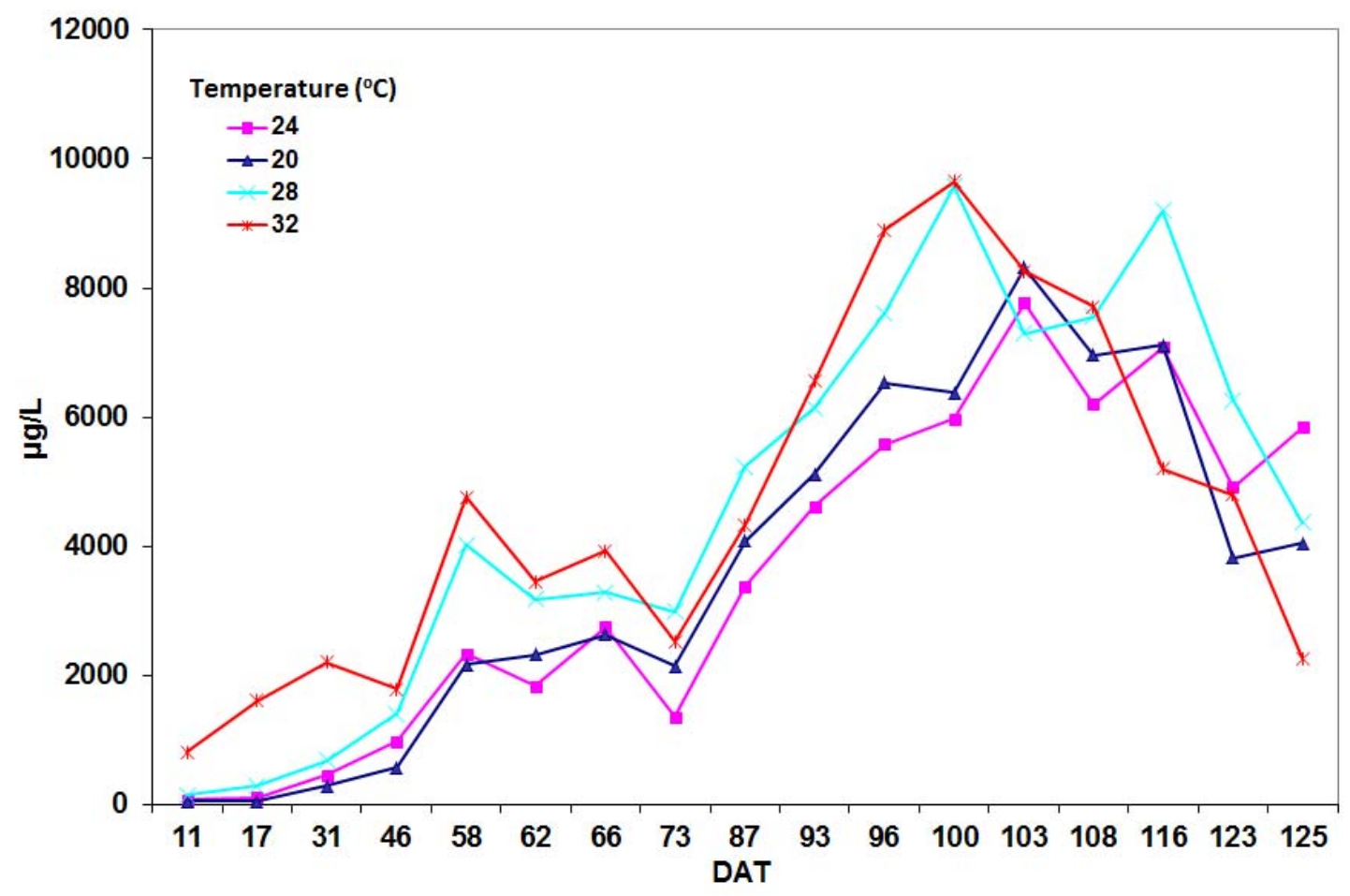

Fig. 4.8: Trends of pore water $\mathrm{CH}_{4}$ concentrations across different temperatures. Concentration of $\mathrm{CH}_{4}$ at $32{ }^{\circ} \mathrm{C}$ is higher till mid-season, but lower than that at $28{ }^{\circ} \mathrm{C}$ thereafter. This is consistent with flux observations, in which fluxes have been found to be higher at for $32{ }^{\circ} \mathrm{C}$ at the start of season, but quickly diminished after mid-season, with concentration at $28^{\circ} \mathrm{C}$ becoming higher beyond this point.

Consistently, higher pore water $\mathrm{CH}_{4}$ concentrations were associated with higher temperatures (Fig. 4.7). This was an indication that the temperature effect on the relationship between pore water $\mathrm{CH}_{4}$ concentration and fluxes seem to exist between 0 and $60 \mathrm{DAT}$. In one observation $\left(5 \mathrm{~cm}, 32{ }^{\circ} \mathrm{C}\right)$, average pore water $\mathrm{CH}_{4}$ concentration was much higher in all than other in other treatments (Fig. 4.7, Fig. 4.8). 

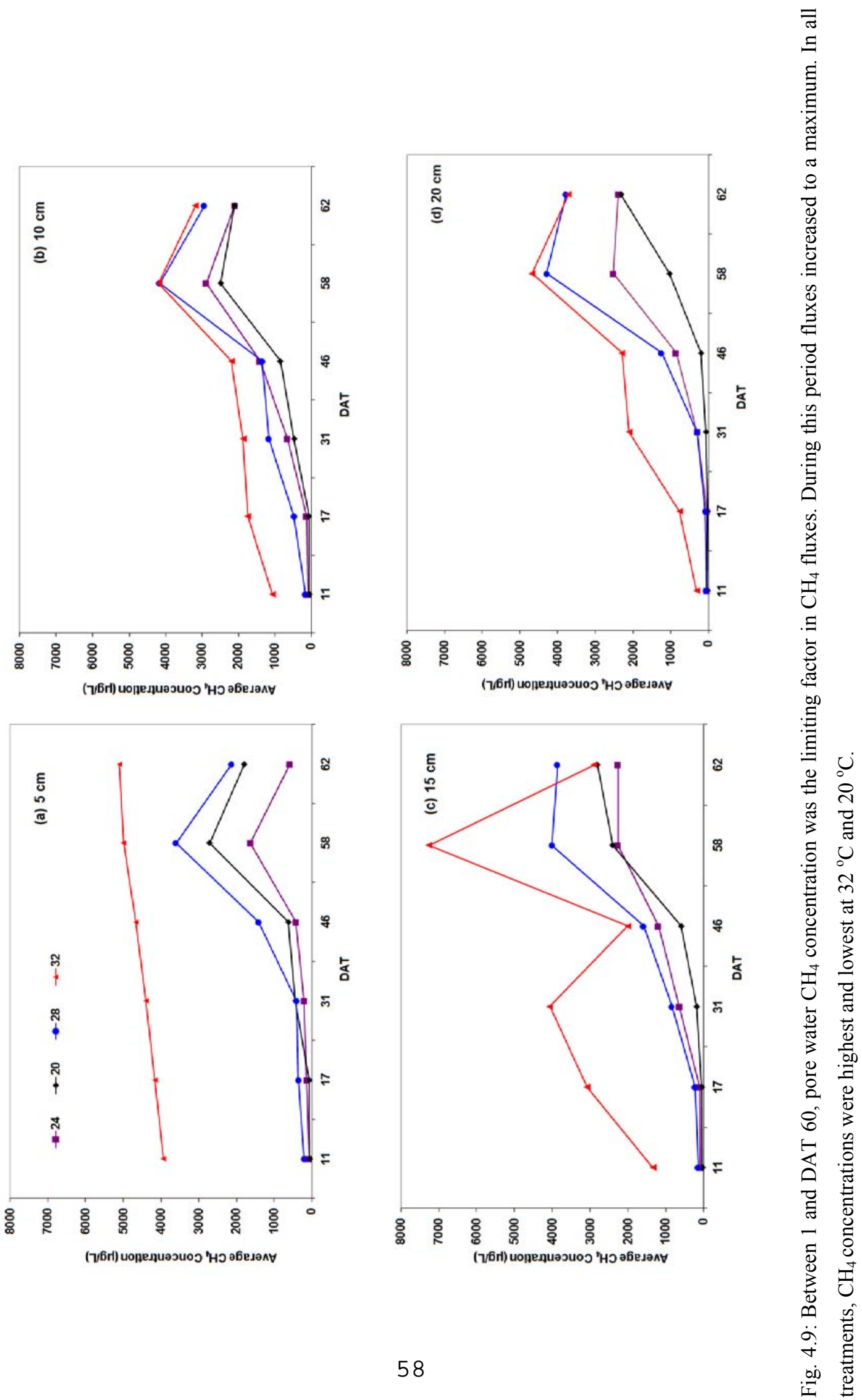
Emission rates from rice fields are correlated to $\mathrm{CH}_{4}$ concentration in the pore water during the first half of the season. Between 1 and DAT 60, pore water $\mathrm{CH}_{4}$ concentration (Fig. 4.9) was the limiting factor in $\mathrm{CH}_{4}$ fluxes (Fig. 4.10). This limiting point could be an indication that fluxes remain almost constant even though $\mathrm{CH}_{4}$ pool increased in the pore water.

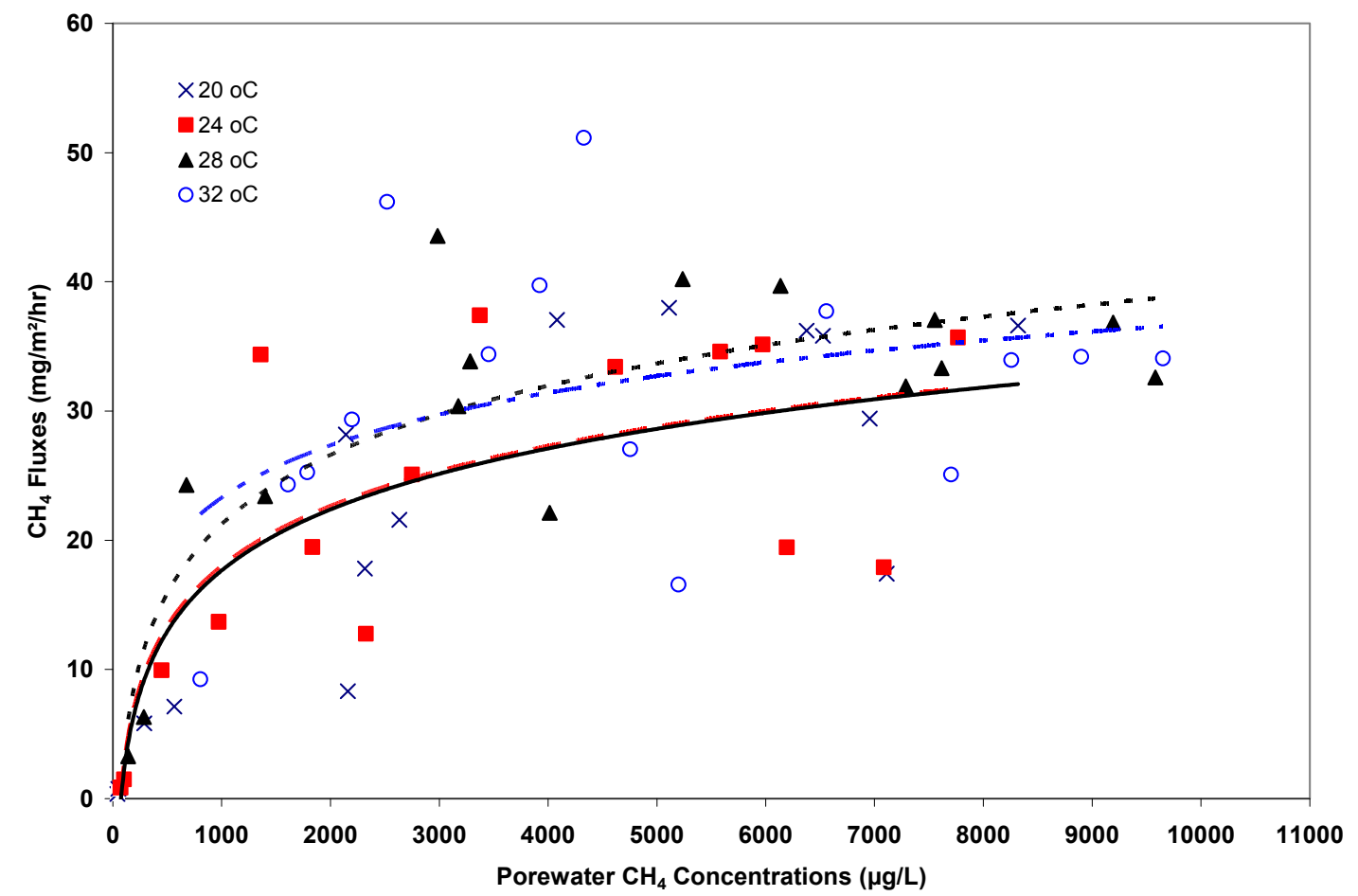

Fig. 4.11: $\mathrm{CH}_{4}$ fluxes reaches maximum $\left(25-40 \mathrm{mg} / \mathrm{m}^{2} / \mathrm{hr}\right.$ ) at $60 \mathrm{DAT}$ (while the pore water concentrations increased from $60 \mu \mathrm{g} / \mathrm{L}$ to $1000 \mu \mathrm{g} / \mathrm{L}$ ), and then level off despite continuous increase in $\mathrm{CH}_{4}$ pore water concentration.

However, the rate of growth was almost constant till mid-season, an indication that increasing temperatures beyond the $28{ }^{\circ} \mathrm{C}$ would not result in continuous increase in the 
rates of pore water $\mathrm{CH}_{4}$ concentration accumulation. This implies that although the process that produces $\mathrm{CH}_{4}$ is temperature-dependent, this process is limited by other factors. One possible factor may be that as the growing season progresses, the $\mathrm{O}_{2}$ from the roots oxidizes the $\mathrm{Fe}(\mathrm{III})$ around the root system, resulting in the formation and accumulation of $\mathrm{Fe}(\mathrm{III})$ oxide precipitates around the roots thereby reducing the root surface area over which the $\mathrm{CH}_{4}$ can diffuse into the root system.

\subsection{Conclusion}

Pore water $\mathrm{CH}_{4}$ concentrations were successfully monitored at different soil temperatures. It was noted that temperature is a limiting and an important factor during the first two months after transplanting. During this period, temperature affected the rate of growth of both fluxes and pore water concentrations. As a result, fluxes also increased with increased dissolved $\mathrm{CH}_{4}$ in the floodwater. The results also suggest that once the $\mathrm{CH}_{4}$ pool in the root zone reaches a value of about $1000 \mu \mathrm{g} / \mathrm{L}$, fluxes will depend on the capacity of the rice plants to transport $\mathrm{CH}_{4}$ to the atmosphere. On the other hand, these results also indicate that the $\mathrm{CH}_{4}$ transport rate in rice plants is a selflimiting process, even though it depends on the plant and root development and temperature among other environmental factors. 


\section{Chapter 5}

Temperature Dependence of Methane Production

\subsection{Summary}

The effect of temperature on $\mathrm{CH}_{4}$ production in rice paddies was investigated using standard incubation techniques. Experiments were performed on four different soil water bath-controlled temperature treatments $\left(20,24,28\right.$, and $\left.32{ }^{\circ} \mathrm{C}\right)$ under continuously flooded conditions. Soil temperatures were continuously measured during the growing season using thermocouples and microloggers. Results showed that after two weeks following flooding, the rate of $\mathrm{CH}_{4}$ production was highly dependent on soil temperature over the season. The calculated seasonal $\mathrm{Q}_{10}$ of $\mathrm{CH}_{4}$ production varied from 2.1 (lower limit) to 3.3 (upper limit), with an average value of 2.6 (90\% confidence level). No seasonal dependence of $\mathrm{Q}_{10}$ value was observed in all treatments. If this observed effect of temperature is representative of all rice paddies, and possibly wetlands, then global warming is likely to enhance the production of $\mathrm{CH}_{4}$, and consequently emissions if oxidation does not increase by the same factor. Considering that the processes involved in the production of $\mathrm{CH}_{4}$ in rice ecosystems is similar to that in natural wetlands, the atmospheric $\mathrm{CH}_{4}$ contribution due to global warming feedback is likely to change the current total biotic $\mathrm{CH}_{4}$ contribution.

\subsection{Introduction}

The most fundamental process in the emission of $\mathrm{CH}_{4}$ from rice agriculture is the production process. However, the rate of $\mathrm{CH}_{4}$ emissions from these ecosystems is a 
composite of production, transport and oxidation processes. In rice paddies, $\mathrm{CH}_{4}$ is produced as a terminal step of the anaerobic breakdown of organic matter (Schütz et al., 1989) by a group of microorganisms called Archaea (Yao and Conrad, 1999; Mitra et al., 2002). This process is driven by a complex food chain of various anaerobic bacteria de-polymerizing and fermenting organic matter (Schütz et al., 1989), resulting in the production of volatile acids and eventually $\mathrm{CH}_{4}$. These methanogenic bacteria utilize substrates such as $\mathrm{H}_{2} / \mathrm{CO}_{2}$, formate, methanol, methylamines, acetate for growth and $\mathrm{CH}_{4}$ production (Conrad 1989; Schütz et al., 1989) under free oxygen and at redox potentials of less than $-150 \mathrm{mV}$ and optimal $\mathrm{pH}$ of 6-8. Thus methanogenesis depends on substrate availability such as amounts of easily degradable organic matter, reducible Fe(III) and sulfate (Watanabe, 1984), and many other environmental factors such as temperature (Tsutsuki and Ponnamperuma 1987). The most important factors that control $\mathrm{CH}_{4}$ production are soil type, rice variety, temperature, soil redox potential, water management and organic carbon or nitrogen (Conrad, 2002). This organic matter is derived from root exudation, sloughed-off root cells and decay of roots (Conrad, 2002). The production and oxidation of $\mathrm{CH}_{4}$ in flooded rice soils are controlled by many soil, plant, and microbial factors. $\mathrm{CH}_{4}$ production rates of soils are significantly and linearly correlated with soil organic matter content (Wang et al., 1999). The extent and duration for which $\mathrm{CH}_{4}$ production is suppressed mainly depends on the ratio of available organic matter to reducible ferric iron (Yao et al., 1999; Watanabe and Kimura, 1999). Rice plants affect $\mathrm{CH}_{4}$ in the root zone by providing methanogenic substrates through root exudates, decaying root tissues, and by respectively transporting $\mathrm{O}_{2}$ and $\mathrm{CH}_{4}$ into and out of the root zone through their aerenchyma. 
Methanogens produce $\mathrm{CH}_{4}$ from either acetate or $\mathrm{H}_{2} / \mathrm{CO}_{2}$ (Conrad, 1989, 1999). Acetate, $\mathrm{H}_{2}$, and $\mathrm{CO}_{2}$ are byproducts of the microbial degradation of organic matter under anoxic conditions. Acetate can either be derived from root exudation or from fermentation (Aulakh et al., 2001).

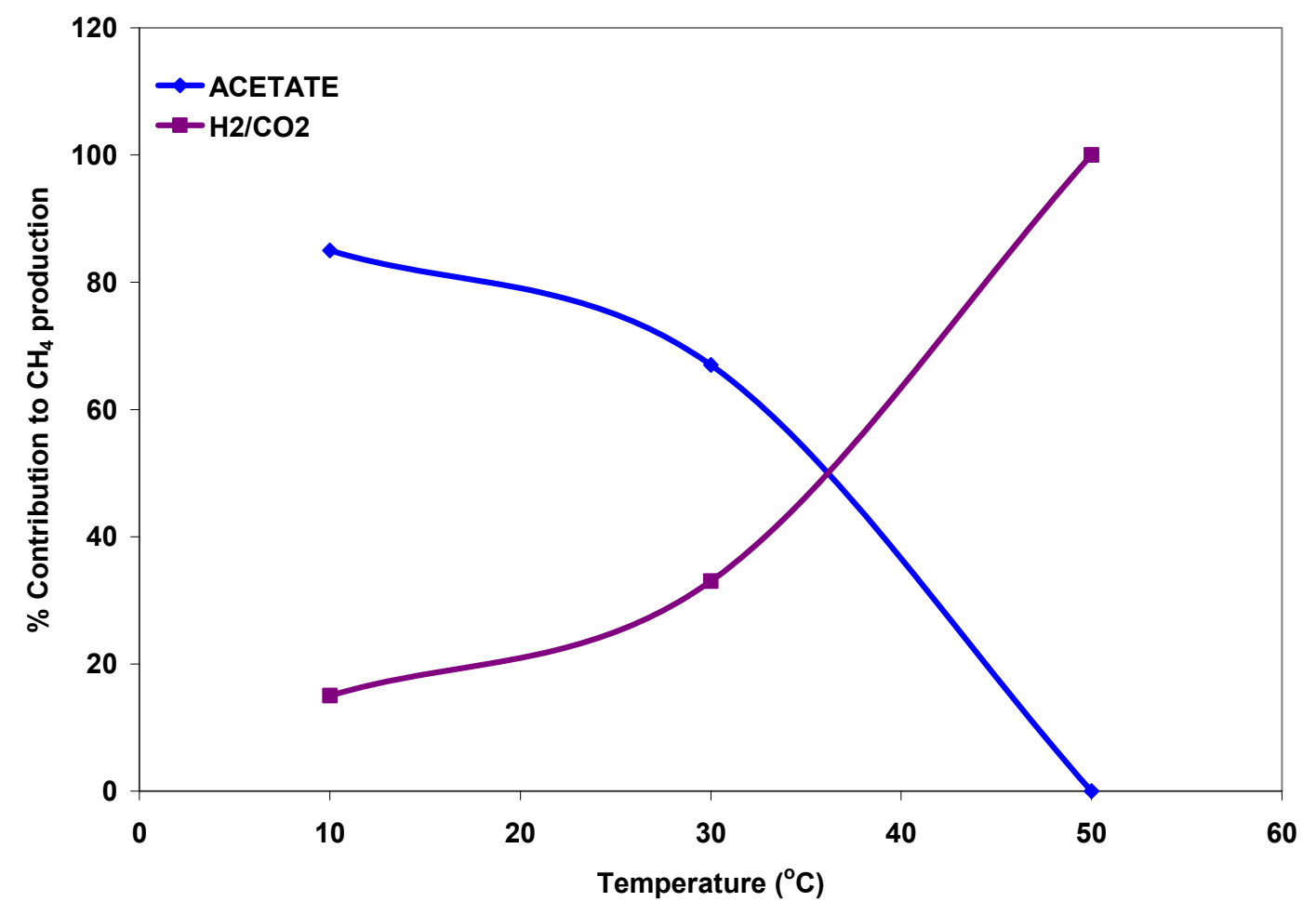

Fig. 5.1: Effect of temperature on the percentage contribution of acetate and $\mathrm{H}_{2} / \mathrm{CO}_{2}$ to methanogenesis in anoxic rice soil. The data shows that as temperature was continuously increased above $35{ }^{\circ} \mathrm{C}, \mathrm{CH}_{4}$ production contribution from $\mathrm{H}_{2} / \mathrm{CO}_{2}$ became predominant, while that from acetate diminished. Data extracted from Conrad (2002).

$\mathrm{CH}_{4}$ production is also inhibited by $\mathrm{NO}_{2}^{-}, \mathrm{NO}$ and $\mathrm{N}_{2} \mathrm{O}$ that accumulate during the reduction of nitrate produced from applied chemical fertilizers. Yao et al. (1999) also found that maximum $\mathrm{CH}_{4}$ production rate was related to both the soil oxidizing and 
reducing capacities. $\mathrm{CH}_{4}$ production is also affected by certain microbial populations that produce methanogenic substrates (Conrad, 2002). Exposure to $\mathrm{O}_{2}$ also inhibits the population growth of methanogens, and hence limits $\mathrm{CH}_{4}$ production. Among environmental factors, temperature has been identified to be very important to the production of $\mathrm{CH}_{4}$ in flooded soils. The reported $\mathrm{Q}_{10}$ values for methane production vary from 1.3 to 28 (van Hulzen at al., 1999; Segers, 1998). An increase in soil temperature increases the rate of organic matter decomposition by microorganisms in the soil, and lowers the redox potential (Tsutsuki and Ponnamperuma, 1987), resulting in increased rate of $\mathrm{CH}_{4}$ production.

The increase in $\mathrm{CH}_{4}$ production with soil temperature means the projected global warming could enhance $\mathrm{CH}_{4}$ production (Rath et al., 2002). Because of the uncertainties in the documented temperature response of $\mathrm{CH}_{4}$ production, an understanding of the temperature feedback mechanisms remains poorly understood (Wang et al., 1999). Because of this uncertainty, most model studies have assumed $\mathrm{Q}_{10}$ values of around 2 to 6 (van Hulzen, 1999; Xu et al., 2007; Huang et al., 1998; Huang et al., 2002; Yu et al., in press). Understanding the temperature - $\mathrm{CH}_{4}$ production link is essential to accurately project future $\mathrm{CH}_{4}$ emissions from rice paddies and possibly wetlands.

\subsection{Aim and Objectives}

The aim was to study the effect of temperature on $\mathrm{CH}_{4}$ production, comparing production rates from both planted and unplanted microcosms under different 
temperature treatments. The objective of this research was to determine the $\mathrm{Q}_{10}$ of $\mathrm{CH}_{4}$ production under carefully controlled environmental conditions.

\subsection{Material and Methods}

We determined the rate of $\mathrm{CH}_{4}$ production at different temperatures $\left(20,24,28,32{ }^{\circ} \mathrm{C}\right)$ using incubation experiments. The soil samples were extracted from both planted and unplanted tubs using sterilized plastic soil corers. The freshly extracted samples were quickly transferred into sterile whirl packs and homogenized before being put into specially designed Erlenmeyer flasks fitted with an airtight seals. The glass jars were equipped with insulated thermocouples and vent pipes with air tight valves.

These containers were immersed in the same water baths that were used to heat both the planted and unplanted tubs (Fig. 5.2). The jars were purged with $99.9 \% \mathrm{~N}_{2}$ before and immediately after placing a sample inside these containers. The first sample was immediately taken, and subsequently every 10 minutes thereafter. A total of four samples were collected in the experiments.

Each time, before a sample was withdrawn, the headspace gas inside the jar was homogenized thoroughly using a syringe and plunger. From each temperature treatment, two-10 mL vials of the headspace gas were collected from two jars, and taken to the laboratory analyzed for $\mathrm{CH}_{4}$ on chromatograph equipped with FID. 


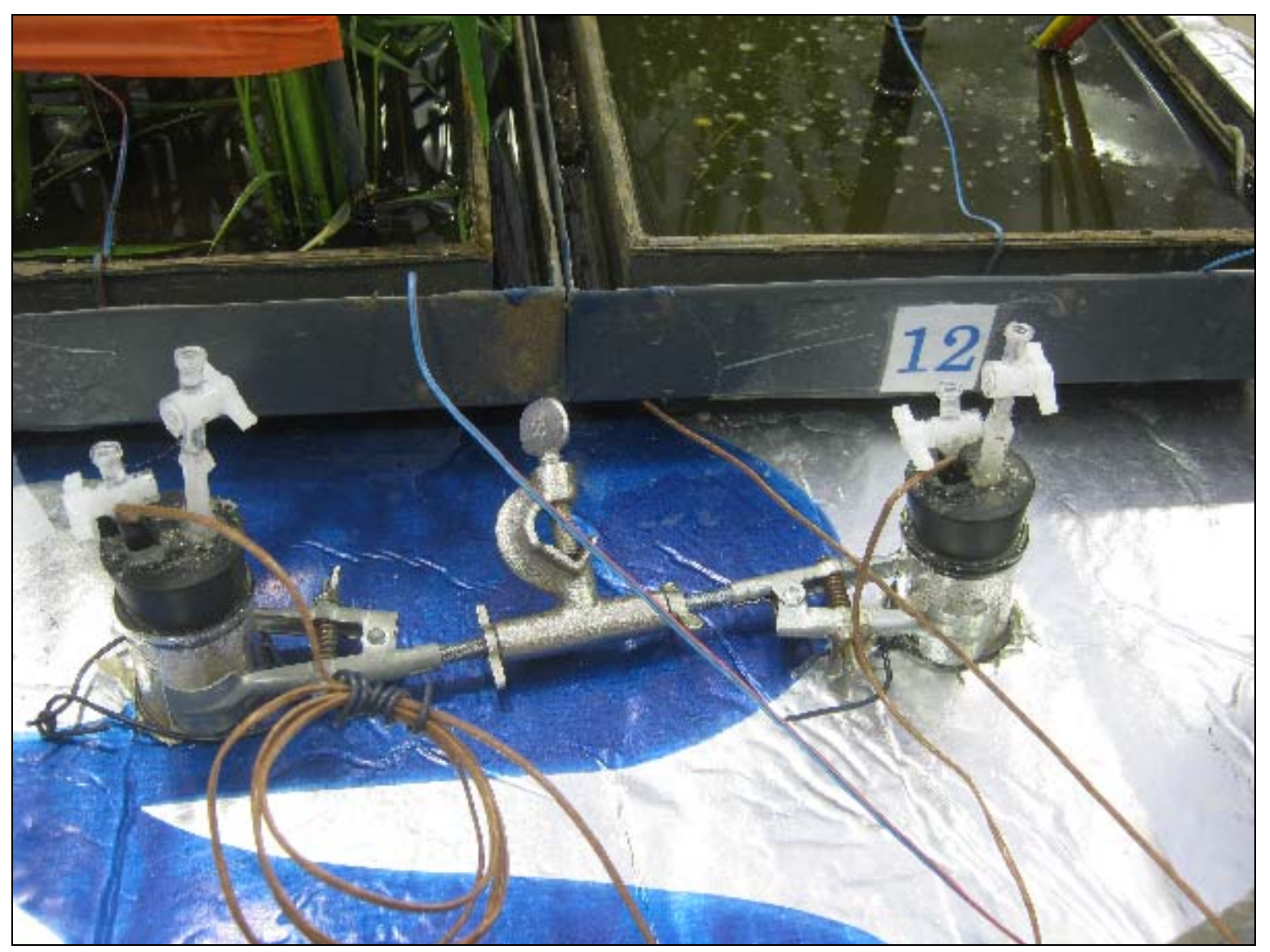

Fig. 5.2: Picture of production jars mounted onto the water bath system. The jars are fitted with valves and thermocouples connected to microloggers (not shown in picture). Temperature was continuously monitored and recorded every 5 minutes during the growing season. The glass jars were purged with $\mathrm{N}_{2}$ several times before each sample was collected.

The production rates for each of the temperatures were calculated as the slope of the plots of concentration versus time. The temperature coefficients of methane production were calculated from mean production rates at four temperature treatments. 


\subsection{Results and Discussion}

\subsubsection{Production Rates}

Consistent with results from other studies (Cicerone and Shetter, 1981; Cicerone et al., 1983; Sass et al., 1991; Neue, 1993; Khalil et al., 2008), $\mathrm{CH}_{4}$ production rates generally increased with time (DAT) over the growing season. The values were almost zero, two weeks after transplanting then increased on the third week. This delay in the production of $\mathrm{CH}_{4}$ is thought to be a characteristic of the soil redox potential, $\mathrm{pH}$, substrate availability, and temperature. For example the production of $\mathrm{CH}_{4}$ have been found to commence hours after flooding in alkaline and calcareous soils, two to three weeks in neutral soils, and five or more weeks in acidic soils (Neue, 1993). The rates continued to increase (with highest rate occurring in highest temperature treatments), reaching a maximum between 96 and 100 DAT (Fig. 5.3). The general increase with DAT observed in all temperature treatments could be caused by several factors that include: population growth of bacteria and Archea following flooding, decay of residual plant material (organic substrate availability) and the growth of plant roots. Roots are thought to both positively and negatively contribute to $\mathrm{CH}_{4}$ production: root oxygen transport suppresses $\mathrm{CH}_{4}$ production, whereas root decay and root exudation promote $\mathrm{CH}_{4}$ production (Sass et al., 1991; Segers, 1998). 


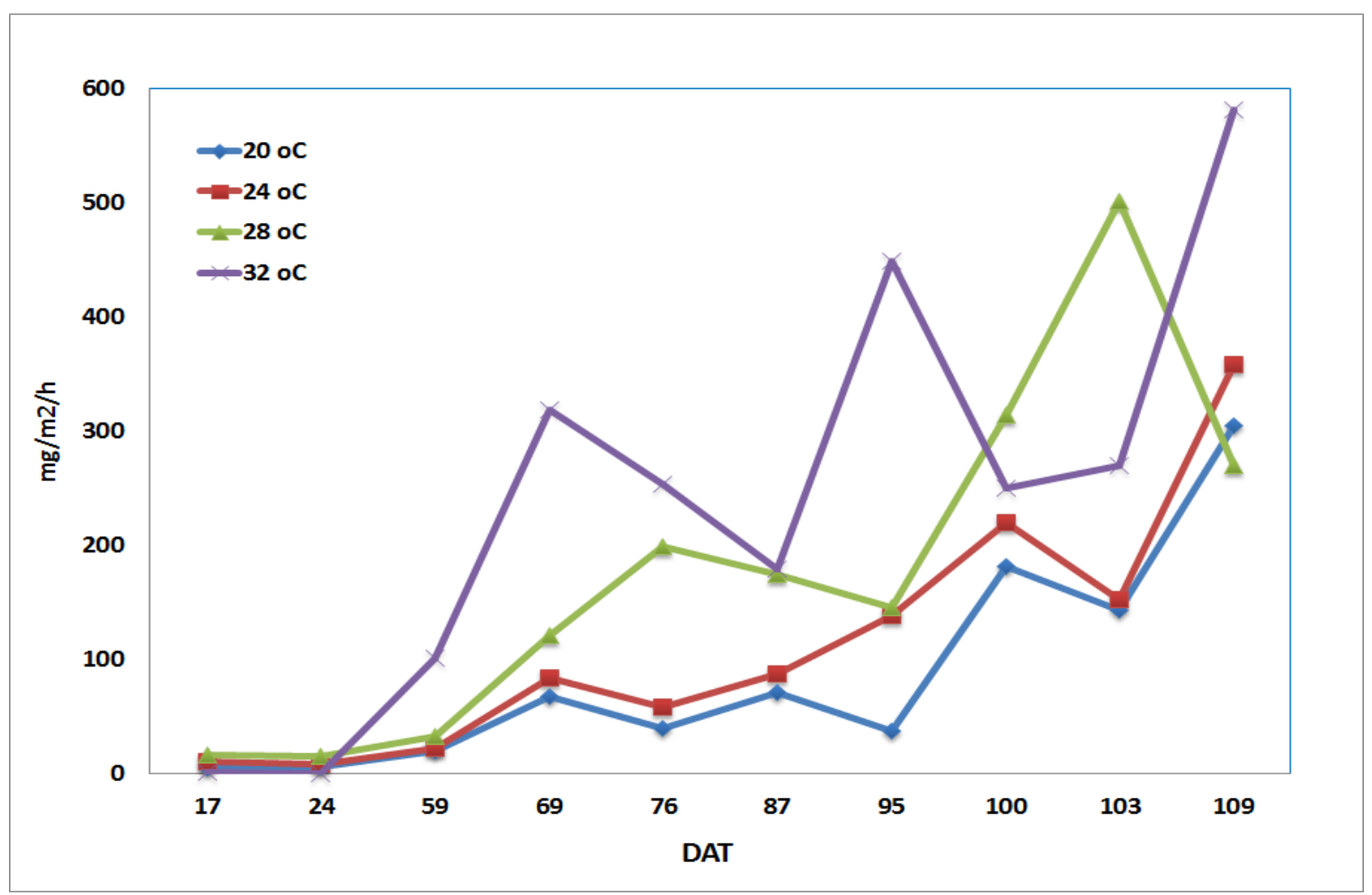

Fig. 5.3: $\mathrm{CH}_{4}$ production rates, showing increases after 2 weeks following flooding. The highest production rates were associated with highest temperature after 17 days following transplanting (DAT).

The highest increase in $\mathrm{CH}_{4}$ production occurred in the set-up with the highest temperature $\left(32{ }^{\circ} \mathrm{C}\right)$. In a similar manner, the $32{ }^{\circ} \mathrm{C}$ temperature treatment had the highest production rate. The explanation for this observation is that immediately after flooding, increasing temperature enhances the reduction of $\mathrm{Fe}^{3+}$ and $\mathrm{SO}_{4}{ }^{-}$ions (van Hulzen et al., 1999) so that the beginning of $\mathrm{CH}_{4}$ production critically depends on temperature (Conrad, 2002). The lowest temperature $\left(20{ }^{\circ} \mathrm{C}\right)$ had the lowest production rate. Results are similar to studies by Aulakh et al. (2001) in which the presence of rice plants lowered the $\mathrm{CH}_{4}$ concentrations in rice tubs, but had no net effect on the $\mathrm{CH}_{4}$ production rates. Chin et al. (1999) observed that decreasing the incubation temperature of rice soil from 30 to $15{ }^{\circ} \mathrm{C}$ resulted in a decrease in the $\mathrm{CH}_{4}$ production. Similarly, 
Wang et al. (1999) found that $\mathrm{CH}_{4}$ production rates that started to increase in the second or third week after flooding, reaching a maximum in the third and fourth week after flooding. It has been found that at temperatures higher than $30{ }^{\circ} \mathrm{C}, \mathrm{CH}_{4}$ is predominantly produced from $\mathrm{H}_{2} / \mathrm{CO}_{2}$, while acetate is no longer consumed and accumulated (Fey et al., 2001). Temperature also significantly affects the pathway of carbon flow since some microbial processes are more sensitive to temperature than others (Conrad, 2002).

When compared with $\mathrm{CH}_{4}$ fluxes and pore water concentration trends, the flux, followed by pore water concentration trends, declined earlier than the production rates, with fluxes declining much earlier than the production rates, consistent with field experimental results reported in other studies (Khalil et al., 2008; Schütz et al., 1989). Temperature affects the growth of microbial populations, producing a non-linear response of $\mathrm{CH}_{4}$ production to temperature. In addition, the availability and increased abundance of substrates strongly enhances the temperature response (Dunfield et al., 1993). The applicability of Arrhenius kinetics may be limited under conditions of changing substrate availability.

\subsubsection{Temperature Dependence of $\mathrm{CH}_{4}$ Production}

The $\mathrm{Q}_{10}$ of $\mathrm{CH}_{4}$ production did not change with increasing DAT, varying from $<1$ and 8.5 (Fig. 5.4). 

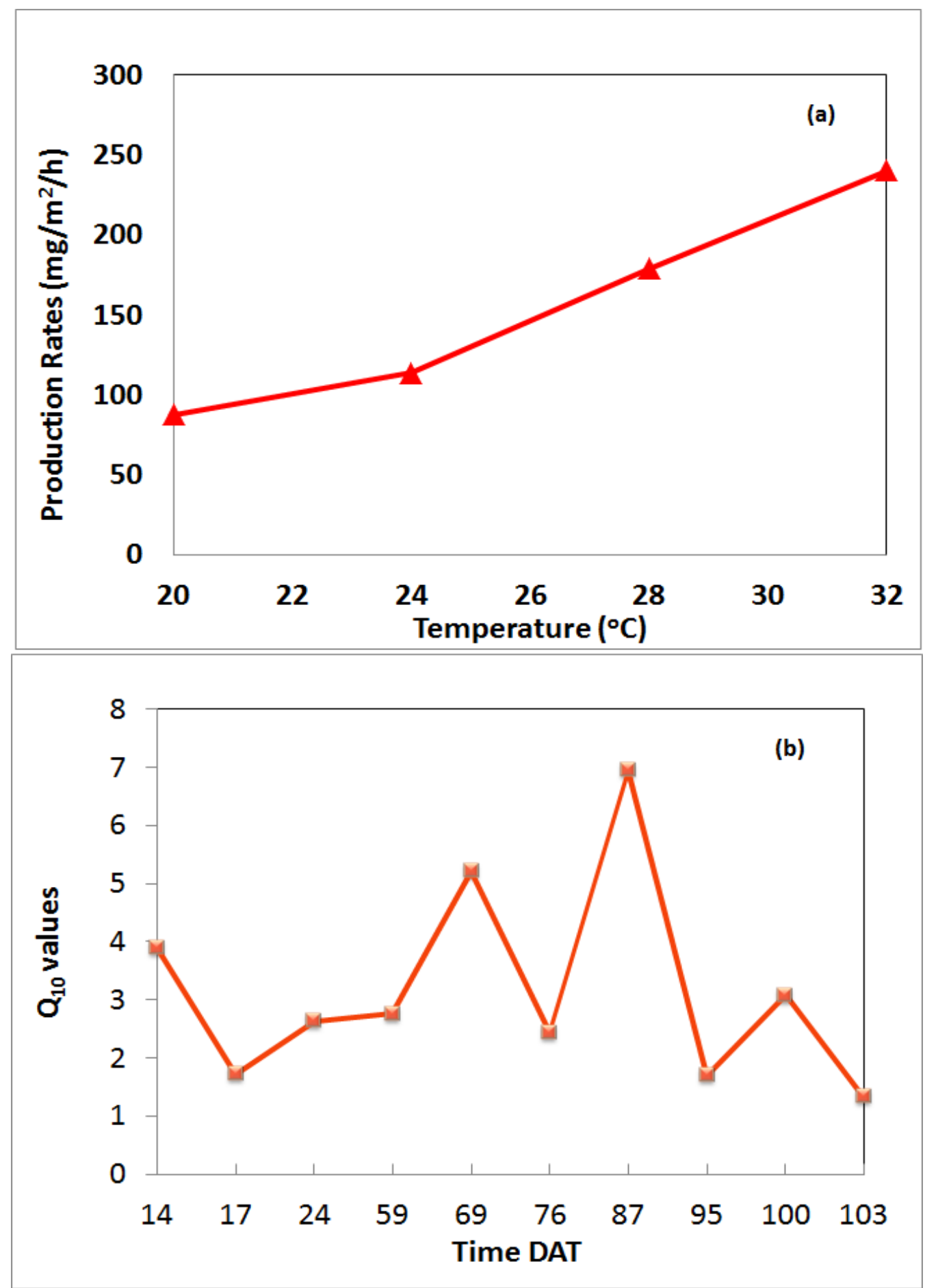

Fig. 5.4: (a) Average $\mathrm{CH}_{4}$ production rates as a function of temperature, and (b) $\mathrm{Q}_{10} \mathrm{~S}$ of $\mathrm{CH}_{4}$ production based on the incubation technique. 
In other studies, $\mathrm{Q}_{10}$ values of $\mathrm{CH}_{4}$ production varied from 1.5 to 3.6 (van Hulzen et al., 1999), and 1.1 to 5.5 (Rath et al., 2002). The seasonally averaged $\mathrm{Q}_{10}$ of production was found to be 2.6, with an upper and a lower limit of 2.1 and 3.3, respectively (90\% confidence level). At low temperatures, electron acceptors and methanogenic biomass activity limit methane production for a longer time leading to low methane production at low temperatures. Bacteria can use a limited number of substrates, of which acetate and hydrogen are considered the most important ones (Segers, 1998). Temperature also affects the diversity of methanogens in the soil. For example, Methanosarcinaceae, which utilize both $\mathrm{H}_{2} / \mathrm{CO}_{2}$ and acetate as the precursor to produce methane, have been found to be more dominant at higher temperature than Methanosaetaceae which only utilize acetate as the precursor for methane.

\subsubsection{Estimation of $\mathrm{CH}_{4}$ Oxidation rates}

By considering the differences between seasonal production rates and fluxes, the seasonal fraction of $\mathrm{CH}_{4}$ oxidized was determined based on the mass-balance approach. Values of oxidation rates varied increased from $50 \mathrm{mg} / \mathrm{m}^{2} / \mathrm{hr}$ to about $230 \mathrm{mg} / \mathrm{m}^{2} / \mathrm{hr}$, following a temperature increase of $20-32{ }^{\circ} \mathrm{C}$. Within the same range, the fraction of $\mathrm{CH}_{4}$ oxidized increased from about 73 to $87 \%$ (Fig. 5.5). The values are consistent with

oxidation rates reported in Schütz et al. (1989). From this data, the calculated seasonal $\mathrm{Q}_{10}$ of oxidation varied between 2.8 (lower limit) to 4.5 (upper limit) with a seasonal average of 3.5 (90\% confidence limit). 

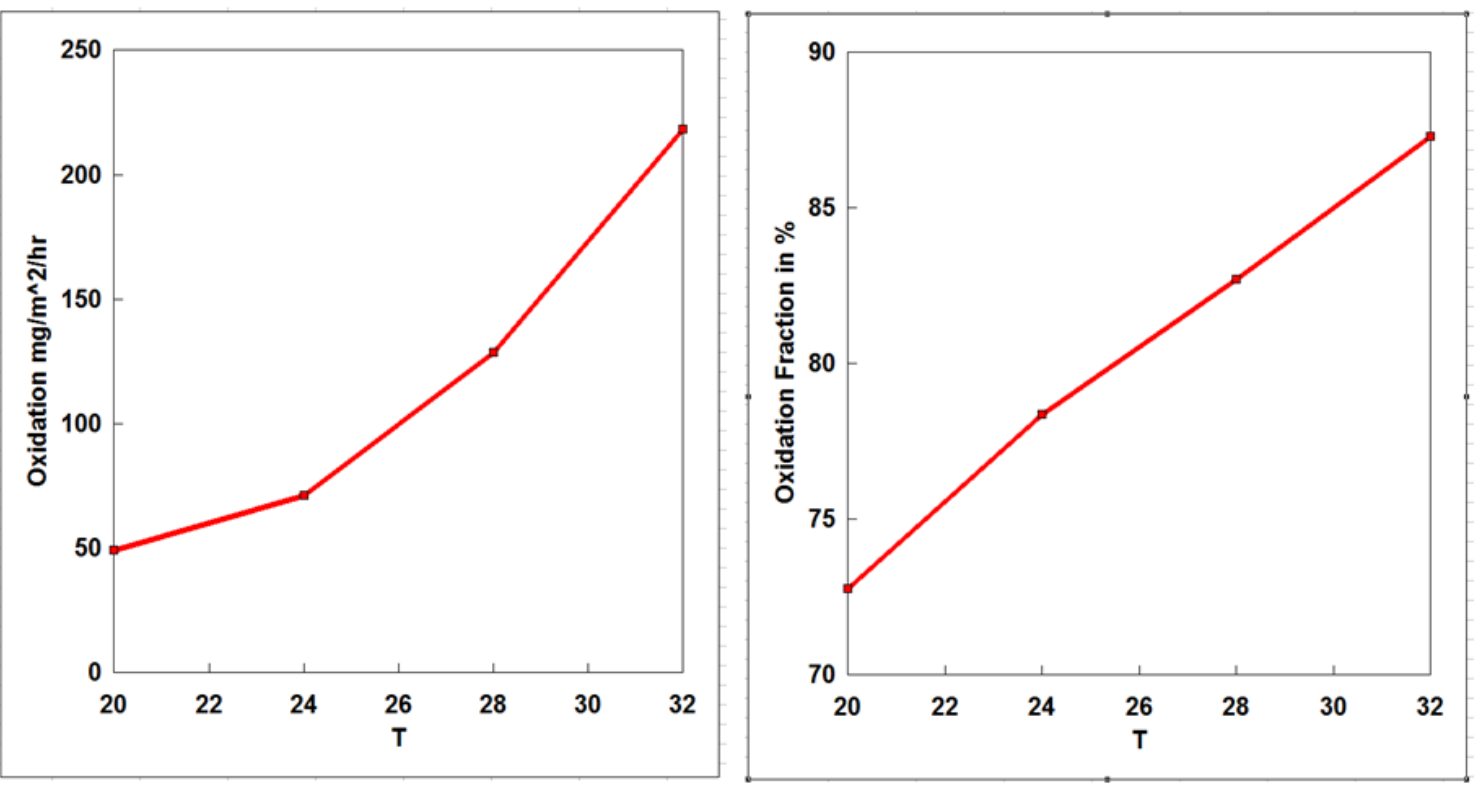

Fig. 5.5: $\mathrm{CH}_{4}$ oxidation rates and fractions plotted against temperature $\left(\mathrm{T},{ }^{\circ} \mathrm{C}\right)$.

\subsubsection{Estimation of $\mathrm{Q}_{10}$ of Transport}

Based on the $\mathrm{Q}_{10}$ s production, flux and oxidation, the $\mathrm{Q}_{10}$ of transport was calculated using the following approach:

$\mathrm{Q}_{10}($ flux $)=\mathrm{Q}_{10}($ production $) \times \frac{\mathrm{Q}_{10}(\text { transport })}{\mathrm{Q}_{10}(\text { oxidation })}$

The $\mathrm{Q}_{10}$ of transport varied from 1.0 (lower limit) to 7.0 (upper limit), with a seasonally averaged value of 2.4 .

\subsection{Conclusion}

The effect of temperature on $\mathrm{CH}_{4}$ production under continuously flooded rice ecosystems was successfully determined in this research. The rate of $\mathrm{CH}_{4}$ production was strongly dependent on soil temperature, with a seasonally averaged $\mathrm{Q}_{10}$ value of 2.6. 
The seasonally averaged $\mathrm{Q}_{10}$ of oxidation and transport were 3.5 and 2.4. The variations, as well as the values found in this research, were less than those reported in literature cited herein, in which values of up to 28 have been presented. Within the range of temperature considered in this research, elevating soil temperature enhances $\mathrm{CH}_{4}$ production in continuously flooded rice ecosystems, and possibly wetlands. 


\section{Chapter 6}

Quantifying Temperature Effect on Methane Oxidation in Rice Ecosystems using Stable Carbon and Hydrogen Isotope Ratios

\subsection{Summary}

The sensitivity of rhizospheric $\mathrm{CH}_{4}$ oxidation to elevated soil temperatures was determined using naturally occurring stable hydrogen and carbon isotopic abundances in water bath temperature-regulated rice microcosms described earlier. $\mathrm{CH}_{4}$ fluxes, below- and aboveground carbon $\left(\delta^{13} \mathrm{C}\right)$ and hydrogen $(\delta \mathrm{D})$ isotopic composition of $\mathrm{CH}_{4}$ was measured using continuous-flow gas chromatography isotope ratio mass spectrometry in Dr. Andrew Rice's laboratory at Portland State University. The belowground pore water samples were collected from each treatment weekly and $\mathrm{CH}_{4}$ was extracted into $\mathrm{N}_{2}$ headspace. Isotopic measurements showed that the mean aboveground $\delta^{13} \mathrm{C}$ values ranged between -60.4 and $-53.0 \%$, with an average of $-56.7 \%$ relative to V-PDB, while $\delta \mathrm{D}$ values ranged between -341.9 and $-273.3 \%$ relative to VSMOW. The ranges for the below-ground isotopic composition were -52.6 to $-45.6 \%$ and -348.3 to $-246.1 \%$ for $\delta^{13} \mathrm{C}$ and $\delta \mathrm{D}$, respectively. $\mathrm{CH}_{4}$ flux ranged from near zero to $30-60 \mathrm{mg} / \mathrm{m}^{2} / \mathrm{hr}$ in mid-season corresponding to a rise in pore water $\mathrm{CH}_{4}$ to $8-12$ $\mathrm{mg} / \mathrm{L}$. These results were integrated and interpreted using an empirically-driven concentration and isotope model to understand $\mathrm{CH}_{4}$ dynamics and to examine the effect of temperature on mechanisms that control $\mathrm{CH}_{4}$ emissions. The $\mathrm{Q}_{10}$ of methane oxidation was found to be 1-2 and 1.4-2.4 from the $\delta^{13} \mathrm{C}$ and $\delta \mathrm{D}$ values, respectively. This study showed that temperature plays a less important role in $\mathrm{CH}_{4}$ oxidation in rice 
paddies compared with production (reported in Chapters 3 and 5) where the average $\mathrm{Q}_{10} \mathrm{~S}$ were 4.6 and 3.1, respectively. Thus the change in the $\mathrm{CH}_{4}$ oxidation efficiency due to elevated soil temperature would not be enough to offset the effect of temperature on $\mathrm{CH}_{4}$ production and emissions, thereby increasing the likelihood of increased $\mathrm{CH}_{4}$ emissions from rice agriculture under future global warming.

\subsection{Introduction}

Rice paddies represent a sizable anthropogenic source of $\mathrm{CH}_{4}$ emissions into the atmosphere. Rhizospheric oxidation is a major sink of $\mathrm{CH}_{4}$ in rice ecosystems. Without this process, $\mathrm{CH}_{4}$ emissions from rice agriculture would be perhaps an order of magnitude higher than the present rates. Yet the impact of global warming on $\mathrm{CH}_{4}$ oxidation, and on the global $\mathrm{CH}_{4}$ atmospheric budget remains poorly understood. Globally, $\mathrm{CH}_{4}$ oxidation is a sink for $\mathrm{CH}_{4}$ and is important in reducing the $\mathrm{CH}_{4}$ emissions into the atmosphere (Hanson and Hanson, 1996; Born et al., 1990). Two principal mechanisms involved are: (1) reactions in the atmosphere, and (2) microbial $\mathrm{CH}_{4}$ oxidation by bacteria in soils. The net flux from rice and wetland ecosystems is a residue of the production and microbial oxidation process. Microbial oxidation of the $\mathrm{CH}_{4}$ produced in the soil is a large fraction of the soil methane pool. As these microbial processes change, the net flux into the atmosphere from these ecosystems will also change. Thus soil microbial $\mathrm{CH}_{4}$ oxidation is considered a key determinant of the rate of change of atmospheric $\mathrm{CH}_{4}$ concentration (Wang and Ineson, 2003). 
It is estimated that up to $90 \%$ of the $\mathrm{CH}_{4}$ produced in flooded rice paddies is oxidized microbially adjacent to the zone of production before reaching the atmosphere (Schütz et al., 1989). Two main aerobic areas contribute to $\mathrm{CH}_{4}$ oxidation (Wang et al., 1997): (I) the oxidized soil surface layer and, (II) the root rhizosphere. The process is mediated by an unidentified community of aerobic methanotrophic bacteria (Conrad, 1996). These aerobic methanotrophs, part of a large group of microorganisms called methylotrophs, reside in the rhizosphere where they use $\mathrm{O}_{2}$ from the atmosphere that diffuses into the soil or the root zone through plants to oxidize $\mathrm{CH}_{4}$. An aerobic surface layer develops around the plant roots. The thickness of this layer is determined by the net consumption and transport rates of $\mathrm{O}_{2}$ supply through plants aerenchyma and intercellular gas space system (Chanton et al., 1992, Nouchi et al., 1990) by diffusion or by mass flow from atmosphere into the root zone. Thus the rate of $\mathrm{O}_{2}$ supply to the rhizosphere is a decisive factor in the magnitude of $\mathrm{CH}_{4}$ emission. Hence, rhizospheric $\mathrm{CH}_{4}$ oxidation is an important internal sink for $\mathrm{CH}_{4}$ produced in the flooded soils, consuming up to $90 \%$ of $\mathrm{CH}_{4}$ production. The presence of $\mathrm{O}_{2}$ in the rhizosphere limits $\mathrm{CH}_{4}$ production and enhances oxidation (Wang et al., 1997). This supply of $\mathrm{O}_{2}$ to the rhizosphere enhances the activity of aerobic methanogens leading to higher $\mathrm{CH}_{4}$ oxidation efficiency. Thus, under these conditions, both plant-mediated $\mathrm{CH}_{4}$ emission and the percentage of $\mathrm{CH}_{4}$ oxidized increase. It is thought that approximately $580 \mathrm{Tg}^{-1}$ of $\mathrm{CH}_{4}$ is produced in flooded rice paddies, but only about 60-100 $\mathrm{Tg} \mathrm{y}^{-1}$ escapes into the atmosphere (Hanson and Hanson, 1996). With projected global warming, persistent shifts in soil temperature could significantly alter the atmospheric $\mathrm{CH}_{4}$ budget. 


\subsubsection{Other Factors Affecting $\mathrm{CH}_{4}$ Oxidation in Flooded Soils}

The elements influencing $\mathrm{CH}_{4}$ oxidation in flooded soils depend on factors that affect methanotrophic activities such as $\mathrm{O}_{2}$, temperature, $\mathrm{CH}_{4}$ availability and the mode of $\mathrm{CH}_{4}$ transport from the production zone to the atmosphere. It is estimated that the optimum temperature for $\mathrm{CH}_{4}$ oxidation ranges between 25 and $30{ }^{\circ} \mathrm{C}$ (Whalen and Reeburgh, 1996). In the same studies, $\mathrm{CH}_{4}$ oxidation has been found to be correlated to temperatures.

The nutritional status of a plant affects its isotopic discrimination, such that wellnourished plants exhibit more positive $\delta^{13} \mathrm{C}$ values by $1-2 \%$ than plants with nitrogen (N) or potassium deficiency (O'Leary, 1981). The kinetics of $\mathrm{CH}_{4}$ oxidation in soils is complex and its dependence on soil $\mathrm{N}$ status remain an area of debate (Reay and Nedwell, 2004). The availability and quantity of nitrogen compounds have been found to have an effect on the oxidation of $\mathrm{CH}_{4}$. Several studies have demonstrated that elevated soil $\mathrm{N}$, particularly in the form of $\mathrm{NH}_{4}{ }^{+}$, may reduce $\mathrm{CH}_{4}$ oxidation rates. In particular, increased inhibition of $\mathrm{CH}_{4}$ oxidation by $\mathrm{NO}_{3}{ }^{-}$has been observed at low $\mathrm{CH}_{4}$ concentrations (Reay and Nedwell, 2004).

Another factor that influences oxidation is the limited supply of gaseous substrates to aerobic methanotrophs. For example, the distribution of aerobic methanotrophs depends on the flow of $\mathrm{CH}_{4}$ from the production (anaerobic) zone and the transport of $\mathrm{O}_{2}$ from the atmosphere into the soil (Hanson and Hanson, 1996). In planted flooded soils, $\mathrm{O}_{2}$ is transported into the root zone via the plants. Another important factor may be the 
consumption of $\mathrm{O}_{2}$ by other microorganisms before it used by aerobic methanotrophs, particularly in soils with high degradable carbon content. The interactive effects of these regulators are uncertain under different environmental conditions.

\subsubsection{Quantifying $\mathrm{CH}_{4}$ oxidation}

Several approaches have been used to quantify $\mathrm{CH}_{4}$ oxidation in the rhizosphere: (I) mass balance calculations based on known concentration of $\mathrm{CH}_{4}$ (Reeburgh, 1976; Rudd and Taylor, 1980; Powelson et al., 2007; Khalil et al., 2008), (II) soil core incubations (Rudd and Taylor 1980), (III) inhibitors such as methyl fluoride (Popp et al., 2000), (IV) inhibition of methanotrophy by using $\mathrm{N}_{2}$, and (V) measurement of ${ }^{13} \mathrm{C}$ isotopic signatures of the produced $\mathrm{CH}_{4}$ and $\mathrm{CO}_{2}$ (Rudd and Taylor, 1980; Chanton et al., 2008a; Powelson et al., 2007; Venkiteswaran and Schiff, 2005; Groot et al., 2003; Conrad et al., 2002; Gerard and Chanton, 1993; Epp and Chanton, 1993). The massbalance method requires $\mathrm{CH}_{4}$ and $\mathrm{CO}_{2}$ emission and production measurements. The rate of $\mathrm{CH}_{4}$ oxidation per unit area is then calculated as a difference between production and emission. Because of the difficulty in accurately quantifying diffusion coefficients, the mass balance technique is associated with uncertainties (Chanton et al., 2009). Physical characteristics of an environment are not preserved in incubation experiments. For example the incubation technique is affected by contamination during sampling, distortion of the physical structure of the soil samples, changes in microbial communities and the changes of environmental conditions in the laboratory such as temperature. 
Of all the methods above, isotopic analysis of soil $\mathrm{CH}_{4}$ is a direct and non-invasive technique used to monitor the $\mathrm{CH}_{4}$ cycle processes at a finer scale than is possible by measurement of surface $\mathrm{CH}_{4}$ emissions only (Whiticar et al., 1986). The technique has found extensive use in the assessment of biogeochemical processes such as $\mathrm{CH}_{4}$ production and oxidation in landfills, terrestrial and marine environments (Nakagawa et al., 2002). The method is based on determining the proportion (fraction) of $\mathrm{CH}_{4}$ oxidized from the differences between stable and non-destructive hydrogen and carbon isotopic ratios. The technique is widely used to quantify $\mathrm{CH}_{4}$ oxidation in rice paddies, temperate soils and natural wetlands because of its advantages over techniques mentioned above: (I) it has a relatively sensitive, which makes it a robust approach for in-situ measurements (Chanton et al., 2008b; Boerjesson et al., 2007; Bodelier et al., 2000), and (II) is non-invasive, leaving the rhizosphere intact compared to incubation or inhibition techniques.

Typically, natural biogenic $\mathrm{CH}_{4}$ has a carbon isotopic composition below -75 \%o (Tab. 6.1), but due to oxidation, $\mathrm{CH}_{4}$ may exhibit ${ }^{13} \mathrm{C}$ enriched values of -30 to $-50 \%$. These methanotrophic bacteria preferentially consume ${ }^{12} \mathrm{CH}_{4}$ and discriminate against the heavier ${ }^{13} \mathrm{CH}_{4}$ (Chanton and Liptay, 2000; De Visscher et al., 2004; Happell et al., 1994; Whiticar 1999) leaving residual $\mathrm{CH}_{4}$ enriched in ${ }^{13} \mathrm{CH}_{4}$ (O'Leary et al., 1988; Reeburgh et al., 1993). The resultant effect is a change in the isotope composition when $\mathrm{CH}_{4}$ is oxidized, thereby altering the isotope ratio. Because of this property, $\mathrm{CH}_{4}$ 
oxidation is estimated by the degree of change between the $\delta^{13} \mathrm{C}$ content of $\mathrm{CH}_{4}$ emitted relative to the $\delta^{13} \mathrm{C}$ of $\mathrm{CH}_{4}$ in the anoxic zone. 


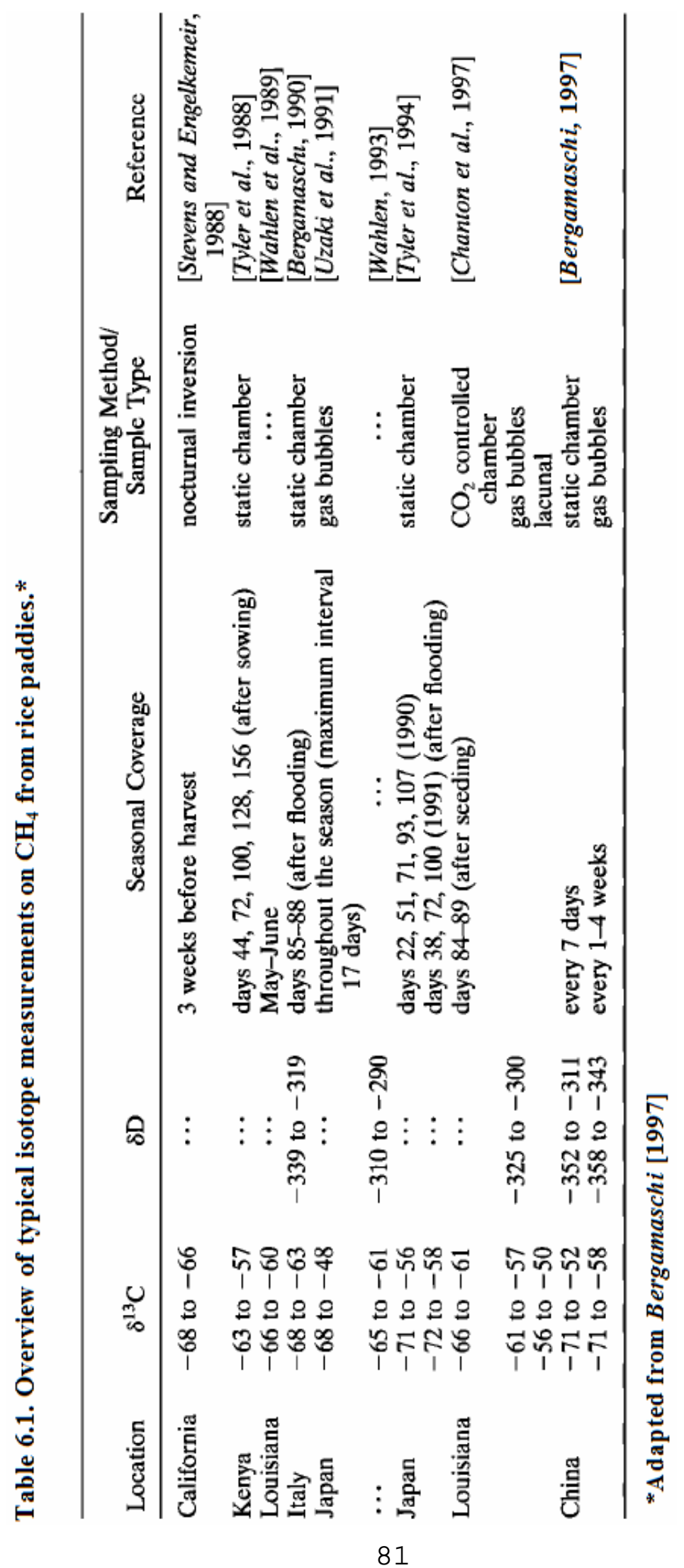


The fractionation due to microbial oxidation is affected by different processes such as transport, temperature (Chanton and Liptay, 2000), methanotrophic activity and $\mathrm{CH}_{4}$ availability (Templeton et al., 2006), and enzymatic reactions or a mixture of all.

\subsubsection{Quantification of $\mathrm{CH}_{4}$ Oxidation}

The carbon isotopic composition is expressed in the standard $\delta$ notation in per mil. (Gonfiantini et al., 1995):

$\delta^{13} C(\%)=\left[\left(R_{\text {sample }} / R_{\text {standard }}\right)-1\right] \times 1000$

Where $\mathrm{R}_{\text {sample }}$ is the carbon-13 abundance ratio given by ${ }^{13} \mathrm{CH}_{4} /{ }^{12} \mathrm{CH}_{4}$ ratio of the sample.

Since absolute values of ${ }^{13} \mathrm{C} /{ }^{12} \mathrm{C}$ are difficult to obtain, the values are reported relative to Vienna Peedee Belemnite (VPDB) (O’Leary, 1981; Gonfiantini et al., 1995). Rstandard $_{\text {s. }}$ is the ${ }^{13} \mathrm{CH}_{4} /{ }^{12} \mathrm{CH}_{4}$ ratio for V-PDB. Negative $\delta^{13} \mathrm{C}$ values indicate that depletion of the ${ }^{13} \mathrm{C}$ isotope is taking place relative to the carbonate standard. In a similar way, just recently, the use of hydrogen isotopes $(\delta \mathrm{D})$ has been used in trying to understand the biogeochemistry of individual $\mathrm{CH}_{4}$ sources (Wahlen, 1994; Quay et al., 1999; Rice et al. 2009; Tyler et al., 1997). The hydrogen isotopic composition, $\delta \mathrm{D}$, is calculated in the same way using the $\mathrm{D} / \mathrm{H}$ ratio for standard mean $(0.0001558)$ for $\mathrm{R}_{\text {standard }}$ (Gonfiantini et al., 1995). The percentage fraction of oxidized $\mathrm{CH}_{4}$ (oxidation efficiency) is determined as a function of isotopic belowground $\mathrm{CH}_{4}\left(\delta_{\mathrm{i}}\right)$, emitted $\mathrm{CH}_{4}\left(\delta_{\mathrm{f}}\right)$, and the kinetic isotope effect (KIE) during oxidation $(\alpha)$ : 


$$
F=\frac{\delta_{i}-\delta_{f}}{(\alpha-1)\left(\delta_{f}+1000\right)}
$$

Where $\delta_{\mathrm{i}}$ is the $\delta^{13} \mathrm{C}$ (or $\delta \mathrm{D}$ ) value in the anoxic zone, $\delta_{\mathrm{f}}$ is the $\delta^{13} \mathrm{C}$ (or $\delta \mathrm{D}$ ) value of emitted $\mathrm{CH}_{4}, \alpha$ is the fractionation factor, $\alpha$ for microbial oxidation and $\alpha_{\text {trans }}$ is the fractionation factor associated with gas transport. The extent of bacterial oxidation is estimated by $\alpha$, which is the difference between the production and the residual $\mathrm{CH}_{4}$. Typical values of $\alpha$ associated with $\delta^{13} \mathrm{C}$ and $\delta \mathrm{D}$ values are presented in Table 6.2. 


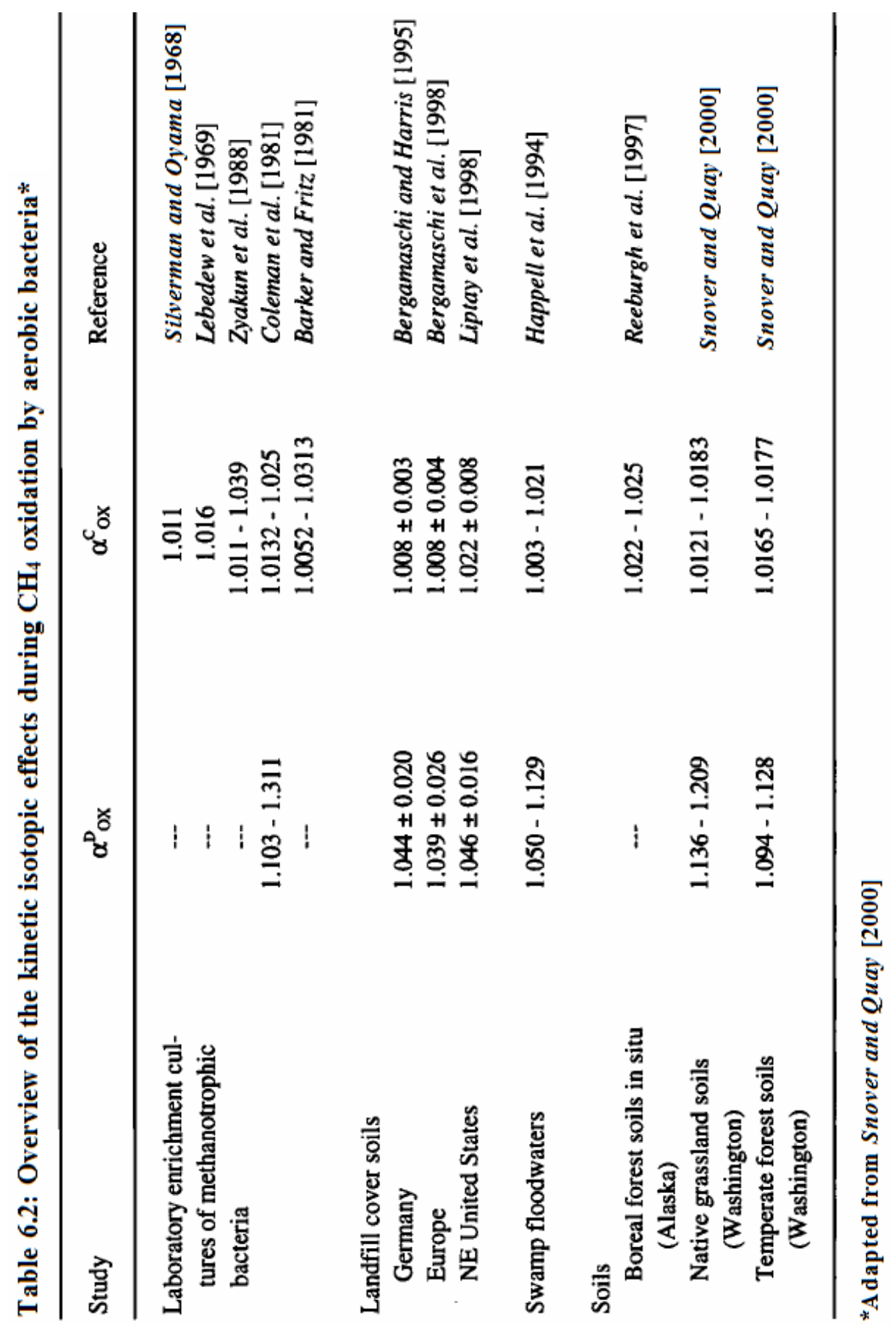


Typically, values of $\alpha_{o x}$ have been found to be dependent on both temperature (Coleman et al. 1981; King et al., 1989 ) and $\mathrm{CH}_{4}$ concentrations, with values lying in the range 1.022 to 1.050 for temperatures between $15^{\circ} \mathrm{C}$ and $26^{\circ} \mathrm{C}$ (Cabral et al., 2010; Tyler et al., 1997; Reeburgh et., 1997). Various models have been developed that relate $\alpha_{o x}$ and soil temperature (Fig. 6.1).

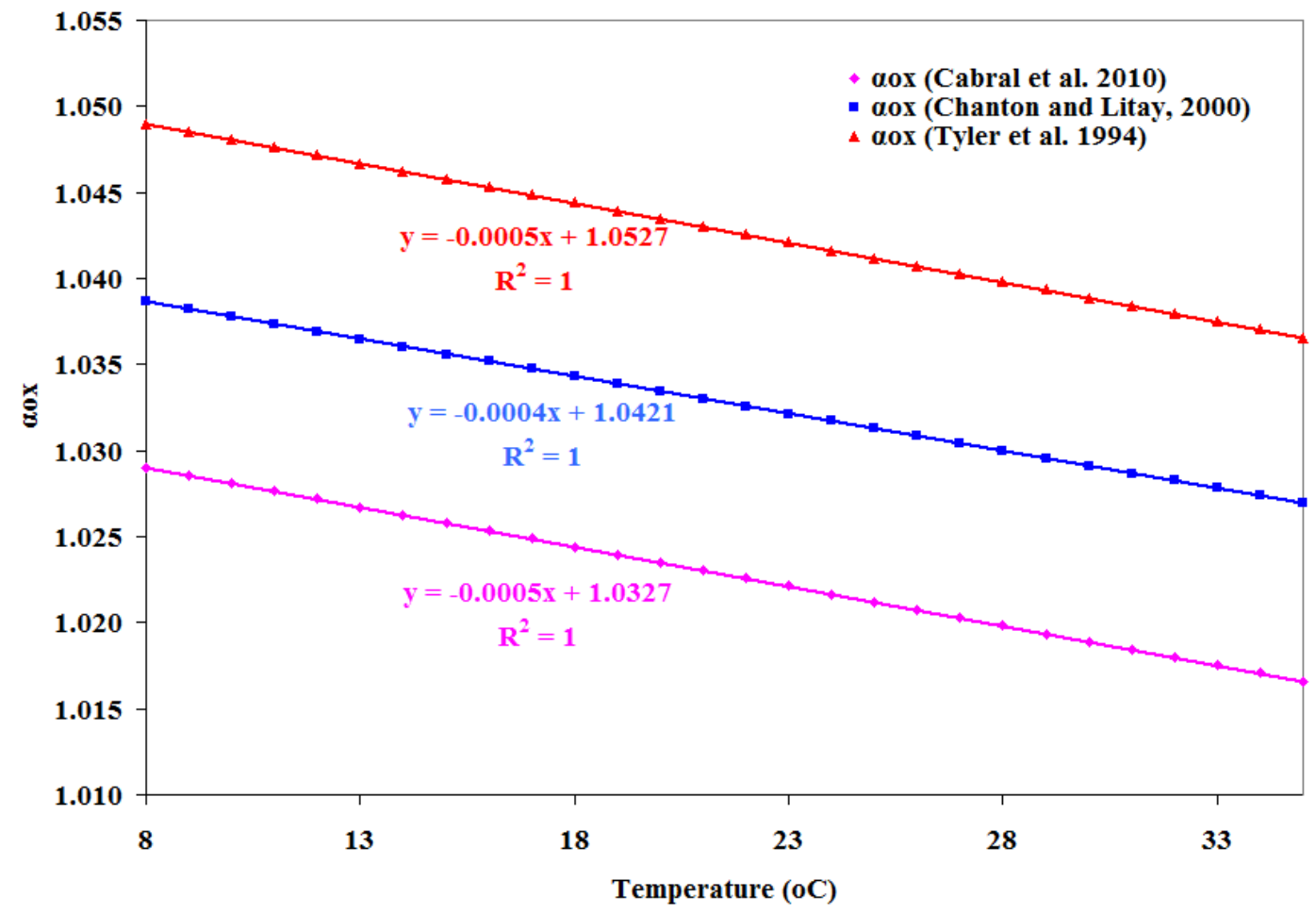

Fig. 6.1: Typical models proposed for the variation of $\alpha_{o x}$ with temperature. There is generally an agreement between the slopes, but with significantly different intercepts.

\subsubsection{Isotope Fractionation by Transport}

Three main modes of $\mathrm{CH}_{4}$ transport from flooded rice paddies (Schutz et al., 1991) associated with ${ }^{13} \mathrm{C}$ isotopic fractionations (Chanton, 2004) are: diffusion, ebullition and 
plant-mediated transport. The relative importance of these three pathways depends on organic loading, changes in temperature and plant density. For example, in bare plots (controls), isotope fractionation of $\mathrm{CH}_{4}$ during transport is mostly due to molecular diffusion in the gas phase and equilibrium partitioning between gas and water. Bubble ebullition across the air-water interface and bulk flow are thought to contribute little or no isotopic fractionation (Chanton, 2004). In rice planted tubs, $\mathrm{CH}_{4}$ transport is predominantly a combination of convective bulk flow (in daylight) and molecular diffusion (at night). The presence of plants also affects the stable isotope distribution of $\mathrm{CH}_{4}$ in both fluxes and pore water through plant-mediated transport mechanisms and aerobic oxidation associated with the roots (Schutz et al., 1989; Chanton and Dacey, 1991). For example, diffusion through plant aerenchyma results in significantly greater rates of transport for ${ }^{12} \mathrm{CH}_{4}$ relative to ${ }^{13} \mathrm{CH}_{4}$ resulting in the enrichment of ${ }^{13} \mathrm{CH}_{4}$ in plant aerenchyma and in the rhizosphere (Chanton, 2004).

While during the day, pressurized through-flow (active transport) is the main mode of gas transport, with little isotopic fractionation of $\mathrm{CH}_{4}$ (Chanton, 2004), the main transport mechanism at night is diffusion (passive transport), which result in massdependent fractionation of emitted $\mathrm{CH}_{4}$ (Chanton and Whiting, 1996). The presence of diffusion results in the release of depleted $\mathrm{CH}_{4}$ in fluxes than in pore water (Chaser et al., 2000). Fractionation in rice plants differs significantly from day to night as molecular diffusion is more important during night time. 
In comparison to bare flooded soils, emissions from flooded soils planted with rice generally release about 9 times more $\mathrm{CH}_{4}$, resulting in a reduction of $\mathrm{CH}_{4}$ partial pressures within the flooded soil, thereby causing a reduction in dissolved $\mathrm{CH}_{4}$ pore water concentrations and $\mathrm{CH}_{4}$ bubbles (Chanton, 2004). The result is a dominant plantmediated transport in rice planted tubs and bubble ebullition and diffusion in non-rice planted tubs.

\subsection{Aim and Objectives}

The major aim of this research was to determine how $\mathrm{CH}_{4}$ oxidation in rice ecosystems will be affected by elevated soil temperatures under global warming. Three objectives were set: (1) determine stable hydrogen and isotopic compositions of $\mathrm{CH}_{4}$ under different soil temperatures; (II) characterize seasonal patterns of $\mathrm{CH}_{4}$ oxidation, and (III) use $\delta^{13} \mathrm{C}$ and $\delta \mathrm{D}$ to calculate fraction and $\mathrm{Q}_{10}$ of $\mathrm{CH}_{4}$ oxidation in rice ecosystems.

\subsection{Materials and Methods}

\subsubsection{Site Characteristics}

The study was performed in a climate-controlled greenhouse experiment as previously stated in Chapter 2. The rice plots were continuously flooded immediately after the rice seedlings were transplanted. These conditions were consistently maintained throughout the sampling period to maintain uniformity in environmental conditions. The fraction of oxidation was determined using in-situ stable isotope tracing technique (Chanton et al., 
1997; Tyler et al., 1997). The method makes use of naturally occurring carbon isotope ratios $\left({ }^{13} \mathrm{C} /{ }^{12} \mathrm{C}\right)$ between above- and below-ground was used in this research.

\subsubsection{Sampling Techniques}

Three types of samples were collected throughout the season. Gas samples for flux measurements were collected from the rice tubs using static chambers as outlined in Chapter 3. Each time the samples above were collected, two $60 \mathrm{~mL}$ samples were withdrawn after 30 minutes using syringes for isotopic analysis. The $60 \mathrm{~mL}$ headspace gas samples were stored in pre-evacuated $30 \mathrm{~mL}$ glass vials with non-reactive $\mathrm{CH}_{4}$ stoppers (Bellco Co. USA) and stored at laboratory temperature for analysis.

Water samples were collected on a weekly basis using plastic peepers that were connected to small perforated cylinders placed at approximately 5, 10, 15 and $20 \mathrm{~cm}$ below the soil surface. The cylinders were placed between the rice rows or in the unplanted tubs (controls). Before pore water sample was collection, about $10 \mathrm{~mL}$ were flushed out of the peepers, and left for about 30 minutes to equilibrate. About $20 \mathrm{~mL}$ of pore water were withdrawn using syringes and taken to the laboratory for analysis. The headspace gas after mixing with $99.9 \% \mathrm{~N}_{2}$ was dried and stored into evacuated $20 \mathrm{~mL}$ glass vials. 


\subsubsection{Isotopic Measurements}

The hydrogen and carbon isotope ratios in the samples were determined using continuous-flow gas chromatography isotope ratio mass spectrometry. For pore water samples where $\mathrm{CH}_{4}$ concentrations were high, extracted samples were injected onto a Pava Plot on column via a 6-point valve with a $100 \mu 1$ sample loop. Above-ground flux samples were enriched prior to analysis by trapping $\mathrm{CH}_{4}$ at $-125 \pm 5{ }^{\circ} \mathrm{C}$ for several minutes. The resulting sample was then focused on a loop of the analytical column immersed in liquid nitrogen. Following the procedure described in Rice et al. (2001; 2010), the sample was warmed and released onto the separation column for analysis. In

all analyses, elutes from the $\mathrm{GC}$ column, $\mathrm{CH}_{4}$ was converted to either $\mathrm{CO}_{2}$ (for $\delta^{13} \mathrm{C}$ ) or $\mathrm{H}_{2}$ (for $\delta \mathrm{D}$ ) in a high temperature furnace. Following high temperature conversion, samples were introduced into a Thermo Scientific Delta $\mathrm{V}$ isotope ratio mass spectrometer in a viscous flow of helium. Isotope ratios were determined by integrating peaks of mass /charge: 44.45 (for $\delta^{13} \mathrm{C}$ ) or 2.3 (for $\delta \mathrm{D}$ ). The isotope ratios were determined with reference to the standards V-PDB (for $\delta^{13} \mathrm{C}$ ) and V-SMOW (for $\delta \mathrm{D}$ ).

To calculate the fraction of $\mathrm{CH}_{4}$ oxidized, the background isotopic composition was accounted for when calculating the isotope ratios $\left(\delta_{\mathrm{E}}\right)$ for $\mathrm{CH}_{4}$ emissions:

$$
\delta_{E}=\frac{c_{F} \delta_{F}-c_{I} \delta_{I}}{c_{F}-c_{I}}
$$

Where $\delta_{\mathrm{I}}$ and $\mathrm{C}_{\mathrm{I}}$ are the $\delta^{13} \mathrm{C}$ or $\delta \mathrm{D}$ and concentration for the initial gas sample and $\delta_{\mathrm{F}}$ and $\mathrm{C}_{\mathrm{F}}$ refer to the $\delta^{13} \mathrm{C}$ or $\delta \mathrm{D}$ and concentration for the final sample. 


\subsubsection{Determination of Fraction of $\mathrm{CH}_{4}$ Oxidized}

From isotopic studies of flux samples from vegetated wetlands, emitted $\mathrm{CH}_{4}$ has been found to be 5-15\% more depleted in $\delta^{13} \mathrm{C}$ than in unplanted samples (O'Leary et al., 1988; O’Leary, 1981). Tyler et al. (1997) and Craig noted in O'Leary (1981) found that $\mathrm{CH}_{4}$ was depleted by $-12 \%$ for rice plants. With this value, the above-ground isotopic composition was adjusted for transport fractionation in order to get the below-ground values. Following the protocol in Tyler et al. (1997), the fractional oxidation was calculated as a function of isotopic below-ground $\mathrm{CH}_{4}$ emitted $\mathrm{CH}_{4}$ and $\alpha$ values from Snover and Quay (2000).

\subsection{Results and Discussion}

\subsubsection{Carbon Isotopic Composition}

Large temporal variations in $\mathrm{CH}_{4}$ fluxes, $\delta^{13} \mathrm{C}$ and $\delta \mathrm{D}$ were observed during the middle of the growing season, in resemblance to those reported in Tyler et al. (1997). The mean above-ground $\delta^{13} \mathrm{C}$ values were between -60.4 and $-53.0 \%$, with an average of $-56.7 \%$ relative to V-PDB. These compare well to reported mean values of between -66 and -50 \%o from temperate rice paddies (Marik et al., 2002; Bergamaschi, 1997). Consistent with results from Indian rice paddies (Rao et al., 2008), the emitted $\mathrm{CH}_{4}$ at the start of the growing season was relatively enriched in ${ }^{13} \mathrm{C}$, then depleted during the middle part of the season, and finally enriched again towards the end of growing season (Fig. 6.2). These seasonal changes are thought to be due to changes in fractionation associated 
with $\mathrm{CH}_{4}$ production, oxidation and transport (Rao et al., 2008) due to plant roots growth and decay.

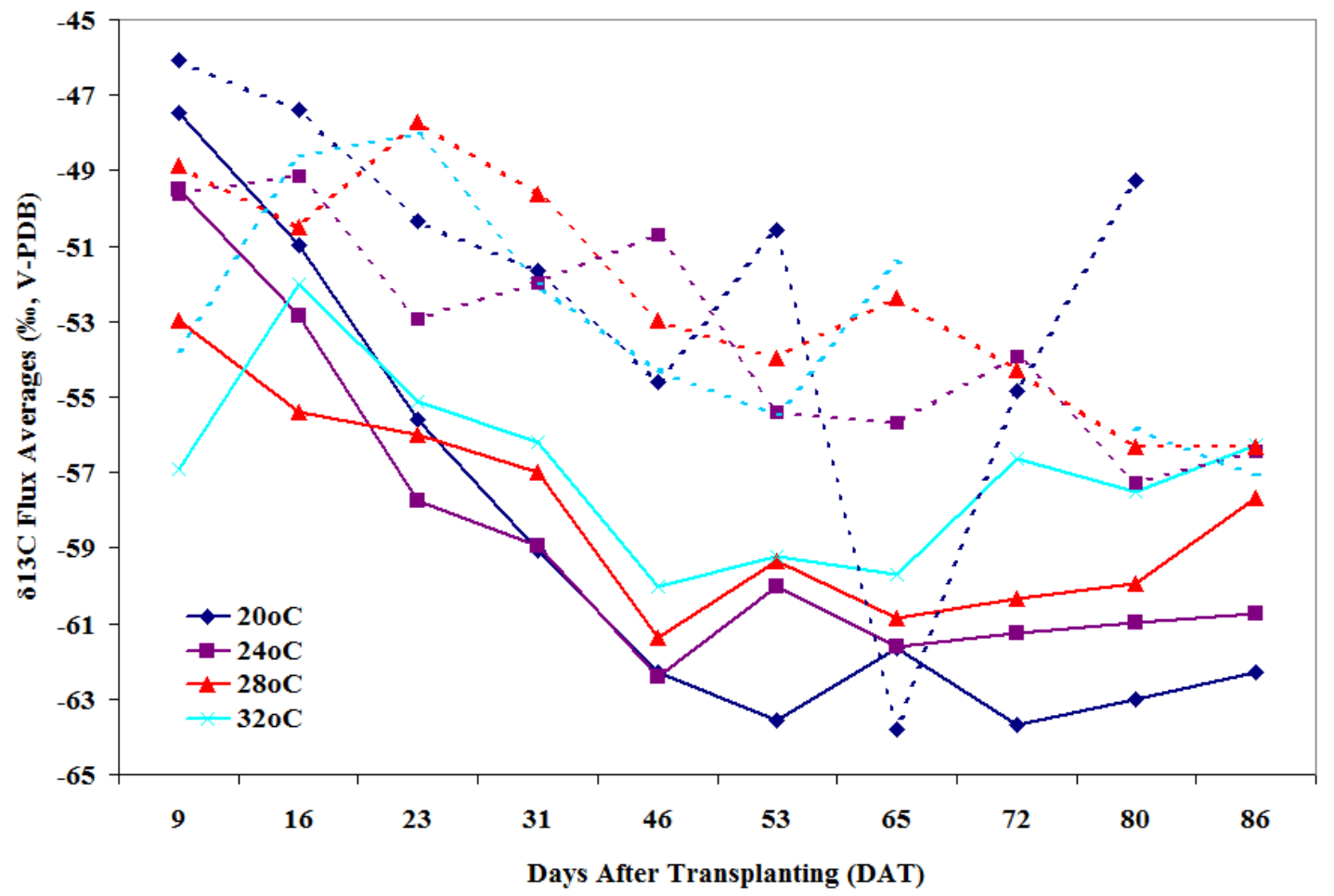

Fig. 6.2: Seasonal variation of $\delta^{13} \mathrm{C}_{\text {of }} \mathrm{CH}_{4}$ emitted from rice planted tubs (solid lines) and unplanted tubs (broken lines) for different temperature treatments. In all treatments, the samples from planted tubs were more depleted during the middle part of the growing season than at the start. That feature was not evident in unplanted (control), except in one particular treatment $\left(20^{\circ} \mathrm{C}\right)$ in which the trend was similar to those in planted tubs.

The isotopic composition of pore water $\mathrm{CH}_{4}$ at $10 \mathrm{~cm}$ depth ranged from -52.6 to -45.6 \%o. Seasonal trends were similar in planted and unplanted tubs, with no distinct differences between different temperature treatments (Fig. 6.3). 


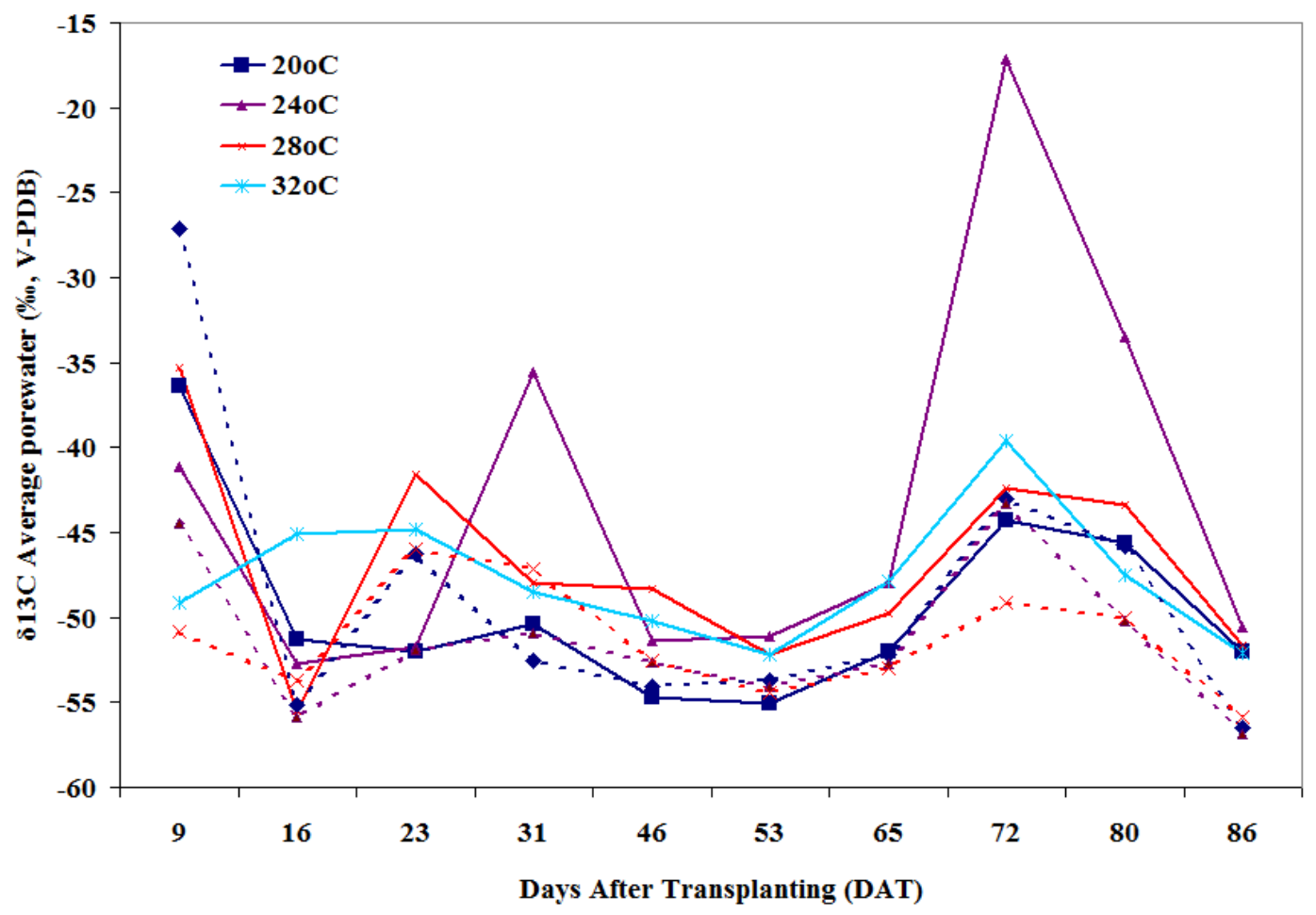

Fig. 6.3: Seasonal variation of $\delta^{13} \mathrm{C}_{\text {of }} \mathrm{CH}_{4}$ in pore water from planted tubs (solid lines) and unplanted tubs (broken lines) for different temperature treatments.

Aboveground $\delta \mathrm{D}$ values ranged between -341.9 and $-273.3 \%$ (mean $-317.0 \%$ ), while the belowground isotopic compositions were -348.3 to $-246.1 \%$ (mean $-308.3 \%$ ) for $\delta \mathrm{D}$, respectively. Large temporal variability is observed in both isotope tracers and is not well correlated with emitted isotopic composition. The variation is comparable to aboveground isotopic composition of between -352 and -311\%o V-SMOW (mean -335.7 $\pm 10 \%$ ) as reported in other studies (Bergamaschi, 1997). Three factors are responsible for these variations: (I) changes in the $\mathrm{CH}_{4}$ formation pathway, (II) changes in isotopic composition of methanogenic precursors, and (III) isotopic fractionation due to $\mathrm{CH}_{4}$ oxidation. 
Similar trend toward depleted $\delta \mathrm{D}$ as DAT increased was observed. For example, the isotopic composition of emitted $\mathrm{CH}_{4}$ in planted tubs ranged from $-64 \%$ to $-47 \% \delta^{13} \mathrm{C}$ versus $\mathrm{V}-\mathrm{PDB}$ and $-354 \%$ to $-146 \% \delta \mathrm{D}$ versus $\mathrm{V}-\mathrm{SMOW}$ with a trend towards more depleted values as the season progressed.

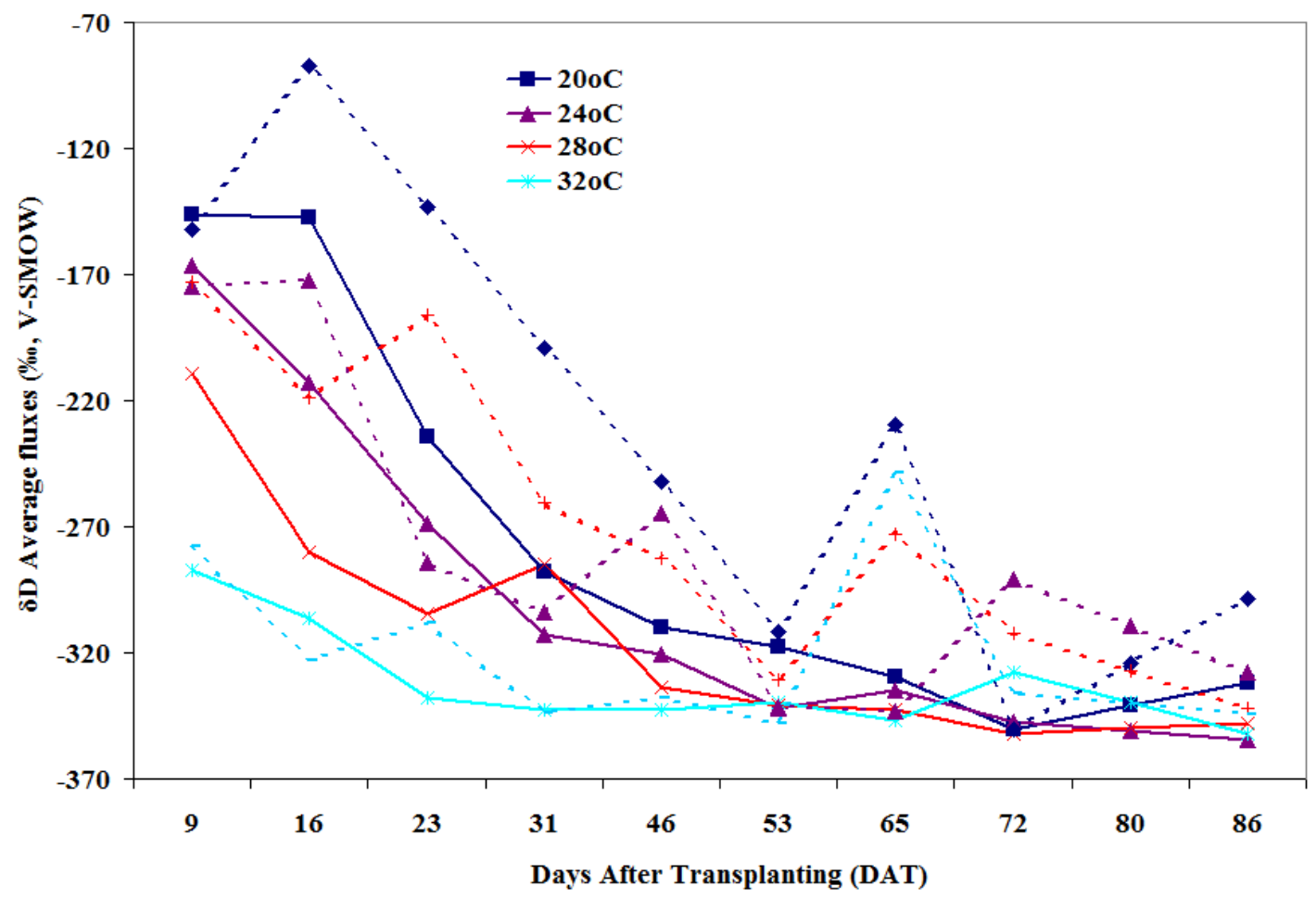

Fig. 6.4: Time series of $\delta \mathrm{D}$ of $\mathrm{CH}_{4}$ showing hydrogen isotopic composition in rice planted tubs (solid lines) and unplanted (control) tubs (broken lines) for different temperature treatments. Generally, the value are enriched at the start, and then depleted till the end of sampling period. 
The isotopic composition of pore water $\mathrm{CH}_{4}$ at $10 \mathrm{~cm}$ depth ranged from -380 to -153 $\%$ \%D (Fig. 6.5). Large temporal variability was observed in both isotope tracers and was not well correlated with emitted isotopic composition.

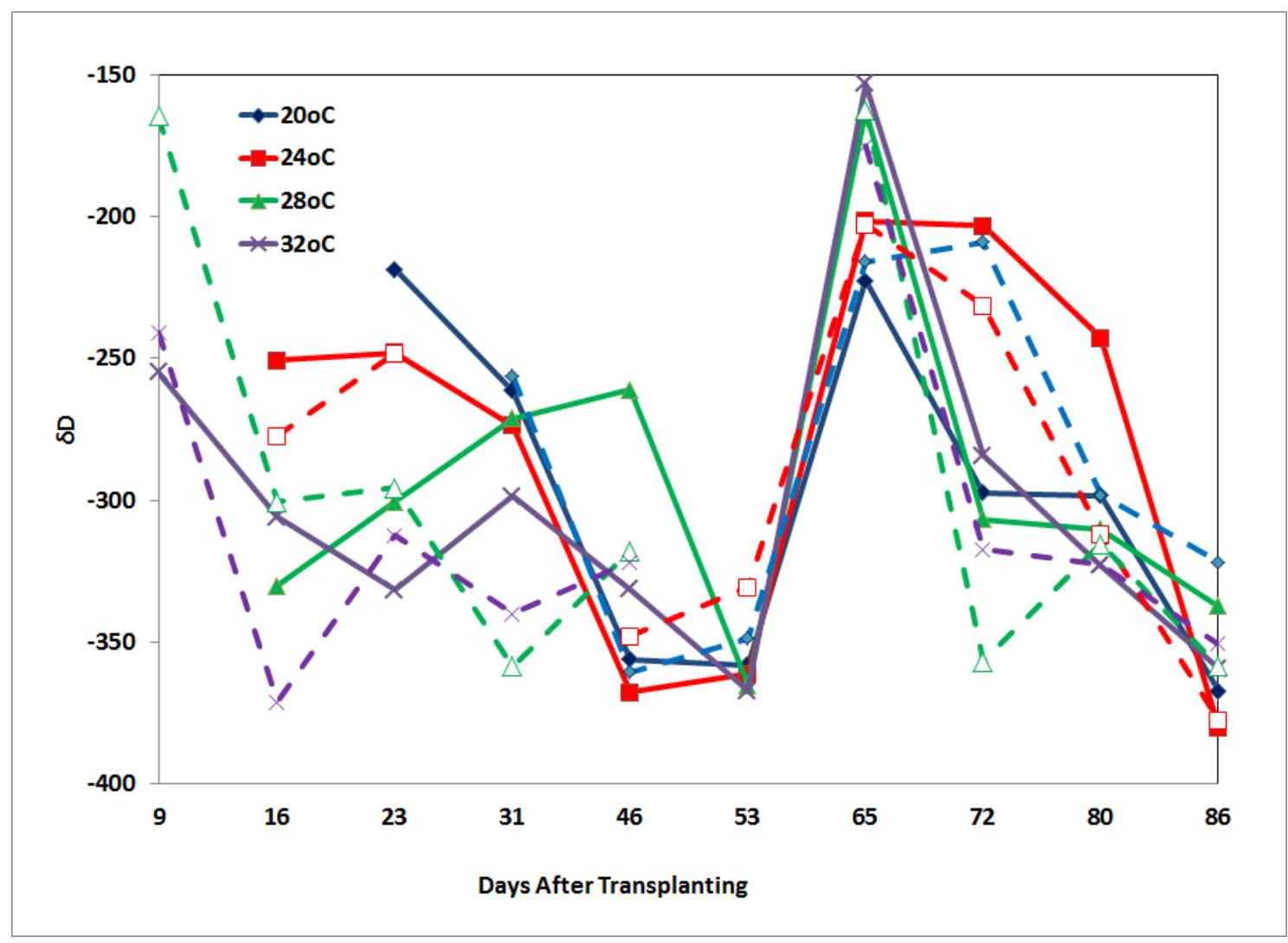

Fig. 6.5: Time series of pore water $\delta \mathrm{D}$ of $\mathrm{CH}_{4}$ showing hydrogen isotopic composition in rice planted tubs (solid lines) and unplanted (control) tubs (broken lines) for different temperature treatments.

By considering the results of classification of bacteria based on $\delta^{13} \mathrm{C}-\mathrm{CH}_{4}$ and $\delta \mathrm{D}-\mathrm{CH}_{4}$ information (Fig. 6.6), the range of results also indicate that the main methanogenic pathway of $\mathrm{CH}_{4}$ formation in this study was predominantly aceticlastic methanogenesis (acetate fermentation), which, respectively, is associated with isotopic composition of - 
65 to -50 \%o V-PDB (Grossman, 2002; Whitcar, 1999) and -400 to -250 \%o (V-SMOW) for $\delta^{13} \mathrm{C}$ and $\delta \mathrm{D}$ (Bergamaschi, 1997).

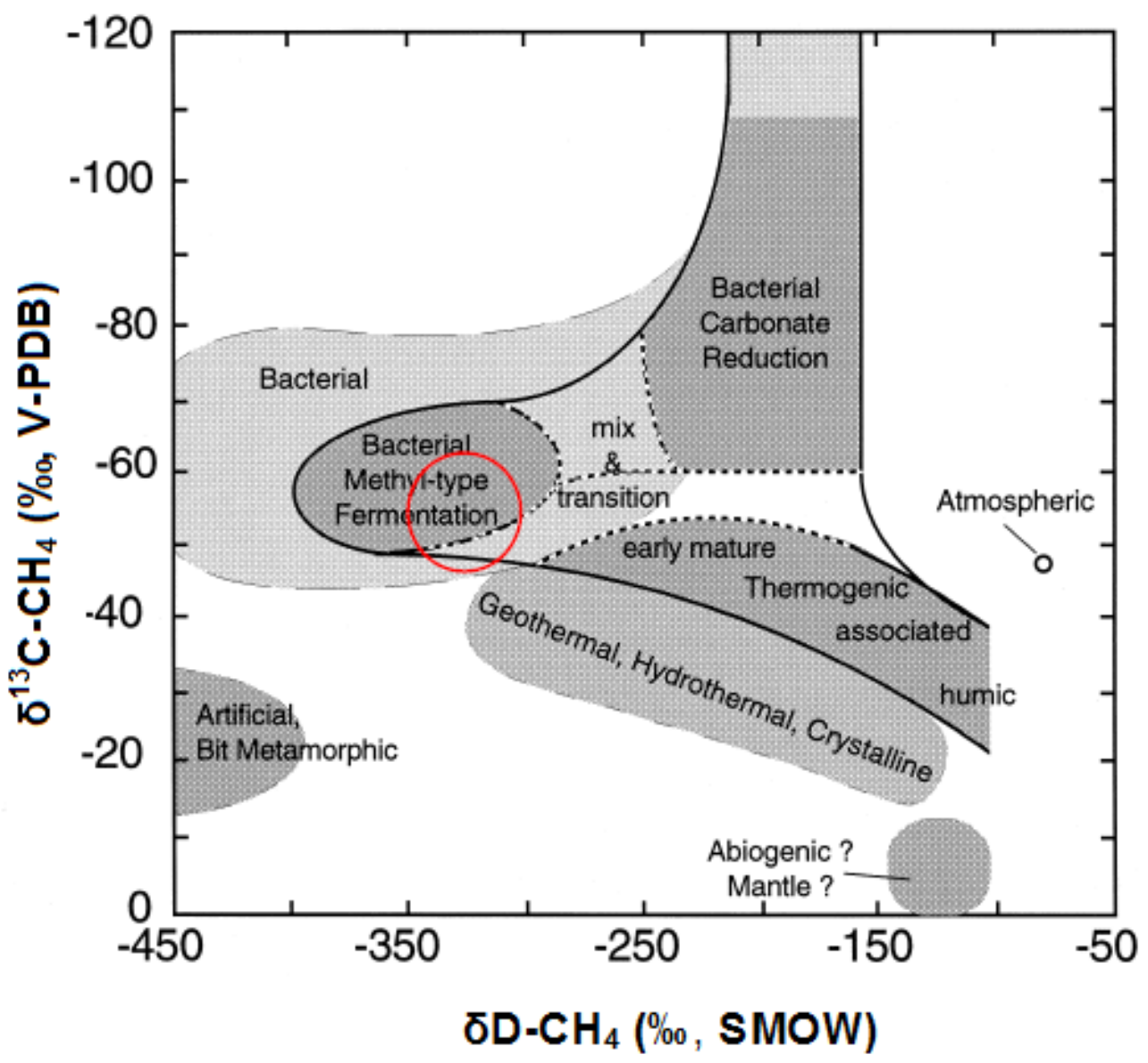

Fig. 6.6: Classification of bacterial and thermogenic natural gas by the combination of $\delta^{13} \mathrm{C}^{-\mathrm{CH}_{4}}$ and $\delta \mathrm{D}-$ $\mathrm{CH}_{4}$ information (Adapted from Whitcar 1999). Compared with $\delta^{13} \mathrm{C}_{-} \mathrm{CH}_{4}$ and $\delta \mathrm{D}-\mathrm{CH}_{4}$ found in this research, results showed that the predominant source of $\mathrm{CH}_{4}$ was acetate (red circle), and not through $\mathrm{CO}_{2}$ reduction.

The other methanogenic pathway for $\mathrm{CH}_{4}$ formation $\left(\mathrm{CO}_{2}\right.$ reduction) is generally more depleted in $\delta^{13} \mathrm{C}$ (-110 to $-60 \%$ V-PDB) and more enriched in $\delta \mathrm{D}(-200$ to $-110 \% \mathrm{~V}$ SMOW) (Bergamaschi, 1997; Whitcar, 1999), and thus, was not the major pathway in this study. 
Emitted values from planted tubs were substantially depleted in $\delta^{13} \mathrm{C}(\sim 6 \%)$ and $\delta \mathrm{D}$ $(\sim 30 \%)$ relative to unplanted (control) tubs, a difference which is understood to result from isotopic fractionation during diffusive (and potentially effusive) transport from the anaerobic zone through the rice plant. Seasonal mean values of $\delta^{13} \mathrm{C}$ were higher at higher temperatures $\left(-59.0 \%,-58.6 \%,-58.0 \%,-57.0 \%, 20-32{ }^{\circ} \mathrm{C}\right)$ and $\delta \mathrm{D}$ was lower at higher temperatures $(-272 \%,-296 \%,-311 \%,-331 \%)$. This effect is not yet well understood.

\subsubsection{Relationships between $\delta^{13} \mathrm{C}$ and $\delta \mathrm{D}$ in Emitted and Dissolved $\mathrm{CH}_{4}$} Very high positive regression coefficients $\left(\mathrm{r}^{2}=0.760\right.$ to 0.957$)$ were found between $\delta^{13} \mathrm{C}$ and $\delta \mathrm{D}$ in temperature treatments $20-28{ }^{\circ} \mathrm{C}$. At $32{ }^{\circ} \mathrm{C}$, the regression coefficient and slope were very low $\left(r^{2}=0.199\right.$; slope $\left.=0.2039\right)$. In these three treatments, the regression curves, the slopes were around 14 (Fig. 6.6). Consistently, Coleman et al. (1981) found change in the $\delta \mathrm{D}$ value of $\mathrm{CH}_{4}$ (which has been partially oxidized by bacteria) is $8-14$ times greater than the change in the $\delta^{13} \mathrm{C}$ value. 


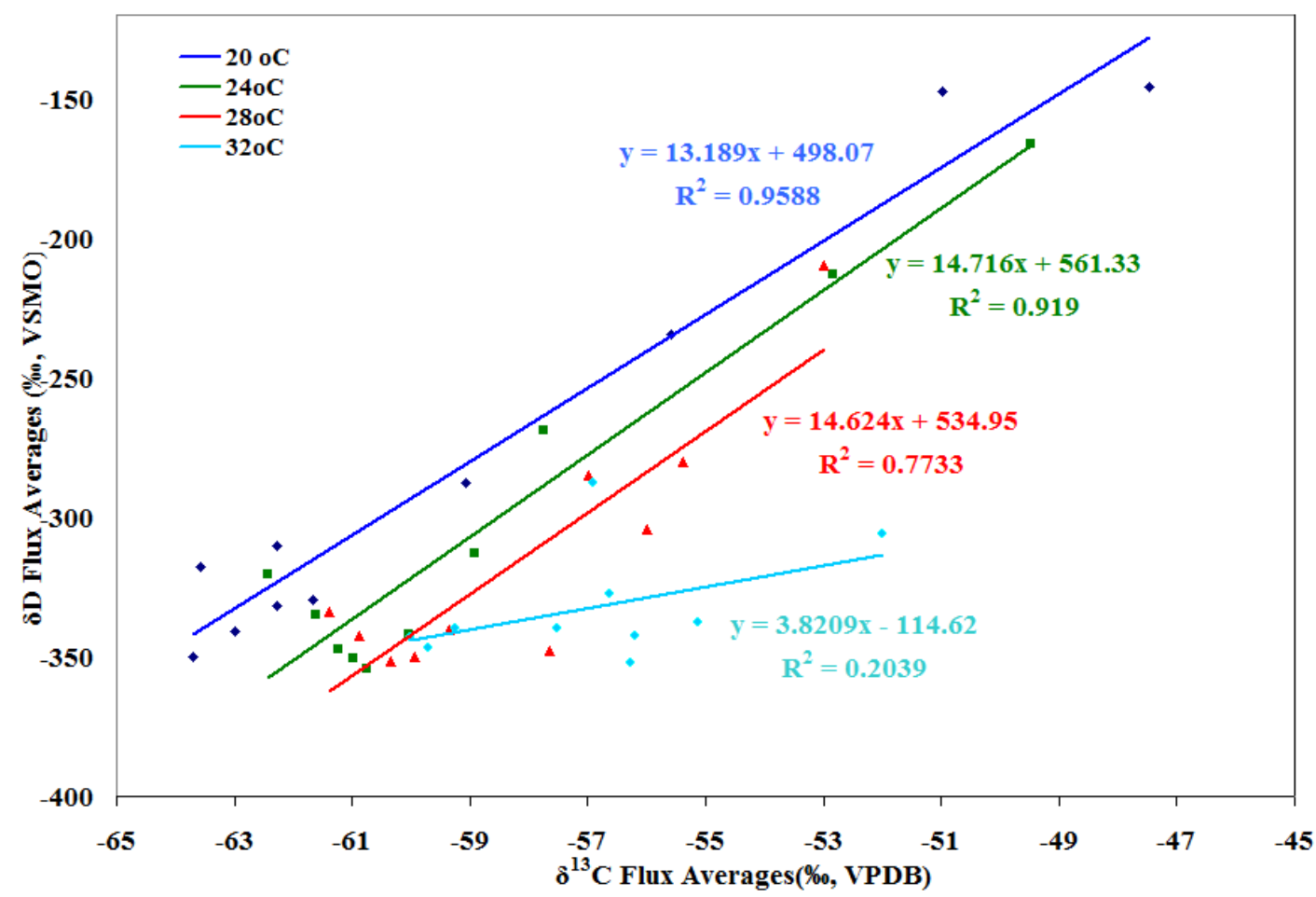

Fig. 6.7: Effect of temperature on the relationship between isotopic composition, $\delta^{13} \mathrm{C}$ and $\delta \mathrm{D}$ values in the air samples from planted tubs.

In general, all regression coefficients were positive, but were higher in lower temperature treatments. Similarly, positive correlations between $\delta^{13} \mathrm{C}$ and $\delta \mathrm{D}(\mathrm{r}=0.51)$ were found from rice fields experiments in China (Bergamaschi, 1997). The results indicate that no major partitioning between methanogenic pathways in the formation of $\mathrm{CH}_{4}$ occurred during the growing season (Sugimoto and Wada, cited in Bergamaschi, 1997). Instead, only one pathway (acetate fermentation) was predominant throughout the season (region circled in red). Differences were found between slopes under the 20 $28{ }^{\circ} \mathrm{C}$ temperature treatments and that at $32{ }^{\circ} \mathrm{C}$, but could not be explained using the results in this research. 
In contrary, no distinct relationship was found between $\delta^{13} \mathrm{C}$ and $\delta \mathrm{D}$ values in pore water from planted tubs (Fig. 6.8), and the regression coefficients were very low $\left(\mathrm{r}^{2}=\right.$ $0.017-0.268)$, but positive.

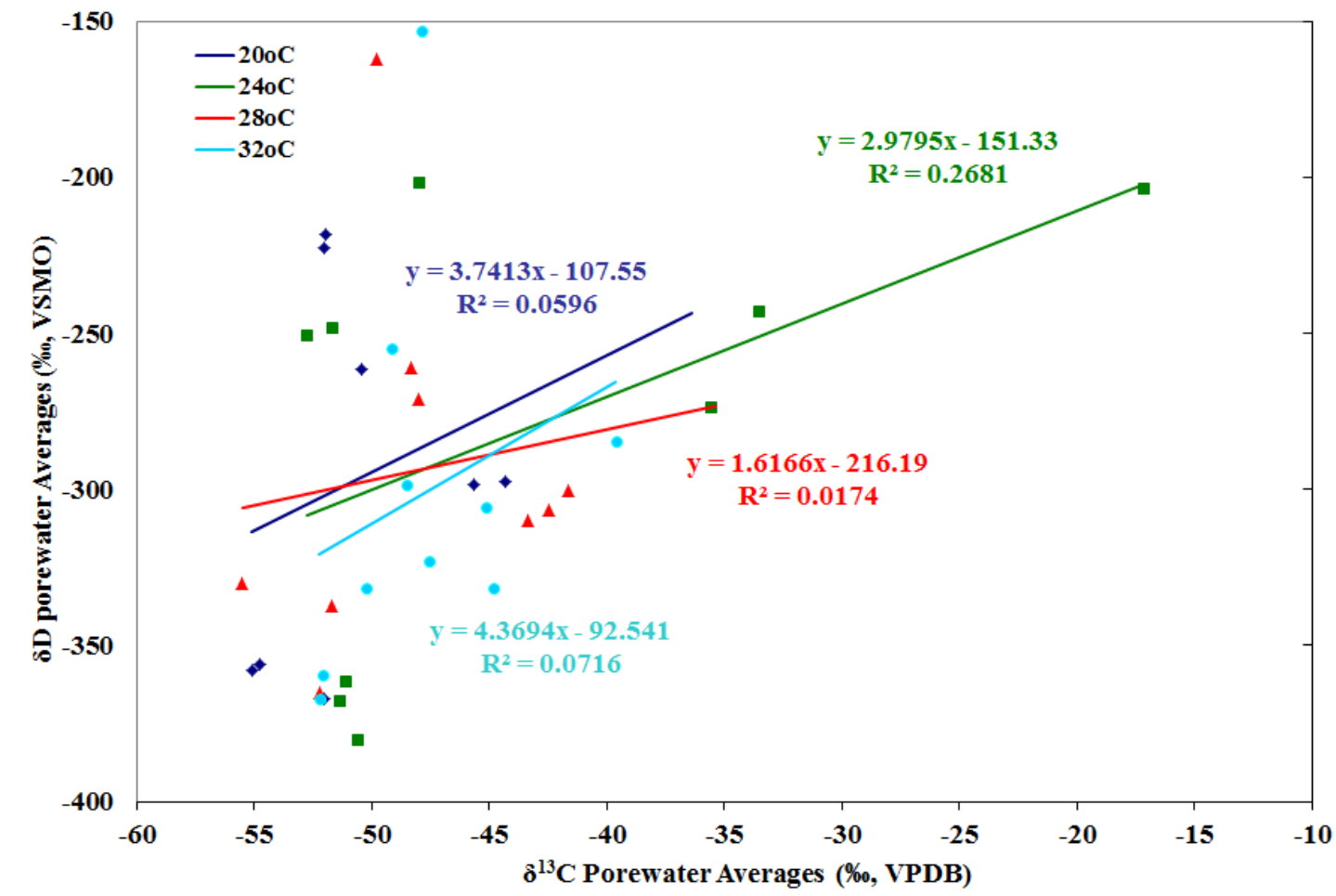

Fig. 6.8: Temperature effect on the relationship between isotopic composition, $\delta^{13} \mathrm{C}$ and $\delta \mathrm{D}$ values in pore water from planted tubs.

Coleman et al. (1981) found positive linear relationships between the fraction of $\mathrm{CH}_{4}$ oxidized and carbon and hydrogen isotopes, but with different regression coefficients. However, the fractions of $\mathrm{CH}_{4}$ oxidized from $\delta^{13} \mathrm{C}$ and $\delta \mathrm{D}$ were not similar in pore water. They concluded that the fractionations of the two isotopes decreased with temperature, and their responses were different under same temperature conditions. 
These results were the first to pinpoint the importance of temperature in $\mathrm{CH}_{4}$ fractionation.

\subsubsection{Fraction of $\mathrm{CH}_{4}$ Oxidized}

The range of the fraction of $\mathrm{CH}_{4}$ oxidized from $\delta^{13} \mathrm{C}$ values was 46 to $87 \%$ in planted tubs. In the controls, the percentage was low, ranging from 26 to $48 \%$. Higher percentage values found in planted tubs are consistent with the present knowledge of $\mathrm{CH}_{4}$ oxidation in flooded rice soils. It is thought that plants, via roots provide aerobic conditions which promote $\mathrm{CH}_{4}$ oxidation, since methanotrophs require oxygen to utilize $\mathrm{CH}_{4}$ as their metabolic source of energy.

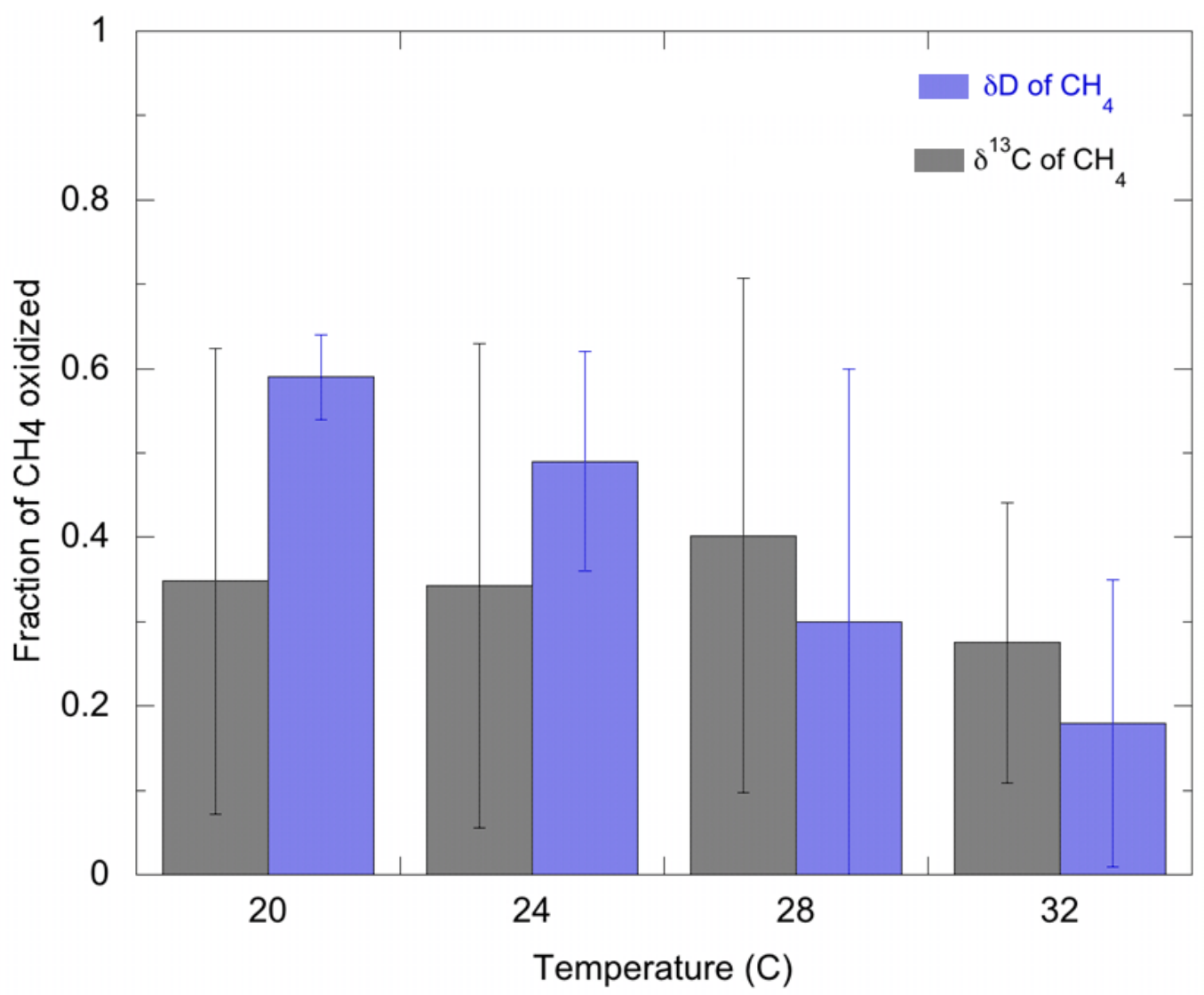

Fig. 6.9: Fraction of $\mathrm{CH}_{4}$ oxidized as determined from $\delta \mathrm{D}$ and $\delta^{13} \mathrm{C}$ values for planted tubs. 
From $\delta \mathrm{D}$ values, the ranges in different temperature treatments were quite variable. The highest mean $\mathrm{CH}_{4}$ oxidation fraction was $60 \%$ (range: $55-65 \%$ ) occurred in the $20{ }^{\circ} \mathrm{C}$ tubs. Among different temperature treatments, the means generally decreased towards higher temperatures.

There were some discrepancies between the estimates of $\delta^{13} \mathrm{C}$ and $\delta \mathrm{D}$-calculated oxidation fractions. To date, there is little information in literature about the dual use of these isotopes as tracers in $\mathrm{CH}_{4}$ oxidation experiments. However, the dual approach provides some means of understanding the uncertainty of these estimates. The reason for the variation in the two estimates could be a result of the differences in the temperature response of the $\alpha_{\mathrm{ox}} \mathrm{s}$ for $\delta^{13} \mathrm{C}$ and $\delta \mathrm{D}$. However, from $\delta^{13} \mathrm{C}$-calculated oxidation fractions, the optimum soil temperature for $\mathrm{CH}_{4}$ oxidation was found to be $28{ }^{\circ} \mathrm{C}$, consistent with values of between $25{ }^{\circ} \mathrm{C}$ and $30{ }^{\circ} \mathrm{C}$ reported in Chanton and Liptay (2000). The $\mathrm{Q}_{10}$ calculated from the fraction of $\mathrm{CH}_{4}$ oxidized were 1-2 and 1.42.4 using $\delta^{13} \mathrm{C}$ and $\delta \mathrm{D}$ values, respectively.

\subsection{Conclusion}

This research clearly showed that temperature is an important factor in $\mathrm{CH}_{4}$ oxidation in rice ecosystems. However, further empirical observations are needed to refine methods used in determining the transport fractionation. The calculated $\mathrm{Q}_{10}$ values were less than average $\mathrm{CH}_{4}$ fluxes and production. Such a scenario would promote increase in $\mathrm{CH}_{4}$ 
production and emissions, resulting in a rising atmospheric $\mathrm{CH}_{4}$ composition under global warming. 


\section{Chapter 7}

Response of $m c r A$ and $p m o A$ Gene Copies and Methane Fluxes to Soil Temperature Changes in Rice Microcosms

\subsection{Summary}

The feedback of global warming on methane emissions from rice agriculture was investigated by examining the link between populations of microbial consortia and elevated soil temperatures within the rhizosphere. Vertical soil profile samples were collected from temperature-controlled rice microcosms. The four water baths, set at different temperatures, each contained four tubs, with one control and three replicates. The soil samples were immediately frozen and stored at $-80{ }^{\circ} \mathrm{C}$, and were pulverized before DNA extraction. The concentration of the methyl coenzyme M reductase $(m c r A)$ and particulate methane monooxygenase $(p m o A)$ genes was determined by qPCR. All qPCR reactions were performed in double $25 \mu$ reactions using the QuantiTect SYBR Green PCR kit. Quantitation of total mcrA gene copies was performed with primers described in Luton et al. (2002) at a final concentration of $0.6 \mu \mathrm{M}$ (Wilson et al., 2010). An FID-equipped Gas Chromatography was used to measure the methane concentration in air samples collected from Plexiglas flux chambers as previously described. Our results showed that methanogens $(m c r A)$ and methanotrophs $(p m o A)$ were preferentially located to certain regions of the soil profile under different soil temperatures. $m c r A$ copies were positively correlated to temperature, whereas no significant response of pmoA copies to temperature was observed. The implication of our results is that higher global temperatures will increase methanogen populations, but not as much for 
methanotrophs, and hence increase $\mathrm{CH}_{4}$ fluxes from rice agriculture. This result supports our work with isotopes described in the previous chapter.

\subsection{Introduction}

In rice fields, $\mathrm{CH}_{4}$ is produced by three different pathways: carbon dioxide reduction, the methylotrophic pathway, and the acetate splitting pathway. The net $\mathrm{CH}_{4}$ fluxes are controlled by the balance between microbial production and consumption of $\mathrm{CH}_{4}$, and by physical processes such as diffusion, ebullition and ventilation. In anoxic freshwater environments, $\mathrm{CH}_{4}$ production is accomplished by a complex microbial community consisting of hydrolytic, syntrophic, homoacetogenic, and methanogenic microorganisms that degrade organic matter under anaerobic conditions (Chin et al., 1999). Temperature is an important factor that controls the rate of $\mathrm{CH}_{4}$ production, and methanogenesis pathway (Peng et al., 2008). In incubation experiments of rice field soils, studies have shown temperature has an effect on the structure and diversity of methanogenic Archaea. Chin et al. (1999) found that members of Methanosarcinaceae were predominant at $30^{\circ} \mathrm{C}$, whereas at $15^{\circ} \mathrm{C}$, the diversity of methanogenic Archaea was larger, comprising members of Methanosaetaceae. Conrad (1999) found that hydrogenotrophic and acetoclastic methanogenesis accounted for about $33 \%$ and $67 \%$ of total $\mathrm{CH}_{4}$ production at $30{ }^{\circ} \mathrm{C}$, respectively. The relative abundances in acetatedependent Methanosaetaceae at low and high temperatures are believed to be regulated by the dependence of acetate on temperature (Peng et al., 2008, Chin et al., 1999). Acetate and $\mathrm{H}_{2}$ or $\mathrm{CO}_{2}$ are the predominant substrates of methanogenic archaea, with 
the contribution from acetate being estimated at between 65 and $80 \%$ of $\mathrm{CH}_{4}$ production (Chin et al., 1999). Methanosaeta and Methanosarcina are the only two genera of methanogens capable of breaking down acetate into methane and carbon dioxide .

Some of the $\mathrm{CH}_{4}$ produced via methanogenesis is consumed and oxidized to $\mathrm{CO}_{2}$ by aerobic methanotrophs (Hanson and Hanson, 1996; Ritchie et al., 1997; Roslev, 1997; Auman, 2000) and the fraction of $\mathrm{CH}_{4}$ that is not oxidized by methanotrophs escapes from anaerobic environments to the atmosphere. Methanotrophs play a very significant role in maintaining the global $\mathrm{CH}_{4}$ budget, and in moderating the impact of global warming on $\mathrm{CH}_{4}$ production from anoxic soils. Methanotrophs are a unique group of methylotrophic bacteria (Ritchie et al., 1997) that utilize a variety of different onecarbon compounds such as methane, methanol, methylated amines, halomethanes, and methylated compounds containing sulfur as sole sources of carbon and energy (Hanson and Hanson, 1996). Two major phylogenetic groups of methanotrophs have been identified and are distinguished by their pathways for assimilation: Type I methanotrophs, which are Gammaproteobacteria, and Type II methanotrophs, which are Alphaproteobacteria (Hanson and Hanson, 1996). Type I methanotrophs assimilate formaldehyde, produced from the oxidation of methane (via methanol) using the ribulose monophosphate pathway. Type II methanotrophs use the serine pathway for formaldehyde assimilation. The pathway conversion efficiencies of Type I and Type II methanotrophs are estimated to be about 65 to $80 \%$ and 40 to $60 \%$, respectively (Auman, 2000). 
Given the complex response of both methanogen and methanotroph communities to various environmental factors, and the IPCC temperature projections of between +1.8 ${ }^{\circ} \mathrm{C}$ (B1 "optimistic" scenario) and $+4{ }^{\circ} \mathrm{C}$ (A1FI "business as usual" scenario) by 2100 (IPCC, 2007c), it is important to understand how increasing temperatures may affect the balance between $\mathrm{CH}_{4}$ production and consumption, and hence, the change in $\mathrm{CH}_{4}$ emissions. In this work, we used the methyl coenzyme $\mathrm{M}$ reductase $(\mathrm{mcr} A)$ and particulate methane monooxygenase ( methanotroph populations within the rice rhizosphere, respectively. The mcrA gene codes for a subunit of the protein complex that catalyzes the final step of methanogenesis in all methanogenic Archaea by reducing coenzyme M binding methyl group to methane (Watanabe et al., 2009), while the pmoA is the $\alpha$-subunit of the particulate methane monooxygenase (Kolb et al., 2003). We also present a quantitative analysis of the relationships between $m c r A$ and $p m o A$ abundance ratios at different soil horizons and soil temperatures and $\mathrm{CH}_{4}$ fluxes.

\subsection{Aims and Objectives}

In this chapter, methods used to detect and quantify methanogens and methanotrophs are presented. Objectively, the experiments were aimed at: (I) Quantifying changes in their populations in response to changes in temperature over the growing season; (II) Determine the location of methanogens and methylotrophs within the depth profile of the root zone; (III) and to investigate the possible link between the diurnal variation in fluxes and bacterial activity, and their response to changes in soil temperature. 


\subsection{Materials and Methods}

Four different temperature treatments, each comprising one unplanted (control) tub and three tubs planted with Oryza sativa L. 'M-103' (- a medium-grain, early maturing semidwarf rice cultivar), were heated using a water bath system whose temperature was maintained as described in Chapter 2.

\subsubsection{Preparation and Collection of Soil Samples}

Soil samples were collected every two weeks from rice tubs using 3/4" x 12" Butyrate Plastic Liners (Forestry Supplies Inc., USA). Because these liners could not be autoclaved, they were first cleaned thoroughly by soaking them in Alconox for about 24 hours and washed three times using de-ionized water, rinsed with $95 \%$ ethanol, and wrapped in aluminum foil before they were put in a $60{ }^{\circ} \mathrm{C}$ drying oven for 12 hours. With sterile gloves, these corers were manually driven into the rice tubs to extract the soil vertical profile sample within the root zone. The duplicate plastic liner-filled samples drawn from each set-up were cut into four equal columns, put into sterile Whirl-packs (VWR International, LLC, USA), and immediately frozen at $-80{ }^{\circ} \mathrm{C}$. 


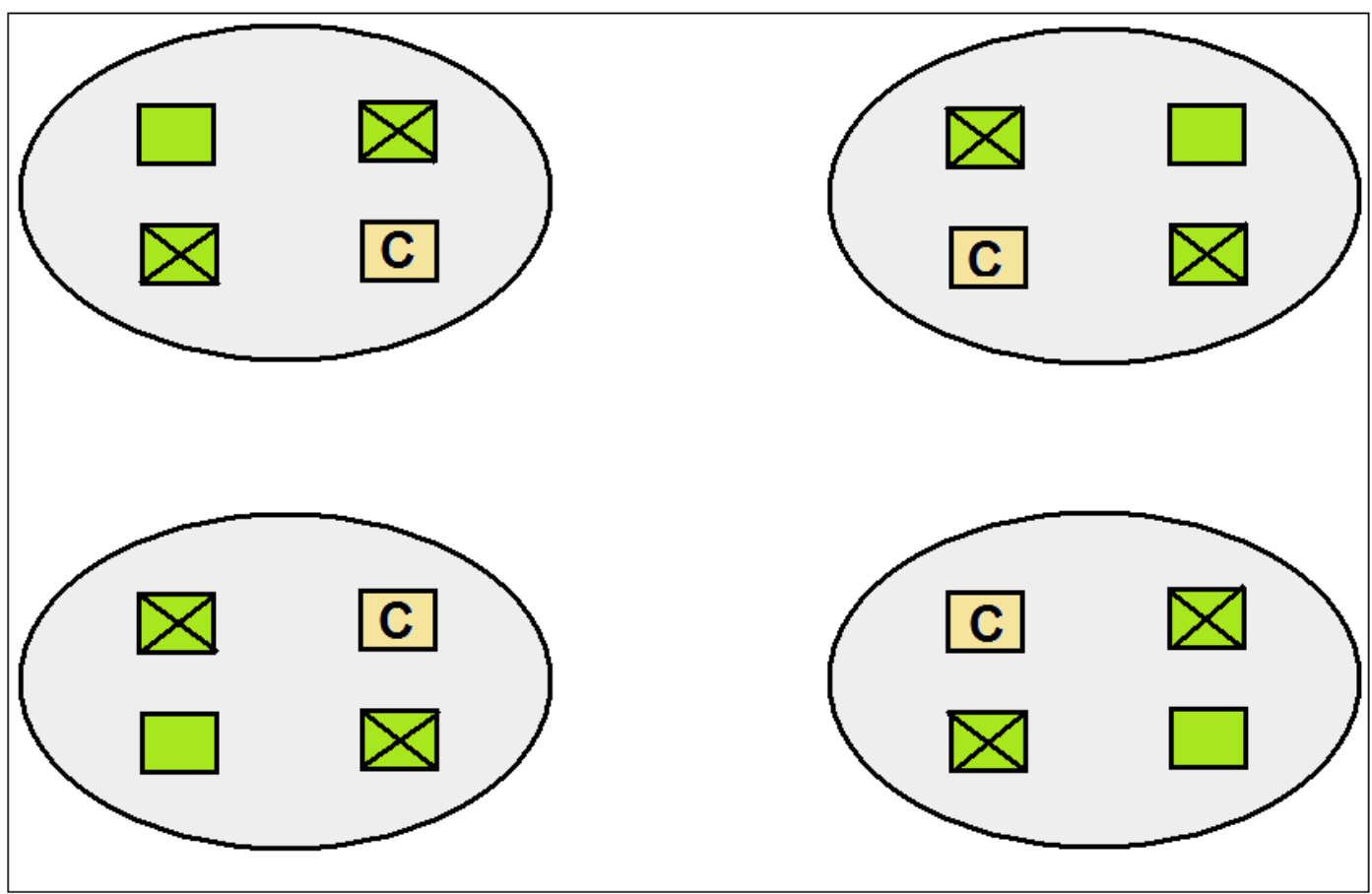

叉ice planted/Sampling pot

C. Bare/ Control pot

Rice planted pot

Fig.7.1: Schematic of the replicates (Rice planted tubs) and tubs from which the soil samples for population studies will be taken (rice-planted sampling tubs), and controls for each set of experiment (unplanted/Control tubs).

\subsubsection{Soil Microbial DNA Extraction, Quantitation and Purity}

Prior to DNA extraction, individual soil samples were homogenized using sterile mortars and pestles. DNA was extracted from approximately $1.4 \mathrm{~g}$ (wet weight) of soil using the UltraCleanTM Soil DNA Kit (Mo Bio Labs, Inc., USA) following the manufacturer's instructions. The DNA yield was determined using a UV/Vis NanoDrop ND-1000-V3.7 Spectrophotometer (Thermo Fisher Scientific Inc., USA). DNA absorbance was measured at $230 \mathrm{~nm}, 260 \mathrm{~nm}$ and $280 \mathrm{~nm}$. The absorbance ratios at $230 / 260 \mathrm{~nm}$ and $260 / 280 \mathrm{~nm}$ were calculated by the NanoDrop ND-1000 software. 


\subsection{3 qPCR Detection of Methanogens and Methanotrophs}

All qPCR reactions were performed in duplicate $25 \mu 1$ reactions using the QuantiTect SYBR Green PCR kit (Qiagen, Valencia, California) run on MJ Mini Opticon RealTime PCR System (BioRad, Hercules, California). Melting curves were performed at the end of each reaction to ensure product integrity. Quantitation of total $m c r A$ gene copies was performed with mcrAf and mcrAr primers (Luton et al., 2002) at a final concentration of $0.6 \mu \mathrm{M}$, following the method of Wilson et al., (2010). The thermal protocol was as follows: $95{ }^{\circ} \mathrm{C}$ for $15 \mathrm{~min}, 40$ cycles of $94{ }^{\circ} \mathrm{C}$ for $30 \mathrm{~s}, 56{ }^{\circ} \mathrm{C}$ for $30 \mathrm{~s}, 72$ ${ }^{\circ} \mathrm{C}$ for $1 \mathrm{~min}$, followed by a single cycle of $82{ }^{\circ} \mathrm{C}$ for $10 \mathrm{~s}$. Plasmids containing the $\mathrm{mcr} A$ gene were used as quantitation standards as previously described (Wilson et al., 2010). In a similar fashion, quantitation of $p m o A$ genes was carried using primers A189f (Holmes et al., 1995) and mb661r (Costello and Lidstrom, 1999). The thermal protocol was as follows: $95{ }^{\circ} \mathrm{C}$ for $15 \mathrm{~min}, 45$ cycles of $94{ }^{\circ} \mathrm{C}$ for $30 \mathrm{~s}, 56{ }^{\circ} \mathrm{C}$ for $30 \mathrm{~s}, 72{ }^{\circ} \mathrm{C}$ for 1 min, followed by a single cycle of $84{ }^{\circ} \mathrm{C}$ for $10 \mathrm{~s}$. The protocol (reaction) temperatures and cycling for $m c r A$ analysis were as shown in Fig. 7.2. 
Thermal Profile Setup

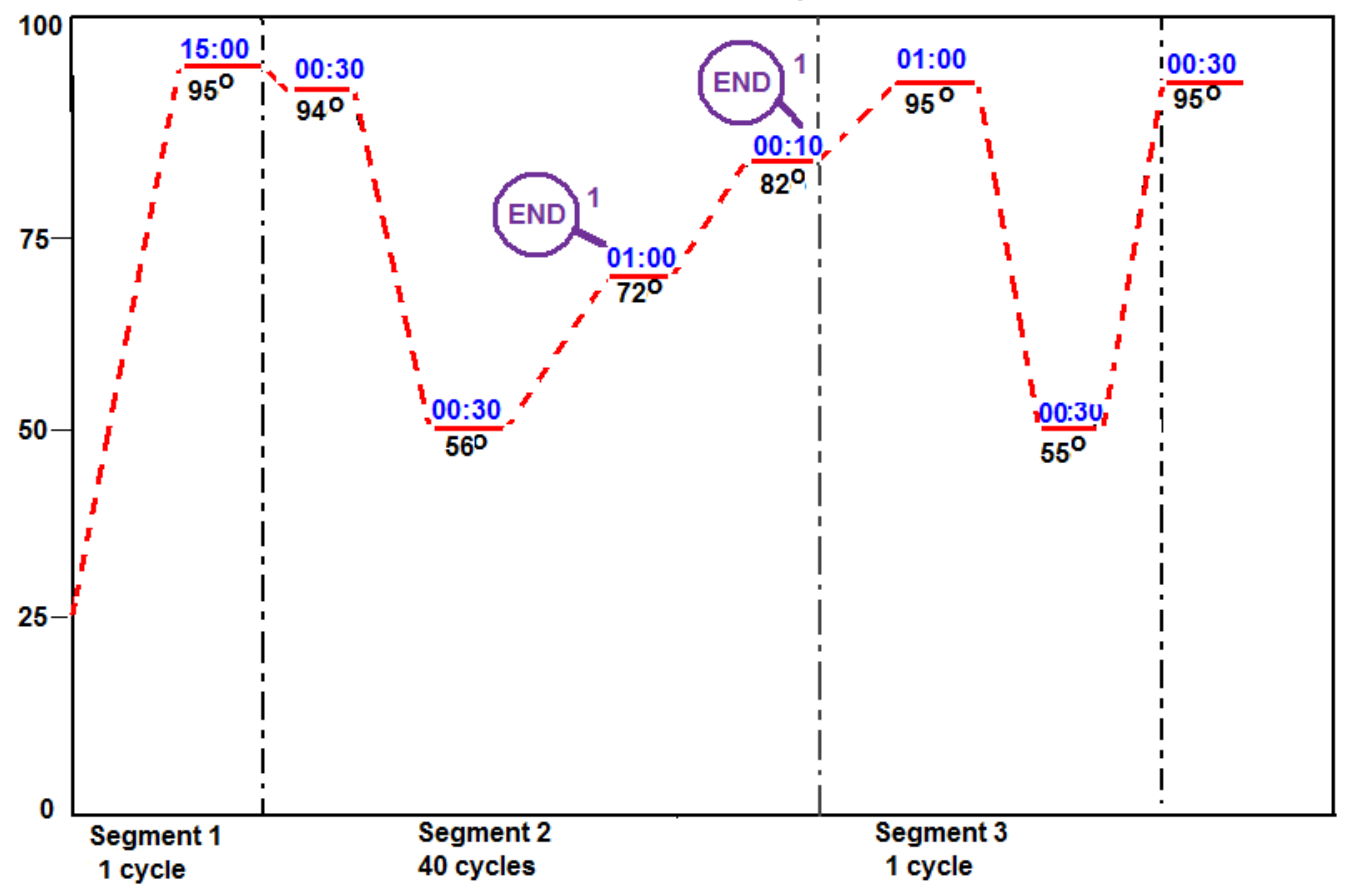

Fig. 7.2: Protocol for the qPCR thermal profile set-up for $m c r A$ gene quantitation were as follows: $95{ }^{\circ} \mathrm{C}$ for $15 \mathrm{~min}, 40$ cycles of $94{ }^{\circ} \mathrm{C}$ for $30 \mathrm{~s}, 56{ }^{\circ} \mathrm{C}$ for $30 \mathrm{~s}, 72{ }^{\circ} \mathrm{C}$ for $1 \mathrm{~min}$, followed by a single cycle of $82{ }^{\circ} \mathrm{C}$ for $10 \mathrm{~s}$.

Genomic DNA of Methylococcus capsulatus str. Bath (ATCC 33009D) was used to generate standard curves for quantitation. qPCR assays of the $m c r A$ and $p m o A$ genes with linear calibration standard curves with regression coefficients $>0.990$ were considered. Both $m c r A$ and $p m o A$ gene concentrations were normalized to dry weight of soil.

\subsection{Statistical Analysis}

One-way analysis of covariance (ANACOVA) was used to test the null hypothesis $\left(\mathrm{H}_{\mathrm{o}}\right)$ that there was no difference between the coefficients of regressions between $p m o A$ and 
$m c r A$ copies, based on a $5 \%$ level of significance. A t-statistic was computed as the difference between the two slopes divided by the standard error of the difference between the slopes, with $\left(\mathrm{N}_{1}+\mathrm{N}_{2}-4\right)$ degrees of freedom, where $\mathrm{N}_{1}$ and $\mathrm{N}_{2}$ were the number of points on each regression equation. $\mathrm{H}_{\mathrm{o}}$ was rejected for any $\mathrm{p}<0.05$.

\subsection{Results and Discussion}

\subsubsection{DNA Purity and Yield.}

To check if the extracted DNA samples contained any qPCR amplifiable quantities, absorbance ratios at 260nm/230nm (DNA/humic acids) and $260 \mathrm{~nm} / 280 \mathrm{~nm}$ (DNA/protein) were measured on a UV/Vis NanoDrop ND-1000-V3.7 Spectrophotometer. Medians of the absorbance ratios at $260 \mathrm{~nm} / 230 \mathrm{~nm}$ and 260 $\mathrm{nm} / 280 \mathrm{~nm}$ ranged from $0.4-0.6$ and $1.75-1.95$, respectively. 


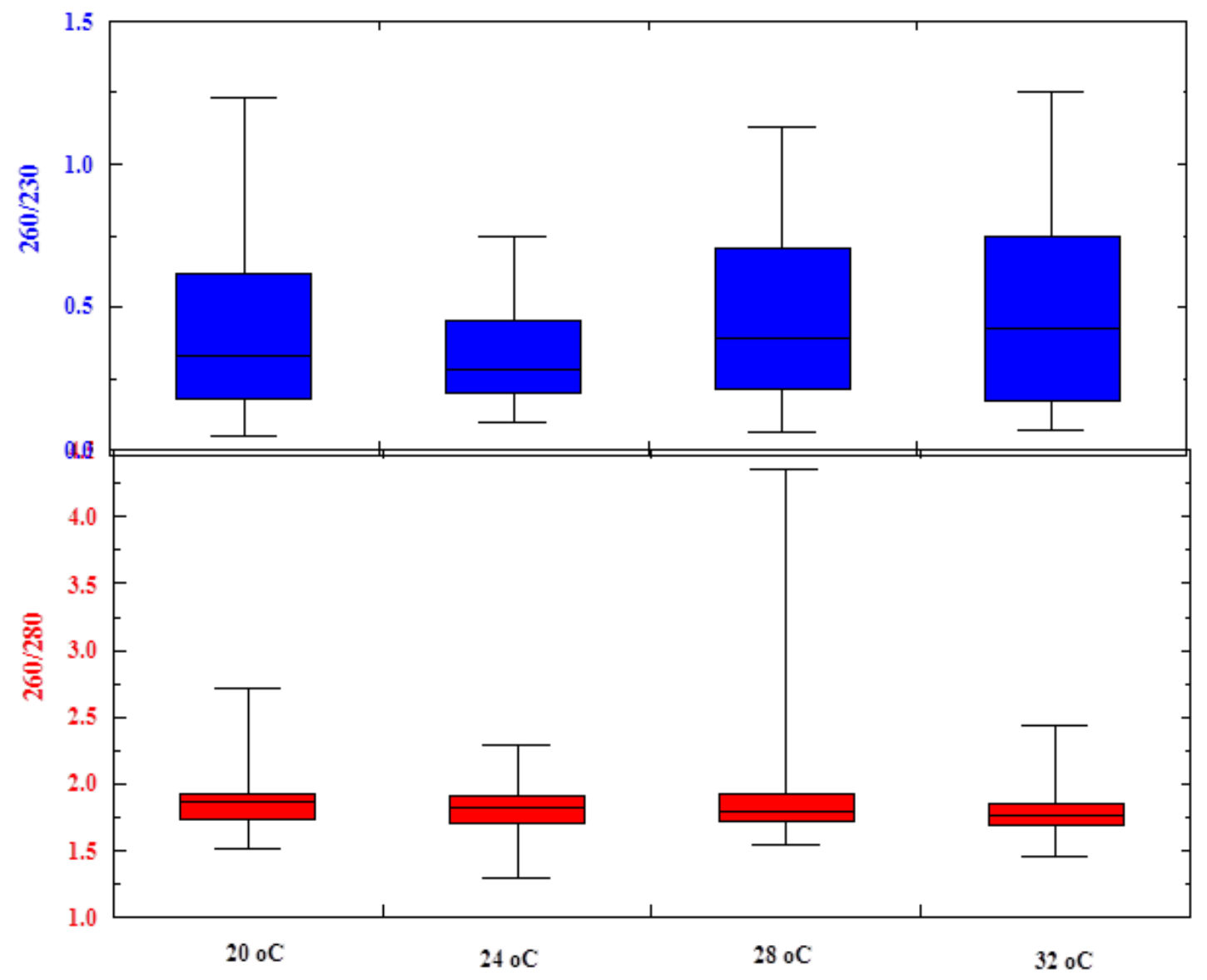

Fig. 7.3: Ratios of 260/230 (e.g. $>2$ ) and 260/280 (e.g. $>1.7$ ) are indicative of pure DNA, while the low ratios are indicative of humic acid and protein contamination, respectively.

The results indicated that DNA was contaminated with more humic acid-like compounds than proteins, and that the level of humic acids in the DNA increased during the course of the experiment (Fig. 7.3). 


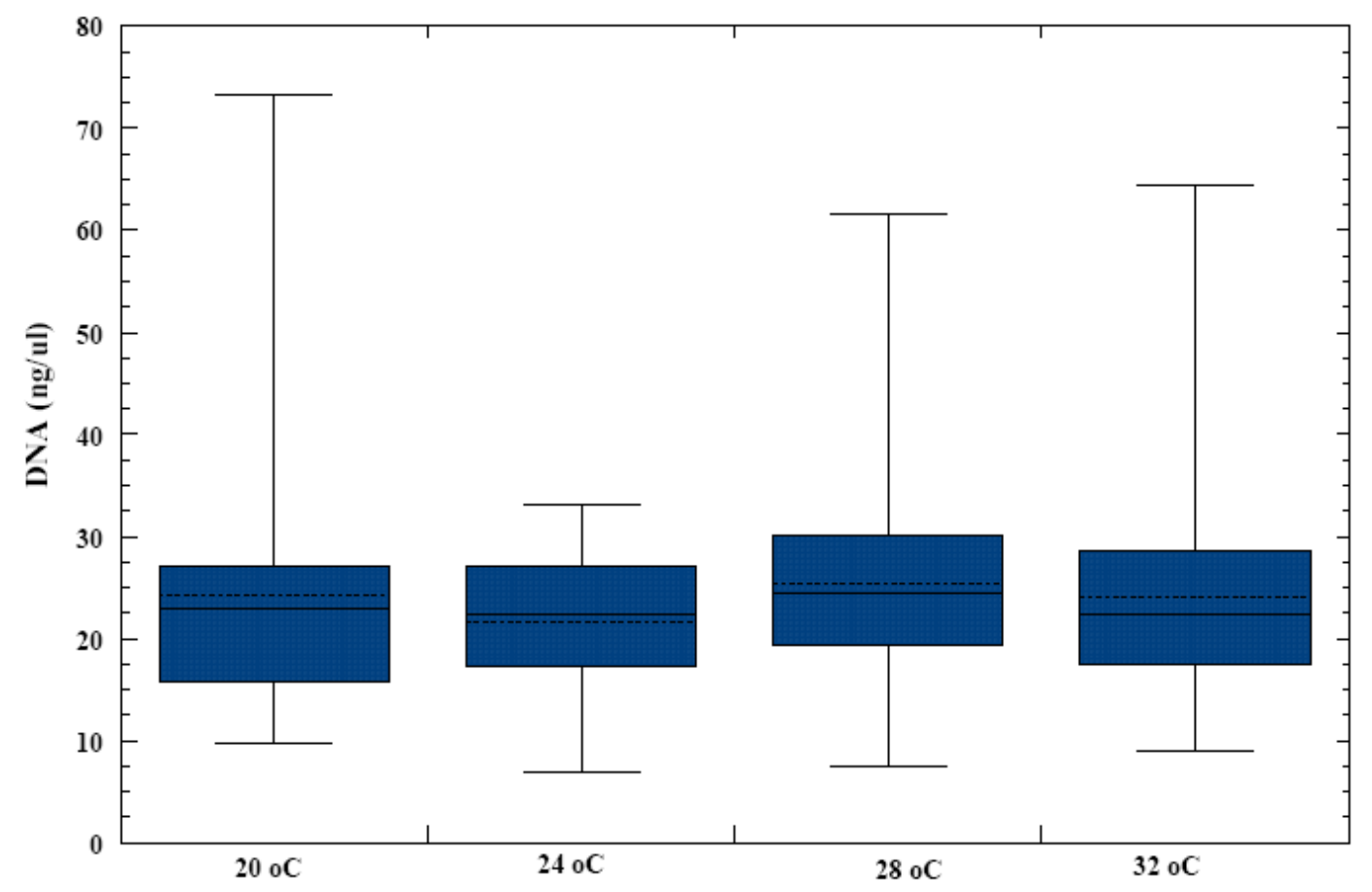

Fig. 7.4: Total DNA yields ranged from of 10 to $45 \mu \mathrm{g}$ of DNA per $\mu$ l. Data showed no notable differences across different temperature treatments.

The level of humic acid contamination slightly increased during the season. The low ratio at $260 \mathrm{~nm} / 230 \mathrm{~nm}$ was an indication that proteins, possibly from bugs in the rice stalks, were the major contaminants of our DNA assays. The total yield ranged from 10 to $45 \mathrm{ng} \mu \mathrm{L}^{-1} \mathrm{~g}^{-1}$ (dry soil), with highest values in $5-15 \mathrm{~cm}$ soil depth (Fig. 7.5). 


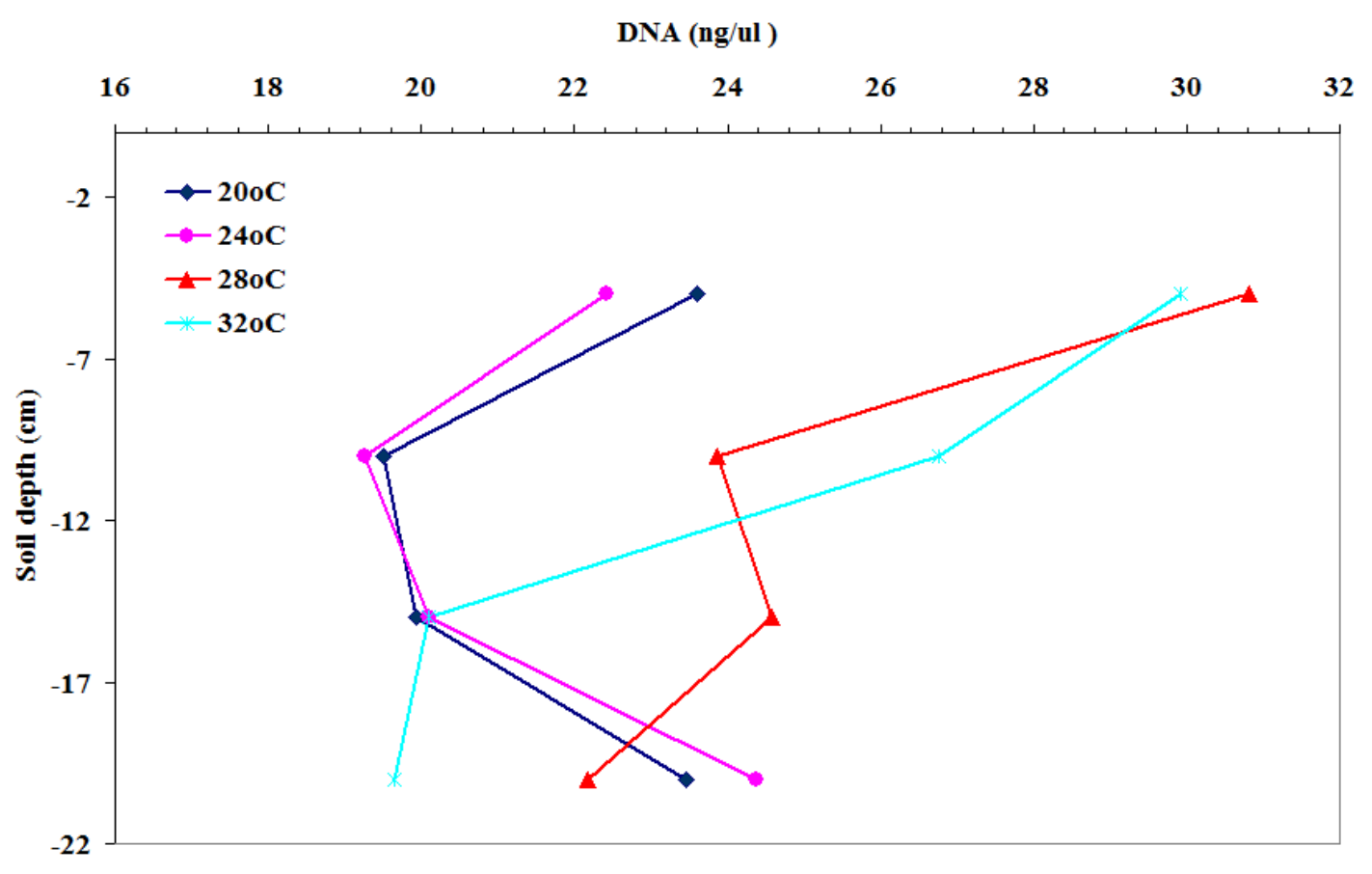

Fig. 7.5: Average values of DNA concentration at different soil horizons at different soil temperature treatment.

Generally, no notable significant change was observed between set-ups at different temperatures, with the mean remaining almost constant at $22 \pm 4 \mu \mathrm{L}^{-1} \mathrm{~g}^{-1}$ (dry soil).

\subsubsection{Abundance of $m c r A$ Genes}

The detection limit of $10^{2}$ of $m c r A$ copies per assay was achieved. The $m c r A$ gene abundance ranged from $5 \times 10^{5}$ to $3 \times 10^{6}$ copies $^{-1}$ of dry soil (Fig. 7.6). The same order of magnitude has been reported in literature (Bodelier and Frenzel, 1999; Bosse and Frenzel, 1997; Gilbert and Frenzel, 1995; Joulian et al., 1997). Orders of magnitude as low as $10^{4}$ copies $\mathrm{g}^{-1}$ (dry soil) were also reported in soils from Japanese rice fields 
(Eusufzai et al., 2010), while higher values of the order of between $10^{5}$ and $10^{7}$ copies $\mathrm{g}^{-1}$ (dry soil) were also found in soils from 15 paddy fields (five different soil types) in north-east China (Wang et al., 2010).

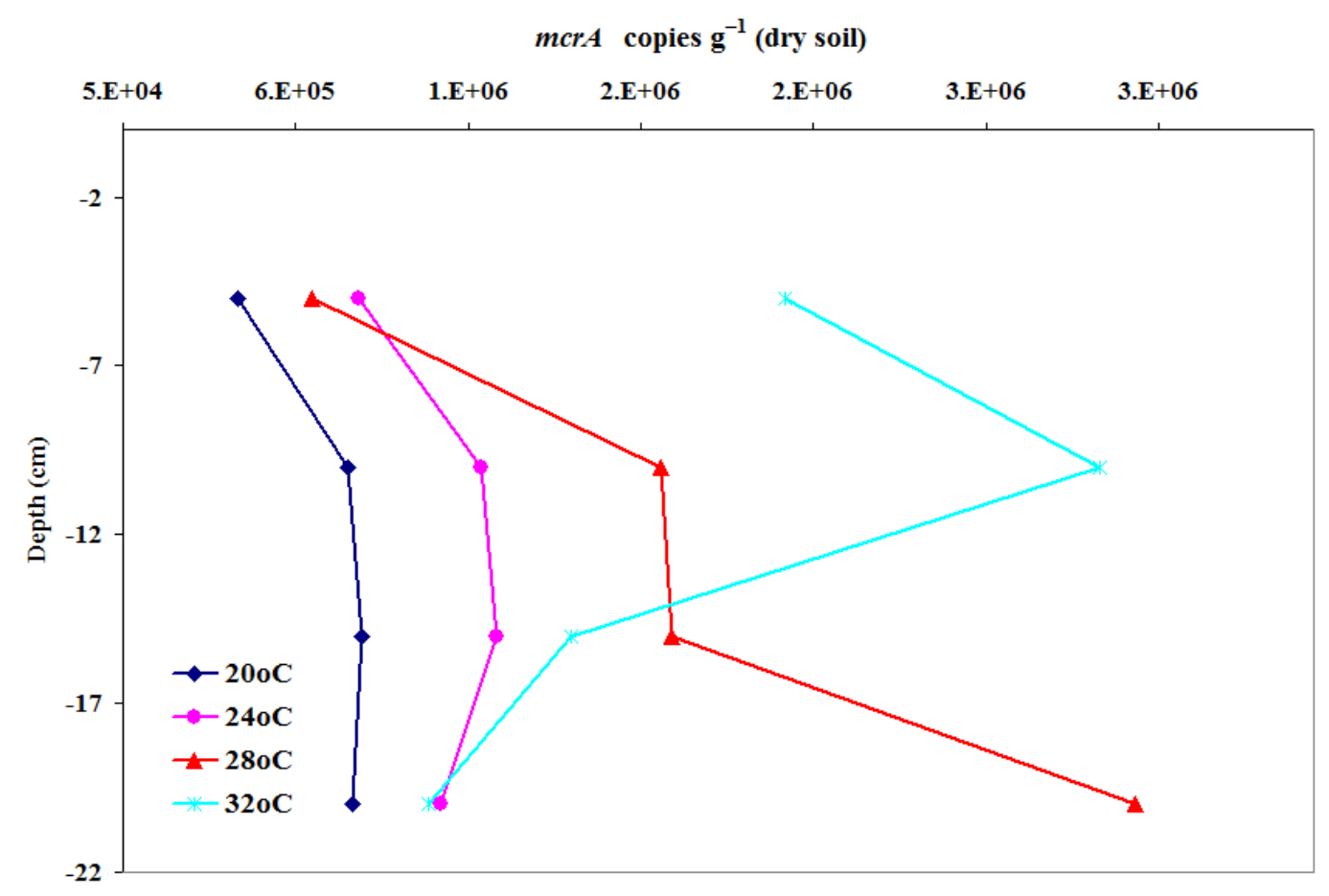

Fig. 7.6: Average values of $m c r A$ copies at different soil horizons at different soil temperature treatment. Highest $m c r A$ copies were found at 28 and $32{ }^{\circ} \mathrm{C}$.

Considering the variation in the orders of magnitude of $m c r A$ copies from incubation and field studies of soils from rice ecosystems, results in this study fell within the median range, and may be considered to be an estimate of the average abundance of $m c r A$ copies in most rice paddies. 
A temperature increase from 20 to $32{ }^{\circ} \mathrm{C}$ resulted in a five-fold increase in $m c r A$ copies in the 5-10 and 10-15 cm soil zone. Similar results have been observed in root and straw amended rice soil core incubation studies (Peng et al., 2008). Within this zone, the mcrA copies were low at the start of the season, approaching an almost steady-state between 54 and 146 days after transplanting (DAT). The results are consistent with observations from Chin et al. (1999) in which a similar trend was observed from rice fields.

\subsubsection{Abundance of $p m o A$ Genes}

The abundance of pmoA genes ranged from $5 \times 10^{4}$ to $4 \times 10^{5}$ copies $\mathrm{g}^{-1}$ of dry soil (Fig. 7.7). In general, our results were comparable to those found in other flooded rice field soils in which orders of magnitude were $10^{4}-10^{6}$ copies $\mathrm{g}^{-1}$ of dry soil (Kolb et al., 2003; Bosse and Frenzel, 1997).

Values of methanotroph populations of orders of magnitude as high as $10^{7}$ copies/g (dry soil) have also been found in the top $0-2 \mathrm{~cm}$ soil cores from straw and straw-burned rice paddies under desaturated soil conditions and early period following flooding/planting (Macalady et al., 2002). Macalady et al. (2002) found that methanotroph growth was highest close to the soil-water interface ( $0-2 \mathrm{~cm}$ soil layer) but lower in bulk soil without rice roots $\left(<10^{6}\right.$ copies/g dry soil $)$ in the zones below the top layer. 


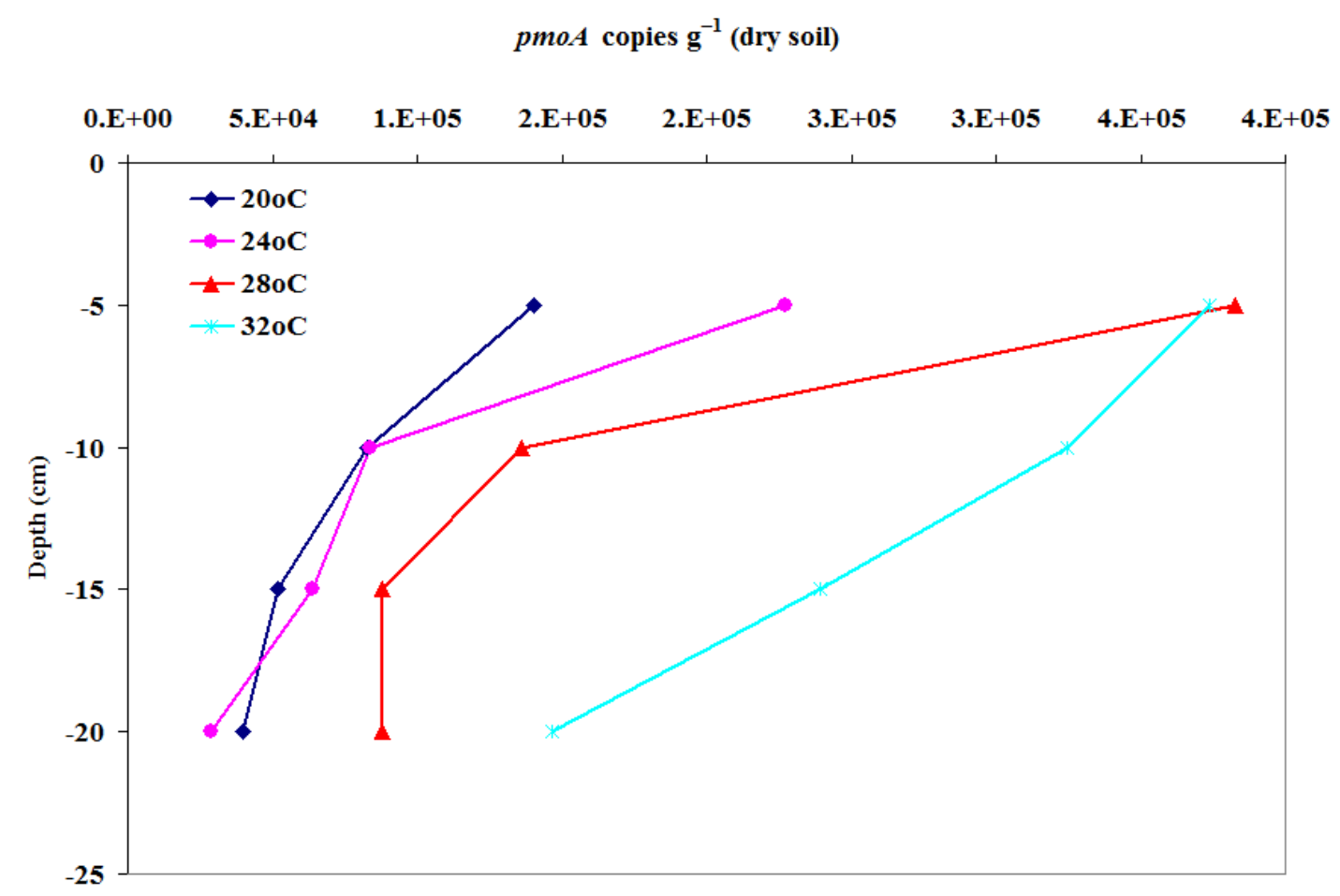

Fig. 7.7: Average values of $p m o A$ copies at different soil horizons at different soil temperature treatment. Highest $p m o A$ copies were found at 28 and $32{ }^{\circ} \mathrm{C}$.

The differences could be a result of the differences in the soil carbon content and texture. Another explanation for these differences is possibly the effect of differences in gas conductance $\left(\mathrm{O}_{2}\right.$ supply into the rhisophere) in different rice cultivars. A higher number of pmoA copies was found in the aerobic top soil horizon $(0-5 \mathrm{~cm})$, an indication that methanotrophy is an aerobic process (Fig. 7.8). 

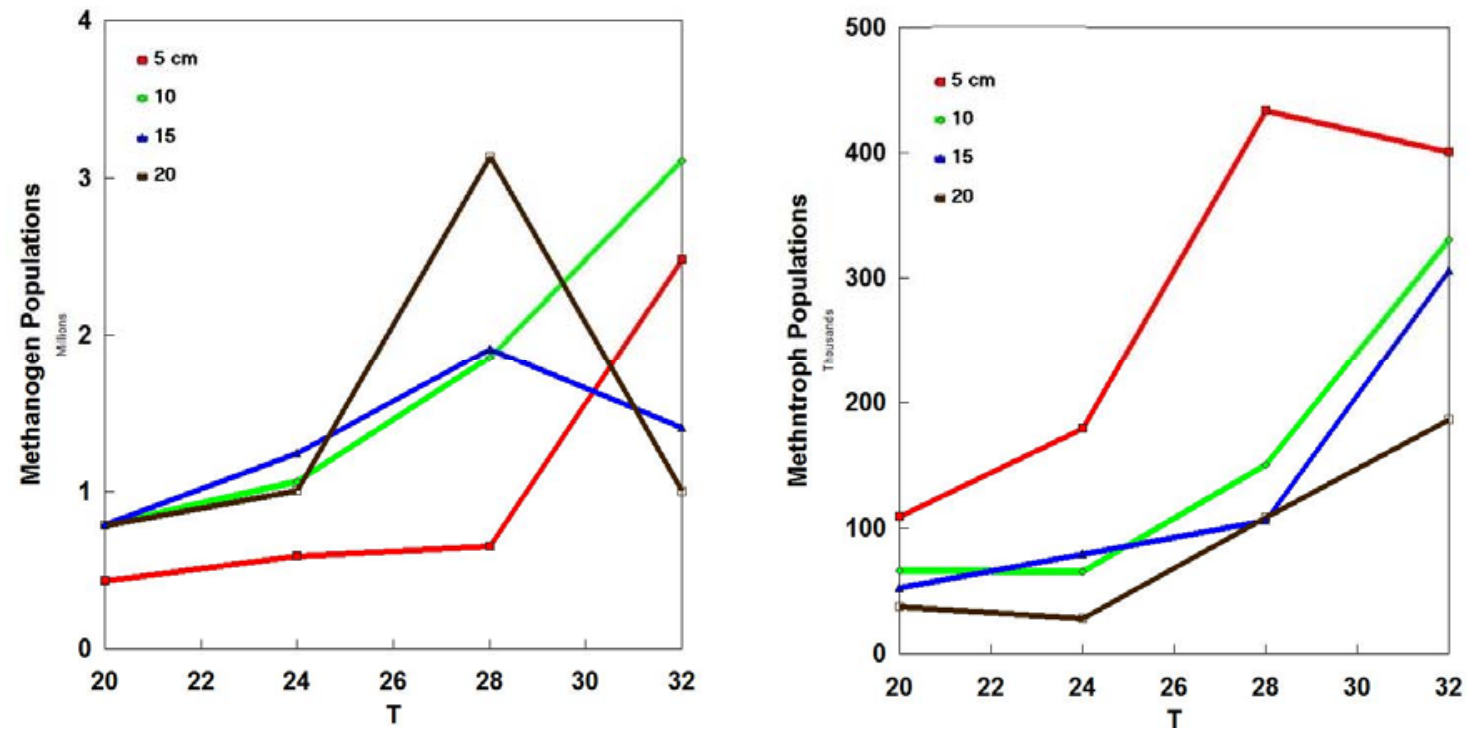

Fig. 7.8: Methanogen and methanotroph populations at different soil horizons at different soil temperature treatments.

Across different temperature treatments, the highest number of $p m o A$ copies occurred at highest temperature (Fig. 7.9). Across different temperatures, no significant change in pmoA abundance was observed at other soil horizons, except at $32^{\circ} \mathrm{C}$. This observation may reflect the difference in the response of different methanotrophic bacteria to elevated temperatures. For example, a change in the methanotrophic community composition in rice field soil at different temperatures has been reported (Chin et al., 1999; Mohanty et al., 2007; Peng et al., 2008).

\subsubsection{Relative Abundance between $m c r A$ and $p m o A$ Genes}

The relatively low number of $p m o A$ to $m c r A$ copies suggested that $\mathrm{CH}_{4}$ oxidation rate was generally lower than production rate given the high $\mathrm{CH}_{4}$ pore water concentration levels that were found in our experiments. Because of fast transport, oxidation in paddy 
fields can be as low as around $30 \%$ of production (Bodelier et al., 2000). If this percentage roughly translates to the relative numbers of $p m o A$ and $m c r A$ copies in rice fields, then results in this research in which the oxidation rates were between 20 and $60 \%$ (in Chapter 6 ) are consistent with those from other studies. In addition, increasing the temperature, increases organic degradation and increases substrate for $\mathrm{CH}_{4}$ production and in the process, depletes $\mathrm{O}_{2}$ and creates anaerobic conditions. The other reason for the low number of $p m o A$ copies is that the soils were amended with chemical fertilizers, which have been found to inhibit $\mathrm{CH}_{4}$ oxidation and decrease carbon conversion efficiency (Roslev et al., 1996). 

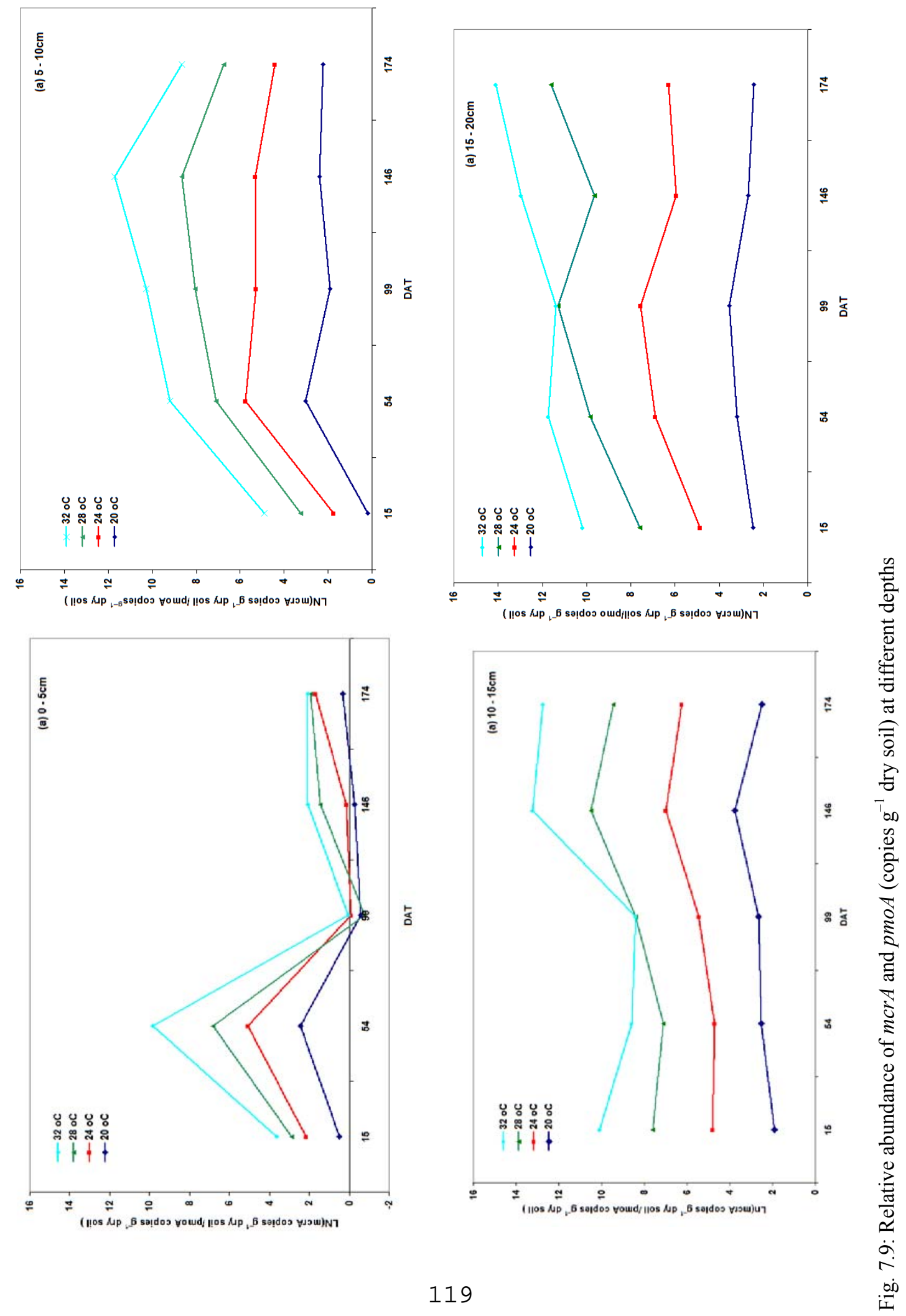
For all temperature treatments, the lowest number of $m c r A$ copies was located in the top soil layer $(0-5 \mathrm{~cm})$, while pmoA copies was mostly abundant in the $0-5 \mathrm{~cm}$ oxygenated soil horizon in all set-ups, but remained fairly constant in the 5-10, 10-15 and $15-20 \mathrm{~cm}$ horizons. Ratios between pmoA and $m c r A$ copies were consistently higher at $28{ }^{\circ} \mathrm{C}$ than at other temperatures (Fig. 7.9). In particular, the highest ratios occurred in the 5-10, 1015 and $15-20 \mathrm{~cm}$ soil cores. Within the $\mathrm{CH}_{4}$ production zone $(5-10$ and $10-15 \mathrm{~cm})$, welldefined stratification of $m c r A$ to $p m o A$ ratios was observed. This, according to our knowledge, is the first time these results have been obtained.

\subsubsection{Regression between pmoA, mcrA Copies and Temperature}

To gain insight into the dependence of pmoA on mcrA copies and indirectly measure oxidation and methanogenesis potential and temperature, linear regression curves were plotted for different temperatures and horizons (Fig. 7.10). Regression coefficients between $p m o A$ and $m c r A$ copies ranged from $0.00-0.92$, with highly significant values in the 5-10 and 10-15 $\mathrm{cm}$ soil horizons, and almost zero elsewhere. To check the dependence of methanotrophs on the population of methanogens, regression coefficients between the two were plotted against soil depth (graphs not shown), and the highest values were found around 5-10 and 10-15 cm horizons, an indication that methanotroph populations are governed by the availability of substrates from methanogens. Thus, the greater the growth of methanogen population, the more $\mathrm{CH}_{4}$ is produced, which in turn stimulates the growth of methanotrophs which depend on the $\mathrm{CH}_{4}$ from methanogenesis as their substrates. 

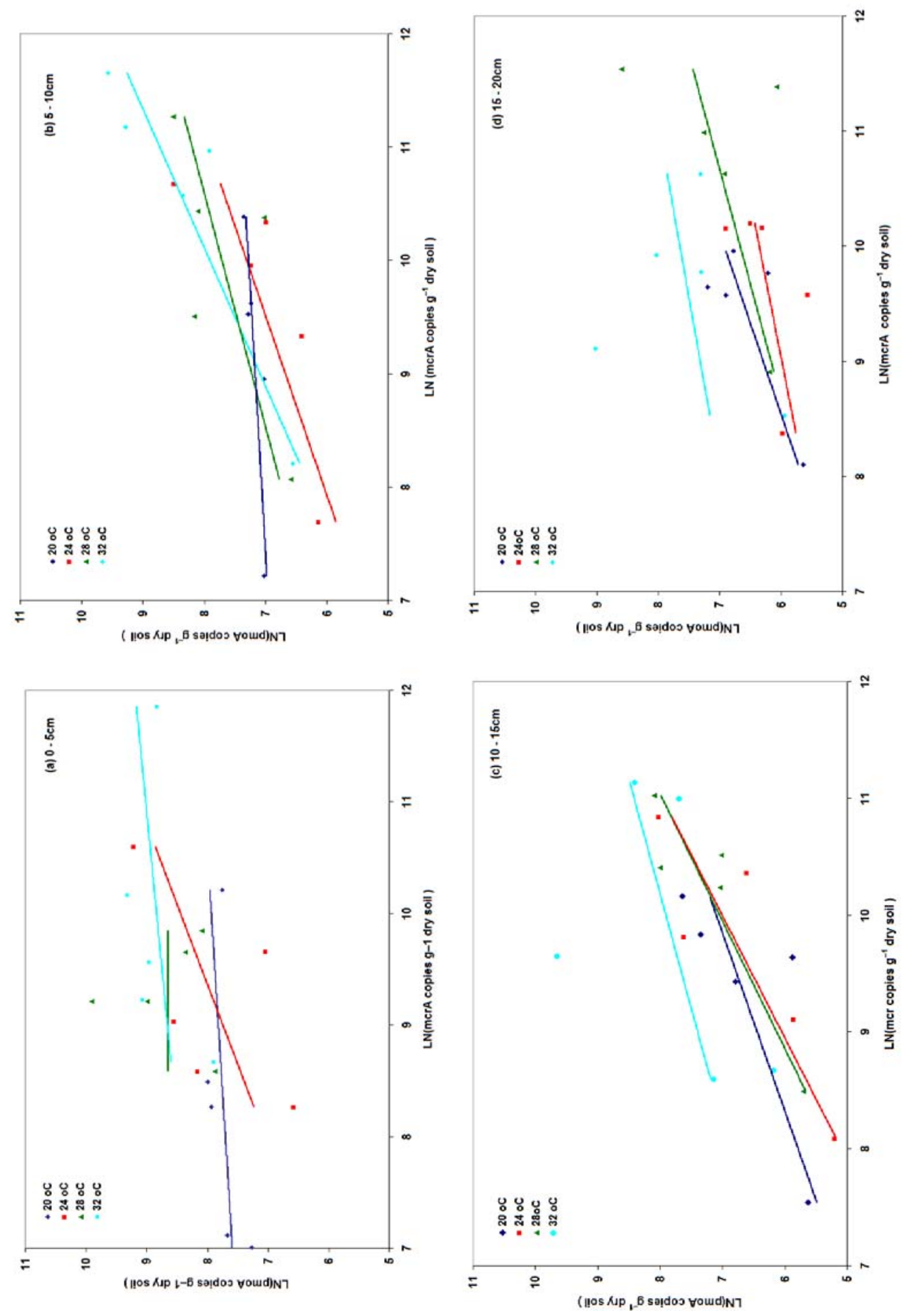

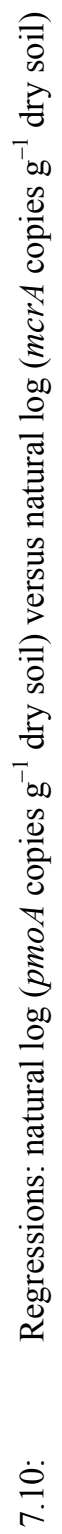


Freitag et al. (2010) found regression coefficients between 0.51 and 0.91 from only two soil layers of $0-10$ and $10-20 \mathrm{~cm}$ from a blanket peat bog. While the observed trends reported by Freitag et al. (2010) are similar to our findings, they found consistently high values in the homogeneous samples from only two soil layers. Homogenization of the samples in the two horizons may have concealed more information about the actual profile of the regression coefficients within the $0-20 \mathrm{~cm}$ soil depth.

Consistent with our results, Joulian et al. (1997) found methanotrophs to be positively correlated with methanogens within the main $\mathrm{CH}_{4}$ production zone. Their results showed that the correlation was strong for acetotrophs and methylotrophs and weak for hydrogenotrophs and concluded that the second group depended on substrates produced by the first group. In our results (Table 7.1), the high regression coefficients in the main $\mathrm{CH}_{4}$ production zone show that methanogens control methanotroph substrate availability, and hence, partly determine the abundance of methanotrophs.

A statistical test ( $5 \%$ level of significance) of the difference between the regression coefficients (Tab. 7.1) using ANACOVA indicated that the slopes between pmoA and $m c r A$ copies were not significantly different from each other in the $0-5 \mathrm{~cm}$ and $15-20$ $\mathrm{cm}$. Across different temperature treatments, the null hypothesis was rejected within the $5-10 \mathrm{~cm}$ soil horizon, meaning, that the regression coefficients were statistically different $(\mathrm{p}<0.05)$ for different temperatures and those in other soil layers. 
Table 7.1. Regression of $p m o A$ (copies $\mathrm{g}^{-1}$ dry soil) to $m c r A$ (copies $\mathrm{g}^{-1}$ dry soil).

\begin{tabular}{|c|c|c|c|c|}
\hline \multirow{2}{*}{$\begin{array}{l}\text { Temp. } \\
{ }^{\circ} \mathrm{C}\end{array}$} & \multicolumn{4}{|c|}{ Regression } \\
\hline & $0-5 \mathrm{~cm}$ depth & $5-10 \mathrm{~cm} \mathrm{depth}$ & $10-15 \mathrm{~cm}$ depth & $15-20 \mathrm{~cm}$ depth \\
\hline 20 & $\begin{array}{l}y=0.1142 x+6.7884 \\
r^{2}=0.2645\end{array}$ & $\begin{array}{l}y=0.1082 x+6.2003 \\
r^{2}=0.7159\end{array}$ & $\begin{array}{l}\mathrm{y}=0.657 \mathrm{x}+0.5344 \\
\mathrm{r}^{2}=0.5847\end{array}$ & $\begin{array}{l}y=0.6338 x+0.5795 \\
r^{2}=0.5787\end{array}$ \\
\hline 24 & $\begin{array}{l}y=0.6984 x+1.462 \\
r^{2}=0.3573\end{array}$ & $\begin{array}{l}y=0.6298 x+1.0053 \\
r^{2}=0.6544\end{array}$ & $\begin{array}{l}\mathrm{y}=0.9524 \mathrm{x}-2.5185 \\
\mathrm{r}^{2}=0.7647\end{array}$ & $\begin{array}{l}y=0.3679 x+2.6794 \\
r^{2}=0.3165\end{array}$ \\
\hline 28 & $\begin{array}{l}y=0.0005 x+8.6413 \\
r^{2}=8 E-08\end{array}$ & $\begin{array}{l}\mathrm{y}=0.484 \mathrm{x}+2.8714 \\
\mathrm{r}^{2}=0.5097\end{array}$ & $\begin{array}{l}\mathrm{y}=0.9142 \mathrm{x}-2.096 \\
\mathrm{r}^{2}=0.8268\end{array}$ & $\begin{array}{l}\mathrm{y}=0.5019 x+1.6428 \\
\mathrm{r}^{2}=0.2716\end{array}$ \\
\hline 32 & $\begin{array}{l}y=0.1803 x+7.0367 \\
r^{2}=0.1623\end{array}$ & $\begin{array}{l}\mathrm{y}=0.8161 \mathrm{x}-0.257 \\
\mathrm{r}^{2}=0.8447\end{array}$ & $\begin{array}{l}\mathrm{y}=0.5079 x+2.8262 \\
\mathrm{r}^{2}=0.2229\end{array}$ & $\begin{array}{l}\mathrm{y}=0.3336 \mathrm{x}+4.314 \\
\mathrm{r}^{2}=0.056\end{array}$ \\
\hline
\end{tabular}

\subsubsection{Relationships between $\mathrm{CH}_{4}$ Fluxes and $m c r A$ and pmo $A$ Copies}

$\mathrm{CH}_{4}$ fluxes increased with increasing abundance of $m c r A$ copies (Fig. 7.11). The observed trends between $\mathrm{CH}_{4}$ fluxes and $m c r A$ copies were strikingly similar to those observed between $\mathrm{CH}_{4}$ fluxes and $m c r A$ gene transcript abundances reported in literature (Freitag et al., 2010; Freitag and Prosser, 2009). 


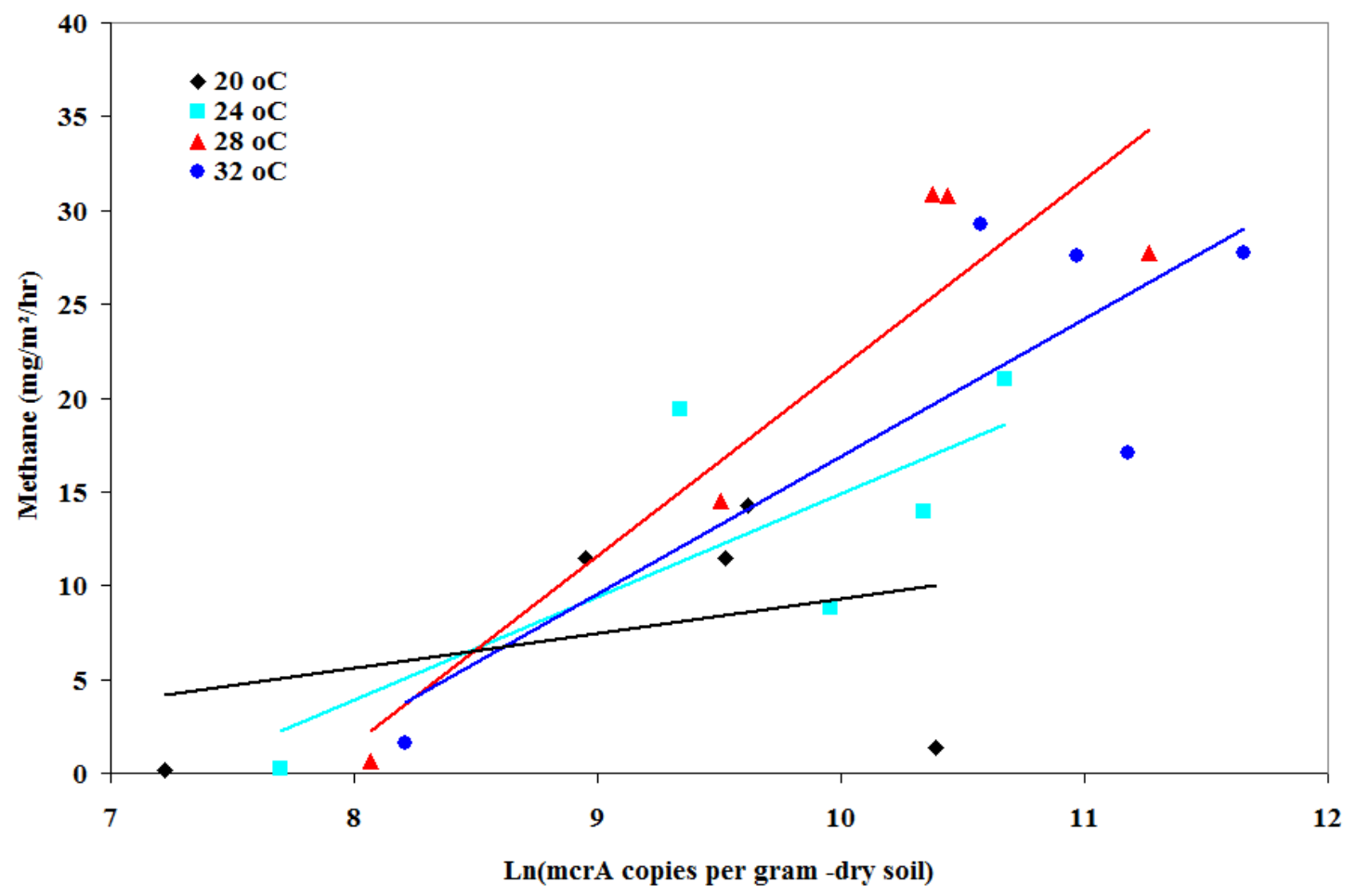

Fig. 7.11: $\mathrm{CH}_{4}$ fluxes vs $m c r A$ a copies at 5-10 $\mathrm{cm}$ depth

From soil sample results, the highest regression coefficient was found at $28{ }^{\circ} \mathrm{C}\left(\mathrm{R}^{2}=\right.$ 0.850), consistent with results from incubation experiments of temperate peat soil slurries by Freitag and Prosser (2009), in which the highest $\mathrm{CH}_{4}$ production rates and mean mRNA transcript/gene abundance ratios occurred between 25 and $30{ }^{\circ} \mathrm{C}\left(\mathrm{R}^{2}=\right.$ $0.790)$.

No well-defined relationship was observed between pmoA copies at any level and $\mathrm{CH}_{4}$ fluxes and soil temperature (Fig. 7.12). Both regression coefficients and slopes were generally low indicating that there is no direct link between methanotroph population and $\mathrm{CH}_{4}$ fluxes. Only in one particular case $\left(0-5 \mathrm{~cm}, 20^{\circ} \mathrm{C}\right)$ was the regression 
coefficient significant. In other studies, (Freitag et al., 2010), regression coefficients ranged between 0.21-0.45 $(\mathrm{n}=4-5)$.

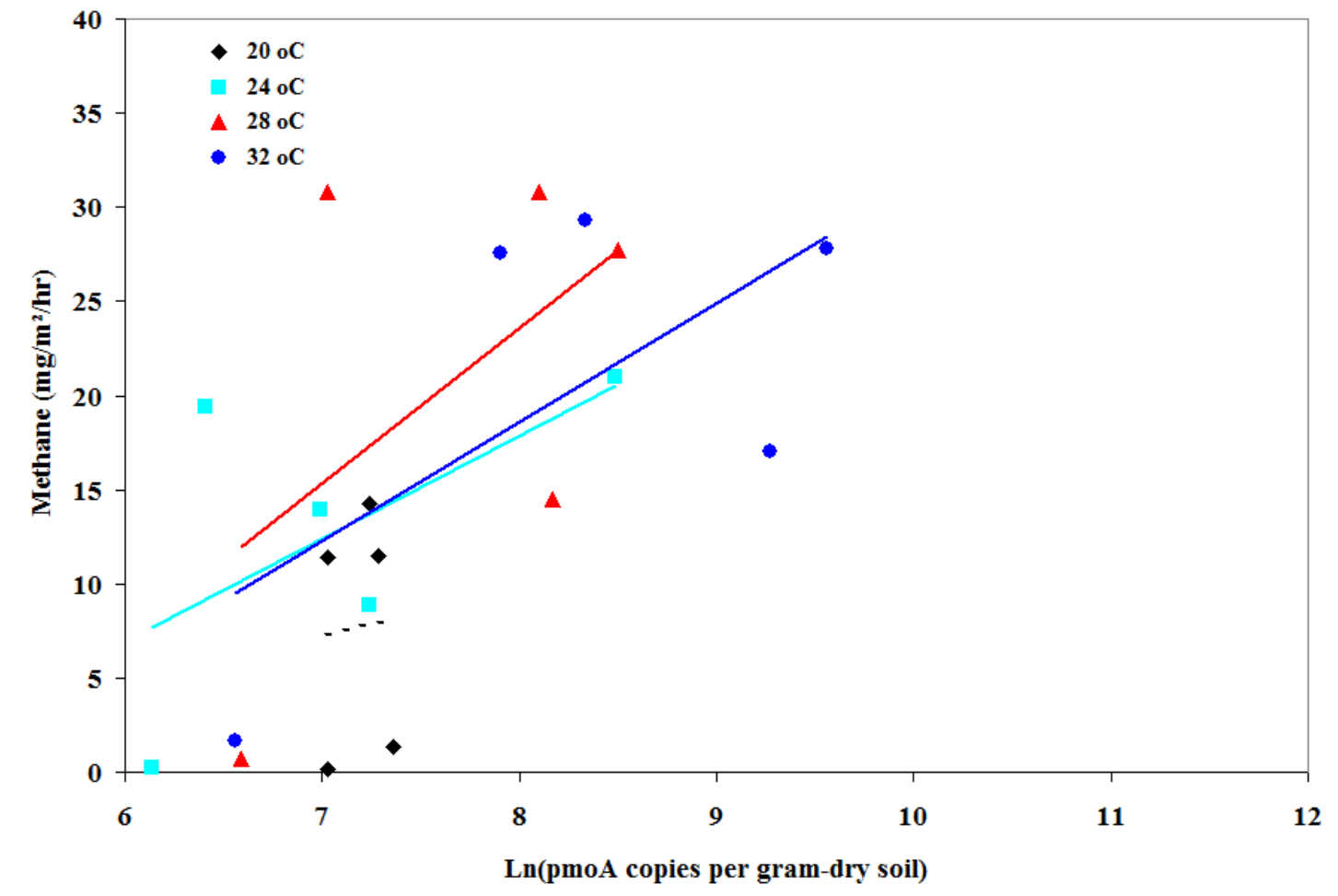

Fig. 7.12: $\mathrm{CH}_{4}$ fluxes vs $p m o A$ copies at $5-10 \mathrm{~cm}$ depth

\subsection{7 $\mathrm{Q}_{10}$ of Methanogens and Methanotrophs}

In general the population of methanogens was found to be higher but less responsive to soil temperature change than methanotrophs (Fig. 7.13). The $\mathrm{Q}_{10}$ of methanogens and methantrophs were calculated based on the populations:

$Q_{10}=\left[\frac{P\left(T_{o}+\Delta\right)}{P\left(T_{o}\right)}\right]^{10 / \Delta}$

Where $\mathrm{P}\left(\mathrm{T}_{0}\right)$ is the population at the base temperature, $\mathrm{T}=20{ }^{\circ} \mathrm{C}$ and $\mathrm{P}(\mathrm{T}+\Delta)$ is the population at any temperature. 
The $\mathrm{Q}_{10}$ of methanogens generally decreased from the top soil horizon to the bottom, while those for methanotrophs slightly increased with soil depth.
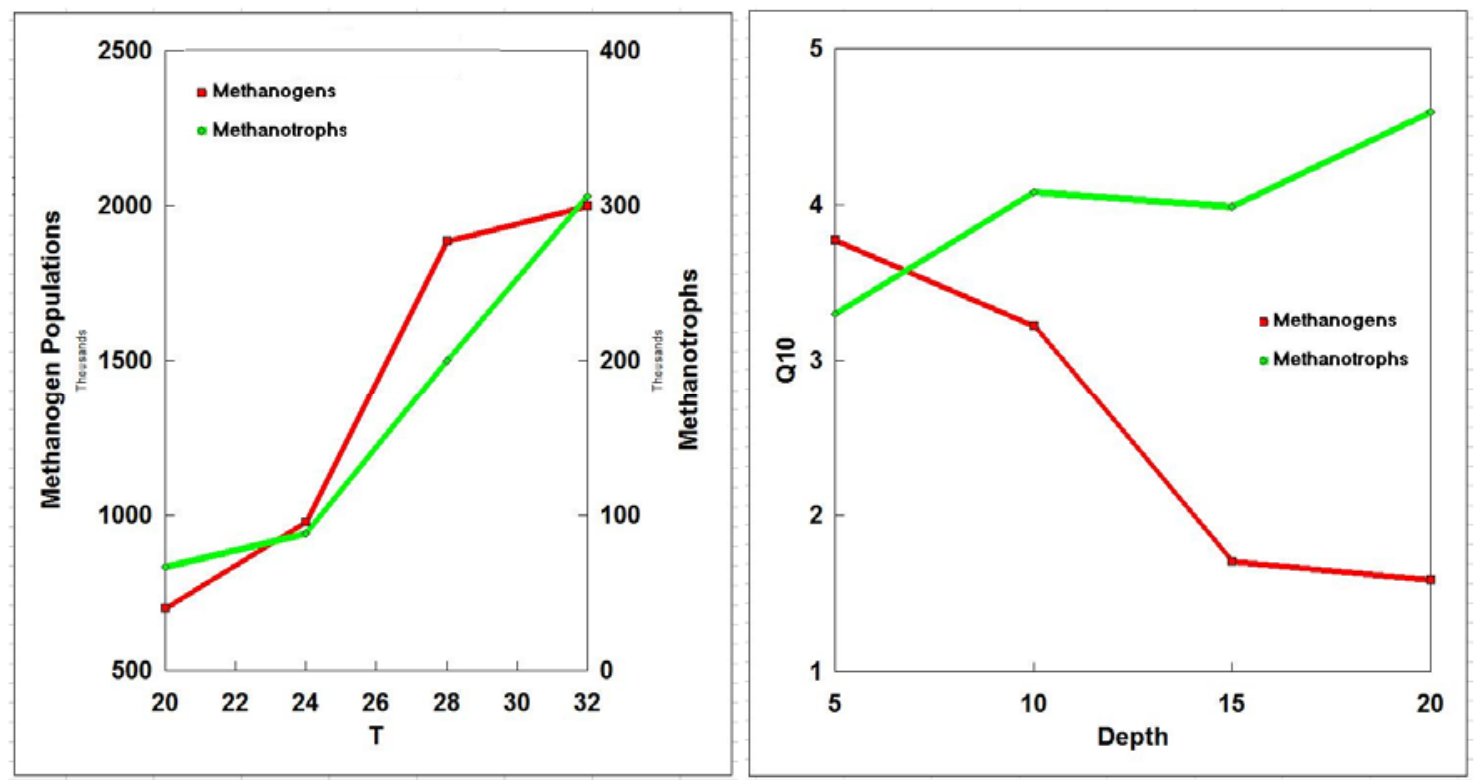

Fig. 7.13: (a) Dependence of methanogen and methanotroph populations on soil temperature. (b) $Q_{10}$ of methanogen and methanotrophs for different soil horizons.

The calculated $\mathrm{Q}_{10} \mathrm{~S}$ values of methanogens were respectively 1.5 and 4.6 for the lower and upper limit, with a seasonal average of 2.6 (90\% confidence level). For methanotrophs, the $\mathrm{Q}_{10} \mathrm{~s}$ were between 2.3 and 6.4, with a seasonal average of 3.8. Within the $10-15 \mathrm{~cm}$, the values were closer to each other.

During the season, the $\mathrm{Q}_{10} \mathrm{~s}$ were generally higher during mid-season, and lower elsewhere. The highest change in values for $\mathrm{Q}_{10}$ values of methanogens were recorded in the top soil horizon $(0-5 \mathrm{~cm})$, while for methanotrophs the change occurred in the 15 - $20 \mathrm{~cm}$ soil layer (7.14). 

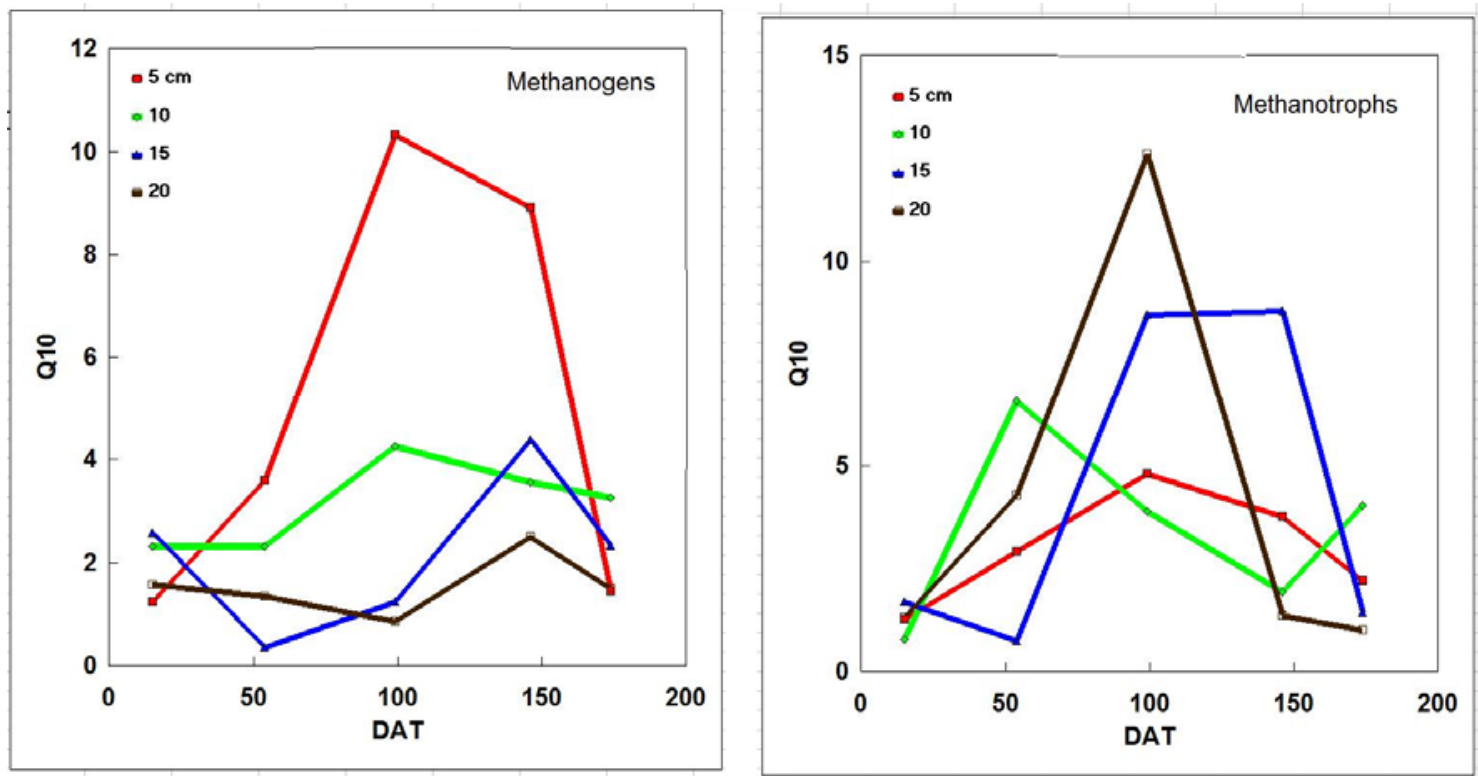

Fig. 7.14: Variation of $\mathrm{Q}_{10}$ values of methanogens and methanotrophs during the season for different temperature treatments and soil depth.

\subsection{Conclusion}

This study showed no significant response of $p m o A$ to temperature, while $m c r A$ populations were positively correlated to temperature. Below the $0-5 \mathrm{~cm}$ horizon, the $m c r A$ copies were more abundant than $p m o A$. High populations of $m c r A$ were weakly correlated to $p m o A$ population in the $5-15 \mathrm{~cm}$ horizon, showing that the relationship between these populations may be more complex than just a linear approximation. The general increase in $\mathrm{CH}_{4}$ fluxes with elevated temperature could stimulate heterotrophs that deplete $\mathrm{O}_{2}$ and create better conditions for increased $\mathrm{CH}_{4}$ production, but are not conducive for $p m o A$. If these results constitute a representative sample of the response of methanogens and methanotrophs to temperature in all rice field soils, then global 
warming is expected to stimulate $\mathrm{CH}_{4}$ fluxes, and hence increase the global atmospheric $\mathrm{CH}_{4}$ budget from rice agriculture and possibly wetlands. 


\section{Chapter 8}

Nitrous Oxide Emissions from Rice Agriculture under Elevated Soil Temperatures

\subsection{Summary}

One of the unknowns in predicting the future concentrations of $\mathrm{N}_{2} \mathrm{O}$ is how the biogenic emissions may change with increasing temperatures. Here results of $\mathrm{N}_{2} \mathrm{O}$ emissions from soil warming experiments to determine the $\mathrm{Q}_{10}$ of fluxes and production from rice ecosystems under different soil temperature treatments are reported. Experiments were conducted between spring of 2009 and summer of 2010. Fluxes were measured using static Plexiglas flux chamber in the same manner as for methane. The variations and comparisons of pore water $\mathrm{N}_{2} \mathrm{O}$ concentrations at four different soil depths are also reported here. $\mathrm{N}_{2} \mathrm{O}$ fluxes were characterized by high temporal variations, ranging from values as high as $1800 \mu \mathrm{g}-\mathrm{N} / \mathrm{m}^{2} / \mathrm{hr}$ during the first two weeks following flooding to almost zero and occasionally negative thereafter. Weak correlations were found between $\mathrm{N}_{2} \mathrm{O}$ fluxes and temperature, with $\mathrm{Q}_{10}$ values ranging from 0.5 to 3.3. High production rates coincided with periods of fertilization, with highest rate occurring at the onset of the growing season. The $\mathrm{Q}_{10}$ values of production varied between 0.4 and 3 . These results indicate the existence of a positive feedback between soil temperature and $\mathrm{N}_{2} \mathrm{O}$ emissions from paddy soils. The implication of these results will be an increase in $\mathrm{N}_{2} \mathrm{O}$ emissions from rice paddies under global warming. However, on a global scale, in addition to the direct effect of soil temperature, the pattern and distribution of future $\mathrm{N}_{2} \mathrm{O}$ emissions from rice paddies (and possibly similar ecosystems) will also be 
determined by how much global warming will affect the pattern and distribution of water tables, since the dominant processes leading to $\mathrm{N}_{2} \mathrm{O}$ production also depend on soil moisture content.

\subsection{Introduction}

Of the estimated $20 \mathrm{Tg}-\mathrm{N}_{2} \mathrm{O}$ annual global $\mathrm{N}_{2} \mathrm{O}$ emissions (Smith, 1997; Smith et al., 1998), about $2-3 \mathrm{Tg} / \mathrm{yr}$ originates from cultivated soils. Emission rates in agricultural systems are related to the quantities of $\mathrm{N}$ used as fertilizers and, where relevant, to recent land use change (Smith, 1997). The constantly increasing atmospheric concentration, as well as the disparities in reports on the effect of temperature on $\mathrm{N}_{2} \mathrm{O}$ emissions from rice agriculture underscores the urgent need to better understand the likely feedback between global warming and these emissions. Per molecule basis, $\mathrm{N}_{2} \mathrm{O}$ is 310 times more potent as a greenhouse gas than $\mathrm{CO}_{2}$. Because of its contribution to global warming, and participation in stratospheric ozone destruction, $\mathrm{N}_{2} \mathrm{O}$ has been studied extensively over the past three decades. Application of $\mathrm{N}$-fertilizer has been identified as a major source of $\mathrm{N}_{2} \mathrm{O}$ in agricultural soils (Towprayoon et al. 2005; Yang et al., 2003; Stehfest and Bouwman, 2006), contributing about $58 \%$ of total anthropogenic emissions (Smith et al., 2007). 


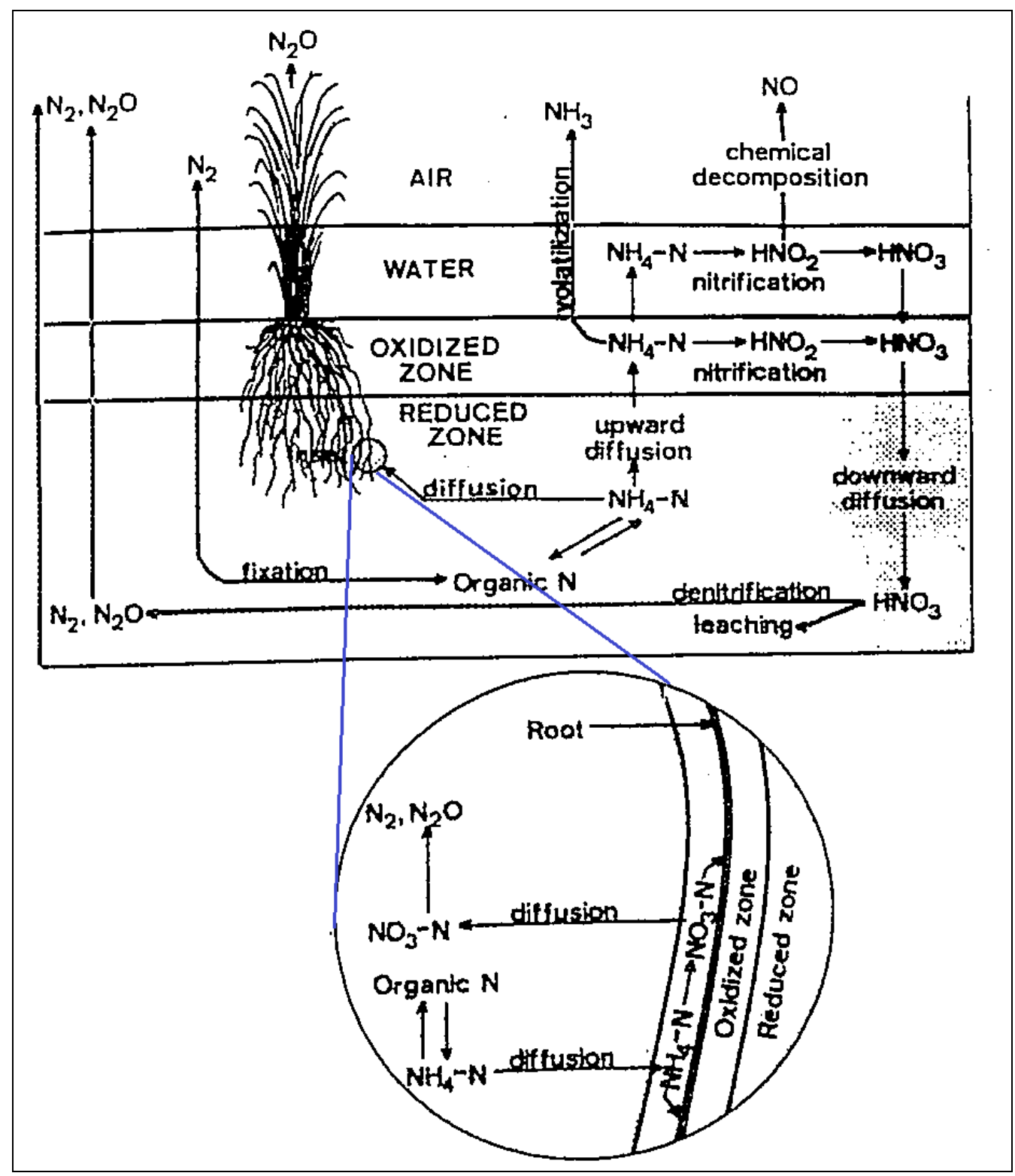

Fig. 8.1: Dominant processes involved in the formation of $\mathrm{N}_{2} \mathrm{O}$ in soils: (I) Nitrification (oxidation of ammonium to nitrite and nitrate, or a biologically induced increase in the oxidation state of nitrogen and occurs under aerobic conditions) and (II) Denitrification (biological reduction of nitrate, $\mathrm{NO}_{3}{ }^{-}$or nitrite, $\mathrm{NO}_{2}{ }^{-}$, to nitrogen oxides or molecular nitrogen under anaerobic conditions). Adapted from Reddy (1982).

In the soil, $\mathrm{N}_{2} \mathrm{O}$ can be formed by various processes depending on the amount of different forms of nitrogen, moisture level, soil temperature, and concentration of $\mathrm{O}_{2}$, 
ammonium and nitrate among other factors. Microbial de-nitrification and nitrification are the key dominant processes of $\mathrm{N}_{2} \mathrm{O}$ within the natural $\mathrm{N}$ cycle (Smith, 1997; Bremner, 1997; Smith et al., 1998; Flessa et al., 2002; Towprayoon et al., 2005). Fine details about other minor sources of $\mathrm{N}_{2} \mathrm{O}$ were clearly outlined in Bremner (1997).

It is thought that denitrification can be either a source or a sink for $\mathrm{N}_{2} \mathrm{O}$, which can either result in the formation of $\mathrm{N}_{2} \mathrm{O}$ (as an intermediate byproduct), or consumption of $\mathrm{N}_{2} \mathrm{O}$, depending on environmental conditions such as $\mathrm{O}_{2}$ levels, $\mathrm{N}$ levels, $\mathrm{pH}$, and temperature (Smith, 1997). Under continuously flooded conditions, such as considered in this research most of the $\mathrm{N}_{2} \mathrm{O}$ is produced by de-nitrification.

Attempts to quantify the direct effect of elevated soil temperature on $\mathrm{N}_{2} \mathrm{O}$ emissions through soil warming studies have not produced a clear conclusion. In some studies, weak and negative correlations between $\mathrm{N}_{2} \mathrm{O}$ fluxes and soil temperatures were reported, while in other studies, positive strong correlations were found. Large temporal variations of flux rates is one key source of error in determining the $\mathrm{Q}_{10}$ of $\mathrm{N}_{2} \mathrm{O}$ fluxes from cultivated soils (Flessa et al. 2002). Khamp et al. (1998) suggested that elevating temperatures leads to both positive and negative effects controlling $\mathrm{N}_{2} \mathrm{O}$ emissions, and the overall effect results in small changes in $\mathrm{N}_{2} \mathrm{O}$ release. It is evident that the effect of soil temperature on $\mathrm{N}_{2} \mathrm{O}$ is complex, and requires further studies to get a full understanding of this feedback. Results from various studies indicate that the overall effect of temperature on $\mathrm{N}_{2} \mathrm{O}$ emissions is generally positive, and that this rate of increase would be steeper when denitrification is more dominant than nitrification 
(Smith, 1997). Two reasons are thought to be responsible for this observation, (I) increased soil respiration, which increases the anaerobic volume in which denitrification takes place, and (II) increased denitrification rate per unit anaerobic volume due to direct effect of temperature increase (Smith, 1997). Here the sensitivity of $\mathrm{N}_{2} \mathrm{O}$ to soil temperature was investigated under carefully controlled soil warming experiments in order to quantify this positive feedback based on the IPCC global warming projections.

\subsection{Aim and Objectives}

The aim of this study was to determine whether global warming would result in increased $\mathrm{N}_{2} \mathrm{O}$ emissions from rice paddies into the atmosphere. The objective of this research was to determine the $\mathrm{Q}_{10} \mathrm{~S}$ of $\mathrm{N}_{2} \mathrm{O}$ production and fluxes under controlled greenhouse experiments in continuously flooded rice microcosms.

\subsection{Materials and Methods}

From the same experimental set-ups and samples to determine the effect of temperature on $\mathrm{CH}_{4}$ (outlined in the preceding chapters), $\mathrm{N}_{2} \mathrm{O}$ emissions and production rates were also determined from experiments described in Chapter 2. $\mathrm{N}_{2} \mathrm{O}$ fluxes and its pore water concentrations were measured every three days and weekly, respectively. The collected samples were analyzed with a GC, equipped with an electron capture detector (ECD). $\mathrm{N}_{2} \mathrm{O}$ fluxes were calculated using a linear regression of the observed concentrations with sampling time. Production rates and $\mathrm{N}_{2} \mathrm{O}$ pore water concentrations were 
determined using the approach outlined in Chapter 3 for determining $\mathrm{CH}_{4}$ production rates and pore water concentrations, respectively.

\subsection{Results and Discussion}

\subsection{1 $\mathrm{N}_{2} \mathrm{O}$ Fluxes}

With the exception of the increase after $\mathrm{N}$-fertilization, $\mathrm{N}_{2} \mathrm{O}$ fluxes were generally low for all temperature treatments. The high $\mathrm{N}_{2} \mathrm{O}$ fluxes that were observed coincided with periods of N-fertilization, and diminished to almost zero afterwards. Similar results have been reported in many experiments (Yang et al., 2003; Ghosh et al., 2003; Lai, 2000). In particular, Gosh et al. (2003) found two sharp peaks in $\mathrm{N}_{2} \mathrm{O}$ emissions just after fertilizer application, one at 2-5 DAT which gradually decreased and a new high during 15-33 DAT. Thereafter, the emissions were zero till 105 DAT for all the treatments. In contrast to higher second $\mathrm{N}_{2} \mathrm{O}$ peaks than the first from their results, our second peaks were consistently lower than the first in all the treatments. The differences in the size of peaks reported in the former studies and those reported herein, could be due to dry spells reported in their results.

Under continuously flooded conditions, the $\mathrm{N}_{2} \mathrm{O}$ emission into atmosphere is suppressed by the pressure of standing water and therefore most of the $\mathrm{N}_{2} \mathrm{O}$ produced gets denitrified to $\mathrm{N}_{2}$ within the soil, whilst under drier conditions, nitrification produces most of the $\mathrm{N}_{2} \mathrm{O}$. If the soil is flooded again, denitrifying bacteria will act on the nitrate released by nitrification to produce more $\mathrm{N}_{2} \mathrm{O}$ (Ghosh et al., 2003). 

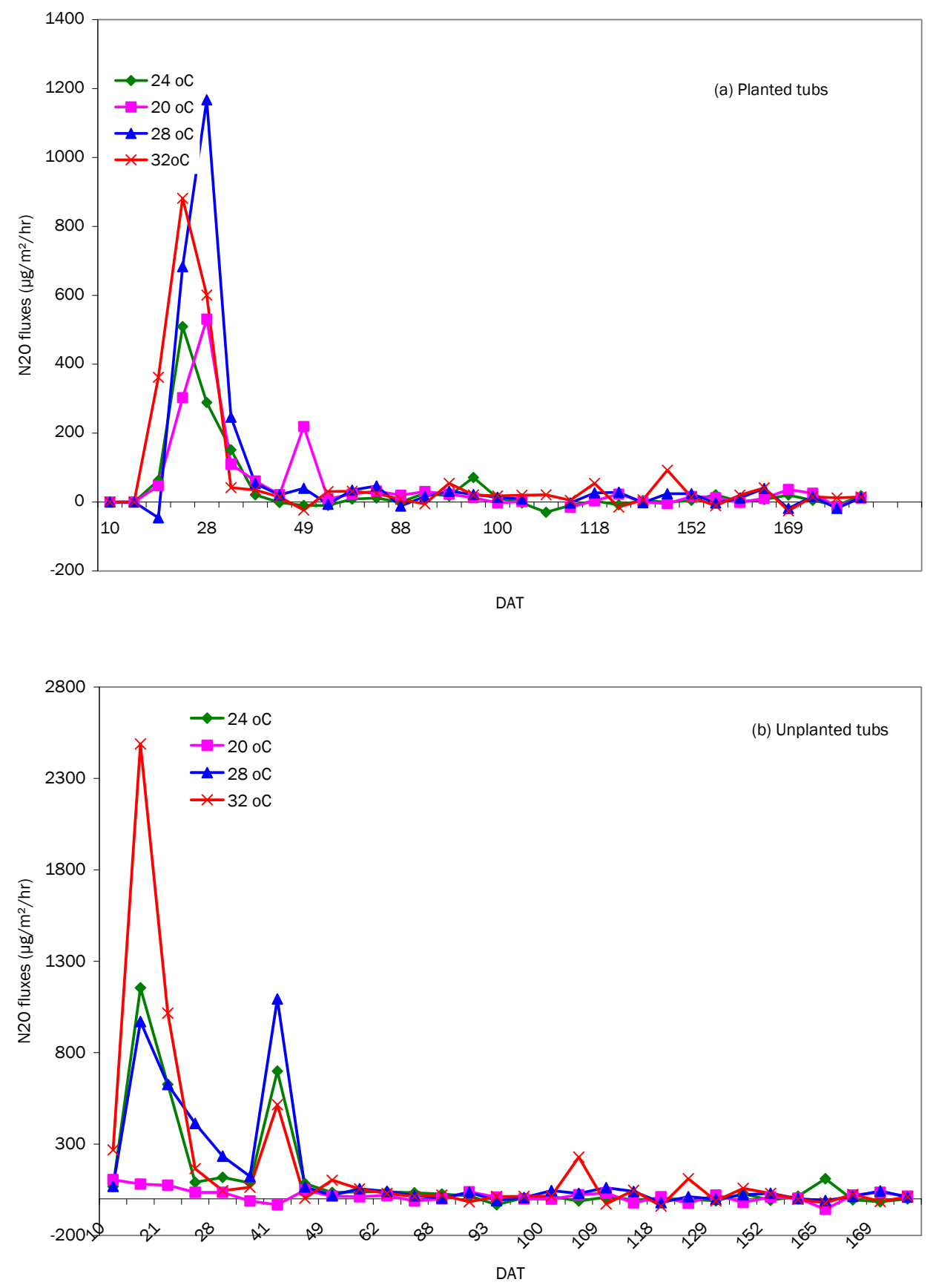

Fig. 8.2: $\mathrm{N}_{2} \mathrm{O}$ emissions from both (a) planted and (b) unplanted tubs. Higher fluxes occurred in unplanted than in planted tubs, and the peaks coincide with episodes of fertilization. Elsewhere, the fluxes were nearly close to zero or slight negative. The impact of temperature was more apparent in unplanted tubs than in planted ones. 
High temporal and spatial variability in $\mathrm{N}_{2} \mathrm{O}$ fluxes was observed both within and between treatments. Two weeks after DAT, fluxes were low and highly variable, with negative $\mathrm{N}_{2} \mathrm{O}$ fluxes occurring on many occasions. The observation was reported in various studies (McHale et al., 1998; Bremer, 1996). $\mathrm{N}_{2} \mathrm{O}$ fluxes were two times higher in unplanted than in planted tubs.

A comparison of $\mathrm{N}_{2} \mathrm{O}$ emissions from planted and unplanted tubs indicated that higher fluxes were consistently found in unplanted than planted tubs. In particular, highest peaks of $\mathrm{N}_{2} \mathrm{O}$ fluxes were associated with the $28{ }^{\circ} \mathrm{C}$ treatment, whilst in unplanted tubs, the highest fluxes occurred in the $32{ }^{\circ} \mathrm{C}$ treatment. Two possibilities could account for these differences, either the $\mathrm{N}$-fertilizer in the planted tubs was quickly used up by the plants at $32{ }^{\circ} \mathrm{C}$, or the diffusion was very high at $32{ }^{\circ} \mathrm{C}$ in unplanted tubs. Either way, the presence of plants seemed to have played a part in the observed differences.

\subsubsection{Effect of Soil Temperature on Fluxes}

Within the $20-32{ }^{\circ} \mathrm{C}$ temperature range considered in our research, the effect of temperature was only evident a short period after N-fertilizer application. From other studies the results have been mixed-up. For example, McHale et al. (1998) did not find any significant relationship between $\mathrm{N}_{2} \mathrm{O}$ and soil temperature. Because of the low emission rates when no $\mathrm{N}$-fertilizer was applied, it would seem as though temperature did not have an effect on $\mathrm{N}_{2} \mathrm{O}$ emissions. To observe the real effect of temperature, only the time averaged $\mathrm{N}_{2} \mathrm{O}$ flux during the peaks were considered (Fig. 8.3). 

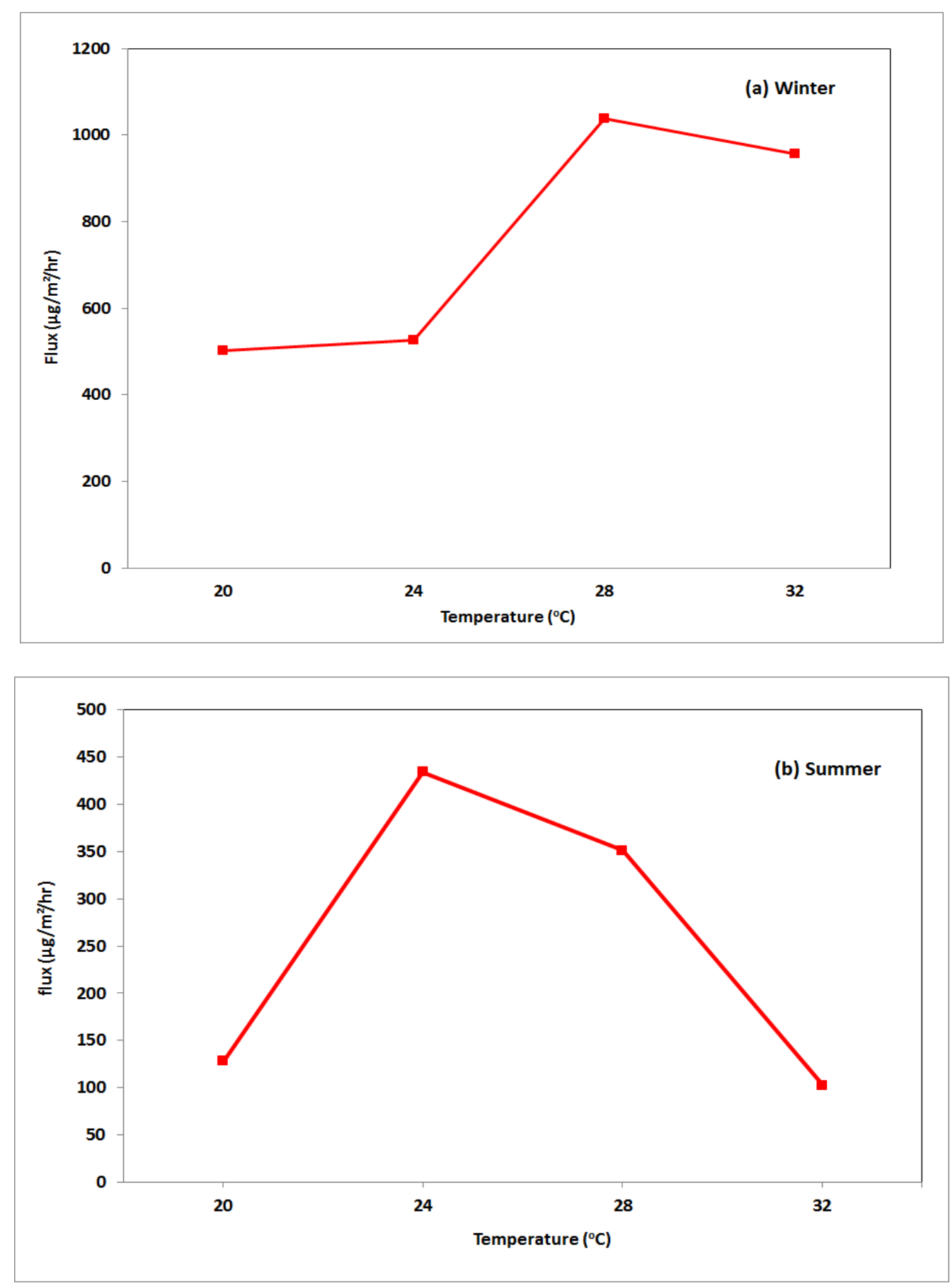

Fig. 8.3: Effect of soil temperature on $\mathrm{N}_{2} \mathrm{O}$ fluxes during (a) Winter and (b) Summer.

Barnard et al. (2005) found that soil warming did not have large direct effects on $\mathrm{N}_{2} \mathrm{O}$ emissions in the field. 

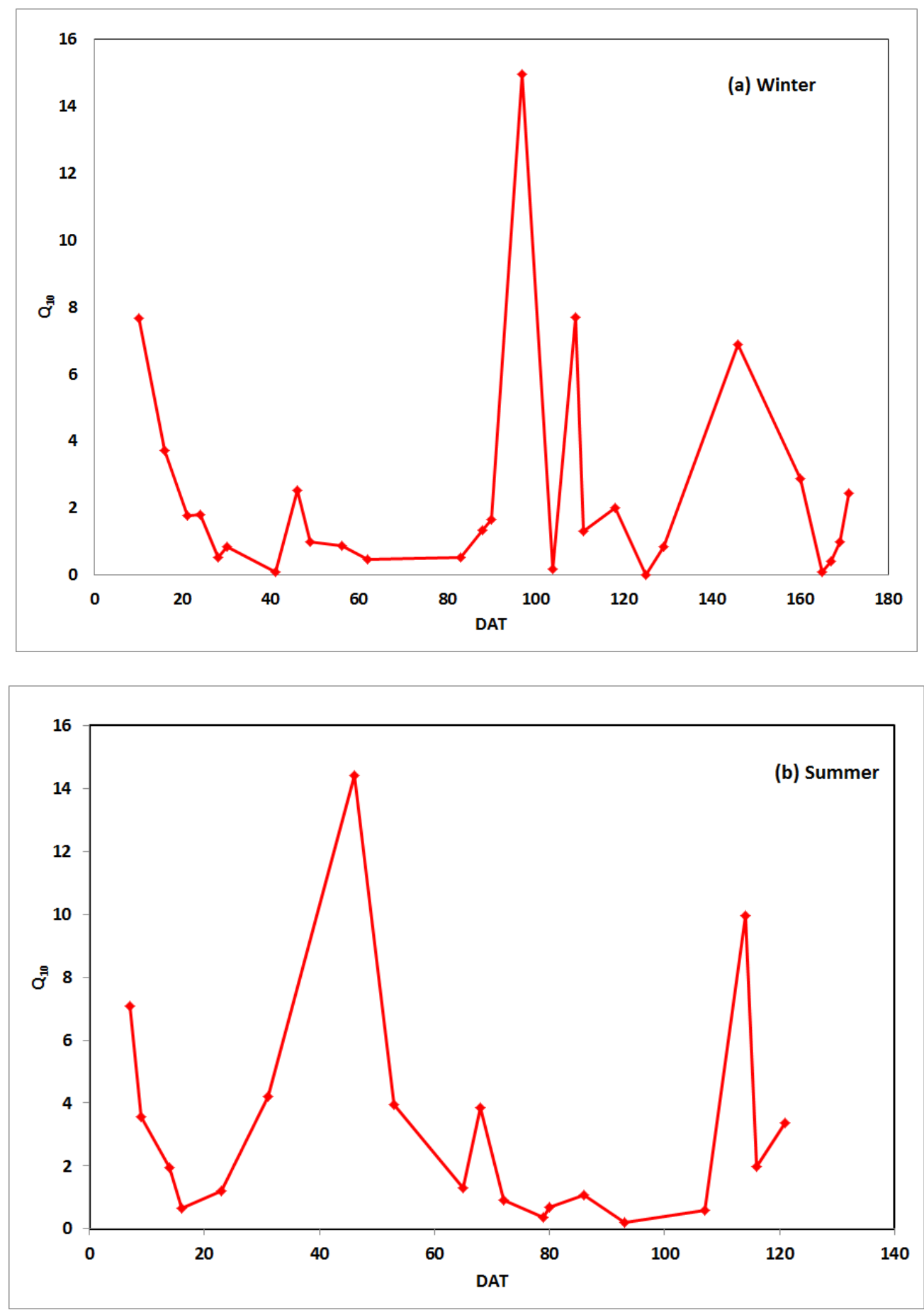

Fig. 8.3: Effect of soil temperature on fluxes as indicated by $\mathrm{Q}_{10}$ values. No discrepancy was observed between the data from (a) Winter and (b) Summer. 
A further test on the effect of temperature was done by calculating the $\mathrm{Q}_{10}$ of the $\mathrm{N}_{2} \mathrm{O}$ fluxes. The $\mathrm{Q}_{10}$ values for fluxes from both seasons ranged between 0.5 and 3.3. The very high values are thought to be associated with de-nitrification (Smith, 1997). $\mathrm{Q}_{10}$ values of between 0.4 and 9.4 were found in other studies (Koponena, 2006; Flessa et al., 2002). Slightly higher values (up to 15 ) on the upper limit of the $\mathrm{Q}_{10}$ were found by Smith et al. (1998).

\subsubsection{Effect of Temperature on $\mathrm{N}_{2} \mathrm{O}$ Production Rates}

High production rates coincided with periods of fertilization. The production rate was high at the start of the season and almost zero elsewhere. Distribution was similar to that for $\mathrm{N}_{2} \mathrm{O}$ fluxes. $\mathrm{Q}_{10}$ values varied between 0.2 and 1.8 (Fig. 8.4). These results are comparable to those from other studies. In particular, $Q_{10}$ s ranging between 0.9 and 3.4 have been measured for $\mathrm{N}_{2} \mathrm{O}$ production from forest soils (Castaldi, 2000). The highest $Q_{10} \mathrm{~S}$ for $\mathrm{N}_{2} \mathrm{O}$ the have been associated with denitrification activity, such that a temperature rise enhances the activity of denitrifiers and increases the volume of the anaerobic soil fraction, where denitrification occurs (Smith, 1997). 


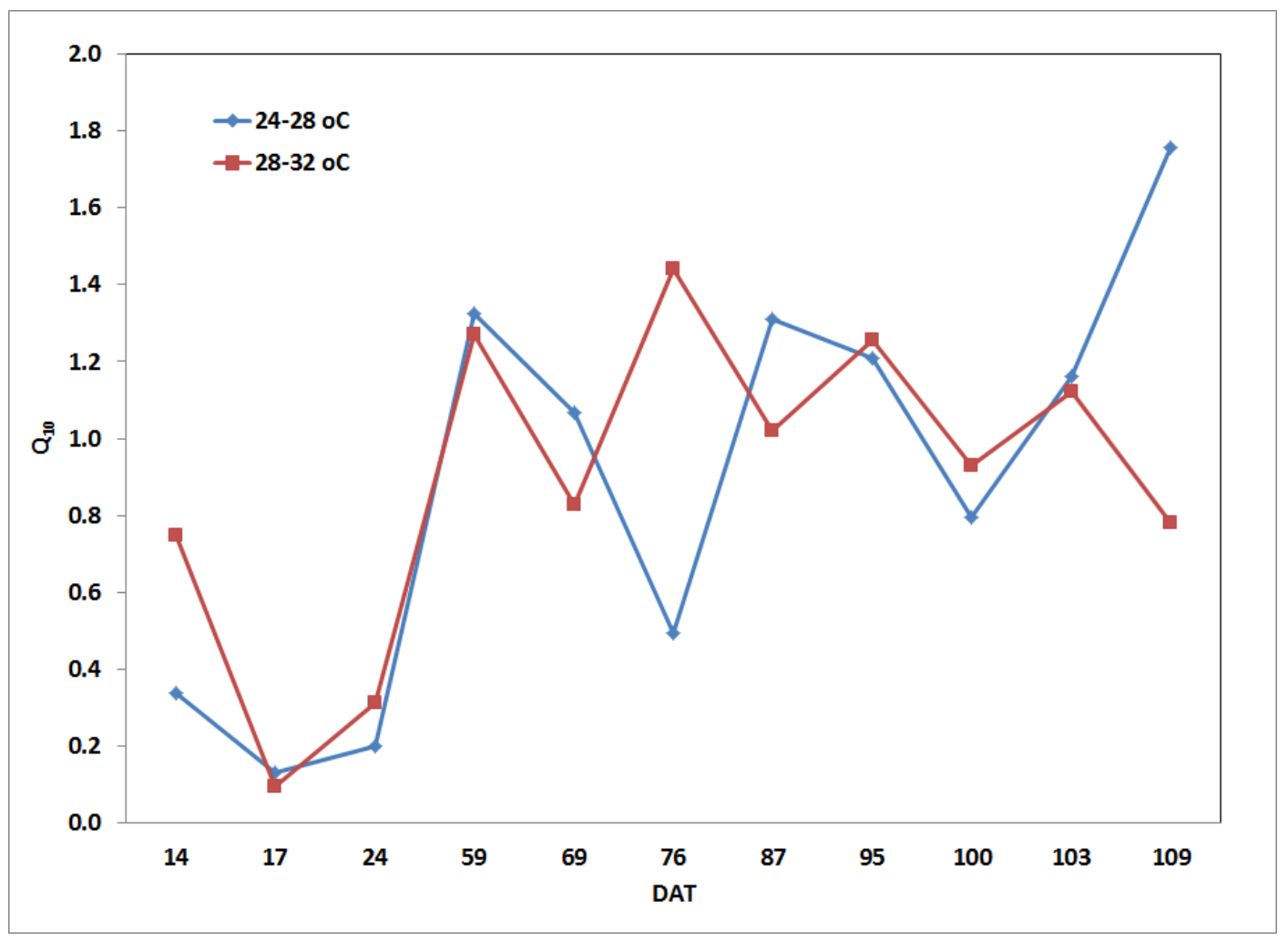

Fig. 8.4: The $\mathrm{Q}_{10} \mathrm{~S}$ of $\mathrm{N}_{2} \mathrm{O}$ were fairly lower than those from fluxes. The values are independent of DAT, and varied from 0.1 to 1.8 . Noteworthy were values below 1 , indicative of decreasing production rates with elevated temperature.

Considering that our experiments were performed under continuously flooded conditions, denitrification was the major source of $\mathrm{N}_{2} \mathrm{O}$. From similar studies, on the effect of temperature on denitrification rate from nine soils $\left(15\right.$ to $\left.45^{\circ} \mathrm{C}\right)$, the $\mathrm{Q}_{10}$ was approximately 2 (Stanford et al., 1975).

\subsubsection{Pore Water Concentrations}

Highest concentration of $\mathrm{N}_{2} \mathrm{O}$ occurred at lowest temperature $\left(20^{\circ} \mathrm{C}\right)$, and lowest concentration at $32{ }^{\circ} \mathrm{C}$. Increasing soil temperature reduces the pore water $\mathrm{N}_{2} \mathrm{O}$ 
concentration in the rhizosphere. Within all treatments, unplanted (control) tubs had the highest $\mathrm{N}_{2} \mathrm{O}$ pore water concentrations. 

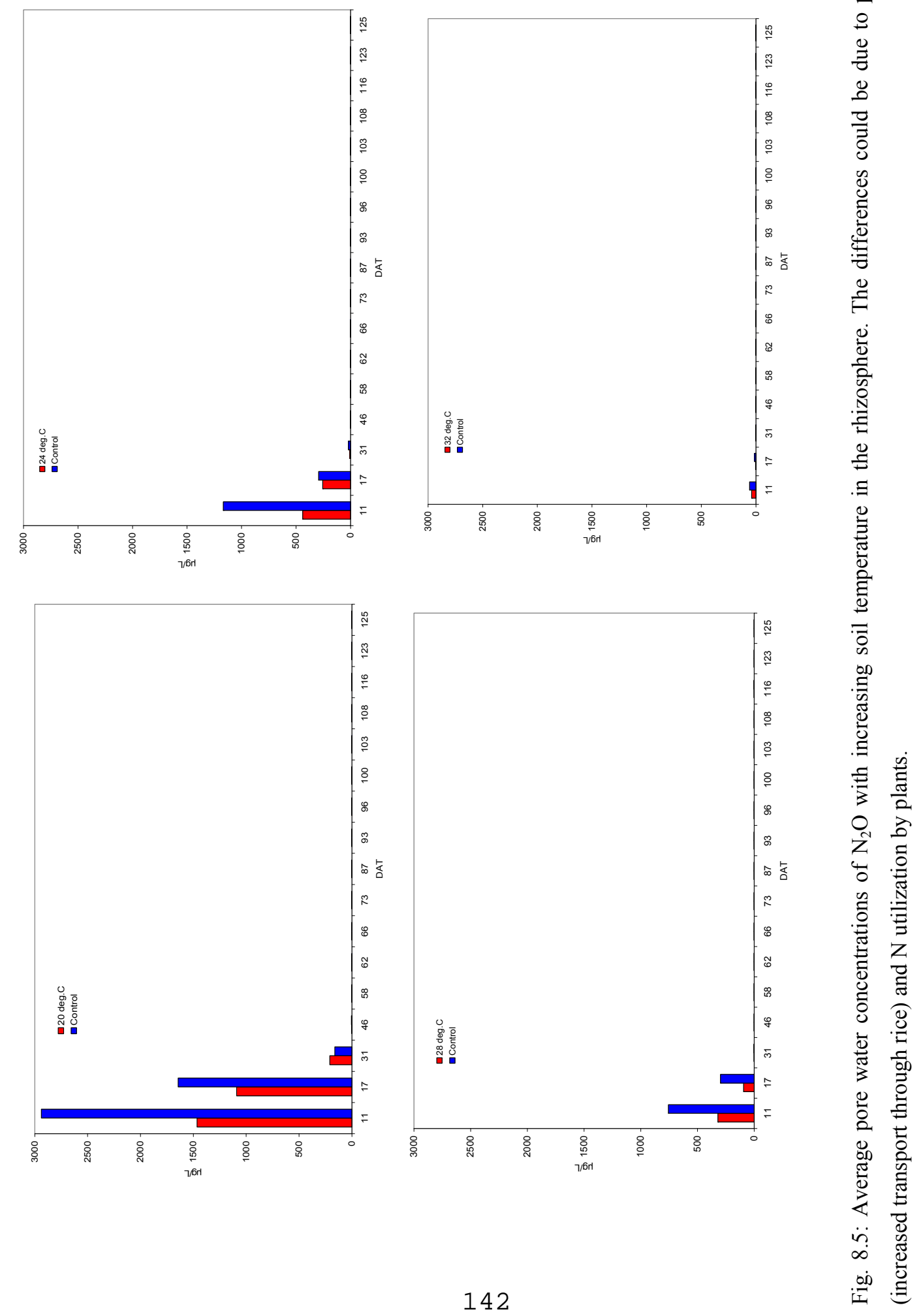
The differences in $\mathrm{N}_{2} \mathrm{O}$ concentrations could be due to a combination of fast transport and plant nitrogen uptake in planted tubs resulting in the depletion of nitrogen compounds that could be used for $\mathrm{N}_{2} \mathrm{O}$ formation. Pore water concentrations were lower in higher soil temperature treatments than lower ones. For example, in both seasons, the $\mathrm{N}_{2} \mathrm{O}$ concentration at $20^{\circ} \mathrm{C}$ was almost 15 times higher than that at $32{ }^{\circ} \mathrm{C}$.

\subsection{Conclusion}

The direct effects of temperature on $\mathrm{N}_{2} \mathrm{O}$ emissions and production were successfully quantified. Spikes of $\mathrm{N}_{2} \mathrm{O}$ emissions coincided with period of nitrogen fertilizer application. Both $\mathrm{N}_{2} \mathrm{O}$ emission and production rates were dependent on soil temperature, with higher $\mathrm{Q}_{10}$ values for fluxes than production. This may be the reason why very high $\mathrm{N}_{2} \mathrm{O}$ fluxes occurred just after flooding, and diminishing to zero elsewhere. The $\mathrm{Q}_{10}$ values found in our research, which are consistent with results from previous experiments and other studies, indicate that global warming will have a direct positive feedback on $\mathrm{N}_{2} \mathrm{O}$ production and emission rates in flooded rice paddies. Nevertheless, the quantity and distribution of future $\mathrm{N}_{2} \mathrm{O}$ emissions will depend on other indirect effects of global warming, such as the regional distribution of soil water content (water tables), and precipitation patterns. 
Chapter 9

Summary and General Conclusion

This dissertation analyzed the potential impact of global warming on $\mathrm{CH}_{4}$ and $\mathrm{N}_{2} \mathrm{O}$ emission from agriculture. A two-year experimental set-up was carried out in the PSU Research Greenhouse, Portland State University, to determine the effect of global warming on $\mathrm{CH}_{4}$ and $\mathrm{N}_{2} \mathrm{O}$ emissions from rice agriculture. Throughout the sampling period, the rice microcosms were continuously flooded and heated using water baths, and only chemical fertilizer was used. This study fully captured the interdependences between temperature and production, oxidation and emissions. The study required the design and development of experiments from which simultaneous measurements of the $\mathrm{Q}_{10} \mathrm{~S}$ of $\mathrm{CH}_{4}$ and $\mathrm{N}_{2} \mathrm{O}$ would be determined. Six experiments were designed and conducted to determine effect of elevated soil temperature on $\mathrm{CH}_{4}$ emission, production and oxidation. The research also involved determining the temperature sensitivity of $\mathrm{N}_{2} \mathrm{O}$, with special focus placed on production, emission and pore water concentrations. The research includes a study of the populations of methanogens and methanotrophs under different temperatures.

This study showed that temperature is an important factor for $\mathrm{CH}_{4}$ emissions from agriculture, and that global warming will result in increased emissions. The magnitude of this feedback is potentially large enough to offset the present atmospheric $\mathrm{CH}_{4}$ concentrations. However, this increase was most evident for soil temperatures blow 30 ${ }^{\circ} \mathrm{C}$. Beyond this temperature, fluxes decreased with increasing temperature. Within the 
root zone, $\mathrm{CH}_{4}$ concentration was only highly dependent on soil temperature during the start of the growing season, with highest concentration in the $10-15 \mathrm{~cm}$ soil horizon. Plants $\mathrm{CH}_{4}$ transport capacity was the predominant limiting factor for fluxes during entire plant growth phase. The rate of $\mathrm{CH}_{4}$ production was highly dependent on both soil temperature and time. The seasonally averaged $\mathrm{Q}_{10}$ of $\mathrm{CH}_{4}$ emission, production and oxidation were 2.0, 2.6 and 3.5, respectively. The population of methanotrophs was more sensitive to changes in soil temperature than methanogens, with seasonally averaged $\mathrm{Q}_{10}$ values of 3.8 compared to 2.6 for methanogenesis. The implication of these results is that global warming is likely to promote $\mathrm{CH}_{4}$ oxidation, and hence reduce the rate of increase of emissions from rice agriculture. Higher $\mathrm{Q}_{10}$ values were also observed during the early part of the season than elsewhere. During this period of the season, rice plants were not well established, and ebullition was the only major $\mathrm{CH}_{4}$ transport from the flooded rice tubs into the atmosphere. Since the ebullition is the major transport in wetlands, and that the processes of $\mathrm{CH}_{4}$ formation and emission are similar those in natural wetlands, which are the largest contributors to atmospheric methane concentration, this positive temperature feedback is likely to contribute a significant additional $\mathrm{CH}_{4}$ increase to the present atmospheric budget if the current global warming trend persists over the next century. Nevertheless, the magnitude of this impact will vary from one region to another due to the spatial variations in temperatures from one region to the other.

Weak regression coefficients were found between $\mathrm{N}_{2} \mathrm{O}$ fluxes and soil temperature and low $\mathrm{Q}_{10}$ values varying from 0.5 to 3.3 were observed. High $\mathrm{N}_{2} \mathrm{O}$ production rates were 
only evident during the period following fertilization. During other sampling periods, fluxes were mostly negative and the pore water concentration of $\mathrm{N}_{2} \mathrm{O}$ was almost zero. Hence, $\mathrm{N}_{2} \mathrm{O}$ emissions were mainly controlled by the availability of suitable substrates such as nitrogen compounds. The results also indicated that under global warming, the direct impact of temperature is not likely to be the major driver of $\mathrm{N}_{2} \mathrm{O}$ emission increase from continuously flooded rice paddies in future. However, since moisture content is known to be one of the major factors that regulate $\mathrm{N}_{2} \mathrm{O}$ emissions from agricultural soils, the pattern and distribution of these emissions will mostly depend on how much global warming will change the factors that affect the regional patterns and distributions of soil wetness. Such factors include water resources (rain, water tables) and water management practices.

While the current research has dealt with the impact of elevated soil temperatures on $\mathrm{CH}_{4}$ and $\mathrm{N}_{2} \mathrm{O}$, future studies are required to determine the $\mathrm{Q}_{10}$ of transport and the transport time of both $\mathrm{CH}_{4}$ and $\mathrm{N}_{2} \mathrm{O}$, possibly by using isotopic experiments. Since on many occasions negative $\mathrm{N}_{2} \mathrm{O}$ fluxes were observed during sampling, additional research is required to quantify how global warming will affect the uptake of $\mathrm{N}_{2} \mathrm{O}$ in agricultural soils. Integrating the results of temperature sensitivities for $\mathrm{CH}_{4}$ and $\mathrm{N}_{2} \mathrm{O}$ for natural wetlands and rice soils into a global model to determine the likely impacts of global warming is also an area for further research, but may require determining the $\mathrm{Q}_{10}$ factors for other ecosystems such as natural wetlands. The use of these models could improve the accuracy of the estimates of these emissions under a changing climate. 
Such a process will require putting into consideration additional input factors such as future rainfall patterns and distribution of surface water resources. 


\section{References}

Abdalla, M., Jones, M., Smith, P. and Williams, M. (2009), Nitrous oxide fluxes and denitrification sensitivity to temperature in Irish pasture soils. Soil Use and Management, 25: 376-388.

Abichou T., D. Powelson, J. Chanton, S. Escoriaza and J. Stern (2006). Characterization of methane flux and oxidation at a solid waste landfill. Environmental Engineering, 132(2): 220-228.

Abichou T., J. Chanton, D. Powelson, J. Fleiger, S. Escoriaza, Y. Lei and J. Stern (2006). Methane flux and oxidation at two types of intermediate landfill covers. Waste Management, 26: 1305-1312.

Alberto M.C.R., J.R.M. Arah, H.U. Neue, R. Wassmann, R.S. Lantin, J.B. Aduna, K.F. Bronson (2000). A sampling technique for the determination of dissolved methane in soil solution. Chemosphere: Global Change Science, 2: 57-63.

Allen Jr, L.H., S.L. Albrecht, W. Colo, n-Guasp, S.A. Covell, J.T. Baker, D. Pan, and K.J. Boot (2003). Methane emissions of rice increased by elevated carbon dioxide and temperature. Environmental Quality, 32: 1978-1991.

Aulakh M.S., R. Wassmann, C. Bueno and H. Rennenberg (2001). Impact of root exudates of different cultivars and plant development stages of rice (Oryza sativa L.) on methane production in a paddy soil. Plant and Soil, 230: 77-86.

Auman A.J., Stolyar, S., Costello, A.M., and Lidstrom, M.E. (2000). Molecular characterization of methanotrophic isolates from freshwater lake sediment. Applied and Environmental Microbiology, 66(12): 5259-5266.

Bergamaschi, P. (1997). Seasonal variations of stable hydrogen and carbon isotope ratios in methane from a Chinese rice paddy. Geophysical Research, 102(D21): 25383-25393.

Bharati, K., S.R. Mohanty, V.R. Rao, T.K. Adhya (2001). Influence of flooded and nonflooded conditions on methane flux from two soils planted to rice. Chemosphere - Global Change Science, 3: 25 - 32.

Bodelier P.L.E. and H.J. Laanbroek (2004). Nitrogen as a regulatory factor of methane oxidation in soils and sediments. FEMS Microbiology Ecology, 47: 265-277.

Bodelier, P.L.E., and Frenzel, P. (1999). Contribution of methanotrophic and nitrifying bacteria to $\mathrm{CH} 4$ and $\mathrm{NH} 4+$ oxidation in the rhizosphere of rice plants as determined by new methods of discrimination. Applied and Environmental Microbiology, 65:1826-183. 
Bodelier, P.L.E., Roslev, P., Henckel, T. and Frenzel, P. (2000). Stimulation by ammonium-based fertilizers of methane oxidation in soil around rice roots. Nature, 403: 421-424.

Borges, R. and Chaney, W. (1989). Root temperature affects mycorrhizal efficacy in Fraxinus pennylvanica Marsh. New Physiology, 112: 411-417.

Bosse, U., and Frenzel, P. (1997). Activity and distribution of methane-oxidizing bacteria in flooded rice soil microcosms and in rice plants (Oryza sativa). Applied and Environmental Microbiology, 63:1199-1207.

Bremner, J.M. (1997). Sources of nitrous oxide in soils. Nutrient Cycling in Agroecosystems, 49: 7-16.

Byrne, B.H., E.R. Austin and B.K. Tays. Methane emissions from flooded rice soils and plants under controlled conditions. Soil Biology and Biochemistry, 27(3): 331 - 339. 1995.

Cabral A.R., M.A. Capanema, J. Gebert, J.F. Moreira and L.B. Jugnia (2010). Quantifying microbial methane oxidation efficiencies in two experimental landfill biocovers using stable isotopes. Water, Air and Soil Pollution, 209: $157-172$.

Castaldi S., Smith K.A. (1998). The effect of different N substrates on biological $\mathrm{N}_{2} \mathrm{O}$ production from forest and agricultural light textured soils. Plant Soil, 199: 229-238.

Castaldi, S. (2000). Responses of nitrous oxide, dinitrogen and carbon dioxide production and oxygen consumption to temperature in forest and agricultural light-textured soils determined by model experiment. Biology and Fertility of Soils, 32: 67-72.

Chanton, J.P., G.J. Whiting, N.E. Blair, C.W. Lindau, and P.K. Bollich (1997). Methane emission from rice: Stable isotopes diurnal variations and $\mathrm{CO}_{2}$ exchange. Global Biogeochemical Cycles, 11(1): 15-27.

Chapuis-Lardy L., A. Metay, M. Martinet, M. Rabenarivo, J. Toucet, J.M. Douzet, T. Razafimbelo, R.L. Rabeharisoa, J. Rakotoarisoa (2009). Geoderma, 148(3-4): 421-427.

Chasar L.S., J.P. Chanton, P.H. Glaser and D.I. Siegel (2000). Methane concentration and stable isotope distribution as evidence of rhizospheric processes: comparison of a fen and bog in the glacial lake Agassiz peatland complex. Annals of Botany, 86: 655-663. 
Cheng, X., Y. Luo, Q. Xu, G. Lin, Q. Zhang, J. Chen and B. Li (2010). Seasonal variation in $\mathrm{CH} 4$ emission and its 13C-isotopic signature from Spartina alterniflora and Scirpus mariqueter soils in an estuarine wetland. Plant Soil, 327: 85-94.

Chidthaisong, A., K-J. Chin, D.L. Valentine, And S.C. Tyler (2002). A comparison of isotope fractionation of carbon and hydrogen from paddy field rice roots and soil bacterial enrichments during $\mathrm{CO} 2 / \mathrm{H} 2$ methanogenesis. Geochimica et Cosmochimica Acta, 66(6): 983-995.

Chin J-K., Lukow, T. and Conrad, R. (1999). Effect of temperature on structure and function of the methanogenic archaeal community in an anoxic rice field soil. Applied Environmental Microbiology, 65(6): 2341-2349.

Cicerone R.J., J.D. Shetter and C.C. Delwiche. 1983. Seasonal variation of methane flux from a Californian rice paddy. Geophysical Research, 88: 11022-11024.

Coleman, D.D., R.J. Bruno and S. Martin (1981). Fractionation of carbon and hydrogen isotopes by methane-oxidizing bacteria. Geochimica et Cosmochimica Acta, 45: 1033-1037.

Conrad R. (2002). Control of microbial methane production in wetland rice fields. Nutrient Cycling in Agroecosystems, 64: 59-69.

Conrad, R. (1996). Soil Microorganisms as Controllers of Atmospheric Trace Gases $\left(\mathrm{H}_{2}\right.$, $\mathrm{CO}, \mathrm{CH}_{4}, \mathrm{OCS}, \mathrm{N}_{2} \mathrm{O}$, and NO). Microbiological Reviews, 60(4): 609-640.

Conrad, R. 1999. Contribution of hydrogen to methane production and control of hydrogen concentrations in methanogenic soils and sediment. FEMS Microbiology and Ecology, 28: 193-202.

Conrad, R., M. Klose, P. Claus (2002). Pathway of $\mathrm{CH}_{4}$ formation in anoxic rice field soil and rice roots determined by 13C-stable isotope fractionation. Chemosphere, 47: 797-806.

Crill et al. (1994). Temperature and $\mathrm{N}$ fertilization effects on methane oxidation in a drained peatland soil. Soil Biology and Biochemistry, 26 (10): 1331-1339.

Damgaard, L.R., N.P. Revsbech, and W. Reichardt (1998). Use of an oxygeninsensitive microscale biosensor for methane to measure methane concentration profiles in a rice paddy. Applied and Environmental Microbiology, 864 - 870 . 
Davidson EA, Swank WT, Perry TO (1986). Distinguishing between nitrification and denitrification as a source of gaseous nitrogen production in soil. Applied and Environmental Microbiology, 52: 1280-1286.

Davidson, E.A. and I.A. Janssens. Temperature sensitivity of soil carbon decomposition and feedbacks to climate change. Nature Reviews, 440: 165 - 173.

Dawson, T.E., S. Mambelli, A.H. Plamboeck, P.H. Templer and K.P. Tu (2002). Stable isotopes in plant ecology. Annual Reviews of Ecological Systems, 33: 507-59.

Deleens, E., I. Treichel and M.H. Otleary (1985). Temperature dependence of carbon isotope fractionation in CAM plants. Plant Physiology, 79: 202-206.

Ding, W., Z. Cai and H. Tsuruta (2004). Diel variation in methane emissions from the stands of Carex lasiocarpa and Deyeuxia angustifolia in a cool temperate freshwater marsh. Atmospheric Environment, 38:181-188

Dörsch P., A. Palojärvi and S. Mommertz. Overwinter greenhouse gas fluxes in two contrasting agricultural habitats (2004). Nutrient Cycling in Agroecosystems, 70: $117-133$.

Farquhar, G.D., M.H. O'Leary and J.A. Berry (1982). On the relationship between carbon isotope discrimination and the intercellular carbon dioxide concentration in leaves. Australian Journal of Plant Physiology, 9: 121-137.

Fey A., P. Claus and R. Conrad (2004). Temporal change of 13C-isotope signatures and methanogenic pathways in rice field soil incubated anoxically at different temperatures. Geochimica et Cosmochimica Acta, 68(2): 293-306.

Flessa H., R. Ruser, R. Schilling, N. Loftfield, J.C. Munch, E.A. Kaiser, F. Beese (2002). $\mathrm{N} 2 \mathrm{O}$ and $\mathrm{CH} 4$ fluxes in potato fields: automated measurement, management effects and temporal variation. Geoderma, 105: 307-325.

Freitag, T.E., Toet, S., Ineson, P. and Prosser, J. (2010). Links between methane flux and transcriptional activities of methanogens and methane oxidizers in a blanket peat bog. FEMS Microbiology and Ecology, 73: 157-165.

Gal'chenko, V.F. (2004). On the problem of anaerobic methane oxidation. Microbiology, 73 (5): 599-608. Translated from Mikrobiologiya, 73(5): 698707.

Gauci, V., D. Fowler, S.J. Chapman and N.B. Dise (2004). Sulfate deposition and temperature controls on methane emission and sulfur forms in peat. Biogeochemistry, 71: 141-162. 
Ghosh S., D. Majumdar, M.C. Jain (2003). Methane and nitrous oxide emissions from an irrigated rice of North India. Chemosphere, 51: 181-195.

Gilbert, B., and Frenzel, P. (1995). Methanotrophic bacteria in the rhizosphere of rice microcosms and their effect on porewater methane concentration and methane emission. Biology and Fertility of Soils, 20: 93-100.

Goevert, D. and R. Conrad (2009). Effect of substrate concentration on carbon isotope fractionation during acetoclastic methanogenesis by methanosarcina barkeri and $\mathrm{m}$. acetivorans and in rice field soil. Applied and Environmental Microbiology, 75(9): 2605-2612.

Gómez, K.E., G. Gonzalez-Gil, A. Lazzaro and M.H. Schroth (2009). Quantifying methane oxidation in a landfill-cover soil by gas push-pull tests. Waste Management, 29: 2518-2526.

Gonfiantini, R., Stichler, W., and Rozanski, K. (1995). Standards and intercomparison materials distributed by the International Atomic Energy Agency for stable isotope measurements, in Reference and intercomparison materials for stable isotopes of light elements, Vienna, Austria, International Atomic Energy Agency, IAEA-TECDOC-825, 13-29.

Goulding, J.L. Monteith, V.R. Phillip (1995). The measurement of nitrous oxide emissions from soil by using chambers [and discussion]. Philosophical Transactions of Royal Society, 351: 327-338.

Gross M.F., M.A. Hardisky, P.L. Wolf and V. Klemas (1993). Relationship among Typha biomass, pore water methane, and reflectance in a Delaware (U.S.A.) brackish marsh. Coastal Research, 9(2): 339 - 355.

Grossman, E.L. (2002). Stable carbon isotopes as indicators of microbial activity in aquifers, in Manual of Environmental Microbiology, 2nd ed., C.J. Hurst et al. (eds.), American Society for Microbiology Press, Washington, DC, p. 728742 .

Neue H.U. and P.A. Roger (1994). Potential of methane emission in major rice ecologies. In: Zepp RG (ed) Climate Biosphere Interaction, New York: Wiley and Sons, p 65-93.

Hanson, R.S., and Hanson, T.E. 1996. Methanotrophic bacteria. Microbiology Reviews, 60: 439-471.

Harden H.S. and J.P. Chanton (1994). Locus of methane release and mass-dependent fractionation from two wetland macrophytes: Limnology and Oceanography, 39(1): 148-154. 
Helmut Schutz, Wolfgang Seiler and Ralf Conrad (1990). Influence of soil temperature on methane emission from rice paddy fields. Biogeochemistry, 11: 77-95.

Heninger. R.L. and White, D.P. (1974). Tree seedling growth at different soil temperatures. Forest Science, 20: 363-367.

Henn, M.R., G. Gleixner and I.H. Chapela (2002). Growth-dependent stable carbon isotope fractionation by Basidiomycete fungi: pattern and physiological process. Applied and Environmental Microbiology, 4956-4964.

Hinrichs, K.-U., A. Boetius (2002). The anaerobic oxidation of methane: new insights in microbial ecology and biogeochemistry. From Wefer G, Billett D, Hebbeln D, Jørgensen BB, Schlüter M., Van Weering T (eds). Ocean Margin Systems. Springer-Verlag Berlin Heidelberg, 457-477.

Holler, T., G. Wegener, K. Knittel, A. Boetius, B. Brunner, M.M. Kuypers, F. Widdel (2009). Substantial $13 \mathrm{C} / 12 \mathrm{C}$ and $\mathrm{D} / \mathrm{H}$ fractionation during anaerobic oxidation of methane by marine consortia enriched in vitro. Environmental Microbiology Reports, 1(5): 370 - 376.

Holzapfel-Pschorn, A., R. Conrad, and W. Seiler. 1985. Production, oxidation and emission of methane in rice paddies. FEMS Microbiological Ecology, 31: 343-351.

Hosono, T. and I. Nouchi (1997). The dependence of methane transport in rice plants on the root zone Temperature. Plant and Soil, 191: 233-240.

Hou A.X., G.X. Chen, Z.P. Wang, O. Van Cleemput, and W.H. Patrick, Jr (2000). Methane and nitrous oxide emissions from a rice field in relation to soil redox and microbiological processes. Soil Science Society American Journal, 64:

Huang, Y., R.L. Sass, F.M. Fisher, Jr (2002). A semi-empirical model of methane emission from flooded rice paddy soils. Global Change Biology, 4(3): 247 268.

Hutton, W.E and Zobell C.E. 1949. The occurrence and characteristics of methaneoxidizing bacteria in marine sediments. Bacteriology, 58(4): 463-473.

Insam, H. and B. Wett (2008). Control of GHG emission at the microbial community level. Waste Management, 28: 699-706.

IPCC (1996). Climate Change 1995: The science of climate change. Cambridge University Press. 
IPCC (2007a). Couplings between changes in the climate system and biogeochemistry. In: Climate Change 2007: The Physical Science Basis. Contribution of Working Group I to the Fourth Assessment Report of the Intergovernmental Panel on Climate Change [Solomon et al. (eds.)]. Cambridge University Press, Cambridge, United Kingdom and New York, NY, USA.

IPCC (2007b). Changes in atmospheric constituents and in radiative forcing. In: Climate Change 2007: The Physical Science Basis. Contribution of Working Group I to the Fourth Assessment Report of the Intergovernmental Panel on Climate Change [Solomon et al. (eds.)].

IPCC (2007c). Global climate projections. In: Climate Change 2007: The Physical Science Basis. Contribution of Working Group I to the Fourth Assessment Report of the Intergovernmental Panel on Climate Change [Solomon et al. (eds.)]. Cambridge University Press, Cambridge, United Kingdom and New York, NY, USA, 2007.

IPCC (2007d). Agriculture. In Climate Change 2007: Mitigation. Contribution of Working Group III to the Fourth Assessment Report of the Intergovernmental Panel on Climate Change [Metz et al. (eds)], Cambridge University Press, Cambridge, United Kingdom and New York, NY, USA.

Jiang C., Wang Y., Zheng X., Zhu B., Huang Y., And Hao Q. (2006). Methane and Nitrous Oxide Emissions from Three Paddy Rice Based Cultivation Systems in Southwest China. Advances in Atmospheric Sciences, 23(3): 415 - 424.

Joulian C., Escoffier, S., Mer, J.L., Neue, H.-U. and Roger, P.A. (1997). Populations and potential activities of methanogens and methanotrophs in rice fields: relations with soil properties. European Journal of Soil Biology, 33 (2): 105116.

Kamp T., H. Steindl, R.E. Hantschel, F. Beese J.-C. Munch (1998). Nitrous oxide emissions from a fallow and wheat field as affected by increased soil temperatures. Biology and Fertility of Soils, 27: 307- 314.

Khalil M.A.K., C. Butenhoff, A.Sithole and M.J. Shearer. The feedback of climate change on methane emissions from terrestrial ecosystems. In preparation.

Khalil, M.A.K. and R.A. Rasmussen, M.-X. Wang and L. Ren (1991). Methane emissions from rice fields in China. Environmental Science and Technology, 25: 979-981.

Khalil, M., Rasmussen, R., Shearer, M., Dalluge, R., Ren, L. and Duan. C.-L. (1998). Factors affecting methane emissions from rice fields. Geophysical Research, 103(D19): 25219-25231. 
Khalil, M.A.K., M.J. Shearer, R.A. Rasmussen, Li Xu, and Jin-Luan Liu (2008). Methane and nitrous oxide emissions from subtropical rice agriculture in China. Geophysical Research, 113, G00A05, doi:10.1029/2007JG000462.

Khalil, M.A.K. and Shearer M. (1993a). Sources of methane: overview. In M.A.K. Khalil (ed.). Atmospheric methane: sources, sinks and role in global change. Springer-Verlag, Berlin Germany, Chapter 10, pp 180-198.

Khalil, M.A.K. and Shearer M. (1993b). Rice agriculture: emissions. In M.A.K. Khalil (ed.). Atmospheric methane: sources, sinks and role in global change. Springer-Verlag, Berlin Germany, Chapter 12, pp 230-253.

Khalil, M.A.K. 1, M.J. Shearer, R.A. Rasmussen, Li Xu, and J-L. Liu (2008a). Methane and nitrous oxide emissions from subtropical rice agriculture in China. Geophysical Research, 113, G00A05, doi:10.1029/2007JG000462,.

Khalil, M.A.K., M.J. Shearer, R.A. Rasmussen, D. Changlin, and L.X. Ren (2008b). Production, oxidation, and emissions of methane from rice fields in China. Geophysical Research, 113: G00A04, doi:10.1029/2007JG000461.

Khalil, M.A.K., R.A. Rasmussen, M.J. Shearer, R.W. Dalluge, L.X. Ren and C-L. Duan. (1998b). Factors affecting methane emissions from rice fields. Geophysical Research, 103 (D19): 25 219-25 231.

Khalil, M.A.K., R.A. Rasmussen, M.J. Shearer, R.W. Dalluge, L.X. Ren and C-L. Duan $(1998 \mathrm{c})$. Measurements of methane emissions from rice fields in China. Geophysical Research, 103 (D19): 25 181-25 210.

Khalil, M.A.K., R.A. Rasmussen, M.J. Shearer, Z.L. Chen, Heng Yao, and J. Yang (1998a). Emissions of methane, nitrous oxide, and other trace gases from rice fields in China. Geophysical Research, 103 (D19): 25 241-25 250.

Khalil, M.A.K., Rasmussen, R.A., and Shearer, M.J. (1989). Trends of atmospheric methane during the 1960s and 1970s. Geophysical Research, 94(D15): 18279-18288.

Khalil, M.A.K., Rasmussen, R.A., Shearer, M.J. (1998e). Flux measurements and sampling strategies: applications to methane emissions from rice fields. Geophysical Research, 103(D19): 25211-25218.

Kimura, M., minoda, and J. Murase (1993). Water soluble materials in paddy soil ecosystem. II Effects of temperature on contents of total organic materials, organic acids, and methane in leachate from submerged paddy soils amended with rice straw. Soil Science and Plant Nutrition, 39: 713 - 724. 
Kipphut G.W. and C.S. Martens (1982). Biogeochemical cycling in an organic-rich coastal marine basin-3. Dissolved gas transport in methane-saturated sediments. Gwchimica Cosmochimica Acta, 46: 2049 - 2060.

Knittel, K. and A. Boetius (2009). Anaerobic oxidation of methane: progress with an unknown process. Annual Reviews of Microbiology, 63: 311-334.

Kolb S., Knief, C., Stubner, S., and Conrad, R. (2003). Quantitative detection of methanotrophs in soil by novel pmoa-targeted real-time PCR assays. Applied and Environmental Microbiology, 69(5): 2423-2429.

Koponena H.T., C.E. Durana, M. Maljanena, J. Hytonen, P.J. Martikainena (2006). Temperature responses of $\mathrm{NO}$ and $\mathrm{N} 2 \mathrm{O}$ emissions from boreal organic soil. Soil Biology and Biochemistry, 38: 1779-1787.

Kreye C., K. Dittert, X. Zheng, X. Zhang, S. Lin, H. Tao, B. Sattelmacher (2007). Fluxes of methane and nitrous oxide in water-saving rice production in north China. Nutrient Cycling in Agroecosystems, 77: 293-304.

Kumaraswamy S., B. Ramakrishnan and N. Sethunathan (2001). Wetlands and aquatic processes methane production and oxidation in an anoxic rice soil as influenced by inorganic redox species. Environmental Quality, 30: 2195-2201.

Liblik, L.K., T.R. Moore, J.L. Bubier and S.D. Robinson (1997). Methane emissions from wetlands in the zone of discontinuous permafrost: Fort Simpson, Northwest Territories, Canada. Global Biogeochemical Cycles, 11(4): 485 494.

Lindau, C.W. (1994). Methane emissions from Louisiana rice fields amended with nitrogen fertilizers. Soil Biology and Biochemistry, 26(3): 353 - 359.

Lu, Y., R. Wassmann, H-U. Neue, C. Huang (1999). Impact of phosphorous supply on root exudation, aerenchyma formation and methane emission of rice plants. Biogeochemistry, 47: 203 - 213.

Lu, Y., R. Wassmann, H-U. Neue, C. Huang (2000). Dynamics of dissolved organic carbon and methane emissions in a flooded rice soil. Soil Science Society American Journal, 64: 2011 - 2017.

Luton, P.E., Wayne, J.M., Sharp, R.J. and Riley, P.W. (2002). The mcrA gene as an alternative to $16 \mathrm{~S}$ rRNA in the phylogenetic analysis of methanogens populations in landfill. Microbiology, 148: 3521-3530. 
Macdonald et al. (1998). Methane emission rates from a northern wetland; response to temperature, water table and transport. Atmospheric Environment, 32(19): $3219-3227$.

Mariko, S., Y. Harazono, N. Owat and I. Nouchi (1991). Methane in flooded soil water and the emission through rice plants to the atmosphere. Environmental and Experimental Botany, 31(3): $343-350$.

Martens, C.S., D.B. Albert, and M.J. Alperin (1999). Stable isotope tracing of anaerobic methane oxidation in the gassy sediments of Eckernforde Bay, German Baltic Sea. American J. of Science, 299: 589-610.

McCrackin, M.L. and J.J. Elser (2010). Atmospheric nitrogen deposition influences denitrification and nitrous oxide production in lakes. Ecology, 91: 528-539.

McHale P.J., M.J. Mitchell, and F.P. Bowles (1998). Soil warming in a northern hardwood forest: trace gas fluxes and leaf litter decomposition. Canadian J. Forestry Research, 28: 1365-1372.

Mer, J.L. and P. Roger (2001). Production, oxidation, emission and consumption of methane by soils: A review. European J. of Soil Biology, 37: 25-50.

Minami, K. (1997). Atmospheric methane and nitrous oxide: sources, sinks and strategies for reducing agricultural emissions. Nutrient Cycling in Agroecosystems, 49: 203-211.

Mitra S., R. Wassmann, M.C. Jain and H. Pathak (2002). Properties of rice soils affecting methane production potentials: 2. Differences in topsoil and subsoil. Nutrient Cycling in Agroecosystems, 64: 183-191.

Mohanty S.R., Bodelier, P.L.E. and Conrad, R. (2007). Effect of temperature on composition of the methanotrophic community in rice field and forest soil. FEMS Microbiology and Ecology, 62: 24-31.

Murase J., Y. Sakai, A. Sugimoto, K. Okubo, and M. Sakamoto (2003). Sources of dissolved methane in Lake Biwa. Limnology, 4: 91 - 99.

Nakagawa, F., N. Yoshida, A. Sugimoto, E. Wada, T. Yoshioka, S. Ueda, P. Vijarnsorn. 2002. Stable isotope and radiocarbon compositions of methane emitted from tropical rice paddies and swamps in Southern Thailand. Biogeochemistry, 61(1): 1-19.

Neff J.C. and G.P. Asner (2001). Dissolved organic carbon in terrestrial ecosystems: Synthesis and a model. Ecosystems, 4: 29- 48. 
Neue H.-U. and P.A. Roger (1994). Potential of methane emission in major rice ecologies. In: Zepp R. G. (Ed.). Climate biosphere interaction: biogenic emissions and environmental effects of climate change. John Wiley and Sons, pp. 65-93.

Neue, H. 1993. Methane emission from rice fields: Wetland rice fields may make a major contribution to global warming. BioScience, 43 (7): 466-473.

O'Leary, M.H. (1981). Carbon isotopic fractionation in plants. Phytochemistry, 20: 553567.

O'leary, M.H., I. Treichel and M. Rooney (1986). Short-Term Measurement of Carbon Isotope Fractionation in Plants. Plant Physiology, 80: 578-582.

Parashar, D.C., P.K. Gupta, J. Rai, R.C. Sharma and N. Singh (1993). Effect of soil temperature on methane emission from paddy fields. Chemosphere, 26(1-4): 247-250.

Pastor, J., J. Solin, S.D. Bridgham, K. Updegraff, C. Harth, P. Weishampel and B. Dewey (2003). Global warming and the export of dissolved organic carbon from boreal peatlands. Oikos, 100: 380-386

Peng J., Lu, Z., Rui, J. and Lu, Y. (2008). Dynamics of the methanogenic archaeal community during plant residue decomposition in an anoxic rice field soil. Applied and Environmental Microbiology, 74(9): 2894-2901.

Peterjohn, W.T., J.M. Melillo, F.P. Bowles, P.A. Steudler (1993). Soil warming and trace gas fluxes: experimental design and preliminary flux results. Oecologia, 93: 18-24.

Prieme, A. (1994). Production and emission of methane in a brackish and a freshwater wetland. Soil biology and Biochemistry, 26(I): 7-18.

Rasmussen, R.A. and Khalil, M.A. (1981). Atmospheric methane: trends and seasonal cycles. Geophysical Research, 86: 9826-9832.

Rath A.K., B. Ramakrishnan, N. Sethunathan (2002). Temperature dependence of methane production in tropical rice soils. Geomicrobiology, 19: 581-592.

Reay, D.S., D.B. Nedwell (2004). Methane oxidation in temperate soils: effects of inorganic N. Soil Biology and Biochemistry, 36: 2059-2065.

Reddy, K.R. (1982). Nitrogen cycling in a flooded-soil ecosystem planted to rice (Oryza sativa L). Plant and Soil, 67: 209 - 220. 
Reeburgh, W.S., A.I. Hirsch, F.J. Sansone, B. N. Popp, and T.M. Rust (1997). Carbon kinetic isotope effect accompanying microbial oxidation of methane in boreal forest soils. Geochimica et Cosmochimica Acta, 61(22): 4761-4767.

Ritchie D.A., Edwards, C., Mcdonald, I.R. and Murrell, J.C. (1997). Detection of methanogens and methanotrophs in natural environments. Global Change Biology, 3: 339-350.

Riveros-Iregui, D.A. and J.Y. King (2008). Isotopic evidence of methane oxidation across the surface water-ground water interface. Wetlands, 28(4): 928-937.

Roslev P., Iversen, N. and Henriksen, K. (1997). Oxidation and assimilation of atmospheric methane by soil methane oxidizers. Applied and Environmental Microbiology, 63(3): 874-880.

Rothfuss, F. and R. Conrad (1993). Vertical profiles of $\mathrm{CH}_{4}$ concentrations, dissolved methanogenic substrates and processes involved in $\mathrm{CH}_{4}$ production in a flooded Italian rice field. Biogeochemistry, 18: 137-152.

Rothfuss, F., F.G.C. Bijnen, R. Conrad, F.J.M. Harren and J. Reuss (1996). Combination of photoacoustic detector with gas diffusion probes for the measurement of methane concentration gradients in submerged paddy soil. Chemosphere, 33(12): 2487 - 2504.

S.C. Tyler, P.M. Grill, and G.W. Brailsford (1994). 13C/12C Fractionation of methane during oxidation in a temperate forested soil. Geochimica et Cosmochimica Acta, 58(6): 1625-1633.

Sansone, F.J., M.E. Holmes, and B.N. Popp (1999). Methane stable isotopic ratios and concentrations as indicators of methane dynamics in estuaries. Global Biogeochemical Cycles, 13(2), 463-474.

Sass R.L., F.M. Fischer, P.A. Harcombe, and F.T. Turner. 1991. Methane production and emission in a Texas rice field. Global Biogeochemical Cycles, 4: 47-68.

Sass, R.L., F.M. Fisher, F.T. Turner, and M.F. Jund (1991). Methane emission from rice fields as influenced by solar radiation, temperature and straw incorporation. Global Biogeochemical Cycles, 5(4): 335-350.

Satpathy, S.N., A.K. Rath, B. Ramakrishnan, V.R. Rao, T.K. Adhya and N. Sethunathan (1997). Diurnal variation in methane efflux at different growth stages of tropical rice. Plant and Soil, 195: 267-271.

Segers R (1998). Methane production and methane consumption: A review of processes underlying wetland methane fluxes. Biogeochemistry, 41(1): 23 - 51. 
Schütz, H., A. Holzapfel-Pschorn, R. Conrad, H Rennenberg, and W. Seiler. 1989. A 3year continuous record on the influence of daytime, season and fertilizer treatment on methane emission rates from an Italian rice paddy field. Geophysical Research, 94: 16405-16416.

Schutz, H., W. Seiler and R. Conrad (1990). Influence of soil temperature on methane emission from rice paddy fields. Biogeochemistry, 11: 11-95.

Schutz, H., Wolfgang Seiler, Ralf Conrad (1989). Processes involved in formation and emission of methane in rice paddies. Biogeochemistry, 7(1): 33-53.

Sebacher, D.I., Harriss R.C. and Bartlett K.B. (1985). Methane emissions to the atmosphere through aquatic plants. Environmental Quality, (14): 40 - 46.

Segers, R. (1998). Methane Production and Methane Consumption: A review of processes underlying wetland methane fluxes. Biogeochemistry, 41(1): 23-51.

Sithole, A. (2009). Experimental methods for measuring the $\mathrm{Q}_{10}$ of methane and nitrous oxide emissions from rice agriculture. MS Thesis. Physics Department, Portland State University. 127p.

Smith K.A., H. Clayton, I.P. McTaggart, P.E. Thomson, J.R.M. Arah, A. Scott, K.W.T. Goulding, J.L. Monteith, V.R. Phillips (1995). The measurement of nitrous oxide emissions from soil by using chambers. Philosophical Transactions: Physical Sciences and Engineering, 351(1696): 327-338.

Smith, K.A. (1997). The potential for feedback effects induced by global warming on emissions of nitrous oxide by soil. Global Change Biology, 3: 327-338

Smith, K.A., P.E. Thomson, H. Clayton, I.P McTaggart and F. Conen (1998). Effects of temperature, water content and nitrogen fertilization on emission of nitrous oxide by soils. Atmospheric Environment, 32(19): 3301-3309.

Smith, P., D. Martino, Z. Cai, D. Gwary, H. Janzen, P. Kumar, B. McCarl, S. Ogle, F. O’Mara, C. Rice, B. Scholes, O. Sirotenko, 2007: Agriculture. In Climate Change 2007: Mitigation. Contribution of Working Group III to the Fourth Assessment Report of the Intergovernmental Panel on Climate Change [B. Metz, O.R. Davidson, P.R. Bosch, R. Dave, L.A. Meyer (eds)], Cambridge University Press, Cambridge, United Kingdom and New York, NY, USA.

Snover, A.K. and P.D. Quay (2000). Hydrogen and carbon kinetic isotope effects during soil uptake of atmospheric methane. Global Biogeochemical Cycles, 14: 2539. 
Sugimoto, A. and E. Wada (1993). Carbon isotopic composition of bacterial methane in a soil incubation experiment: Contributions of acetate and $\mathrm{CO}_{2} / \mathrm{H}_{2}$, Geochim. Cosmochim. Acta, 57: 4015-4027.

Stanford, G., S. Dzienia and R.A. Vander-Pol (1975). Effect of temperature on denitrification rate in soils. Soil Science Society of America Journal, 39(5): 867-870.

Steinberg L.M. and Regan, J.M. (2009). mcrA-targeted real-time quantitative PCR method to examine methanogens communities. Applied Environmental Microbiology, 75(13): 4435-4442.

Towprayoon S., K. Smakgahn, S. Poonkaew (2005).Mitigation of methane and nitrous oxide emissions from drained irrigated rice fields. Chemosphere, 59: 15471556.

Turner, N.C. and Jarvis, P.G. (1975). Photosynthesis in Sitka spruce (Picea sitchensis (Bong.) Caw.) IV. Response to soil temperature. Botany, 12: 561-576.

Tyler, S.C., R. S. Bilek, R.L. Sass and F.M. Fisher (1997). Methane oxidation and pathways of production in a Texas paddy field deduced from measurements of flux, $\delta 13 \mathrm{C}$, and $\delta \mathrm{D}$ of CH4. Global Biogeochemical Cycles, 11(3): 323-348.

V. Gauci, D. Fowler, S.J. Chapman and N.B. Dise (2004). Sulfate deposition and temperature controls on methane emission and sulfur forms in peat. Biogeochemistry, 71: 141-162.

Valentine D.L., D.C. Blanton, W.S. Reeburgh, and M. Kastner (2001). Water column methane oxidation adjacent to an area of active hydrate dissociation. Eel River Basin. Geochimica et Cosmochimica Acta, 65(16): 2633-2640.

van Hulzen, J.B., R. Segers, P.M. van Bodegom, P.A. Lefelaar (1999). Temperature effects on soil methane production: an explanation for observed variability. Soil Biology and Biochemistry, 31: 1919-1929.

Wang B., H.U. Neue, H.P. Samonte (1997). The effect of controlled soil temperature on diel $\mathrm{CH}_{4}$ emission variation. Chemosphere, 35(9): 2083-2092.

Wang B., H.U. Neue1, H.P. Samonte (1999). Factors controlling diel patterns of methane emission via rice. Nutrient Cycling in Agroecosystems, 53: 229-235.

Wang B., Y. Xu , Z. Wang, Z. Li, Y. Ding Y. Guo (1999). Methane production potentials of twenty-eight rice soils in China. Biology and Fertility of Soils, 29: 74-80. 
Wang, B., H.U. Neue, and H.P. Samonte (1999). Factors controlling diel patterns of methane emission via rice. Nutrient Cycling in Agroecosystems, 53: 229-235.

Wang, Z.P., D. Zeng and W.H. Patrick Jr (1997). Characteristics of methane oxidation in a flooded rice soil profile. Nutrient Cycling in Agroecosystems, 49: 97-103.

Wassmann, R., Lantin, R.S., Neue H-U. (eds) (2000). Methane emissions from major rice ecosystems in Asia. Development in Plant and Soil Sciences (91). Kluwer Academic Publishers, Dordrecht.

Watanabe T., Kimura, M., Asakawa, S. (2009). Distinct members of a stable methanogenic archaeal community transcribe mcrA genes under flooded and drained conditions in Japanese paddy field soil. Soil Biology and Biochemistry, 41: 276-285.

Watanabe, A., H. Yamada and M. Kimura (2005). Analysis of temperature effects on seasonal and interannual variation in $\mathrm{CH} 4$ emission from rice-planted pots. Agriculture, Ecosystems and Environment, 105: 439-443.

Whalen, S.C., and W.S. Reeburgh, 1996. Moisture and temperature sensitivity of CH4 oxidation in boreal soils. Soil Biological and Biochemistry, 28: 1271-1281.

Whiticar, M.J., 1999. Carbon and hydrogen isotope systematics of bacterial formation and oxidation of methane. Chemical Geology, 161 (1-3): 291-314.

Whiting, G.J. and Chanton, J.P. (1993). Primary production control of methane emission from wetlands. Nature, 364: 794-795.

Wilson, J.O., P.M. Crill, K.B. Bartlett, D.I. Sebacher, R.C. Harriss and R. Sass (1989). Seasonal variations of methane from a temperate swamp. Biogeochemistry, $8(1): 55-71$.

X. Chen, M.L. Cabrera, L. Zhang, J. Wu, Y. Shi, W.T. Yu and S.M. Shen (2002). Nitrous oxide emission from upland crops and crop-soil systems in northeastern China. Nutrient Cycling in Agroecosystems, 62: 241-247.

Xu, S., P.R. Jaffé and D.L. Mauzerall (2007). A process-based model for methane emission from flooded rice paddy systems. Ecological Modelling, 205(3-4): 475-491

Yang S-S., C-M. Liu c, C-M. Lai, Y-L. Liu (2003). Estimation of methane and nitrous oxide emission from paddy fields and uplands during 1990-2000 in Taiwan. Chemosphere, 52: 1295-1305. 
Yao H., and Z.L. Chen (1994a). Effect of chemical fertilizer on methane emission from rice paddies. Geophysical Research, 99(D8): 16 463-16470.

Yao H., and Z.L. Chen (1994b). Seasonal variation of methane flux from Chinese rice paddy in semi arid, temperature region. Geophysical Research, 99(D8): 16471-16477.

Yao H., R. Conrad, R. Wassmann and H.U. Neue (1999). Effect of soil characteristics on sequential reduction and methane production in sixteen rice paddy soils from China, the Philippines, and Italy. Biogeochemistry, 47: 269-295.

Yao, H. and R. Conrad (1999). Thermodynamics of methane production in different rice paddy soils from China, the Philippines and Italy. Soil Biology and Biochemistry, 31: 463-473.

Yu, Z.,X. Shangguan, D. Pollard and E.J. Barron. Simulating methane emission from a Chinese rice field as influenced by fertilizer and water level. Hydrology Processes (in press). DOI: 10.1002/hyp.1304

Zhiyong, P., O. Hua, Z. Caiping, X. Xingliang (2009). Profile of methane concentrations in soil and atmosphere in Alpine steppe ecosystem on Tibetan Plateau. Resources and Environment, 7(1): DOI C92 X3

Zou J., Y. Huang, L. Zong, X. Zheng, and Y. Wang (2004). Carbon dioxide, methane, and nitrous oxide emissions from a rice-wheat rotation as affected by crop residue incorporation and temperature. Advances in Atmospheric Sciences, 21(5): 691-698. 
Appendix A

Seasonal average temperature data

Table A.1: Average soil temperature data measured for different treatments.

\begin{tabular}{|c|c|c|c|c|}
\hline Date & WB1 $\left({ }^{\circ} \mathrm{C}\right)$ & WB2 $\left({ }^{\circ} \mathrm{C}\right)$ & WB3 $\left({ }^{\circ} \mathrm{C}\right)$ & WB4 $\left({ }^{\circ} \mathrm{C}\right)$ \\
\hline $10 / 30 / 2009$ & 21.1 & 23.8 & 23.8 & 24.9 \\
\hline $11 / 4 / 2009$ & 21.2 & 23.4 & 28.0 & 32.1 \\
\hline $11 / 5 / 2009$ & 22.0 & 23.5 & 24.9 & 26.7 \\
\hline $11 / 8 / 2009$ & 20.7 & 23.9 & 27.4 & 32.5 \\
\hline $11 / 12 / 2009$ & 20.2 & 25.9 & 27.5 & 32.4 \\
\hline $11 / 14 / 2009$ & 20.3 & 24.8 & 27.9 & 31.8 \\
\hline $11 / 18 / 2009$ & 19.9 & 24.4 & 27.1 & 32.5 \\
\hline $11 / 25 / 2009$ & 20.2 & 24.5 & 27.4 & 33.0 \\
\hline $11 / 30 / 2009$ & 20.2 & 23.8 & 27.9 & 32.9 \\
\hline $12 / 3 / 2009$ & 19.6 & 23.4 & 28.0 & 32.2 \\
\hline $12 / 3 / 2009$ & 19.6 & 23.4 & 27.6 & 31.7 \\
\hline $12 / 10 / 2009$ & 19.4 & 24.2 & 25.7 & 28.8 \\
\hline $12 / 26 / 2009$ & 20.2 & 23.6 & 27.8 & 32.7 \\
\hline $1 / 6 / 2010$ & 20.0 & 23.5 & 26.9 & 30.9 \\
\hline $1 / 13 / 2010$ & 20.3 & 23.6 & 27.9 & 31.8 \\
\hline $1 / 16 / 2010$ & 20.4 & 23.6 & 28.0 & 30.9 \\
\hline $1 / 20 / 2010$ & 20.6 & 23.6 & 27.9 & 29.0 \\
\hline $1 / 23 / 2010$ & 20.2 & 23.4 & 27.9 & 32.4 \\
\hline $1 / 27 / 2010$ & 20.3 & 23.5 & 27.9 & 32.0 \\
\hline $2 / 1 / 2010$ & 20.2 & 23.4 & 27.9 & 31.8 \\
\hline $2 / 3 / 2010$ & 20.4 & 23.5 & 28.0 & 31.7 \\
\hline $2 / 14 / 2010$ & 19.5 & 20.6 & 26.6 & 32.0 \\
\hline $2 / 14 / 2010$ & 20.5 & 23.6 & 26.6 & 32.0 \\
\hline $2 / 21 / 2010$ & 20.4 & 22.9 & 27.7 & 32.0 \\
\hline $3 / 10 / 2010$ & 20.6 & 23.0 & 27.6 & 31.9 \\
\hline $3 / 16 / 2010$ & 20.4 & 22.9 & 27.6 & 31.3 \\
\hline $3 / 24 / 2010$ & 20.6 & 22.8 & 27.4 & 31.6 \\
\hline $3 / 29 / 2010$ & 21.2 & 23.1 & 27.9 & 32.1 \\
\hline $3 / 31 / 2010$ & 20.8 & 23.3 & 28.0 & 31.9 \\
\hline $4 / 2 / 2010$ & 20.2 & 23.0 & 27.9 & 32.5 \\
\hline 4/7/2010 & 20.3 & 23.1 & 28.1 & 32.1 \\
\hline
\end{tabular}


Appendix B

Average $\mathrm{CH}_{4}$ and $\mathrm{N}_{2} \mathrm{O}$ Flux Data

Table B.1: Average of average $\mathrm{CH}_{4}$ fluxes $\left(\mathrm{mg} / \mathrm{m}^{2} / \mathrm{hr}\right)$ from planted tubs from season 1

\begin{tabular}{|c|c|c|c|c|}
\hline Date & WB2 & WB1 & WB3 & WB4 \\
\hline $10 / 25 / 2009$ & 0.2 & 0.1 & 0.1 & 0.2 \\
\hline 10/31/2009 & 0.3 & 0.2 & 0.7 & 1.6 \\
\hline $11 / 5 / 2009$ & 0.9 & 0.4 & 3.8 & 14.9 \\
\hline $11 / 8 / 2009$ & 1.5 & 0.4 & 5.4 & 13.6 \\
\hline $11 / 12 / 2009$ & 2.0 & 0.6 & 5.4 & 10.5 \\
\hline 11/14/2009 & 2.4 & 0.6 & 6.1 & 15.7 \\
\hline $11 / 25 / 2009$ & 2.9 & 0.6 & 5.2 & 15.6 \\
\hline 11/30/2009 & 2.6 & 0.6 & 7.4 & 12.1 \\
\hline $12 / 3 / 2009$ & 4.3 & 0.9 & 10.9 & 12.4 \\
\hline $12 / 10 / 2009$ & 8.8 & 1.4 & 14.5 & 27.8 \\
\hline $12 / 16 / 2009$ & 14.5 & 3.5 & 22.3 & 15.4 \\
\hline $1 / 6 / 2010$ & 22.9 & 10.0 & 28.9 & 19.1 \\
\hline $1 / 11 / 2010$ & 14.9 & 10.3 & 29.7 & 21.1 \\
\hline $1 / 13 / 2010$ & 24.7 & 11.5 & 27.9 & 18.4 \\
\hline $1 / 16 / 2010$ & 14.0 & 12.9 & 25.7 & 21.1 \\
\hline $1 / 20 / 2010$ & 14.0 & 11.4 & 27.7 & 29.3 \\
\hline $1 / 23 / 2010$ & 12.9 & 14.3 & 24.0 & 17.9 \\
\hline $1 / 27 / 2010$ & 15.7 & 12.1 & 25.9 & 19.5 \\
\hline $2 / 1 / 2010$ & 31.7 & 12.0 & 39.0 & 20.7 \\
\hline $2 / 3 / 2010$ & 19.3 & 12.5 & 34.7 & 19.9 \\
\hline $2 / 10 / 2010$ & 18.9 & 12.3 & 22.7 & 21.4 \\
\hline $2 / 17 / 2010$ & 13.5 & 12.6 & 15.4 & 24.7 \\
\hline $2 / 21 / 2010$ & 16.6 & 12.5 & 19.4 & 18.1 \\
\hline $3 / 10 / 2010$ & 22.7 & 14.3 & 46.3 & 27.6 \\
\hline $3 / 16 / 2010$ & 26.3 & 17.1 & 33.0 & 26.4 \\
\hline $3 / 24 / 2010$ & 29.8 & 17.0 & 34.4 & 24.2 \\
\hline $3 / 29 / 2010$ & 35.0 & 17.1 & 36.5 & 22.0 \\
\hline $3 / 31 / 2010$ & 29.4 & 20.7 & 32.0 & 23.5 \\
\hline $4 / 2 / 2010$ & 22.5 & 14.5 & 27.8 & 18.0 \\
\hline 4/4/2010 & 21.0 & 11.5 & 30.8 & 17.1 \\
\hline
\end{tabular}


Table B. 2: Average of average $\mathrm{CH}_{4}$ fluxes $\left(\mathrm{mg} / \mathrm{m}^{2} / \mathrm{hr}\right)$ from planted tubs from season 2

\begin{tabular}{|c|c|c|c|c|}
\hline Date & WB2 & WB1 & WB3 & WB4 \\
\hline $4 / 24 / 2010$ & 0.2 & 0.1 & 1.0 & 1.0 \\
\hline $4 / 26 / 2010$ & 0.4 & 0.1 & 1.7 & 3.7 \\
\hline $5 / 1 / 2010$ & 1.3 & 0.6 & 4.8 & 14.7 \\
\hline $5 / 3 / 2010$ & 1.5 & 0.8 & 6.3 & 24.3 \\
\hline $5 / 10 / 2010$ & 4.8 & 2.3 & 13.1 & 26.8 \\
\hline $5 / 18 / 2010$ & 9.9 & 5.8 & 24.3 & 29.3 \\
\hline $6 / 2 / 2010$ & 13.7 & 7.1 & 23.4 & 25.3 \\
\hline 6/9/2010 & 12.8 & 8.3 & 22.1 & 27.0 \\
\hline $6 / 17 / 2010$ & 19.5 & 17.8 & 30.4 & 34.4 \\
\hline $6 / 21 / 2010$ & 25.1 & 21.6 & 33.8 & 39.7 \\
\hline $6 / 24 / 2010$ & 25.5 & 25.4 & 37.6 & 56.5 \\
\hline $6 / 28 / 2010$ & 31.2 & 28.9 & 44.8 & 53.7 \\
\hline $6 / 30 / 2010$ & 37.5 & 27.5 & 42.3 & 38.7 \\
\hline $7 / 5 / 2010$ & 30.7 & 26.9 & 36.6 & 43.4 \\
\hline $7 / 6 / 2010$ & 25.1 & 32.0 & 28.8 & 51.5 \\
\hline $7 / 12 / 2010$ & 37.4 & 37.0 & 40.2 & 51.1 \\
\hline $7 / 19 / 2010$ & 33.4 & 38.0 & 39.7 & 37.7 \\
\hline $7 / 23 / 2010$ & 34.6 & 35.8 & 33.3 & 34.2 \\
\hline $7 / 28 / 2010$ & 35.7 & 36.6 & 31.9 & 33.9 \\
\hline $8 / 2 / 2010$ & 19.5 & 29.4 & 37.0 & 25.1 \\
\hline $8 / 9 / 2010$ & 31.8 & 32.9 & 24.5 & 19.7 \\
\hline $8 / 11 / 2010$ & 17.9 & 17.4 & 36.8 & 16.6 \\
\hline
\end{tabular}


Table B.3: Average of average $\mathrm{N}_{2} \mathrm{O}$ fluxes $\left(\mu \mathrm{g} / \mathrm{m}^{2} / \mathrm{hr}\right)$ from planted tubs from season 1 .

\begin{tabular}{lcccc}
\hline Date & WB2 & WB1 & WB3 & WB4 \\
\hline $10 / 25 / 2009$ & 62.5 & 47.3 & -45.6 & 361.8 \\
$10 / 31 / 2009$ & 509.2 & 302.8 & 683.5 & 881.5 \\
$11 / 5 / 2009$ & 288.7 & 530.6 & 1167.3 & 600.6 \\
$11 / 8 / 2009$ & 151.8 & 110.0 & 246.2 & 41.9 \\
$11 / 12 / 2009$ & 21.0 & 61.2 & 53.7 & 35.0 \\
$11 / 14 / 2009$ & -1.5 & 21.5 & 20.4 & 14.8 \\
$11 / 25 / 2009$ & -9.7 & 218.9 & 40.0 & -23.7 \\
$11 / 30 / 2009$ & -9.9 & 9.0 & -6.2 & 30.5 \\
$12 / 3 / 2009$ & 8.6 & 22.7 & 34.3 & 31.1 \\
$12 / 10 / 2009$ & 11.6 & 31.6 & 46.8 & 25.2 \\
$12 / 16 / 2009$ & -0.3 & 19.4 & -11.7 & 7.4 \\
$1 / 6 / 2010$ & 25.7 & 30.7 & 16.3 & -5.4 \\
$1 / 11 / 2010$ & 17.6 & 22.6 & 31.1 & 54.3 \\
$1 / 13 / 2010$ & 71.3 & 12.6 & 22.0 & 20.6 \\
$1 / 16 / 2010$ & 11.8 & -2.3 & 13.9 & 17.7 \\
$1 / 20 / 2010$ & -2.7 & 1.0 & 8.6 & 19.8 \\
$1 / 23 / 2010$ & -29.4 & - & - & 20.9 \\
$1 / 27 / 2010$ & -9.8 & -15.0 & -2.5 & 4.9 \\
$2 / 1 / 2010$ & 3.0 & 3.4 & 26.5 & 54.1 \\
$2 / 3 / 2010$ & -8.1 & 23.0 & 28.3 & -14.7 \\
$2 / 10 / 2010$ & 4.6 & 1.0 & -2.2 & 6.0 \\
$2 / 17 / 2010$ & -0.4 & -4.7 & 24.0 & 92.3 \\
$2 / 21 / 2010$ & 4.9 & 16.2 & 23.9 & 14.2 \\
$3 / 10 / 2010$ & 21.0 & 12.5 & -2.6 & -10.9 \\
$3 / 16 / 2010$ & 0.8 & -1.0 & 11.8 & 20.1 \\
$3 / 24 / 2010$ & 7.1 & 10.9 & 39.6 & 41.2 \\
$3 / 29 / 2010$ & 20.0 & 36.4 & -18.7 & -25.6 \\
$3 / 31 / 2010$ & 4.9 & 25.6 & 16.1 & 12.1 \\
$4 / 2 / 2010$ & -10.3 & -12.9 & -18.3 & 14.7 \\
$4 / 4 / 2010$ & 18.6 & 11.8 & 12.8 & \\
\hline & & & & \\
\hline
\end{tabular}


Table B.4: Average of average $\mathrm{N}_{2} \mathrm{O}$ fluxes $\left(\mu \mathrm{g} / \mathrm{m}^{2} / \mathrm{hr}\right)$ from planted tubs from season 2 .

\begin{tabular}{|c|c|c|c|c|}
\hline Date & WB2 & WB1 & WB3 & WB4 \\
\hline $4 / 24 / 2010$ & 822.5 & 146.4 & 702.4 & - \\
\hline $4 / 26 / 2010$ & 604.1 & 118.7 & 442.4 & 267.9 \\
\hline $5 / 1 / 2010$ & 53.8 & 38.7 & 82.8 & 38.3 \\
\hline $5 / 3 / 2010$ & 23.4 & 33.9 & 33.2 & 1.6 \\
\hline $5 / 10 / 2010$ & 21.1 & 19.0 & 9.4 & 40.1 \\
\hline $5 / 18 / 2010$ & 21.1 & 8.6 & 11.5 & 15.6 \\
\hline $6 / 2 / 2010$ & 12.6 & -1.4 & -11.7 & 15.2 \\
\hline $6 / 9 / 2010$ & 28.1 & 12.8 & 31.2 & 22.5 \\
\hline $6 / 17 / 2010$ & 15.3 & -21.5 & 97.9 & 46.4 \\
\hline $6 / 21 / 2010$ & 5.7 & 8.3 & 1.9 & 34.9 \\
\hline $6 / 24 / 2010$ & -6.6 & 8.3 & 27.1 & 34.9 \\
\hline $6 / 28 / 2010$ & -6.6 & -14.4 & 4.6 & -27.3 \\
\hline $6 / 30 / 2010$ & 19.7 & -3.4 & 1.9 & 8.2 \\
\hline $7 / 5 / 2010$ & -24.2 & -36.5 & -1.8 & 17.2 \\
\hline $7 / 6 / 2010$ & 3.0 & -15.1 & -13.5 & -6.4 \\
\hline $7 / 12 / 2010$ & -2.9 & 15.8 & 23.2 & 7.1 \\
\hline $7 / 19 / 2010$ & -37.9 & -72.7 & 44.6 & 56.4 \\
\hline $7 / 23 / 2010$ & 11.1 & -40.3 & 4.6 & 20.7 \\
\hline $7 / 28 / 2010$ & 8.4 & -1.3 & 4.6 & 21.5 \\
\hline $8 / 2 / 2010$ & -18.8 & -20.4 & -12.4 & -6.5 \\
\hline $8 / 9 / 2010$ & -27.1 & -10.8 & 11.4 & 1.5 \\
\hline $8 / 11 / 2010$ & -3.6 & 8.2 & 22.2 & 3.5 \\
\hline $8 / 16 / 2010$ & 41.6 & 3.4 & -13.2 & 14.6 \\
\hline
\end{tabular}


Appendix C

Average $\mathrm{CH}_{4}$ and $\mathrm{N}_{2} \mathrm{O}$ Production Data

Table C.1: Average $\mathrm{CH}_{4}$ production data $\left(\mathrm{mg} / \mathrm{m}^{2} / \mathrm{hr}\right)$

\begin{tabular}{lcccc}
\hline Date & WB1 & WB2 & WB3 & WB4 \\
\hline $5 / 1 / 2010$ & 51.3 & 23.3 & 84.4 & 6.8 \\
$5 / 4 / 2010$ & 40.7 & 29.9 & 74.9 & 3.7 \\
$5 / 11 / 2010$ & 108.9 & 100.1 & 162.3 & 506.7 \\
$6 / 15 / 2010$ & 419.2 & 338.3 & 604.2 & 1592.9 \\
$6 / 25 / 2010$ & 289.3 & 198.3 & 996.1 & 1269.5 \\
$7 / 2 / 2010$ & 435.2 & 357.3 & 874.3 & 895.4 \\
$7 / 13 / 2010$ & 694.0 & 186.0 & 727.2 & 2244.9 \\
$7 / 21 / 2010$ & 1100.5 & 909.3 & 1567.4 & 1248.2 \\
$7 / 26 / 2010$ & 763.6 & 715.5 & 2504.8 & 1350.3 \\
$7 / 29 / 2010$ & 1787.8 & 1523.2 & 1349.2 & 2904.2 \\
$8 / 4 / 2010$ & $*$ & $*$ & 2323.2 & 1869.0 \\
\hline
\end{tabular}

Table C.2: Average $\mathrm{N}_{2} \mathrm{O}$ production data $\left(\mu \mathrm{g} / \mathrm{m}^{2} / \mathrm{hr}\right)$

\begin{tabular}{lcccc}
\hline Date & WB1 & WB2 & WB3 & WB4 \\
\hline $5 / 1 / 2010$ & 18.02 & 10.10 & 8.98 & 18.67 \\
$5 / 4 / 2010$ & 103.21 & 55.55 & 8.09 & 10.19 \\
$5 / 11 / 2010$ & 21.60 & 8.96 & 7.74 & 5.73 \\
$6 / 15 / 2010$ & 6.44 & 6.66 & 8.78 & 6.29 \\
$6 / 25 / 2010$ & 8.32 & 9.01 & 7.25 & 5.99 \\
$7 / 2 / 2010$ & 10.48 & 6.20 & 7.75 & 25.51 \\
$7 / 13 / 2010$ & 8.17 & 9.97 & 7.41 & 9.04 \\
$7 / 21 / 2010$ & 6.85 & 7.09 & 8.16 & 8.40 \\
$7 / 26 / 2010$ & 8.10 & 7.26 & 6.60 & 8.31 \\
$7 / 29 / 2010$ & 8.26 & 8.37 & 9.66 & 7.78 \\
$8 / 4 / 2010$ & 10.62 & 7.58 & 6.99 & 9.56 \\
\hline
\end{tabular}




\section{Appendix D}

\section{Pore Water $\mathrm{CH}_{4}$ and $\mathrm{N}_{2} \mathrm{O}$ concentrations}

Table D.1: Average $\mathrm{CH}_{4}$ pore water concentration $(\mu \mathrm{g} / \mathrm{L})$ data

\begin{tabular}{lcccc}
\hline Date & WB2 & WB1 & WB3 & WB4 \\
\hline $4 / 28 / 2010$ & 72.6 & 41.7 & 141.7 & 804.8 \\
$5 / 4 / 2010$ & 103.0 & 51.4 & 284.0 & 1609.2 \\
$5 / 18 / 2010$ & 447.9 & 288.7 & 676.5 & 2198.3 \\
$6 / 2 / 2010$ & 973.0 & 564.7 & 1399.4 & 1787.6 \\
$6 / 14 / 2010$ & 2325.6 & 2160.1 & 4014.7 & 4754.3 \\
$6 / 18 / 2010$ & 1835.1 & 2317.3 & 3175.0 & 3454.5 \\
$6 / 22 / 2010$ & 2750.5 & 2633.3 & 3284.0 & 3922.9 \\
$6 / 29 / 2010$ & 1359.9 & 2142.1 & 2984.7 & 2521.2 \\
$7 / 13 / 2010$ & 3372.9 & 4081.1 & 5236.2 & 4328.5 \\
$7 / 19 / 2010$ & 4617.6 & 5111.3 & 6135.3 & 6557.1 \\
$7 / 22 / 2010$ & 5581.2 & 6525.4 & 7615.7 & 8899.0 \\
$7 / 26 / 2010$ & 5971.7 & 6376.7 & 9580.7 & 9651.0 \\
$7 / 29 / 2010$ & 7766.8 & 8318.9 & 7287.2 & 8256.2 \\
$8 / 3 / 2010$ & 6193.9 & 6953.8 & 7554.1 & 7703.9 \\
$8 / 11 / 2010$ & 7084.1 & 7111.3 & 9191.9 & 5197.3 \\
$8 / 18 / 2010$ & 4911.1 & 3813.0 & 6254.4 & 4790.1 \\
$8 / 20 / 2010$ & 5836.7 & 4041.4 & 4361.5 & 2259.0 \\
Average & 3372.9 & 3813.0 & 4361.5 & 4328.5 \\
STDEV & 2568.7 & 2703.9 & 3034.1 & 2737.5 \\
\hline & & & &
\end{tabular}


Table D.2: Average $\mathrm{N}_{2} \mathrm{O}$ pore water concentration $(\mu \mathrm{g} / \mathrm{L})$ data

\begin{tabular}{lcccc}
\hline Date & WB2 & WB1 & WB3 & WB4 \\
\hline $4 / 28 / 2010$ & 438.7 & 1465.1 & 319.6 & 40.0 \\
$5 / 4 / 2010$ & 255.6 & 1090.3 & 93.8 & 3.3 \\
$5 / 18 / 2010$ & 6.4 & 209.0 & 0.8 & 0.7 \\
$6 / 2 / 2010$ & 1.3 & 2.2 & 1.4 & 1.1 \\
$6 / 14 / 2010$ & 0.6 & 0.7 & 0.6 & 0.6 \\
$6 / 18 / 2010$ & 1.0 & 1.1 & 0.8 & 0.9 \\
$6 / 22 / 2010$ & 0.3 & 0.7 & 0.3 & 0.4 \\
$6 / 29 / 2010$ & 0.3 & 0.7 & 0.6 & 0.5 \\
$7 / 13 / 2010$ & 1.4 & 1.3 & 1.1 & 1.2 \\
$7 / 19 / 2010$ & 0.6 & 0.6 & 0.5 & 0.5 \\
$7 / 22 / 2010$ & 0.6 & 0.9 & 1.0 & 0.9 \\
$7 / 26 / 2010$ & 1.2 & 1.3 & 1.4 & 1.4 \\
$7 / 29 / 2010$ & 1.0 & 1.1 & 1.1 & 1.0 \\
$8 / 3 / 2010$ & 0.9 & 0.9 & 0.8 & 0.7 \\
$8 / 11 / 2010$ & 0.9 & 1.4 & 0.9 & 0.9 \\
$8 / 18 / 2010$ & 0.5 & 0.5 & 0.6 & 0.5 \\
$8 / 20 / 2010$ & 0.8 & 1.7 & 0.8 & 1.1 \\
\hline
\end{tabular}




\section{Appendix E}

\section{Average $\mathrm{CH}_{4}$ Isotope Measurements}

Table E.1: Seasonal average $\delta^{13} \mathrm{C}$ measured in flux samples from planted tubs (per mil)

\begin{tabular}{ccccc}
\hline DAT & WB1 & WB2 & WB3 & WB4 \\
\hline 9 & -47.465 & -49.485 & -52.982 & -56.905 \\
16 & -50.987 & -52.835 & -55.381 & -52.000 \\
23 & -55.590 & -57.749 & -55.987 & -55.135 \\
31 & -59.073 & -58.926 & -56.992 & -56.202 \\
46 & -62.289 & -62.428 & -61.377 & -60.006 \\
53 & -63.570 & -60.029 & -59.355 & -59.241 \\
65 & -61.659 & -61.619 & -60.869 & -59.711 \\
72 & -63.702 & -61.240 & -60.337 & -56.632 \\
80 & -62.989 & -60.977 & -59.948 & -57.507 \\
86 & -62.280 & -60.751 & -57.658 & -56.285 \\
\hline
\end{tabular}

Table E.2: Seasonal average $\delta^{13} \mathrm{C}$ measurements in flux samples from unplanted tubs

\begin{tabular}{ccccc}
\hline Date & WB1 & WB2 & WB3 & WB4 \\
\hline 9 & -46.083 & -49.63 & -48.859 & -53.771 \\
16 & -47.403 & -49.127 & -50.481 & -48.616 \\
23 & -50.355 & -52.921 & -47.705 & -48.018 \\
31 & -51.650 & -51.988 & -49.618 & -52.018 \\
46 & -54.595 & -50.692 & -52.962 & -54.290 \\
53 & -50.587 & -55.407 & -53.963 & -55.472 \\
65 & -63.796 & -55.677 & -52.366 & -51.454 \\
72 & -54.858 & -53.932 & -54.273 & $*$ \\
80 & -49.272 & -57.281 & -56.295 & -55.826 \\
86 & -46.083 & -56.437 & -56.334 & -57.060 \\
\hline
\end{tabular}


Table E.3: Seasonal average $\delta D$ values from flux samples (per mil)

\begin{tabular}{cccccccc}
\hline \multicolumn{3}{c}{$\delta$ D in fluxes from planted tubs } & \multicolumn{3}{c}{$\delta$ in fluxes from unplanted tubs } \\
\hline WB1 & WB2 & WB3 & WB4 & WB1 & WB2 & WB3 & WB4 \\
-146.046 & -166.382 & -209.546 & -287.525 & -151.878 & -174.952 & -172.768 & -277.643 \\
-147.235 & -212.793 & -280.145 & -306.022 & -87.427 & -172.137 & -218.847 & -322.953 \\
-234.46 & -268.766 & -304.434 & -337.628 & -143.203 & -284.005 & -186.047 & -308.278 \\
-287.884 & -312.999 & -284.767 & -342.698 & -199.287 & -304.213 & -260.519 & -344.032 \\
-309.998 & -320.447 & -333.797 & -342.777 & -251.886 & -264.365 & -282.675 & -338.05 \\
-317.715 & -341.855 & -340.58 & -339.573 & -311.462 & -341.453 & -330.48 & -347.87 \\
-329.468 & -334.977 & -342.555 & -347.007 & -229.64 & -343.223 & -273.266 & -248.686 \\
-350.217 & -347.207 & -351.853 & -327.494 & -350.081 & -290.649 & -311.98 & -336.047 \\
-340.916 & -350.789 & -349.817 & -339.8 & -324.291 & -309.332 & -326.923 & -340.26 \\
-331.616 & -354.371 & -347.782 & -352.106 & -298.5 & -328.014 & -341.866 & -344.473 \\
\hline
\end{tabular}

Table E.4: Seasonal average $\delta^{13} \mathrm{C}$ values from pore water samples (per mil)

\begin{tabular}{cccccccc}
\hline \multicolumn{3}{c}{$\begin{array}{c}\text { Average } \delta^{13} \mathrm{C} \text { values in pore water } \\
\text { from planted tubs }\end{array}$} & \multicolumn{3}{c}{ Average $\delta^{13} \mathrm{C}$ values in pore water from } \\
unplanted tubs
\end{tabular}


Table E.5: Seasonal average $\delta \mathrm{D}$ values from pore water measurements (per mil)

\begin{tabular}{cccccccc}
\hline \multicolumn{4}{c}{ SD Averages in pore water } & \multicolumn{5}{c}{ SD averages in pore water } \\
from planted tubs & & & Wnplanted tubs \\
\hline WB1 & WB2 & WB3 & WB4 & WB1 & WB2 & WB3 & WB4 \\
$*$ & $*$ & $*$ & -254.92 & $*$ & $*$ & -164.5 & -240.8 \\
$*$ & -250.695 & -330.13 & -305.918 & $*$ & -277.35 & -300.7 & -371.17 \\
-218.503 & -248.073 & -300.608 & -331.81 & $*$ & -248.154 & -295.6 & -312.57 \\
-261.415 & -273.68 & -271.195 & -298.53 & -256.03 & $*$ & -358.7 & -340.065 \\
-356.315 & -367.688 & -261.105 & -331.518 & -360.645 & -348.105 & -317.9 & -321.955 \\
-358.198 & -361.465 & -365.31 & -367.35 & -348.73 & -330.675 & $*$ & $*$ \\
-222.476 & -201.412 & -162.474 & -152.959 & -215.853 & -202.823 & -162.2 & -175.161 \\
-297.353 & -203.298 & -306.89 & -284.405 & -208.8 & -231.513 & -357.0 & -317.475 \\
-298.335 & -242.815 & -310.218 & -323.145 & -298.175 & -311.925 & -315.4 & -322.775 \\
-367.288 & -380.133 & -337.405 & -359.38 & -321.757 & -377.605 & -358.8 & -350.72 \\
\hline
\end{tabular}

